\title{
THE SALINE INTERFACE OF A SHALLOW UNCONFINED AQUIFER, RANGITIKEI DELTA
}

By

Desirée S. A. Craig

A thesis submitted to Victoria University of Wellington in fulfilment of the requirements for the degree of

Master of Science

in Physical Geography

Victoria University of Wellington

2008 


\section{Abstract}

The coastal communities of Tangimoana and Scott's Ferry have a long history of using shallow groundwater bores. The cumulative effect of pumping over decades could influence the saline interface given the close proximity of the communities to the seashore and river estuary. It is important to quantify the effects of pumping on both the shallow groundwater system and the dynamics of the saline interface. This is necessary to protect the groundwater system against saline intrusion especially given the increasing number of high volume groundwater consents to support dairying.

Resistivity soundings and traverses, coupled with chemical analyses of groundwater samples, were found to be an effective method for defining the saline interface of the shallow groundwater aquifer under the Rangitikei delta. The saline interface extends from the salt marsh to beneath the farmland north of Tangimoana. The interface is a zone of diffusion with freshwater and brackish water mixing from the estuary. The interface is currently located on the outskirts of Tangimoana, and it is likely to extend beneath the township. The infiltration of brackish surface waters into sediments of the salt marsh form a surficial mixing zone that decreases with distance from the salt marsh. There is no indication of salinity in the area to the north of the Rangitikei delta. This area is most at risk of contamination from saline intrusion because of high volume groundwater abstractions, even though these abstractions are from deeper aquifers.

The shallow groundwater beneath Tangimoana showed high concentrations of $\mathrm{Ca}$ and $\mathrm{HCO}_{3}$ ions. This may be a result of carbonate dissolution, which can occur when saline and freshwater mix. This creates groundwater that is under-saturated with calcium. The mixing water dissolves carbonates and increases the concentrations of $\mathrm{Ca}$ and $\mathrm{HCO}_{3}$. The major source of sodium and chloride was likely rainwater with evaporated solutes from seawater.

The saline interface near Tangimoana appears to be relatively static, but the estuary and salt marsh are areas of low relief. There are preferential flows paths across the salt marsh to the farmland. These factors make the shallow groundwater in the Rangitikei delta vulnerable to saline intrusion. 


\section{Acknowledgements}

I would like to thank the many people who have contributed to this research with their generous support and assistance.

I would like to gratefully acknowledge the efforts of my supervisors. Dr Malcolm Ingham, always made time in his busy schedule; his ideas, discussions, editing, help in the field, and encouragement has been greatly appreciated. Dr Jack McConchie for his patience, support, advice, editing, and resources, these have been invaluable.

I would like to thank Horizons Regional Council, for their generous financial support. I am particularly grateful to Hisham Zarour, for providing me with critical bore log data and information.

To Ian Brown Associates, especially Ian Calman who so kindly provided me with AEM survey maps and profiles, and for freely providing his time to discuss these.

Particular thanks and acknowledgement go to the residents of Tangimoana and Scott's Ferry for allowing me to sample the groundwater from their bores. To Mr and Mrs Ellison for their invaluable knowledge of the shallow groundwater bores in Tangimoana. To the Pedleys for generously allowing me to access to their property for my field work.

I would also like to thank Francie Morrow and Lizzie Ingham for their help in the field. Francie also shared her resources and ideas with me.

Lastly, this research would not have been possible without the endless support, motivation, and encouragement of my friends and family. It has meant so much to me. 


\section{Table of Contents}

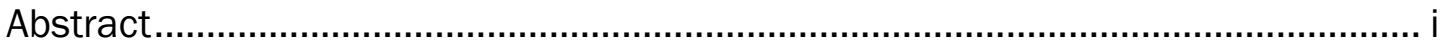

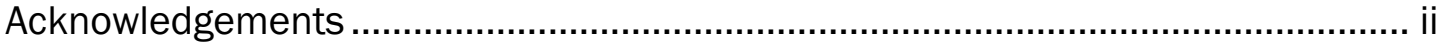

List of Figures .................................................................................................

List of Tables …................................................................................................... vii

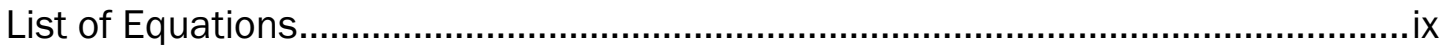

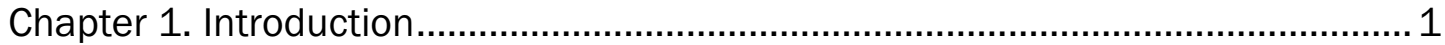

Chapter 2. Groundwater in a coastal environment ............................................... 5

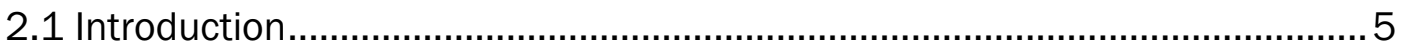

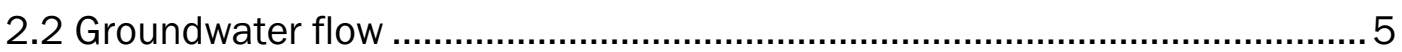

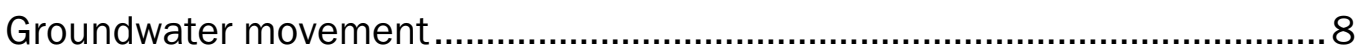

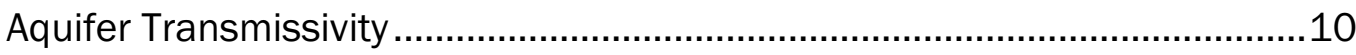

2.3 Coastal aquifers and the saline interface ..................................................10

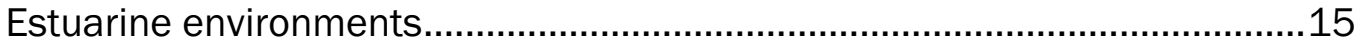

The effect of wells on the saline interface …..............................................16

2.4 Investigating the saline interface ..................................................................

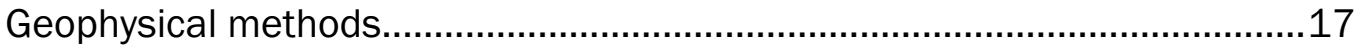

Direct Current resistivity ................................................................................ 18

Airborne electromagnetic surveys...............................................................19

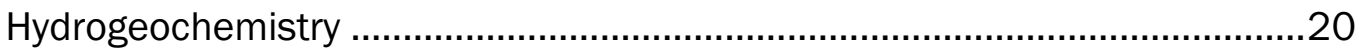

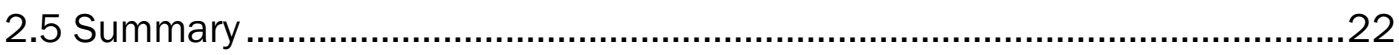

Chapter 3. The study area - Rangitikei delta.....................................................23

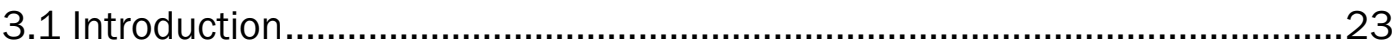

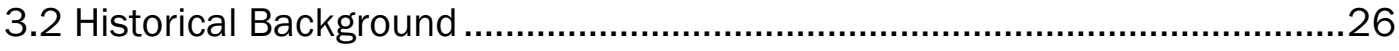

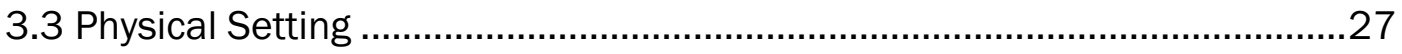

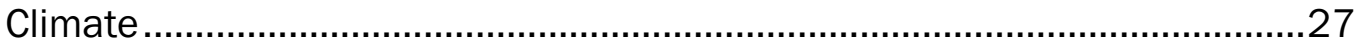

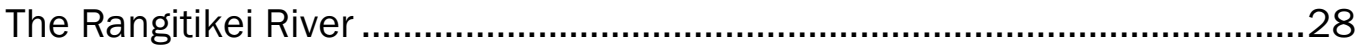

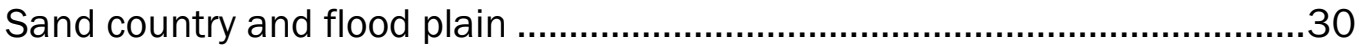

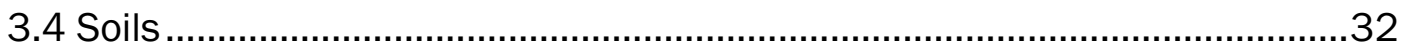

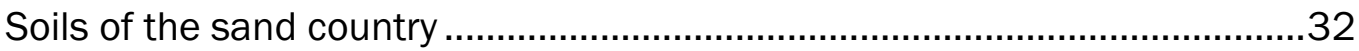

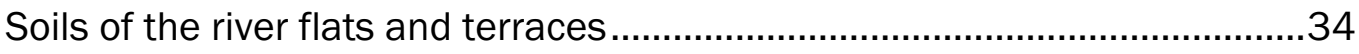

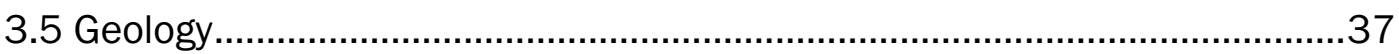

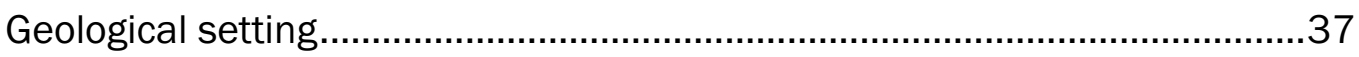




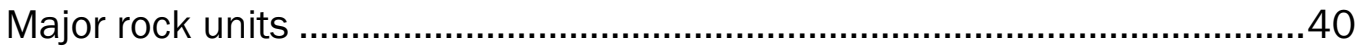

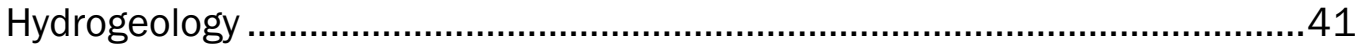

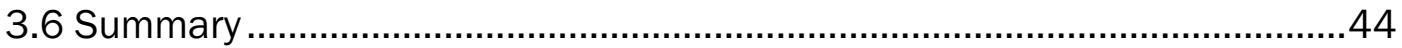

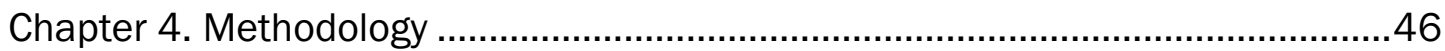

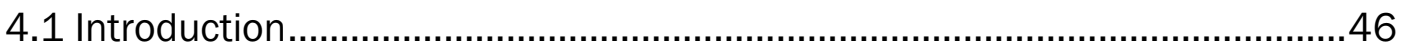

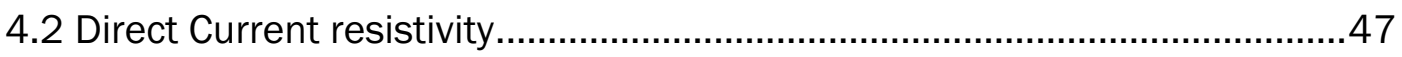

Vertical electrical soundings ....................................................................4 4

Electrical resistivity traversing................................................................ 51

4.3 Airborne geophysical survey .................................................................5

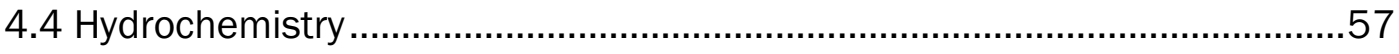

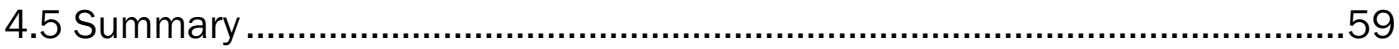

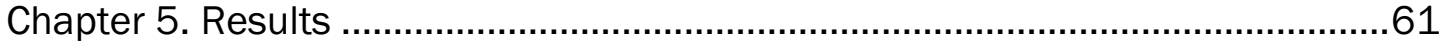

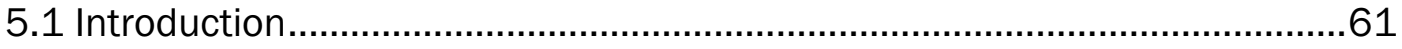

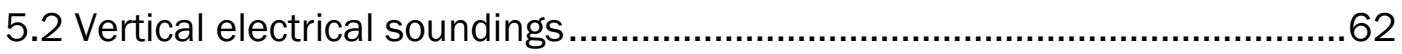

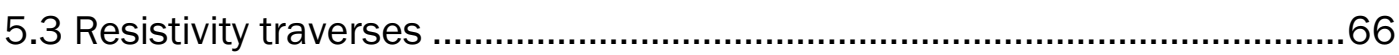

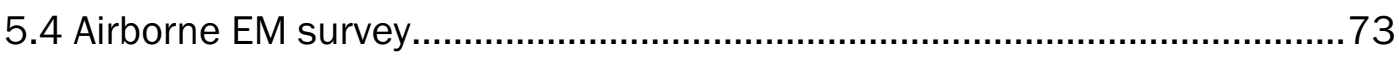

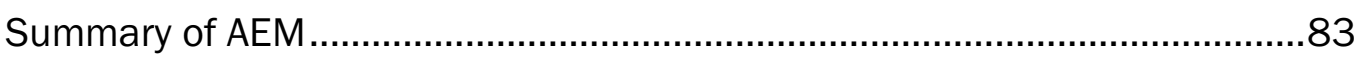

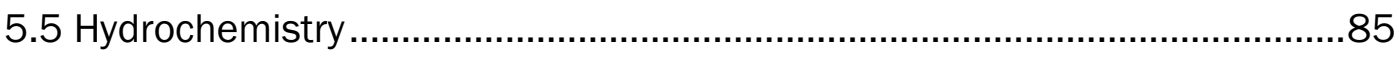

Water chemistry analyses...................................................................... 86

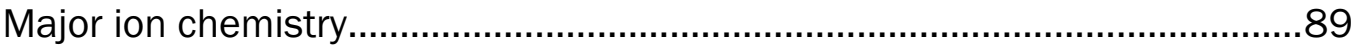

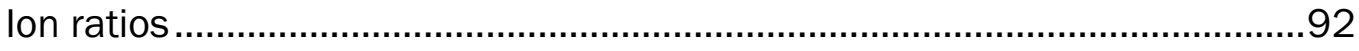

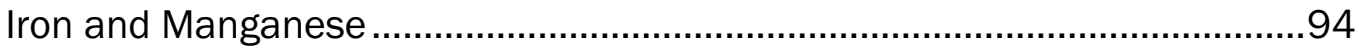

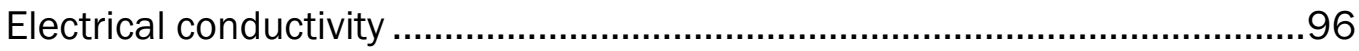

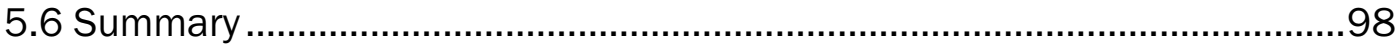

Chapter 6. Interpretation and Discussion ...........................................................99

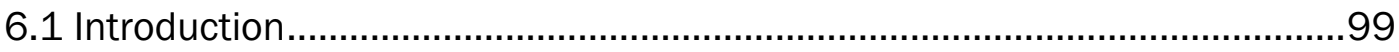

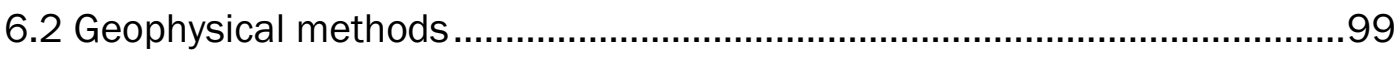

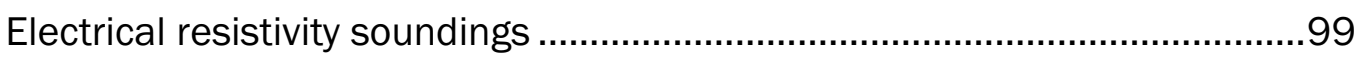

Electrical resistivity traverses................................................................ 100

Airborne electromagnetic survey ............................................................. 102

Summary of geophysical methods ............................................................... 104

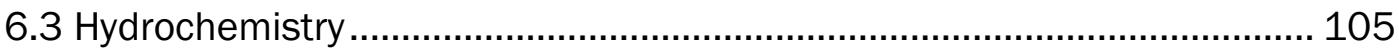

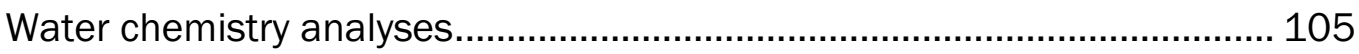

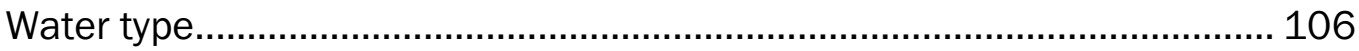




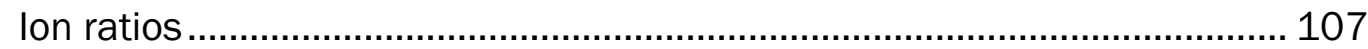

Iron and manganese ions ..................................................................... 108

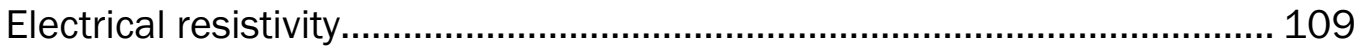

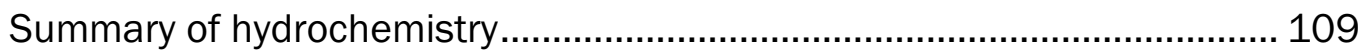

6.4 Integration of hydrochemistry and geophysical..................................... 110

Formation factor........................................................................................ 111

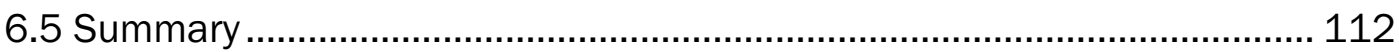

Chapter 7. Conclusion and Implications.......................................................... 114

7.1 Summary and conclusions...................................................................... 114

7.2 Implications for groundwater management ............................................. 116

7.3 Recommendations for future research................................................. 117

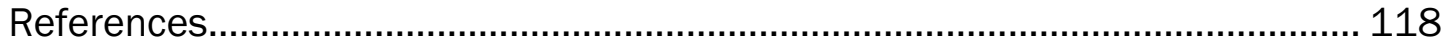

Appendices

Appendix 1: Hydrochemistry

Appendix 2: Sounding curves

Appendix 3: Resistivity traverses 


\section{List of Figures}

$\begin{array}{lll}2.1 & \text { Local, intermediate and regional groundwater flow systems } & 7\end{array}$

2.2 The Ghyben-Herzberg saline interface 11

2.3. Freshwater - saltwater interface in an idealised coastal aquifer 12

2.4 Spreading due to mechanical dispersion and molecular diffusion 13

$\begin{array}{lll}2.5 & \text { Discharging well capturing brackish water } & 16\end{array}$

2.6 Relationship between flow regimes and hydrochemical properties in 21 groundwater

3.1 The location of the Rangitikei Catchment and study area 24

3.2 The location of the Rangitikei River mouth, Tangimoana, 24 and Scott's Ferry

3.3 Vegetation cover of the Rangitikei delta 25

3.4 The main channel through the Rangitikei estuary prior to modification 30

3.5 Map showing the dune phases 31

3.6 Soil Series of the Rangitikei delta 34

3.7 Relation of soil series to topography of river flats 35

3.8 Section between Tangimoana and the Ruahine Ranges showing the 39 relationship between structure and relief

3.9 Geological subdivision of the Manawatu-Horowhenua area 41

3.10 The surface extent of major water quality zones in the 42 Manawatu-Horowhenua region

3.11 Section through the Holocene marine wedge near Tangimoana 43

3.12 Modelled drawdown in the Upper Aquifer group in the 44 Rangitikei delta area

4.1 The Schlumberger configuration and modelled sounding curve 48

4.2 Location of soundings and sampled groundwater bores 50

4.3 The arrangement of electrodes for a 2-D electrical survey 51

4.4 Locations of traverses W1-W5 52

4.5 The ARES-G4 equipment used for resistivity traverses 53

4.6 The helicopter and "bird" used for the airborne EM survey 56

4.7 Airborne geophysical surveys and tie lines 56

4.8 Geophysical survey lines of interest in relation to traverses 57

5.1 Comparison of soundings S2 and S4 with bore logs 63

5.2 Sounding curves of S1 and S6 64

5.3 Variation in apparent resistivity at $10 \mathrm{~m}$ depth 66

5.4 A 2-dimensional inversion model of Traverse W1 67 
5.5 A 2-dimensional inversion model of Traverse W4 68

5.6 A 2-dimensional robust inversion model of Traverse W4 69

5.7 A 2-dimensional inversion model of Traverse W2 69

5.8 A 2-dimensional inversion model of Traverse W3 70

5.9 A 2-dimensional inversion model of Traverse W5 71

$\begin{array}{lll}5.10 & \text { Compiled traverses } & 72\end{array}$

5.11 A lateral resistivity map for the frequency of $40 \mathrm{k} \mathrm{Hz}$

5.12 A lateral resistivity map for the frequency of $8200 \mathrm{~Hz}$

5.13 A lateral resistivity map for the frequency of $1800 \mathrm{~Hz} \quad 76$

$\begin{array}{lll}5.14 & \text { Resistivity profile Sgy30220 } & 78\end{array}$

5.15 Resistivity profile Sgy30230 80

5.16 Resistivity profile Sgy30240 82

5.17 Resistivity profile Sgy30250 84

5.18 Locations of sampled groundwater bores 86

$\begin{array}{ll}5.19 \text { Stiff diagrams of groundwater samples } & 91\end{array}$

$\begin{array}{ll}5.20 & \text { Bivariate plot of Calcium and Bicarbonate }\end{array}$

$\begin{array}{ll}5.21 & \text { Bivariate plot of Sodium and Chloride } 93\end{array}$

5.22 Bivariate plot of Calcium and Chloride 94

5.23 Concentration of dissolved Fe ions in groundwater sampled 95

5.24 Concentration of dissolved Mn ions in groundwater sampled 96

5.25 Relationship between electrical conductivity and total dissolved solids $\quad 97$ 


\section{List of Tables}

2.1 Range of hydraulic conductivities for various sediments 9

5.1 Chemical composition of groundwater samples 88

5.2 The water type of groundwater sampled 89

5.3 The electrical conductivity, electrical resistivity, and calculated total 97 dissolved solids of the groundwater sampled

6.1 The calculated formation factor for the geological units present 111 in the traverses

6.2 Estimated fluid resistivity, conductivity, and TDS for the bulk resistivity contours 


\section{List of Equations}

2.1 Hydrologic budget 6

2.2 Darcy's law 8

2.3 Transient, saturated flow continuity equation 9

$\begin{array}{lll}2.4 & \text { Transmissivity } & 10\end{array}$

2.5 Ghyben-Herzberg approximation 11

2.6 Ghyben-Herzberg relation 11

2.7 Longitudinal coefficient of hydrodynamic dispersion 12

2.8 Archie's Law 18

$\begin{array}{lll}2.9 & \text { Formation factor } & 18\end{array}$

$\begin{array}{lll}4.1 & \text { Schlumberger geometric factor } & 47\end{array}$

4.2 Wenner geometric factor 51

$\begin{array}{lll}4.3 & \text { Total dissolved solids equation } & 58\end{array}$ 


\section{Chapter 1.}

Introduction

Coastal aquifers are vital sources of fresh water throughout the world. Population growth and agricultural development in coastal areas has increased the demand for freshwater. As a result of this demand more stress is being placed on coastal aquifers. Saltwater intrusion is arguably the most common contamination problem in aquifers, and a major constraint imposed on groundwater utilisation (Bear et al., 1999). Saline contamination of freshwater resources can cause significant social, economic and environmental costs.

A natural equilibrium exists between discharging fresh groundwater and seawater in coastal aquifers. This is referred to as the saline interface in this study, but it is also known as the sea/saltwater-freshwater interface. The position of the saline interface is dynamic and depends on the geological formation, hydraulic gradient, topography, and the quantity of freshwater moving through the aquifer system (Schwartz and Zhang, 2003). A reduction in groundwater recharge, or an increase in abstraction, can reduce the hydraulic gradient, the freshwater hydrostatic pressure, and the movement of freshwater. This can cause the saline interface to move landwards resulting in saline intrusion and a reduction in water quality. The chloride concentration indicative of saline intruded groundwater is $300 \mathrm{mg} / \mathrm{l}$. As seawater has a chloride concentration of approximately $19 \mathrm{~g} / \mathrm{l}$, very little seawater is required to contaminant freshwater (McDonald et al., 1998). Therefore, proactive management of coastal aquifers is essential to ensure sustainable water resource development. 
In estuarine environments, the saline interface is influenced by a number of processes forming a complex and variable system. The density contrast between fresh groundwater and saline water leads to mixing and convective circulation at the saline interface. The interface is thus characterised by a zone of diffusion as the saline water mixes with the discharging freshwater. Tidal activity can induce a fluctuating water table changing the position of the interface. Infiltration of surface waters into the sediments can also form a surficial mixing zone (Westbrook et al., 2005).

There has been little research along the Horowhenua-Manawatu coast on the problem of saline intrusion. However, Gyopari (2005) identified the Rangitikei delta as a high risk area because of the increase in consented high volume abstractions (approximately $31,500 \mathrm{~m}^{3} /$ day). These consents are largely for abstractions from the Foxton aquifer, a shallow unconfined/semi-confined aquifer.

The number of groundwater abstraction consents has increased greatly since 2000 . The coastal communities of Tangimoana and Scott's Ferry also have a long history of using shallow groundwater bores to supplement the water supply. Many of the bores in Tangimoana and Scott's Ferry, however, are not recorded on the Horizons Regional Council (HRC) database. The cumulative effect of pumping over decades is likely to have influenced the saline interface given the close proximity of the communities to the seashore, the shallow depth of the boreholes, the low peizometric gradient, and the variable but often high transmissivities of the groundwater. Previous research at Te Horo beach found that the cumulative effect of years of abstraction from shallow groundwater bores had caused the saline interface to move $10 \mathrm{~m}$ further inland (Wilson et al., 2006).

It is important to quantify the effects of pumping on both the shallow groundwater system, and the dynamics of the saline interface. This is necessary to protect the groundwater against saline intrusion in the face of an increased number of high volume groundwater consents. Locating the saline/freshwater interface and monitoring its dynamics are essential for sustainable management of coastal groundwater systems. The position of the saline interface, however, is not static and is likely to be a transitional zone of changing salinity rather than a distinct boundary. Therefore it is unlikely that discrete measurements will detect these changes (Ingham et al., 2006). 
Changes in water chemistry occur across the saline interface. Distinct differences between the solute concentrations mean that the electrical conductivity of seawater is approximately 100 times greater than that of freshwater (Ingham et al., 2006). Because of this difference in electrical conductivity, the change between saline and fresh water can be readily determined using geophysical resistivity techniques. Resistivity is recognised as an efficient technique for assessing groundwater resources, and it has a wide application on shallow aquifers (Sherif et al., 2006). Resistivity techniques have the advantage of being non intrusive, relatively inexpensive, and can be used for rapid and economical monitoring over large areas. However, there are some limitations to resistivity techniques. Formations with similar resistivity are sometimes hard to distinguish, and the cause of low resistivity from reduced water quality is not easily determined (Choudhury and Saha, 2004).

Chemical analyses of groundwater samples are helpful in studying the hydrogeological conditions and saline contamination of aquifers. Chemical methods of groundwater investigation are most useful in areas with a high concentration of boreholes. However, chemical analysis of water can also be used to indicate saline intrusion and can be used to calibrate the salinity indicated by geophysical methods. The chemistry of seawater is generally uniform and stable because of the long term residence of the major constituents (Jones et al., 1999). Saline intrusion is typically identified by the presence of $\mathrm{Cl}^{-}$in high concentrations; and the ratios of $\mathrm{Ca}^{2+} / \mathrm{Cl}^{-}, \mathrm{Cl}^{-} / \mathrm{Br}^{-}, \mathrm{Na}^{+} / \mathrm{Cl}^{-}, \mathrm{Ca}^{2+} / \mathrm{Mg}^{2+}$ and boron isotopes.

The primary aim of this research was to determine the characteristics and dynamics of the saline interface of the shallow unconfined aquifer in the vicinity of Tangimoana, Scott's Ferry at the Rangitikei River estuary. Specifically, the objectives of this research were to:

- Define the freshwater boundaries of the shallow groundwater in the Rangitikei delta.

- Determine the location, shape and dynamics of the saline interface of the shallow unconfined aquifer.

- Identify the species, and movement of total dissolved solids in the shallow groundwater. 
This study used techniques such as vertical electrical sounding (VES) and resistivity traversing to determine the location and shape of the saline interface. These results were then compared to those from frequency domain electromagnetic methods. Water quality sampling allowed the determination of the species of total dissolved solids present in the groundwater. The cation-anion associations were used to characterise the source and movement of the saltwater in the aquifer. 


\section{Chapter 2.}

\section{Groundwater in a coastal environment}

\subsection{Introduction}

Groundwater is a major source of freshwater, accounting for almost $99 \%$ of the total volume of circulating freshwater today (Younger, 2007). With much of the world's population living along coasts, coastal aquifers are very important sources of freshwater. These aquifers are connected to the sea and an interface exists between the fresh and saline waters. In many areas around the world this saline interface has moved landward causing saline intrusion when groundwater abstraction has exceeded recharge (Bear et al., 1999). An understanding of the recharge, movement and interaction of groundwater are essential to provide adequate management of water resources. This chapter provides a discussion of groundwater movement, saline interfaces and groundwater/surface water interactions. It focuses specifically on unconfined aquifers, and provides a basis for the methodologies used in this study.

\subsection{Groundwater flow}

Groundwater flow systems define water movement from zones of recharge to zones of discharge. Toth (1963) recognised a hierarchal order of three distinct groundwater flow systems; local, intermediate and regional. These systems were distinguished on the basis that groundwater moves along flow paths that are organised in space. Groundwater 
systems are largely controlled by climate, geology and topography. Climate has a major influence on the groundwater system hydrologic budget. Precipitation affects recharge, and ambient conditions such as atmospheric temperature, humidity and solar radiation affect evapotranspiration (Sophocleous, 2002; Younger, 2007). The water stored in a groundwater system can be described using a hydrologic budget:

$$
I+G_{\text {in }}-G_{\text {out }}-Q_{g}-E T_{g}=\Delta S_{g}
$$

where:

$$
\begin{aligned}
& \text { I } \quad=\text { Inputs into the system i.e. infiltration from rainfall or surface bodies } \\
& G_{\text {in }} \quad=\text { Groundwater flow into the system } \\
& G_{\text {out }} \quad=\text { Groundwater flow out of the system } \\
& E T_{g} \quad=\text { Evapotranspiration } \\
& Q_{g} \quad=\text { Groundwater flow into surface waters } \\
& \Delta S_{g} \quad=\text { Changes in water storage }
\end{aligned}
$$

(After Equation 1.6.2 in Todd and Mays (2005), page 21)

The geology and topography of an area are the major controls on how groundwater will flow, and where the recharge and discharge zones of the system are located. Geological parameters such as stratigraphic relationships, structure and aquifer heterogeneity can affect areas of recharge and discharge. They also control the hydraulic characteristics of a groundwater system (Freeze \& Cherry, 1979). Groundwater will flow from recharge areas to discharge areas along preferential flow paths that have the highest permeability. Zones of high permeability within the groundwater media will act as 'drains'. This will increase the vertical gradient in the overlying media, and reduce the horizontal gradient resulting in an increased rate of groundwater flow (Freeze and Cherry, 1979; Sophocleous, 2002).

The topography of an area defines the scale of a flow system, as it affects the recharge and discharge zones of the system (Toth, 1962; Toth, 1963). Local flow systems develop in areas of pronounced topographic relief. Recharged local flow systems will discharge from a topographic high to an adjacent topographic low, usually into surface water 
bodies. They are the shallowest, and the most dynamic system as most groundwatersurface water interactions occur in the local flow system (Winter et al., 1998). The largest amount of groundwater flow is in a local flow system. It is mostly affected by seasonal variations in recharge, and has relatively shallow and transient conditions. Topography determines hydraulic gradient and so affects the groundwater flow direction. The relative relief of an area will determine how far water will travel between its recharge and discharge points. In an area of homogeneous geology, the watertable is often a subdued version of surface topography. Beneath an undulating surface, such as a dune field, a groundwater system will develop with a water table that mirrors the land surface, provided that precipitation is relatively uniform (Hubbert, 1940; Schwartz and Zhang, 2003; Toth, 1963).

Local flow systems are underlain by intermediate and regional flow systems. An intermediate flow system has at least one topographic high and low located between the recharge and discharges area. However, it does not occupy the highest and lowest elevated places (Toth, 1963). A regional groundwater flow system will recharge from the water divide and discharge to the lowest topographic area in the catchment. This flow system will develop when topographic relief is negligible, and local and intermediate groundwater flow systems are stagnant (Figure 2.1).

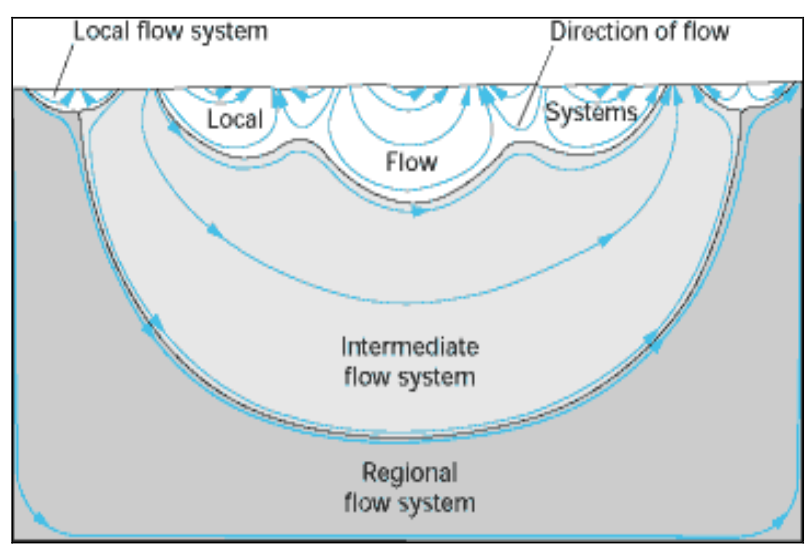

Figure 2.1 Local, intermediate and regional groundwater flow systems (From Winter et al. 1998, modified from Toth, 1963) 


\section{Groundwater movement}

Groundwater flow in an aquifer is defined by Darcy's Law. It expresses the velocity of groundwater flow as a function of the hydraulic gradient and hydraulic conductivity of the aquifer medium.

$$
V=-K(d h / d l)
$$

where:

$V \quad=$ Groundwater flow velocity (m/day)

$K=$ Hydraulic conductivity ( $\mathrm{m} /$ day)

$d h / d l=$ Hydraulic gradient

(After Equation 2.3 in Freeze and Cherry (1979), page 16)

The hydraulic gradient determines the direction, and relative velocity of groundwater flow. It is the measure of the change in hydraulic head $(d h)$ across a given distance $(d l)$. The hydraulic head represents the potential energy of the subsurface water at any given point and is determined from the water level pressure and elevation of the point relative to a specified datum (Younger, 2007). Groundwater flows from a high hydraulic head to a lower hydraulic head (Bear, 2007).

Hydraulic conductivity is the specific discharge per unit of hydraulic gradient. It expresses the ease with which a fluid can move through a porous matrix (Freeze and Cherry, 1979). The properties of the medium matrix that determine hydraulic conductivity are mainly grain/pore size distribution, shape of grains, tortuosity, specific surface area and porosity (Bear, 2007). In a saturated zone, the hydraulic conductivity will largely depend on the geometry and distribution of the pore spaces. A highly permeable unit, such as sand or gravel will have a large hydraulic conductivity. While less permeable units, for example clay or silt, will have a relatively small value (Table 2.1) (Schwartz and Zhang, 2003). 
Table 2.1 Range of hydraulic conductivities for various sediments (after Table 3.4 in Schwartz and Zhang (2003), page 51).

\begin{tabular}{|l|l|}
\hline Material & Hydraulic Conductivity $(\mathrm{m} / \mathrm{s})$ \\
\hline Gravel & $3 \times 10^{-4}-3 \times 10^{-2}$ \\
\hline Coarse sand & $9 \times 10^{-7}-6 \times 10^{-3}$ \\
\hline Medium sand & $9 \times 10^{-7}-5 \times 10^{-4}$ \\
\hline Fine sand & $2 \times 10^{-7}-2 \times 10^{-4}$ \\
\hline Silt, Loess & $1 \times 10^{-9}-2 \times 10^{-5}$ \\
\hline Clay & $1 \times 10^{-11}-4.7 \times 10^{-9}$ \\
\hline
\end{tabular}

The groundwater flow in an aquifer is actually three-dimensional. However, as most aquifers are thin relative to their horizontal dimensions, it can be assumed that flow is essentially horizontal (Bear, 2007). The Dupuit-Forchheimer approximation assumes that in unconfined aquifers most groundwater flowlines are horizontal and equipotentials are vertical. The hydraulic gradient is assumed to be equal to the slope of the water table and it does not vary with depth (Freeze and Cherry, 1979). Except near recharge and discharge zones, groundwater flow is therefore assumed to be horizontal.

As groundwater flow in an aquifer is treated as essentially two-dimensional, Darcy's Law is modified by combining it with a differential continuity equation to describe the flow of pore water (Bear, 2007). The corresponding equation for two-dimensional, transient, saturated flow through a cross-section in a soil medium, as predominantly occurs in tidal marshes is described as:

$$
\frac{\partial^{2} h}{\partial x^{2}}+\frac{\partial^{2} h}{\partial z^{2}}=\frac{S_{S}}{K} \frac{\partial h}{\partial t}
$$

Where $K$ is the hydraulic conductivity (m/day), $d h / d x$ is the gradient in hydraulic head in the $x$ direction, $x$ and $z$ represent the respective horizontal and vertical directions in the flow field, and $S_{S}$ is the specific yield (After Harvey et al, 1987). The specific yield 
refers to the storage property of an unconfined aquifer. It is directly related to the porosity of the matrix and it is defined as the volume of water that an unconfined aquifer releases from storage per unit surface of aquifer per unit decline in the water table (Freeze and Cherry, 1979).

\section{Aquifer Transmissivity}

The transmissivity of an unconfined aquifer is defined by the rate of flow per unit width through the entire thickness of an aquifer per unit hydraulic gradient. This concept is, however, only valid in two dimensional or aquifer type flow (Bear, 2007).

$$
T=K b
$$

where:

$T=$ transmissivity

$K=$ hydraulic conductivity

$b=$ the saturated thickness of the aquifer

\subsection{Coastal aquifers and the saline interface}

Coastal aquifers that are hydraulically connected to the sea have a saline interface where a zone of contact is formed between the lighter freshwater and the denser underlying sea water within the pore spaces of sediments (Bear, 2007). There are two different approaches to studying the saline interface. The first assumes that the saline interface is a sharp boundary between immiscible freshwater and saltwater and leads to the GhybenHerzberg approximation (Figure 2.2). Under simple hydrostatic conditions in a homogeneous, unconfined coastal aquifer, the depth of the interface between salt water and fresh water must be related to the height of the water table (Freeze and Cherry, 1979). The Ghyben-Herzberg approximation assumes that the saline interface is a sharp boundary between freshwater of density $\rho_{\mathrm{f}}$ and salt water density of $\rho_{\mathrm{s}}$. At the coast there is zero head $\left(\mathrm{z}_{\mathrm{w}}\right)$ of fresh water. Equating hydrostatic pressures below sea level 
leads to the relation between the saline interface below sea level as a function of the fresh water head $\left(\mathrm{z}_{\mathrm{w}}\right)$ as:

$$
Z_{s}=\frac{\rho_{f}}{\rho_{s}-\rho_{f}} Z_{w}
$$

$$
\text { As } \rho_{\mathrm{f}}=1000 \mathrm{~kg} / \mathrm{m}^{3} \text { and } \rho_{\mathrm{s}}=1025 \mathrm{~kg} / \mathrm{m}^{3} \text {, then: }
$$

$$
z_{s}=40 z_{w}
$$

(After Equation 8.76 and 8.77 in Freeze and Cherry, (1979) page 376)

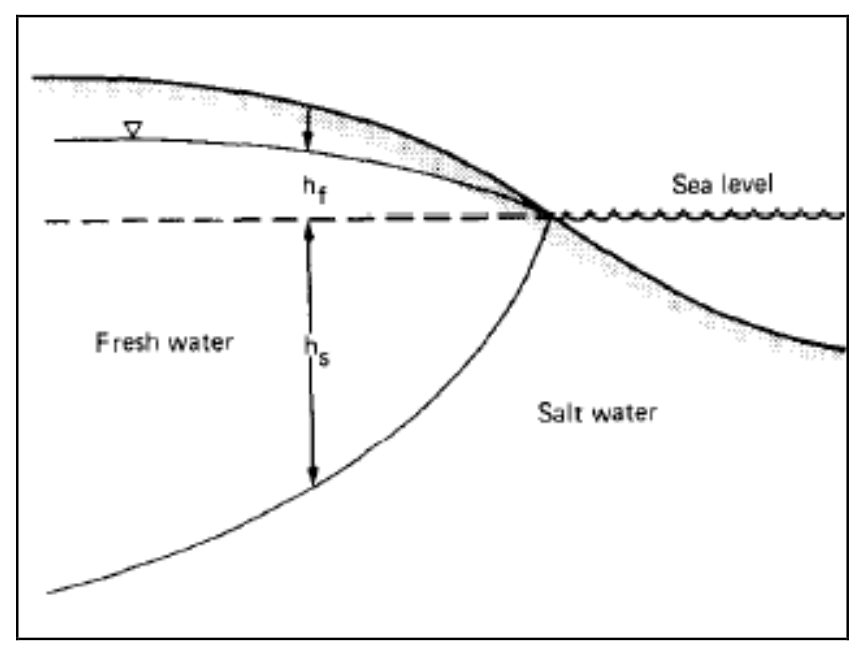

Figure 2.2 The Ghyben-Herzberg saline interface. The height of the interface is denoted as $h_{s}$ in this diagram. (From Essaid, 1986)

The pressures are equal on both sides of the interface for an equilibrium condition to exist. The mixing of fresh groundwater and seawater is not considered. The GhybenHerzberg solution is appropriate when groundwater flow is large and the interface is small compared to the size of the aquifer (Bear, 2007).

The alternative density-dependant solute transport approach assumes that the saline and fresh waters are miscible fluids and that the saline interface is a transition zone caused by hydrodynamic dispersion (Bear, 2007; Ranjan et al., 2006). Fresh and saline waters 
are miscible fluids. Therefore the saline interface is actually a transition zone caused by the processes of dispersion and molecular diffusion (Bear, 2007). Across the saline interface, the density of the mixed water changes from fresh water to that of sea water (Figure 2.3). The size of the zone is controlled by the dispersive characteristics of the aquifer medium. There has been much study of the saline interface, and the dynamics of the two miscible fluids in a porous media (Bear, 2007; Watson et al., 2002).

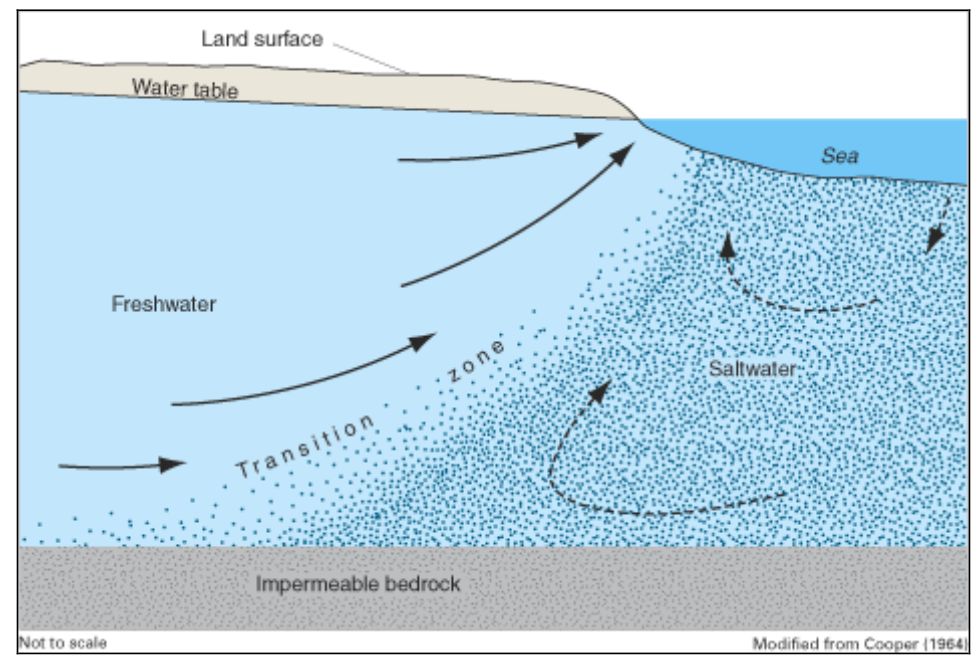

Figure 2.3. Freshwater - Saltwater interface in an idealised coastal aquifer (From Barlow, 2003)

Hydrodynamic dispersion describes the spreading of a solute, in this case saline water, at the macroscopic level. This results from both the mechanical dispersion and the molecular diffusion that occurs at a microscopic level (Bear, 2007). Hydrodynamic dispersion in a porous medium describes the gradual spread of a solute within a groundwater flow. It is the spread that occurs beyond what would be expected by flow alone, and cannot fully be explained by Darcy's Law. The longitudinal coefficient of hydrodynamic dispersion is described as:

$$
D_{L}=\alpha_{L} \bar{v}+D^{*}
$$

where:

$\alpha_{L}=$ dynamic longitudinal dispersivity, a characteristic property of the porous medium 
$\bar{v}=$ average linear groundwater velocity

$D^{*}=$ molecular diffusion or effective diffusion coefficient

(After Equation 8.8.5 in Todd and Mays (2005) page 382)

At a microscopic level inside the pore, the flow velocity varies in both magnitude and direction across any pore cross section. The maximum velocity will vary according to pore size, and the shape of the interconnected pore space (Figure 2.4a) (Bear, 2007). The streamlines or flow paths fluctuate in space with respect to the mean direction of flow. This causes spreading of the solute. Flow is longitudinal in the direction of the average flow but also moves transversely as the streamline moves around the pores (Figure 2.4b). This spreading is referred to as mechanical dispersion or convective dispersion. Mechanical dispersion is affected by inhomogeneity within pores and grains, and variations in permeability from one flow domain to the next on a macroscopic scale.

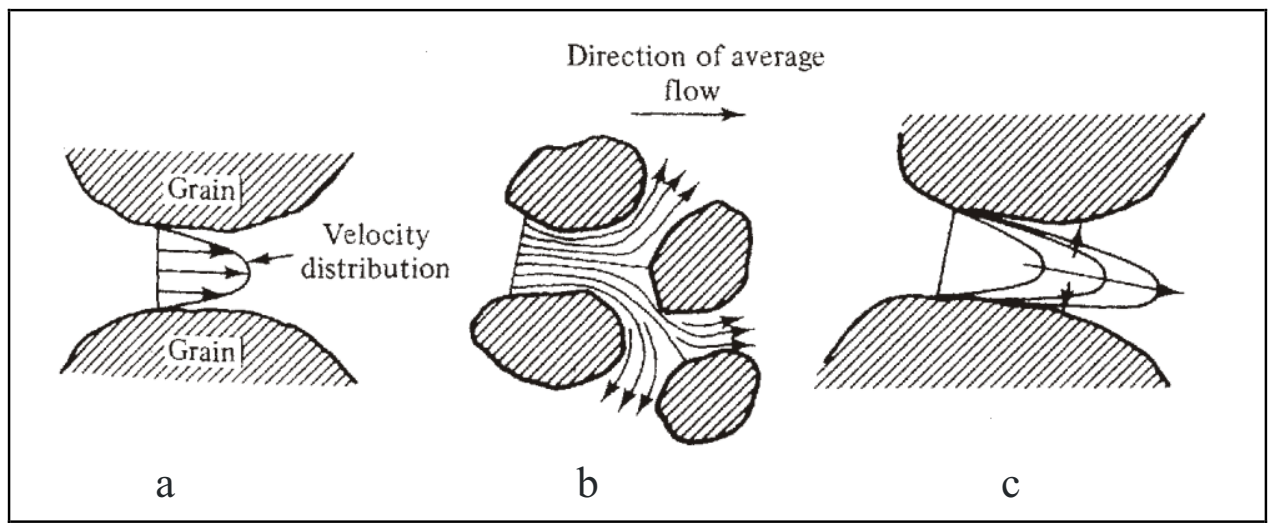

Figure 2.4 Spreading due to mechanical dispersion and molecular diffusion (From Bear, 2007).

Once the solute is spread via mechanical dispersion, a concentration gradient is produced. Molecular diffusion is the process where solute ions move under the influence of their kinetic energy in the opposite direction to the concentration gradient (Freeze and Cherry, 1979). This produces an additional flux of solute from areas of higher concentration to lower concentration. Molecular diffusion will try to equalise the concentrations along the streamline, and between adjacent streamlines, causing 
molecular diffusion across them (Figure 2.4c). It is molecular diffusion that makes the phenomenon of hydrodynamic dispersion irreversible (Bear, 2007).

Diffusion mixes the salt into the adjacent fresh water and the solute may interact with the solid surface of the porous matrix. This interaction may result in adsorption of particles onto the solid surface, causing deposition or solution of the solid matrix through ion exchange. These interactions can change the concentration of the solute, in turn changing the density and viscosity of the groundwater, and this affects the flow regime. During a falling tide, fresher water penetrates along the same paths and gain salt by diffusion. The permeability and preferential flow paths may be changed by the solute interaction with the solid surface of the porous matrix. Precipitation of solids can restrict some flow paths while dissolution will enlarge existing paths, or open new ones (Bear, 2007; Moore, 1999).

The saline interface is rarely stable either in space or time. Its position and size depend on many factors, including the hydraulic gradient, the quantity of freshwater moving through the aquifer system, the density contrast between freshwater and sea water, tidal fluctuations, and the effect of beach slope (Barlow, 2003; Mao et al., 2006; Nielsen, 1990; Schwartz and Zhang, 2003). A reduction in groundwater recharge, or an increase in abstraction, can reduce the hydraulic gradient, the freshwater hydrostatic pressure, and therefore the movement of freshwater. Analytical solutions have modelled tide-induced groundwater fluctuations, and quantified the effect of beach slope, aquifer leakage, density differences and tidal signal (Cartwright et al., 2004; Mao et al., 2006; Nielsen, 1990).

Landward movement of the saline interface can occur as a result of tidal oscillation; this effect is more pronounced at the top of the aquifer near the water table than at its base. This is because of salt water seeping into the aquifer at higher tide levels. This effect is greater in a low relief beach (Ataie-Ashtiani et al., 1999). However, as the tidal signal propagates inland, the amplitude of the groundwater fluctuation decreases exponentially as the phase of the signal is shifted (Mao et al., 2006; Nielson, 1990). The tidal oscillation has a reduced effect on the inland movement of the interface if the aquifer is much deeper than the amplitude of the tidal oscillation (Ataie-Ashtiani et al., 1999). Morrow (2007) found that there was no significant movement of the saline interface 
over a tidal cycle at Paraparaumu Beach on the Kapiti Coast. Tides appeared to only affect the saline interface at the tide cycle scale when the interface was located beneath the beach and within the reach of wave run-up. In such situations the dynamics of the saline interface were more strongly influenced by seawater infiltration from wave run-up than the change in tidal level.

\section{Estuarine environments}

In estuarine environments, the saline interface is influenced by a number of processes forming a complex and variable system. The density contrasts between fresh surface water and saline water leads to mixing and convective circulation within the estuary. The system is therefore characterised by a zone of diffusion, or a wedge, as the saline water mixes with the discharging freshwater. Density contrasts between the brackish estuarine water and adjacent fresh groundwater systems are sufficient to drive mixed-convection cells. This allows the circulation of brackish water in the aquifer. It also provides a mechanism to transport nutrients and contaminants between the nutrient rich pore fluids in the estuary and the groundwater (Westbrook et al., 2005; Trefry et al., 2007).

The groundwater flow in estuarine environments is influenced by a number of hydrologic factors that vary temporally. These factors include annual changes in the mean tide, fluctuations over a tidal cycle, storm surges, and seasonal variations in rainfall and evopotranspiration (Carter et al., 2008; Trefry et al., 2007; Westbrook et al., 2005).Tidal activity can induce a fluctuating water table, changing the position of the interface. Infiltration of brackish estuarine waters into sediments can occur during spring tides and storm surges. This forms a surficial mixing zone in the surface soil matrix and the underlying aquifer (Westbrook et al., 2005). The rate of evapotranspiration significantly influences salt concentration in the surface soil matrix. Rainfall infiltration dilutes the salt concentration in the surface soils, and moves the salt into the saturated zone (Hughes et al., 1998; Nuttle and Harvey, 1994). 


\section{The effect of wells on the saline interface}

The saline interface can move vertically upward in response to a pumping well in the freshwater zone (Bower et al., 1999). Analytical and numerical solutions for determining the pumping rate at which the cone will become unstable have been developed. These are based on both the sharp interface approach, and the density dependant solute transport approach (Reilly and Goodman, 1987, Strack, 1976). A stable cone in the interface can develop at some depth beneath the pumping well, and the well will discharge freshwater under certain conditions. At the critical pumping rate, the apex of the cone is still below the bottom of the well, but the cone is in the highest position at which it can remain stable. If the critical pumping rate is exceeded, the cone can become unstable and the interface will move upwards to the bottom of the well. Flow will then occur within the saline water (Figure 2.5) (Bear, 2007). The discharge of the well will become partially saline. The critical pumping rate is determined by local hydrologic conditions (Bower et al., 1999; Reilly and Goodman, 1987).

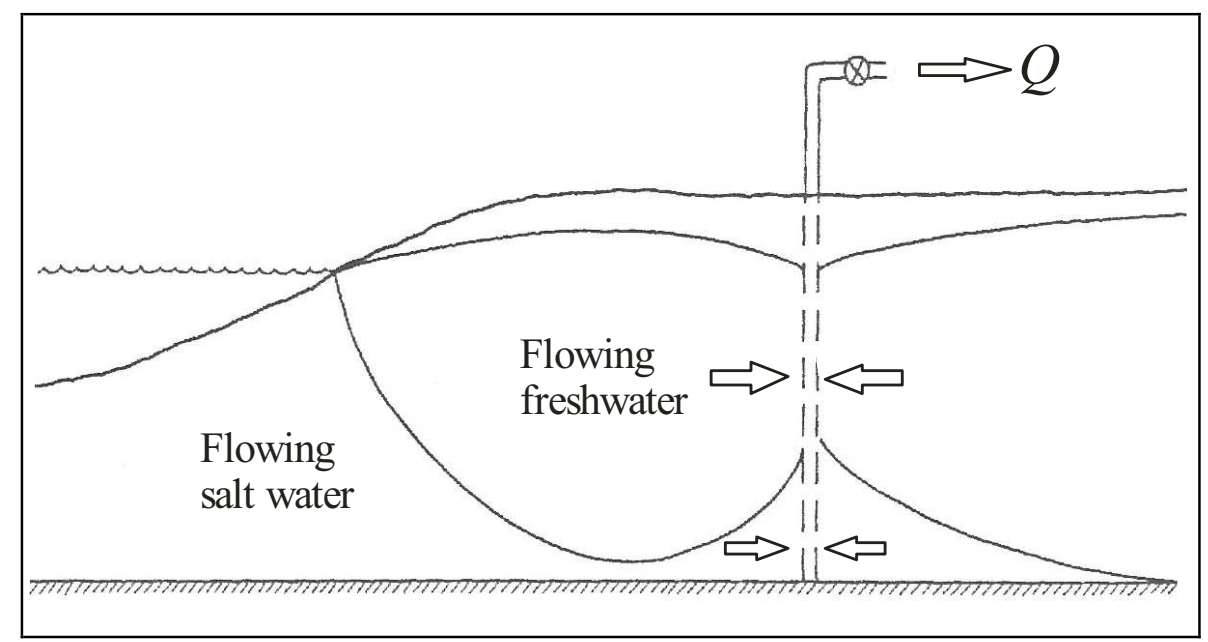

Figure 2.5 Discharging well capturing brackish water (From Strack, 1976) 


\subsection{Investigating the saline interface}

Saline intrusion is a phenomenon that has occurred in many coastal aquifers worldwide. Extensive research has been carried out to understand the saline interface and mechanisms of saline intrusion since the discoveries of Badon-Ghyben and Herzberg over a century ago (Bear and Cheng, 1999). The quantitative understanding of the dynamics of movement and diffusion between freshwater and saltwater in a coastal aquifer are essential for managing coastal groundwater systems. There have been many previous field investigations of the saline interface in coastal aquifers throughout the world. These have provided a basis for understanding the complicated mechanisms and dynamics of the interface. Such investigations have used methods such as geophysical techniques, to locate the saline interface and detect the presence of saltwater in coastal aquifers; and geochemistry analysis to identify the presence and source of salinity.

\section{Geophysical methods}

Geophysical methods can be used to measure the spatial distribution of the physical properties of the subsurface specifically related to the position of water and its quality, and the position and properties of geologic units (Stewart, 1999). Geophysical methods, however, do not directly determine water quality or the geologic units. These must be interpreted from the distribution and magnitude of the physical properties found from geophysical surveys. Electrical methods are the most widely used geophysical method for delineating the saline interface. This is because electrical resistivity is an intrinsic function of groundwater chemistry, and the degree of saline intrusion can be readily interpreted. Electrical methods also have the advantages of being non-intrusive, economical, and are relatively fast (Sherif et al., 2004; Wilson et al., 2006). Such electrical methods include direct current (DC) resistivity and electromagnetic methods (EM). 


\section{Direct Current resistivity}

DC resistivity methods can be used to measure the bulk resistivity of the subsurface. Bulk resistivity represents the resistivity of the entire subsurface, including both the solid and liquid phases. Electrical resistivity is the property which controls the amount of current that passes through a rock when a potential difference is applied, given by ohms law, $V=I R,(V)$ voltage, $(I)$ current, $(R)$ resistance. The resistivity of pore fluid depends upon the concentration of ions in the fluid. Saline water has high concentrations of total dissolved solids, mostly sodium and chloride ions, which are highly conductive. Therefore, water with high salinity has very low resistivity, approximately $0.3 \Omega \mathrm{m}$ for seawater (Wilson et al., 2006). DC resistivity introduces electrical currents into the ground through current electrodes in contact with the soil. The resulting electrical potential (voltage) is measured between two potential electrodes (Stewart, 1999).

The bulk resistivity of the upper few hundred metres of subsurface is largely a function of fluid conductivity and of saturated permeability. With increasing depth the resistivity of the rock becomes more important as pore spaces are closed by pressure (Kirsch, 2006). Bulk resistivity can be described by Archie's law:

$$
\rho=a \phi^{-m} S^{-n} \rho_{w}
$$

where:

$\phi=$ the porosity of the rock

$S=$ the fraction of pores that are fluid filled

$\rho_{w}=$ the fluid resistivity

$a, m, n$ are all constants that depend upon the formation

The values of, $\phi, S, a, m$, and $n$ all relate to the properties of the aquifer medium. They are often abbreviated to $F$, known as the formation factor, giving the equation:

$$
\rho=\rho_{w} \cdot F
$$


The most frequently used DC resistivity technique has been vertical electrical sounding (VES) (Stewart, 1999; Wilson et al., 2006). VES produces a one-dimensional model on the assumption that resistivity varies with depth beneath the centre of an electrode spread. It assumes a horizontal layering of the resistivity structure. Alternatively resistivity traversing can be used to produce a two-dimensional profile showing both lateral and vertical changes of the subsurface. It uses a large number of electrodes in a straight line, generally with equal spacings between them (Ernstson and Kirsch, 2006; Ingham et al., 2006)

\section{Airborne electromagnetic surveys}

The use of an electromagnetic system allows the response of the ground to the propagation of electromagnetic fields to be measured. A primary electromagnetic field is used to induce currents in the ground through a time varying magnetic field produced by frequency controlled AC currents in a transmitter coil. The currents induced in the ground are called eddy currents and a secondary magnetic field is produced by these currents. The strength of the secondary magnetic field is related to the strength of the eddy currents. This is directly related to the conductivity of the earth; the more conductive the earth is the stronger the eddy currents in the ground. A receiver coil senses the sum of the primary and secondary fields. The depth of investigation is determined by the frequency, and the interpreted output is an apparent resistivity map for each frequency (Stewart, 1999).

As the EM method does not require direct contact with the ground, the transmitter and receiver that detect the resultant field can be towed from an aircraft in a sensor or a "bird" (Stewart, 1999). Airborne EM systems were largely developed in the 1950's for mineral exploration (Fountain, 1998) but have found wide acceptance for environmental and engineering applications (Fitterman and Yin, 2004). The advantages of using a helicopter for airborne EM surveys are the ability to fly at a low altitude with a slow flying speed. This allows for maximum anomaly resolution and sensitivity to weak conductors. 


\section{Hydrogeochemistry}

Typically changes in water chemistry occur across the saline interface with distinct differences between the solute concentrations of seawater and fresh groundwater. These changes allow the early stages of saline intrusion to be identified. The chemistry of seawater is generally uniform and stable because of the long term residence of the dominant constituents (Jones et al., 1999). These constituents are major cations $\mathrm{Ca}^{2+}$, $\mathrm{Mg}^{2+}, \mathrm{Na}^{+}$, and $\mathrm{K}^{+}$; and major anions $\mathrm{Cl}^{-}$, and $\mathrm{SO}_{4}^{-}$. Seawater contains approximately $35,000 \mathrm{mg} / \mathrm{L}$ of dissolved solids. The combined $\mathrm{Cl}^{-}$and $\mathrm{Na}^{+}$account for $84 \%$ of the total concentration. Seawater has an excess of $\mathrm{Cl}^{-}$over the alkali $\left(\mathrm{Na}^{+}\right.$and $\left.\mathrm{K}^{+}\right) . \mathrm{Mg}^{2+}$ concentrations are generally greater than $\mathrm{Ca}^{2+}$.

Fresh groundwater, however, tends to have highly variable chemical components. These depend on the geology of the recharge catchment, the aquifer media, and residence time. The dominant constituents of fresh groundwater are the anions $\mathrm{HCO}_{3}{ }^{-}, \mathrm{SO}_{4}{ }^{-}$and $\mathrm{Cl}^{-}$; while the cation $\mathrm{Ca}^{2+}$ tends to be predominant over $\mathrm{Mg}^{2+}$. The most commonly used chemical indication of seawater mixing with freshwater is the presence of chloride ions. Concentrations range from higher than background values to slightly less than seawater concentrations (Richter and Kreitler, 1993). The ratios of $\mathrm{Ca}^{2+} / \mathrm{Na}^{+}, \mathrm{Cl}^{-} / \mathrm{Br}^{-}, \mathrm{Na}^{+} / \mathrm{Cl}^{-}$, $\mathrm{Ca}^{2+} / \mathrm{Mg}^{2+}, \mathrm{SO}_{4}{ }^{-} / \mathrm{Cl}^{-}$and boron isotopes can be used to determine the extent of mixing, residence time, and the source of high total dissolved solids (Jones et al., 1999; Richter and Kreitler, 1993).

The chemical composition of seawater changes within the saline interface as it diffuses with freshwater in response to mixing and chemical reactions (Richter and Kreitler, 1993). Ion-exchange, dissolution/precipitation, and redox reactions can occur in the soil matrix (Hiroshiro et al., 2006). Ion-exchange reactions occur at the front of the zone of diffusion (Figure 2.6), where the solid matrix has free negative surface charges that are occupied by cations. In a fresh water aquifer these cations are predominantly calcium ions; in saltwater they are sodium ions. In response to the landward movement of seawater, an ion exchange reaction occurs and sodium is taken out of solution. Calcium will be released from mineral exchange sites. This $\mathrm{Na}-\mathrm{Ca}$ exchange is most common, but Mg-K exchange can also occur (Richter and Kreitler, 1993). 
Mixing of saline and freshwater can dissolve carbonates. This results in increased concentrations of calcium and bicarbonate. Additional calcium carbonate dissolution may occur in the presence of sulphate reduction because of the change in $\mathrm{pH}$ and $\mathrm{CO}_{2}$ of the water. The sulphate present in seawater is reduced by the fresh groundwater because of the presence of organic rich sediments, such as those found in estuarine environments. This decreases the sulphate concentration. As seawater passes through estuarine sediments it may become enriched with minor constituents such as iodide, strontium and fluoride. These are generally concentrated in estuarine sediments (Richter and Kreitler, 1993).

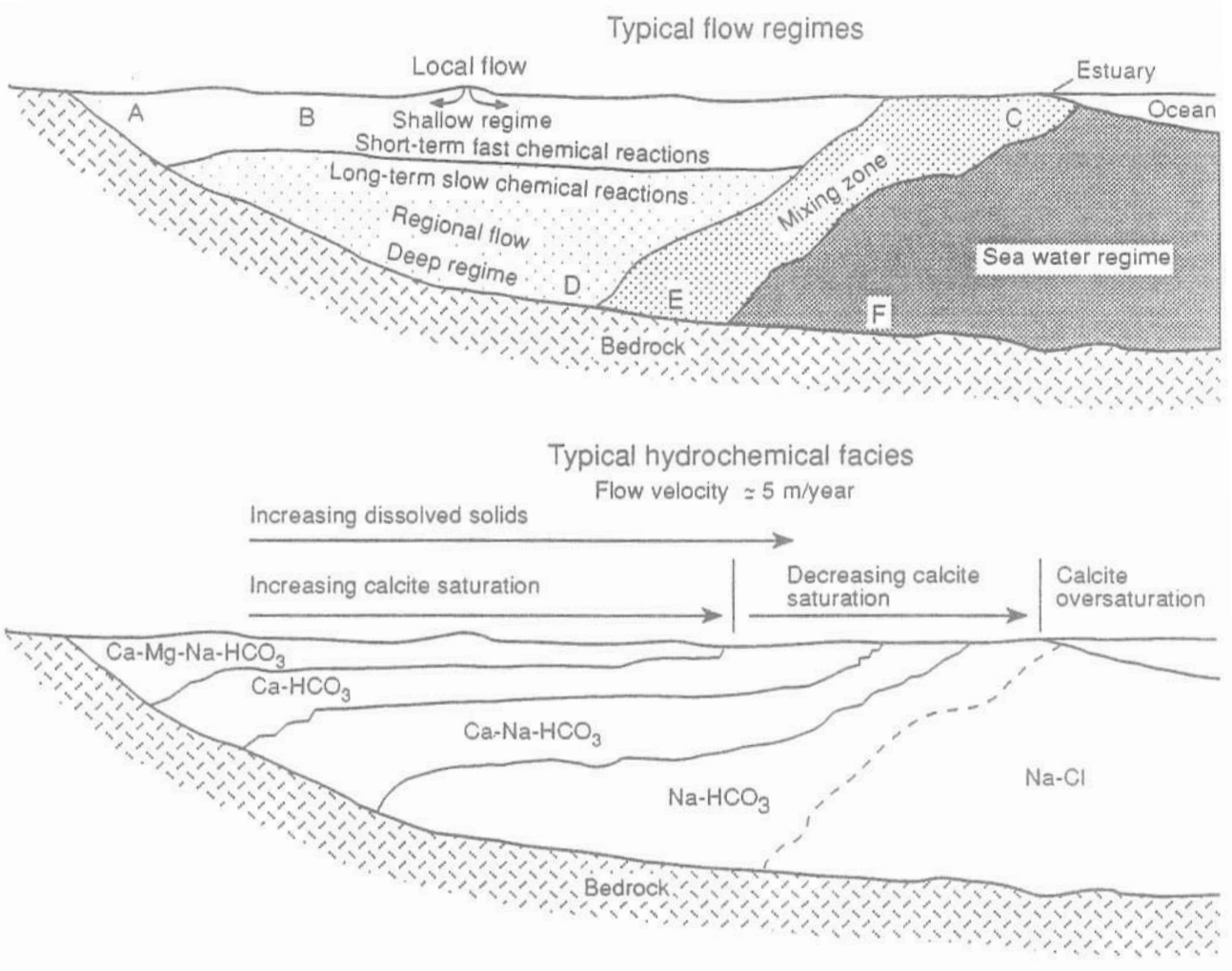

A Feldspar hydrolysis; clay alteration; pyrite oxidation where lagoons exist, poois, and sewage discharge

B Gas generation; ionic exchange; mineral weathering

C Estuary environment; local and regional sea-water encroachment; heavy-metal mobilization

D Solution and precipitation of carbonates; ionic exchange; sultate reduction: evaporite solution; peat and lignite decomposition

E Mineral alterations; cement deposition; dolomitization

F Man-made effects where deep injection of waste water occurs

Figure 2.6 Relationship between flow regimes and hydrochemical properties in groundwater (From Richter and Kreitler, 1993). 


\subsection{Summary}

Groundwater flow is controlled by the hydraulic gradient and hydraulic conductivity of an aquifer. It can be described by Darcy's Law in conjunction with a continuity equation. Groundwater flow is influenced significantly by the topography and geology of a region as these affect both the hydraulic gradient and conductivity. Coastal aquifers that are hydraulically connected to the sea have a saline interface. This transition zone is created by hydrodynamic dispersion of the lighter freshwater flowing to the sea, and the denser underlying sea water within the pore spaces of sediments. The saline interface within an estuary environment is more complex. This is because of additional factors that include annual changes in the mean tide, fluctuations over a tidal cycle, storm surges, and seasonal variations in rainfall and evapotranspiration. The quantitative understanding of the dynamics of movement and diffusion between freshwater and saltwater in a coastal aquifer are essential for managing coastal groundwater systems. Such investigations have used geophysical techniques: to locate the saline interface, and detect the presence of saltwater in coastal aquifers; and, geochemistry analysis to identify the presence and source of salinity. 


\section{Chapter 3.}

\section{The study area - Rangitikei delta}

\subsection{Introduction}

The Rangitikei catchment lies between latitudes $39^{\circ} 04^{\prime}$ and $40^{\circ} 20^{\prime}$ south, and longitudes $175^{\circ} 13^{\prime}$ and $176^{\circ} 12^{\prime}$ east in the south-west of the North Island of New Zealand (Figure 3.1). The catchment is bounded by the Kaimanawa Ranges to the northeast, the Ruahine Ranges in the east, and the Tasman Sea on the west (Milne, 1973). The study area focussed upon the mouth of the Rangitikei River, located approximately $40 \mathrm{~km}$ southeast of Wanganui along the Manawatu coast. The community of Tangimoana (pop. 276) is located on the southern side of the river; with the smaller community of Scott's Ferry located on the northern side (Figure 3.2). Tangimoana and Scott's Ferry do not have a reticulated water supply or sewage infrastructure. The residents have septic tank systems, and are reliant on rainwater and their own shallow groundwater bores ( $\sim 8-15 \mathrm{~m}$ deep) for water supply. The Rangitikei delta is part of the Manawatu Coastal Groundwater Zone (MCGZ). The MCGZ has been designated by Horizons Regional Council (HRC) for managing saltwater intrusion hazard. The zone extends southwards from the Rangitikei River to the Manawatu River and from the coast inland for approximately $10 \mathrm{~km}$ (Gyopari, 2005). 


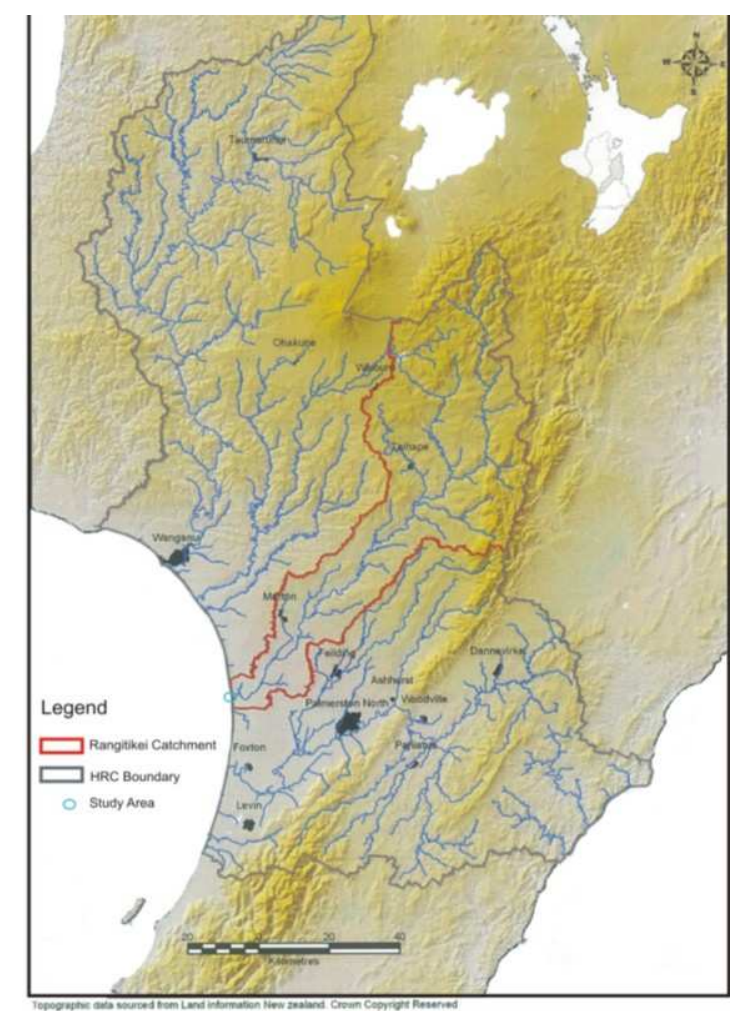

Figure 3.1 The location of the Rangitikei Catchment and study area. After HRC (2004b).

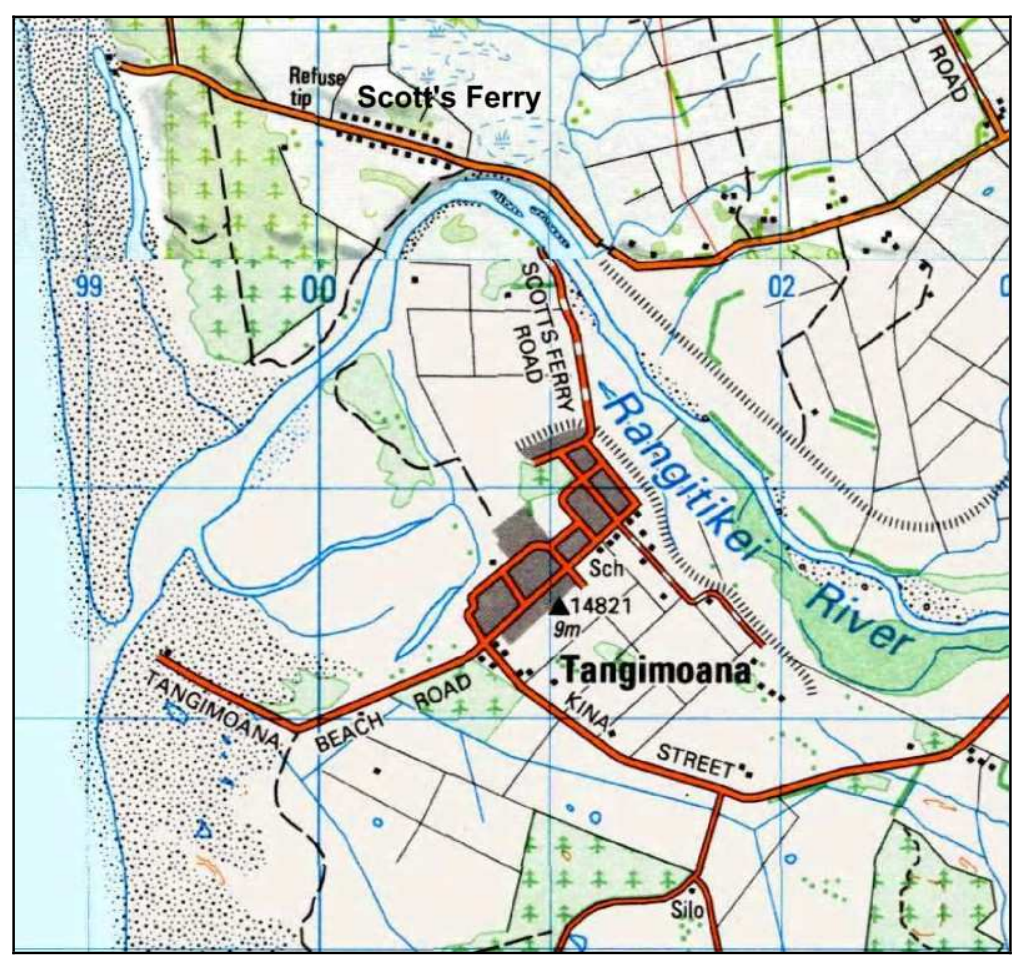

Figure 3.2 The location of the Rangitikei River mouth, Tangimoana, and Scott's Ferry (MapToaster Topo NZ, Map series 1:50,000 [260] ${ }^{+}$. Sheet: S24 1999, scale 1:31069) 
Local industry includes a timber treatment plant on the outskirts of Tangimoana, and Landcorp manages an extensive area of land mainly for sheep and as pine plantation. On the northern side of the river is the Santoft pine plantation (Figure 3.3). Grassland makes up approximately $76 \%$ of the total vegetation in the Rangitikei District. Tussock, native scrub and planted forest each make up approximately 5\% (MAF, 2002). Dairy farming has recently become more intensive in the area and irrigation is now a common practice. This has the potential to affect both the surface water and groundwater in the region. Landuse on the alluvial flats is predominately cropping, dairy and sheep farming. Agriculture on the river terraces is mostly sheep farming, wheat and barley cropping, with some dairy. On the steeper country agriculture is mainly sheep farming.

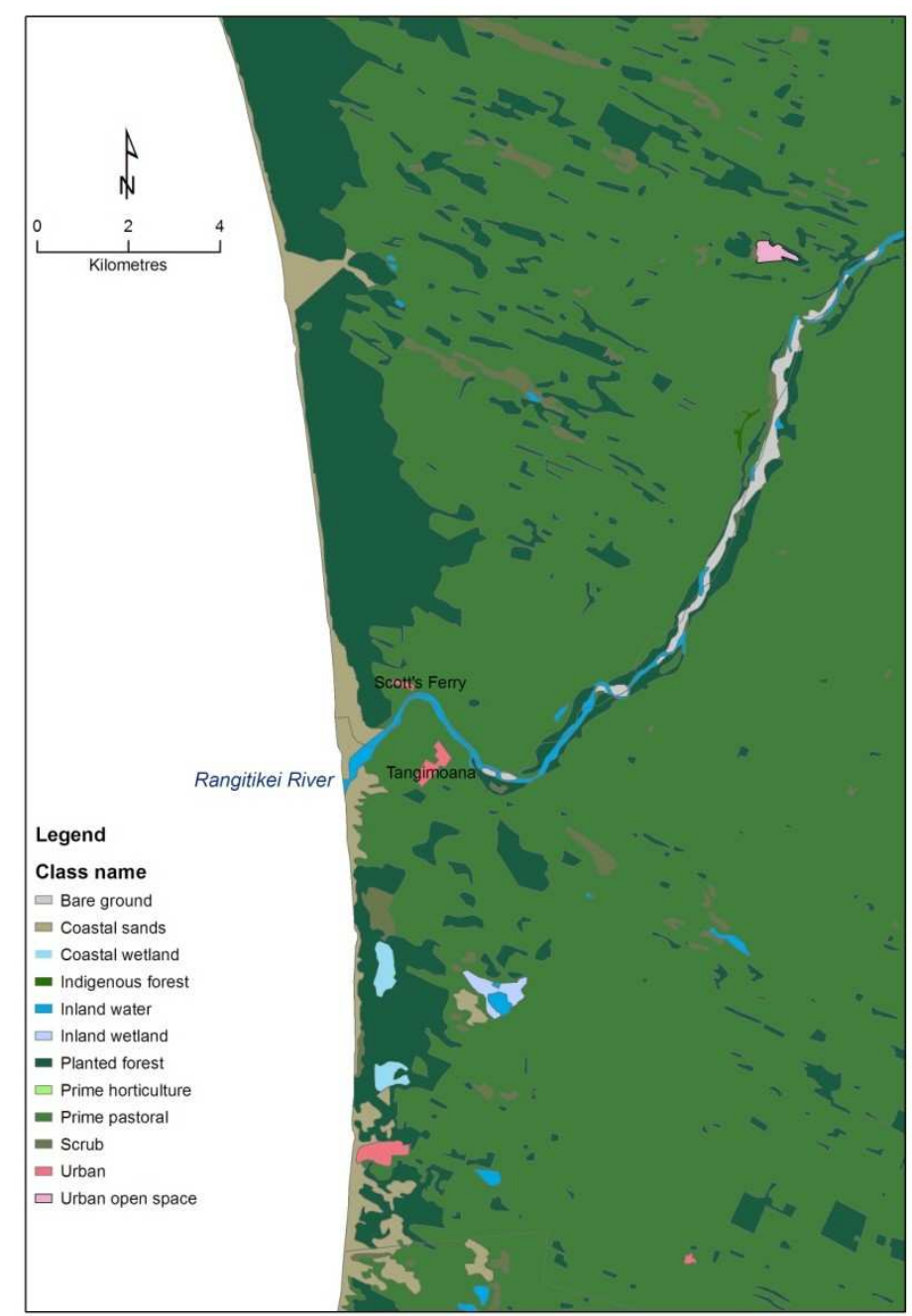

Figure 3.3 Vegetation cover of the Rangitikei delta. NZLRI 


\subsection{Historical Background}

The study area is located in New Zealand's largest parabolic transgressive dunefield. Human disturbances have changed vegetation conditions in the coastal area, and are thought to be the cause of at least one dune phase. The lowlands and the hill country of the Manawatu region were vegetated with tall conifer-broadleaf and podocarp forest, with small patches of beech forest (Heerdegen and Shepherd, 1992). Observations of the bush remnants in the region indicate that well established forests were growing on the Motuiti and Waitarere dunes. Hesp (2001) proposed that the landward dunes were likely to have been largely forested; and the more seaward dunes had "a mosaic of kahikatea, totara, cabbage tree dominated swamp, and deflation plain forest". Forest cover in coastal Manawatu may have been greatly reduced by Maori. They used fire to encourage the growth of bracken fern, and used timber for pa construction, and other needs (Hesp, 2001).

By the 1840's the dune country was largely fernland, grassland, shrubland or swamp. Europeans began to influence the landscape and vegetation as the beach became a coastal highway for travellers moving along the coast. Stock grazing began in 1840's when settlers began leasing land from Maori. It was typical to graze stock on the foredune and adjacent landward dunes. This activity had a major impact on the coastal vegetation and the dunes (Hesp, 2001).

The Rangitikei-Turakina Block was purchased in 1849. This block of land was approximately $105,220 \mathrm{Ha}$. It was bounded by the coast to the west and the Rangitikei and Turakina rivers to the north and south. It went inland between these rivers to a boundary line beyond Porewa to near Makahau. The land was largely sand dunes and swampland, but along the northern boundary it was covered in dense native vegetation (Laurenson, 1979) The Rangitikei-Manawatu Block was purchased in 1866 and was approximately 89,260 Ha. Fire was used to clear the scrublands, and the wetlands were drained and modified. By the 1860's the area was open sandy country, scrub and fernland with a few small patches of bush remaining (Hesp, 2001). Sambar deer and rabbits were introduced to the Rangitikei District in the 1870's. They contributed to the reduction of native plant cover, spinifex, Pingao and sand tussock. 
The primary agriculture in the region was sheep farming followed by wheat and barley cropping. Dairy cows arrived with the first settlers and grew quickly with co-operative dairy factories at Bulls, Rata and Taihape (Laurenson, 1979). By the 1970's sheep and cattle farming dominated in the region; with dairying restricted to the fertile river valleys and to a lesser extent the sand country. More recently the region has experienced rapid growth in dairy farming with more intensive farming practices and the use of irrigation.

\subsection{Physical Setting}

\section{Climate}

The Manawatu-Rangitikei plains lie within the western Wellington climatic district, characterised by moderate temperatures without great extremes, warm summers and mild winters (Cowie et al., 1967). The annual range in mean temperature from summer to winter is $9-10{ }^{\circ} \mathrm{C}$ with a similar diurnal range (Burgess, 1988; Heerdegen and Shepherd, 1992). February is the warmest month and July the coldest (Milne, 1973). Temperatures in January and February exceed $25^{\circ} \mathrm{C}$ for about $15-20$ days each year, but they rarely reach $30^{\circ} \mathrm{C}$. Hours of sunshine increase towards the coast where approximately 2000 hours are recorded annually.

The Rangitikei region is exposed to prevailing west to northwest winds that occur 30-50 percent of the time. In exposed coastal and lowland areas wind speeds are approximately 15-18 km, with little seasonal variation. Coastal hills, and the Tararua Ranges, create a barrier to the prevailing north-western flows. This creates a tendency for surface winds to be deflected along the line of ranges in a north or north eastern direction (Burgess, 1988).

The Manawatu coast has a high energy shore, with wave heights commonly exceeding 3 $\mathrm{m}$. The coast is influenced by the warm, saline water of the easterly D'Urville Current. Surface water temperatures range between 13 and $19^{\circ} \mathrm{C}$, with salinities between $35.3 \%$ and $34.4 \%$. The maximum tidal range of this area is $2.4 \mathrm{~m}$. Beach width between tides can reach $150 \mathrm{~m}$ (HRC, 2002). 
Although rainfall is reliable, and is generally evenly distributed throughout the year (Heerdegen and Shepherd, 1992), the coastal and lowland area of the Manawatu is one of the driest areas in the North Island. Orographic rainfall spreads westward from the Ruahine and Tararua Ranges. Rainfall increases from $870 \mathrm{~mm}$ at the coast, to more 1200 $\mathrm{mm}$ in more elevated areas. Over $2200 \mathrm{~mm}$ falls in the Ruahine Ranges The mean annual precipitation for the Rangitikei Catchment is $1215 \mathrm{~mm}$ ( HRC, 2004b).

Rainfall is usually adequate for agriculture except during summer when a wilting point deficit occurs. There is then not enough moisture for plant growth so irrigation is required. This deficit happens on an average of 10-15 days in both January and February (Burgess, 1988). Actual evapotranspiration averages less than $1 \mathrm{~mm}$ per day in June and 4-5 $\mathrm{mm}$ per day in January on lowland pasture.

\section{The Rangitikei River}

The characteristics and dynamics of the Rangitikei River are important to the surfacegroundwater interactions in this investigation. The interaction between the Rangitikei River and groundwater is dynamic. It can change between gaining and losing flows along reaches of the river, and through time (HRC, 2004b). Therefore, the dynamics of the river are likely to have an impact on the local saline interface. The Rangitikei River has a history of flooding. A major flood occurred in February 2004, the fourth largest in the Rangitikei Rivers recorded history. Residents of Tangimoana and Scott's Ferry were evacuated and many homes were unable to be inhabited again for eight months. Floodwaters can significantly alter the quality of the shallow groundwater in the region.

The Rangitikei River is a major drainage artery in the Manawatu (Heerdegen and Shepherd, 1992). Its catchment extends over $3933 \mathrm{~km}^{2}$. The headwaters of the Rangitikei River are in the Kaimanawa Range, approximately 1,725 m asl. The river flows in a southerly direction north of Taihape, and then in a south-west direction until it reaches the coast near the township of Tangimoana (Milne, 1973). The rivers major tributaries are the Moawhango, Hautaupu and Kauwhatau Rivers. The gradient of the river progressively increases upstream and has a sufficient energy to transport coarse gravels to the sea (Milne, 1973; Begg et al 2005). 
The Rangitikei River has a National Water Conservation Order that protects the upper and middle parts of the catchment. The Order preserves the "outstanding wild and scenic characteristics, the outstanding recreational fishing, and the wildlife habitat features" of the upper river. The Order also protects the "outstanding scenic characteristics and the outstanding recreational and fisheries features of the middle river". The Tongariro Power Development (TPD) hydroelectricity scheme abstracts approximately $16 \%$ of the mean annual low flow from the headwaters of the Rangitikei River via the Moawhango Diversion (HRC, 2004b).

The Rangitikei River has highly variable flows. High flows usually occur during the winter months following high rainfall. The largest mean flows occur in the months of July $\left(135.3 \mathrm{~m}^{3} / \mathrm{s}\right)$ and August $\left(121.8 \mathrm{~m}^{3} / \mathrm{s}\right)$. During the drier periods, usually between January and March, flows can be as low as $10 \mathrm{~m}^{3} / \mathrm{s}$. The minimum flow in the coastal Rangitikei management zone is $10.23 \mathrm{~m}^{3} / \mathrm{s}$. At flows below this water abstraction is reduced to stock and domestic supply but all other abstractions are ceased (HRC, 2004b).

The Rangitikei River estuary is part of the Department of Conservation's Tawhirihoe Scientific Reserve. Approximately half of the estuarine area is covered by salt marsh, situated south of the main river channel. The salt marsh is completely inundated during spring tides, and is an important buffer zone for the estuary (HRC, 2002). Prior to the 1960's, the main channel through the estuary flowed further south, close to Tangimoana. The channel was straightened for flood protection purposes and now flows directly to the sea (Figure 3.4). The position of the river mouth is still mobile and tends to migrate back and forth along the coast (Geology Society of New Zealand, 1986). The Rangitikei estuary was a small tidal basin during the mid Holocene that experienced rapid infilling. The estuary survived because of the development of sand/gravel bars at the river mouth (Heerdegen and Shepherd, 1992). 


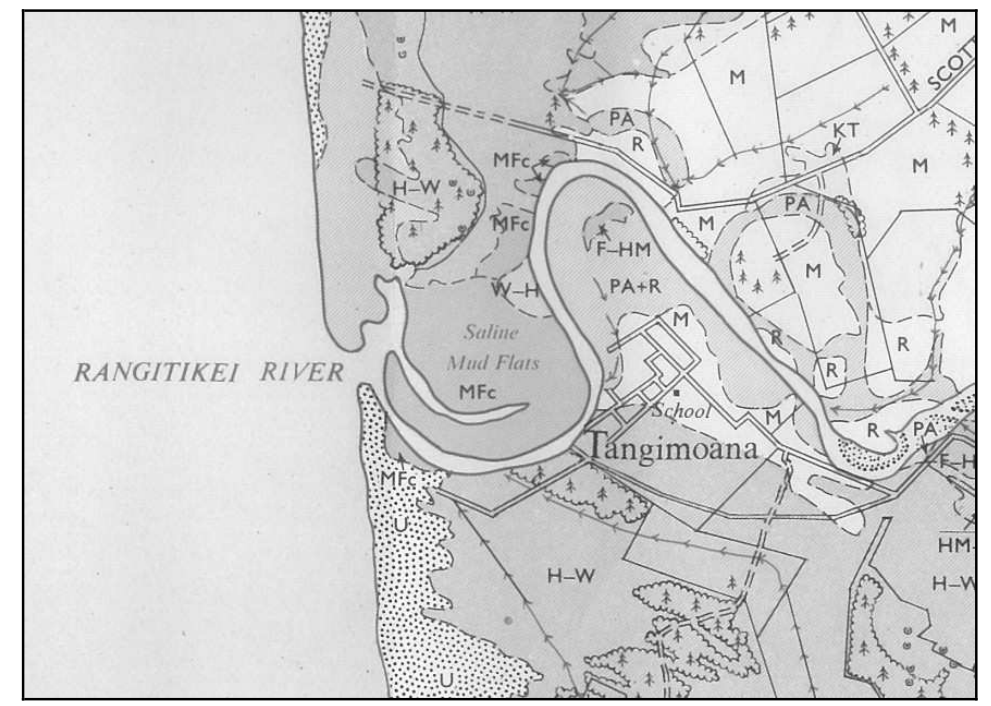

Figure 3.4 The main channel through the Rangitikei estuary prior to modification. After Cowie et al., (1966).

Consented water abstraction in the Rangitikei catchment is largely from surface water, which comprises of $75 \%$ of consented volumes. Water abstraction in the Rangitikei Catchment is used for agriculture (78\%), water supply (15\%) and industry (7\%). Approximately $68 \%$ of the catchment's surface water abstraction, and $95 \%$ of the catchments groundwater abstraction, occurs below Onepuhi. This is in the coastal management zone of the Rangitikei. $79 \%$ of these abstractions are used for agriculture, $11 \%$ for industry and $10 \%$ for water supply. Based on the HRC consents database, the maximum daily total water use in the catchment, excluding the TPD hydroelectricity abstraction, was 228,240 $\mathrm{m}^{3} /$ day, as of 1 January 2004 (HRC, 2004b).

\section{Sand country and flood plain}

The geomorphology of the coastal area near the Rangitikei River reflects the fluvial and coastal processes operating. The coast of the Manawatu has prograded approximately 4 $\mathrm{km}$ since modern sea level was attained 6,500 years ago (Muckersie and Shepherd, 1995). The coast is characterised by a wide sandy foreshore, large dynamic sand dunes, and inter-dune swamps that have migrated inland (Heerdegen and Shepherd, 1992). The prevailing west-north westerly winds have eroded the sandy foredunes to form the largest transgressive dunefield in New Zealand. The dunefield consists largely of stabilised and parabolic dunes with some composite and nested hillocks. 
Cowie (1963) identified three Holocene dune phases, largely on pedological data. More recent dating has produced accurate dates for these dune phases (Figure 3.5). The Foxton phase is the oldest. Based on radiocarbon dating it is estimated to have been initiated about 6500 years ago and continued to generate for 2000 years (Heerdegen and Shepherd, 1992; Muckersie and Shepherd, 1995). The Motuiti phase was initiated between 3500 and 1300 years ago. It is thought that the first and second phases moved simultaneously until around 1600 years ago. The youngest phase, the Waitarere phase (140 yrs - present), is thought to be two separate phases. The first was probably initiated 300-400 BP, and stabilised prior to 1889. European disturbance of the vegetated foredunes likely led to renewed dune movement (Muckersie and Shepherd, 1995).

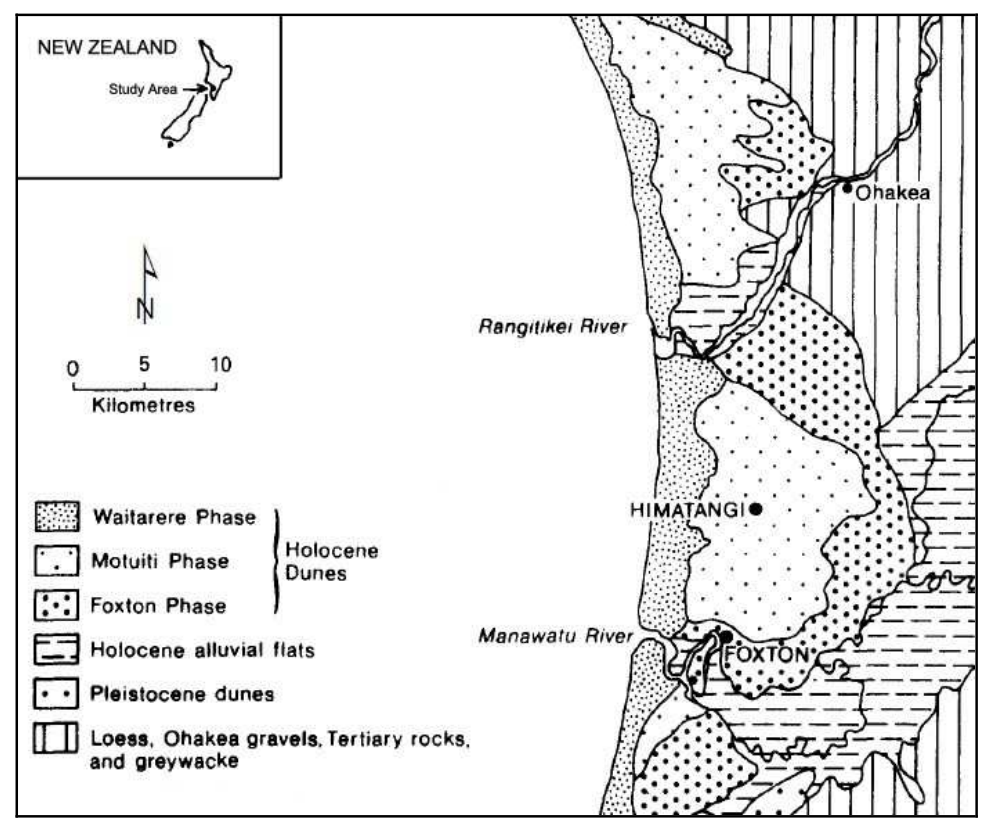

Figure 3.5 Map showing the dune phases as identified by Cowie 1963. After Muckersie and Shepherd (1995).

A large number of dune lakes occur on the Manawatu-Horowhenua coast in association with the three major dune phases (Lowe and Green, 1992). Many lakes are concentrated in a line 3-4 km inland between Tangimoana and Foxton. They occur near the junction of the Himatangi anticline with the Holocene dunefield. These dune barrage lakes are believed to be relatively recent, and probably formed during the Motuiti phase (Heerdegen and Shepherd, 1992) in response to continued progradation of the coastal plain. They include: dammed valley lakes, that were formed as a dune blocked a valley 
draining to the coast; and dune-contact lakes, that formed in depressions between two dunes, or between dune belts. The coastal area alternates between dunes and sand country. This affects drainage and plays an important role in the formation of soils, formation/orientation of dunes, and the position of the water table.

\subsection{Soils}

The soils of the coastal plain of the Rangitikei delta are important for the shallow coastal aquifer system. Soil type affects the infiltration of rainfall recharge. The drainage characteristics of each soil also highlights soil moisture deficiencies, and determines where irrigation is more likely to be effective. The parent material of most of the soils is aeolian sand, largely derived from greywacke. It contains a significant proportion of quartz, feldspar (with minor constituents of hypersthenes), augite, and hornblende derived from volcanic material from the Taranaki and Taupo regions (Cowie et al, 1967).

\section{Soils of the sand country}

The soils of the sand country occur on the dunes and plains. The dune soils are largely associated with the Waitarere, Motuiti and Foxton dune phases (Figure 3.6). A separate soil type was identified on each of the phases (Cowie et al., 1967). The soils of the dunes have sandy textures, and are weakly developed with moderate to severe moisture deficiencies (Campbell, 1978) The Waitarere phase is represented by Waitarere Sand that mostly borders the coast. It shows excessive drainage, limited profile development, and a susceptibility to wind erosion. The Motuiti Sand also has excessive drainage with a shallow topsoil. The Foxton series is the oldest, and most consolidated, of the dune soils. It still has somewhat excessive drainage.

Subdivision of the soils that occur on the sand plains is based on drainage and humification of the topsoil (Figure 3.6). Hokio, Himatangi, Pukepuke, Awahou and Carnarvon soils occur on the flats. They have coarse textures, weak profile development 
and poor to imperfect drainage. The Hokio series corresponds with the Waitarere dune phase. The soils are predominantly sandy. They have little profile development and somewhat excessive drainage, except for Hokio sand, peaty phase. This occurs on poorly drained low-lying sand plains where the water table is near the surface.

Himatangi and Pukepuke are the next oldest series and they occur on the Motuiti phase. The Himatangi weakly mottled sand and sand soils have somewhat excessive and free drainage, and are susceptible to wind erosion. Topsoils are deeper than the Hokio series. Pukepuke series range from imperfectly drained to very poorly drained soils that occur on the lower lying sand plains. They range from black sand to brown sandy loam.

Awahou soils occur on the drier sand plains, and the Carnarvon series occurs on the wetter low-lying sands of the Foxton phase. The Awahou series consists of Awahou loamy sand and Awahou sandy loam. Both of these soils are freely drained, and soil moisture is inadequate during summer. The Carnarvon series are formed on the wetter part of the sand plains. They are poorer drained and more gleyed than the Awahou soils. 


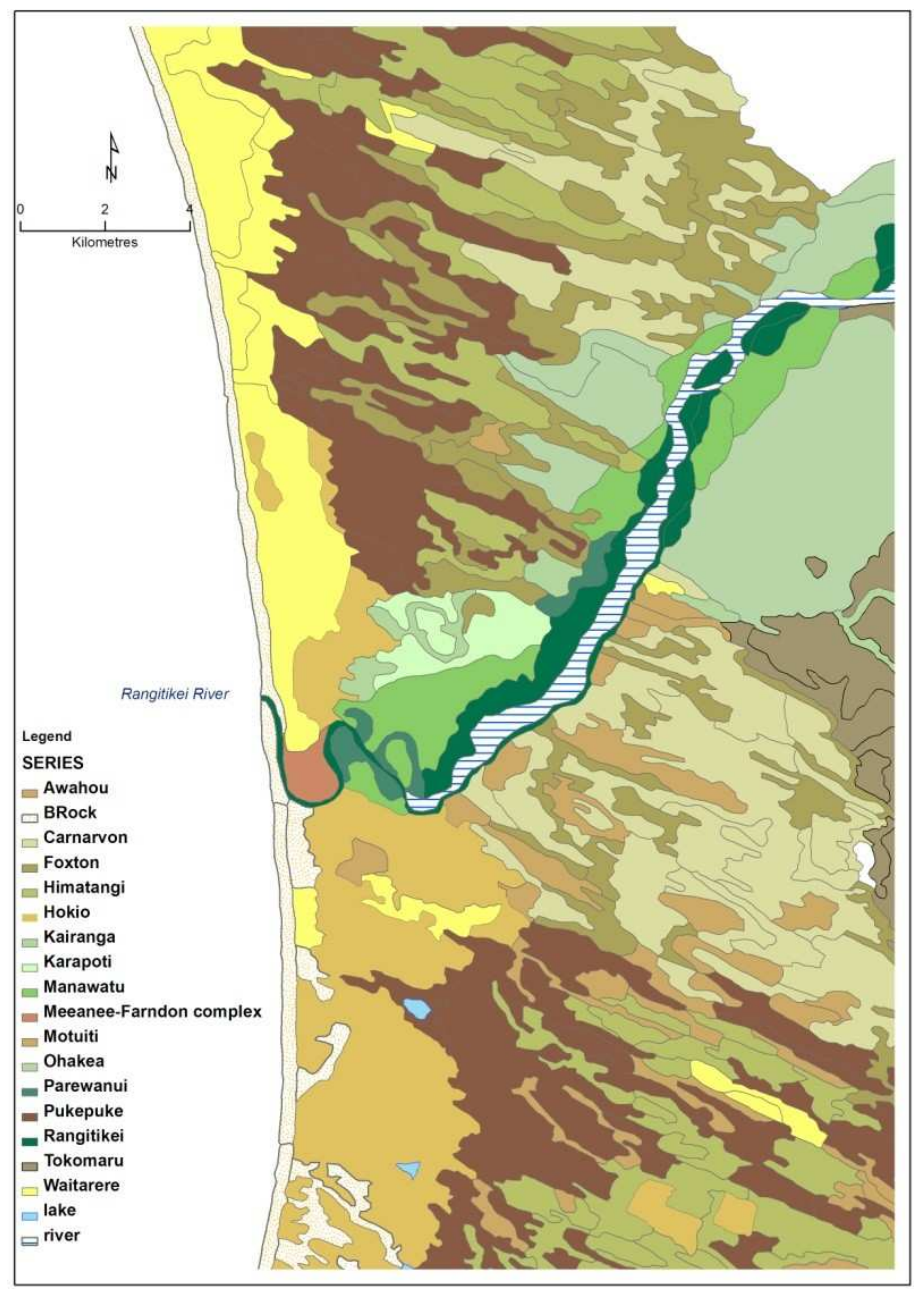

Figure 3.6 Soil Series of the Rangitikei delta. NZLRI

\section{Soils of the river flats and terraces}

Cowie et al. (1967) surveyed the coastal areas of the Rangitikei County and described the soils of the Rangitikei river flats and terraces bordering the lower reaches of the river (Figure 3.6, Figure 3.7). Additions of alluvium deposited by frequent flooding have interrupted soil formation processes so there is a lack of distinct soil horizons. The levees obstruct drainage and produce a high water table on the low lying river flats. The soils of the river flats are formed from well-sorted alluvium deposited in thin layers over existing soils during periodic flooding. The content of sand, silt, and clay varies over short distances. Coarser deposits usually occur near the river with the finer deposits further away on the lower parts of the flood plain. 
The river terraces are approximately 9-15 $\mathrm{m}$ above the present river course (Cowie et al., 1967). Soils on the older river terraces are formed from old alluvium. They are generally well-drained with well-developed profiles. This includes Ashhurst, Kawhatau and Kopua soil series (Campbell, 1978). The Crofton, Pouwhakaura, Ohakea, and Raumiti soil series are formed from old alluvium and colluvium. These soils have well-developed profiles that are fine textured, and moderately well drained.

Cowie et al. (1967) determined five soil series on the river flats based on soil drainage and the rate of accumulation of alluvium (Figure 3.7). A sixth series, the MeaneeFarndon complex was defined for saline soils. This series occurs on the low flats at the river mouth, and includes sandy loam to clay loam. Saline floodwaters or water logging by brackish waters has increased soluble salts in the soil. It is this soil series that is predominantly found on the salt marsh located on southern side of the river where much of the field investigation has taken place. The remaining soil series are briefly summarised.

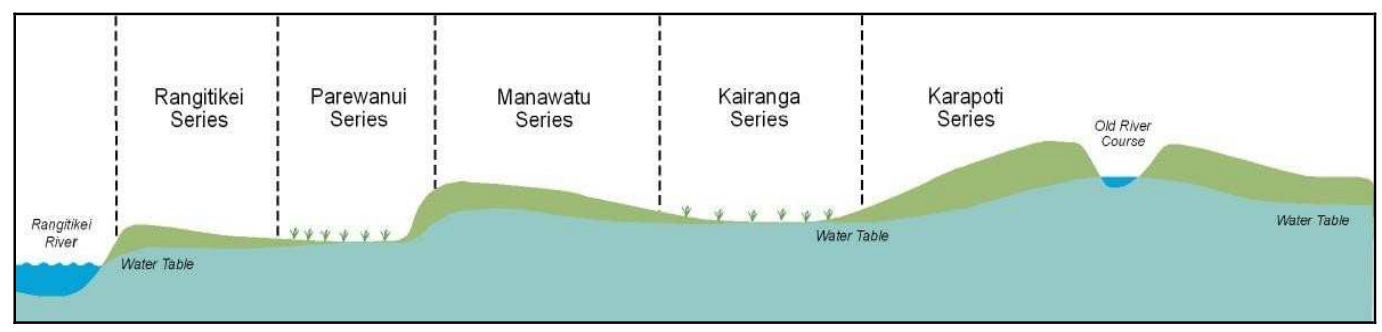

Figure 3.7 Relation of soil series to topography of river flats. After Cowie et al. (1967).

\section{Rangitikei Series}

The Rangitikei soil series are formed on the river flats and levees of the river. Alluvium accumulates rapidly because of frequent flooding. The characteristic type of soil within the Rangitikei series is the Rangitikei loamy sand. The Rangitikei soil series includes excessively and well-drained soils that are predominantly sandy; although most of the soil does not excessively dry out because of seepage from higher ground.

\section{Parewanui Series}

The Parewanui soil series are formed on low-lying areas that are frequently flooded. They consist of finer alluvium than the Rangitikei series as it is further away from the 
river. The Parewanui series is composed solely of Parewanui silt loam, a rapidly accumulating gley recent soil. The soil is poorly drained and seepage from higher ground maintains the water table at a high level. This soil series is located landward of the salt marsh on the south side of the river.

\section{Manawatu Series}

The Manawatu soil series are formed on higher flats than the Rangitikei series. Flooding is less frequent, and accumulation of alluvium is slower. This series has deeper top soils and yellow subsoil that is more distinct than the Parewanui series. Manawatu fine sandy loam is characteristic of the series. Soils in the series range from freely drained to moderately well-drained.

\section{Kairanga Series}

The Kairanga soil series are formed on low-lying parts of river flats. Seepage from the bordering higher areas keep the water table high. Accumulation of alluvium is slow and topsoil is deeper and distinct. Kairanga silt loam, Kairanga fine sandy loam, Kairanga sandy loam, and Kairanga heavy silt loam all occur in the series. The soils have naturally high fertility, but water logging occurs because of poorly drained, slowly accumulating, gley recent soils.

\section{Karapoti Series}

The Karapoti soil series are formed on the higher parts of the river flats, and do not receive alluvium from flooding. The topsoil is shallower and the subsoil is more compact than the Manawatu series. Karapoti loamy sand is characteristic of the series and occasional pieces of pumice occur in the soils. The soils tend to dry off in summer.

The characteristics of the Meanee-Farndon complex and the Parewanui soil series are important as they occur on the southern side of the river in the area where much of the field investigation has occurred. The drainage, accumulation of alluvium and occurrence of soluble salts in the soil are critical when interpreting the results of the resistivity soundings and traverses. 


\subsection{Geology}

Groundwater flow is controlled by geological parameters such as stratigraphic relationships, structure and aquifer heterogeneity (Freeze \& Cherry, 1979). These parameters can affect areas of recharge and discharge, and control the hydraulic characteristics of a groundwater system. Geology is therefore of fundamental importance to the study of groundwater. As the medium of an aquifer, the geology controls the movement and chemistry of groundwater, and defines the boundaries of an aquifer. Geological structure, depositional processes, and geological features; such as active faults and folding, all affect the presence and continuity of aquifers and aquicludes (Begg et al., 2005). Therefore, an understanding of the geological setting of a groundwater investigation is essential when interpreting the characteristics of an aquifer. The geological setting and hydrogeology is briefly described in this study. However, the geology of the Manawatu is complex and much research has been devoted to this subject. Complete descriptions of the geology of the Manawatu and the Wanganui Basin are available (Anderton, 1981; Fleming, 1953; Jackson et al., 1998; Milne, 1973; Naish and Kamp, 1995; Te Punga 1952).

\section{Geological setting}

The deposits and associated landforms of the Rangitikei Basin have been strongly influenced by the interaction of cyclic climatic fluctuations and the tectonic deformation associated with the Hikurangi subduction zone (Heerdegen and Shepherd, 1992; Milne, 1973). The landforms of the region are young. Most of the Manawatu was submerged during the late Tertiary Period, and it is composed largely of sedimentary rocks. These range from 150-180 million years BP to present day alluvial and marine deposits (Heerdegen and Shepherd, 1992).

The axial Ruahine and Kaimanawa ranges lie to the east and north-east of the catchment. The ranges are cut into an uplifted block of strongly deformed and faulted greywacke sandstones, argillites, and submarine volcanic rocks. In the Kaimanawa ranges the rocks have been locally metamorphosed to low grade schist (Milne, 1973). The ranges were thought to be initiated in the Pliocene by the upwarping of greywacke basement and 
marine cover beds into broad anticlinal domes which trended NNE-SSW (Heerdegen and Shepherd, 1992). The Ruahine Range is on the western margin of a zone of intense shearing and compression.

The hill country and terraced lands of the Rangitikei catchment lie on the eastern boundary of the Wanganui Basin. This is a large marine sedimentary basin that extended east from near Mt Taranaki to the axial ranges. The Wanganui Basin is a depression that accumulated over $4000 \mathrm{~m}$ of marine sediments above the Torlesse greywacke basement during Plio-Pleistocene time. The basin is faulted by north-north-east striking faults. Tectonic deformation during the upper Quaternary has caused the northern part of the basin to be uplifted and tilted to the southwest. Before this tilting, the central and lower parts of the Rangitikei Basin consisted of shallow seas with fluvial deltas (Fleming, 1953). Broad uplift around the margins of the Wanganui Basin began during the Pleistocene. The rates of uplift range from $0.3 \mathrm{~mm} / \mathrm{y}$ in the south to $1 \mathrm{~mm} / \mathrm{y}$ in the north east.

During the cold climatic episodes of the late Pleistocene permanent ice/snow may have been present on the Ruahine ranges. Although no glacial landforms have been recognised in the ranges, the conditions would have allowed periglacial processes (Heerdegen and Shepherd, 1992). The vegetation line was substantially lowered causing extensive areas of bare rock to be exposed above $900 \mathrm{~m}$ (Milne, 1973). Intense freezethaw action in areas of bare rock, especially on steeper slopes, resulted in physical weathering of surface material. The volume of debris was so great that rivers aggraded. They formed wide floodplains that generally occupied the width of their valley floors. Loess was deposited, from the bare floodplains onto the surrounding landscape. The loess now forms an extensive mantle over flat and rolling surfaces below 900m (Milne, 1973).

The combination of uplift with the cyclic climatic and sea level changes of the Pleistocene Epoch led to the development of suites of marine and river terraces. The marine terraces developed as successively older interglacial coastal terraces were raised as a result of uplift and the relative interglacial sea level fell (Heerdegen and Shepherd, 1992). As the climate grew warmer and vegetation cover increased, the sediment supply for rivers to transport decreased. The rivers then downcut into the river bed and the 
underlying bedrock. Steady uplift enabled the formation of river terraces to be maintained at successively lower levels. The accumulation of loess ceased as rivers downcut, and abandoned floodplains revegetated. It was likely that chemical weathering increased with the warmer climate, and soils developed in the upper levels of the deposited loess (Milne, 1973).

A series of NNE striking active faults cut across the region. They are likely to be reverse faults and are associated with folding. The faults have had a significant influence on the young deposits in the region. The anticlines consist of Pliocene and older marine sands and silts that have been progressively lifted above the influence of alluvial action. River channels have also been confined to the synclines between the faults. The anticlines are located in the Mt Stewart, Marton, Fielding, Himatangi and Pohangina areas (Figure 3.8, Figure 3.9). The Rangitikei Fault has been mapped along the northwest of the Rangitikei River almost as far as the coast (Begg et al., 2005).

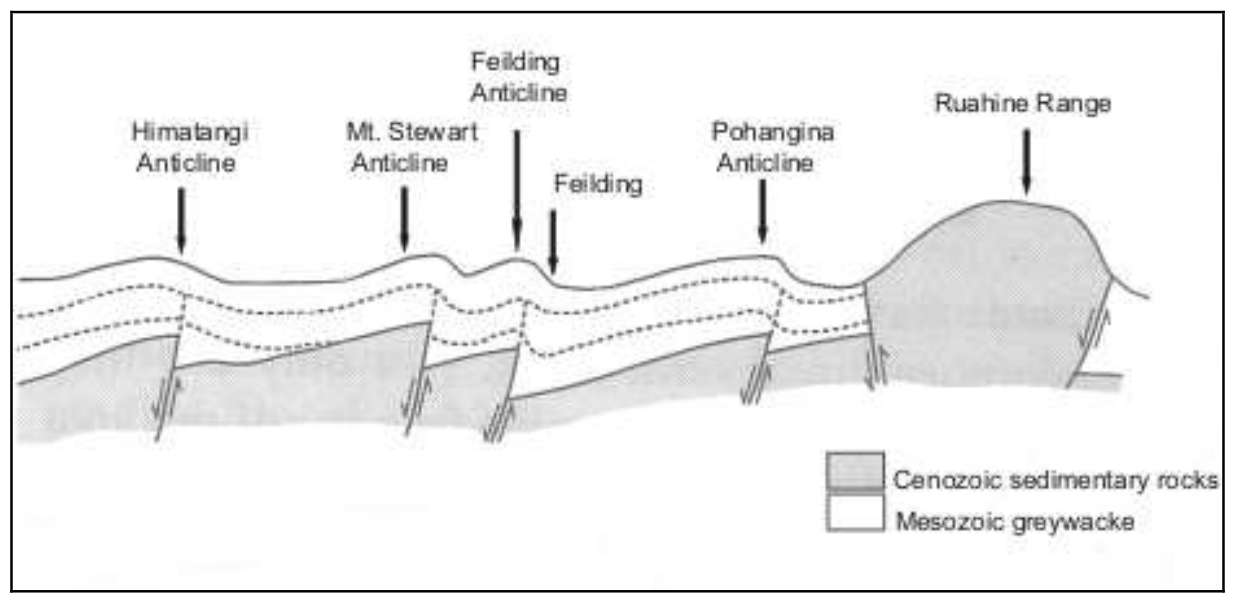

Figure 3.8 Section between Tangimoana and the Ruahine Ranges showing the relationship between structure and relief. Cover beds of Tertiary and Quaternary age are draped over basement greywacke. After Heerdegen and Shepherd (1992). 


\section{Major rock units}

The geological units are briefly summarised from Begg et al. (2005), with some reference to hydrogeology. The rocks that form the Ruahine Ranges are comprised of old, hard Torlesse Terrane Greywacke (260-150 Ma) (Unit 1, Figure 3.9). These rocks are also likely to underlie the younger deposits of the hill country and the ManawatuHorowhenua Plain. The predominant rock type is hard quartzofeldspathic sandstone and interbedded mudstone, and ranges from Permian to late Jurassic in age. The rocks in this unit are commonly deformed, show several generations of folding and faulting, and are usually steeply dipping. The joints and non-mineralised shear and fault planes provide these rocks with some capacity to store groundwater. They produce sporadic perennial springs that yield high quality water. However, the rock group has low permeability and so has limited groundwater storativity.

The Wanganui Basin Pliocene and Early Quaternary marine deposits (Unit 2, Figure 3.9) underlie most of the dissected hill country. The unit consists mainly of siltstone, mudstone, sandstone, pumiceous sand and minor limestone and conglomerate. Marine fossils are common within most of these rocks that were deposited from the Late Pleistocene to the Late Castlecliff (c. 3.6 - $0.7 \mathrm{Ma}$ ). This unit overlies an extended sequence of Miocene and Pliocene marine deposits that dip south and southwest. The sandstone and pumiceous sand formations have significant pore space but their extents are limited by confining silt and mud beds.

The Late Castlecliffian to middle Quaternary deposits (Unit 3) are distributed as a belt along the southern margin of the Wanganui Basin Pliocene and Early Quaternary marine deposits (Unit 2). This unit is a result of the geological change that occurred when the region emerged from the sea, around $700 \mathrm{ka}$ to $400 \mathrm{ka}$. The rocks in this unit are representative of warm climate high sea level stand marine benches. These benches are underlain by sand and cool climate low-level stand aggradational fans that are underlain by gravels. Both are mantled with loess deposits. The marine and marginal marine deposits and pumice deposits of the early and middle Quaternary have sufficient porosity and permeability for minor rainfall recharge. Some subunits are also capable of being aquifers (Figure 3.10). 
Holocene and Last glacial deposits (Unit 4) (less than 128ka) in the Rangitikei catchment are predominantly gravels; deposited by the aggradation and reworking by rivers occupying wide and braided courses. Holocene silt, peat and aeolian sand deposits also extend across a large area of the coastal plain. Some gravel deposits are clay-bound and have fine grained overbank, swamp or lacustrine deposits. The sequence of deposits shows unconformities from sea level change and tectonic deformation. The Holocene deposits form the most productive aquifers in the region.

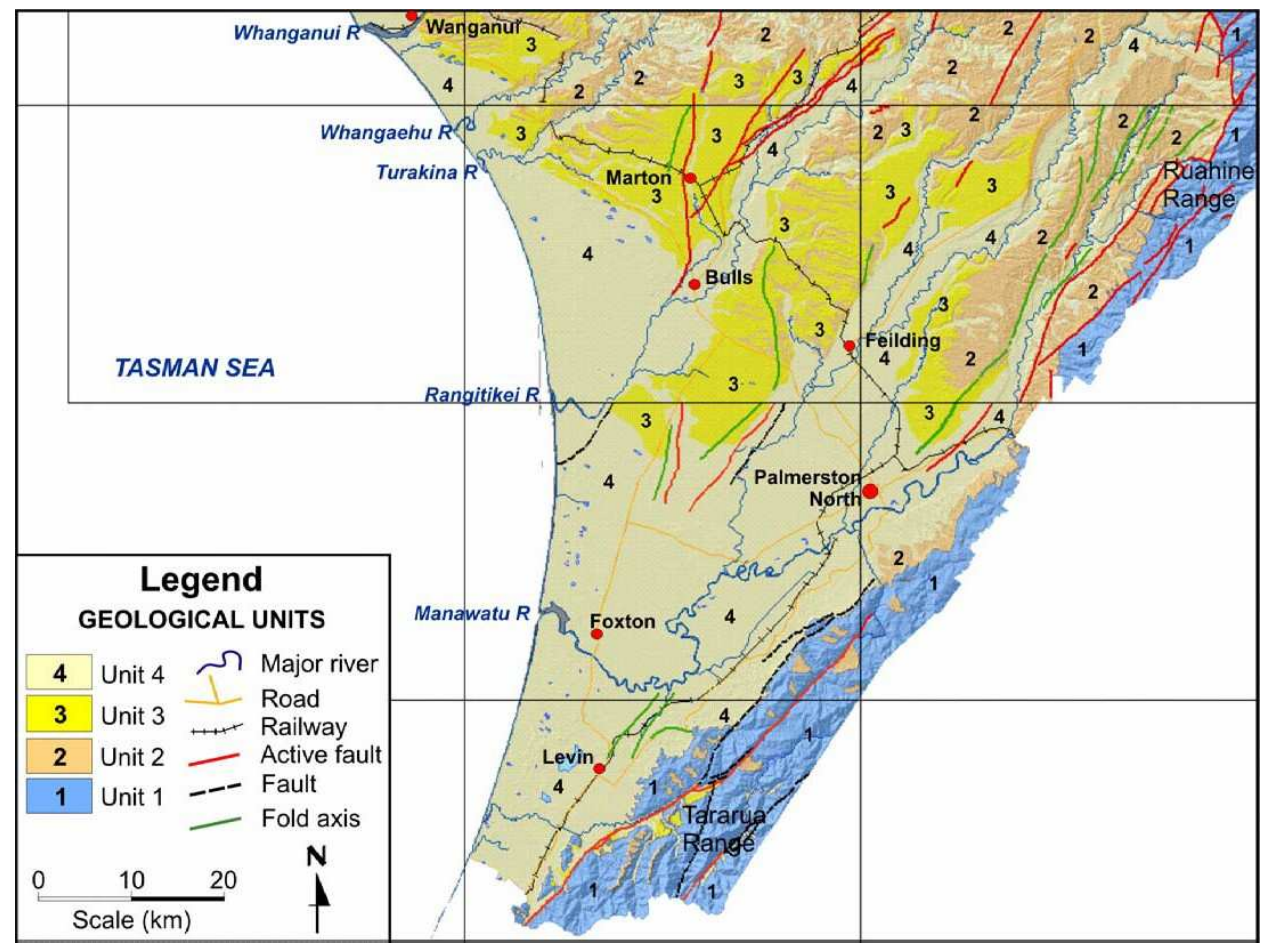

Figure 3.9 Geological subdivision of the Manawatu-Horowhenua area. From Begg et al., (2005).

\section{Hydrogeology}

At least three well-defined Quaternary age aquifer zones comprising unconsolidated glacial gravel and sand aquifers have been identified in coastal Manawatu. The Horizons Regional Council have categorised the aquifers in the region into two separate groups. The Upper Aquifer group comprises the shallow groundwater resource and includes the Foxton Aquifer and its overlying Holocene formations. This aquifer is shallow, and unconfined/semi confined. The Lower Aquifer Group contains the Quaternary aquifers; 
of these the Himatangi aquifer is confined and overlies the Opiki aquifer as well as older marine formations. The shallow and deep systems are thought to be separate resources because of extensive aquitards underlying the Foxton aquifer (HRC, 2004a).

Regional groundwater flow approximates surface water drainage and flows south and south-west towards the coast (Bekesi, 1998). The transmissivity of the upper aquifer sequence is approximately $1000 \mathrm{~m}^{2} /$ day and storativity ranges between $1 \times 10^{-3}$ and $5 \mathrm{x}$ $10^{-3}$ (Gyopari, 2005). The Foxton aquifer receives recharge over much of the Manawatu Plains through rainfall infiltration and localised river bed leakage (Figure 3.10). It is also likely that rainfall recharge also occurs locally on the anticlines.

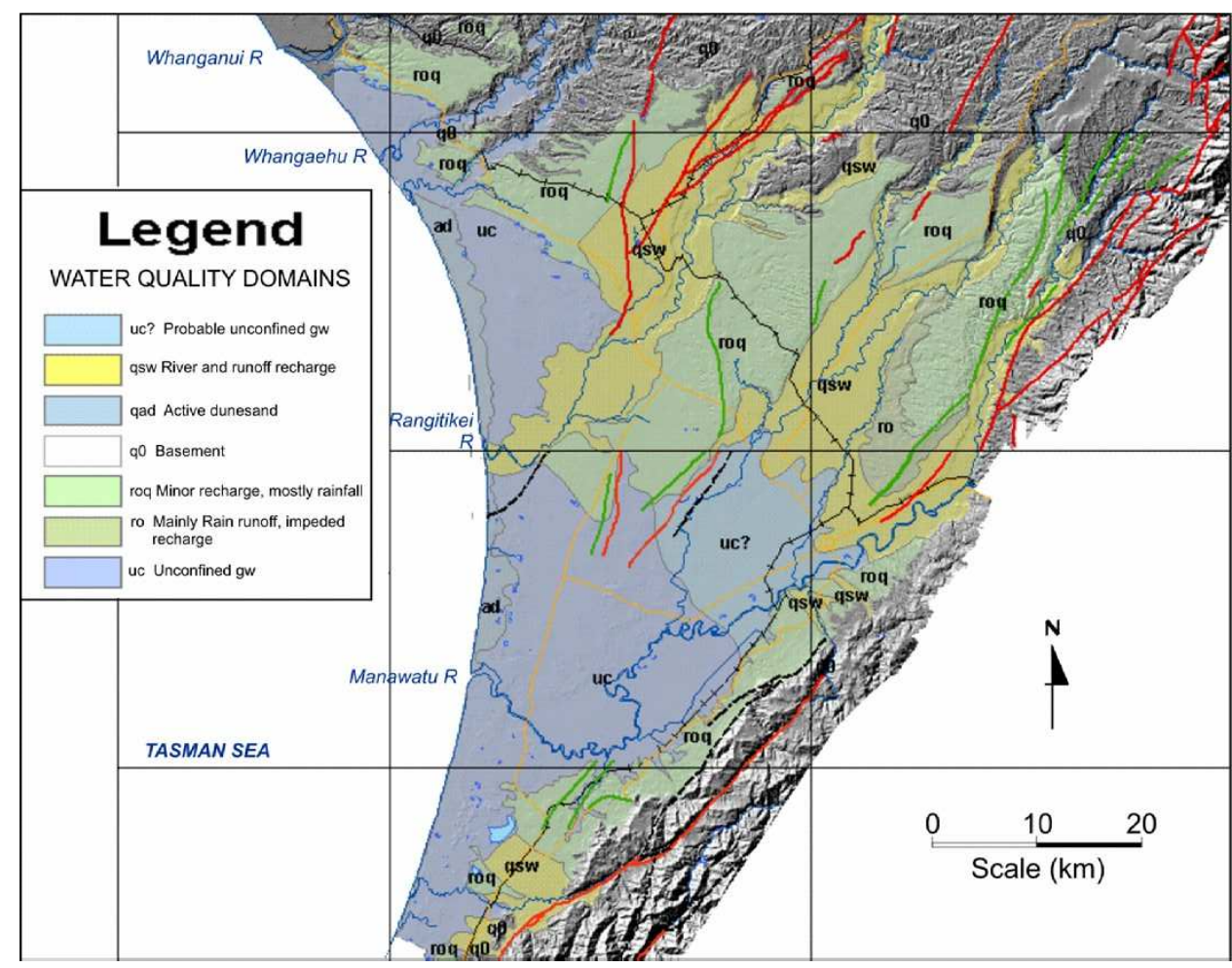

Figure 3.10 The surface extent of major water quality zones in the ManawatuHorowhenua region as derived by Begg et al (2005). The red lines are active faults, the green lines are fold axes or anticlines, the black lines are faults with no recorded activity. 
The lithology of the seaward margin of the Foxton aquifers is composed of Holocene marine sands and gravel (Figure 3.11). Gravelly marine sands to a depth of $5 \mathrm{~m}$ below msl overlie fine sand with some pebbly and silty horizons. The base of the Holocene marine sediments consists of Ohakea gravels to the west and Pleistocene sands to the east. The gravel, derived from the Rangitikei River, is composed of 95\% greywacke, and $5 \%$ andesite. Modern sea-floor sediments at similar depths off shore consist of mainly of fine sand. They have a higher silt/clay fraction and lack a gravelly layer (Geological Society New Zealand, 1986). Borehole log data from Tangimoana suggests that the upper gravelly marine sand layer has some isolated silt, and peat horizons. Borehole logs near Scott's Ferry suggest more heterogeneity of the gravelly marine sand wedge, with several clay and silt horizons.

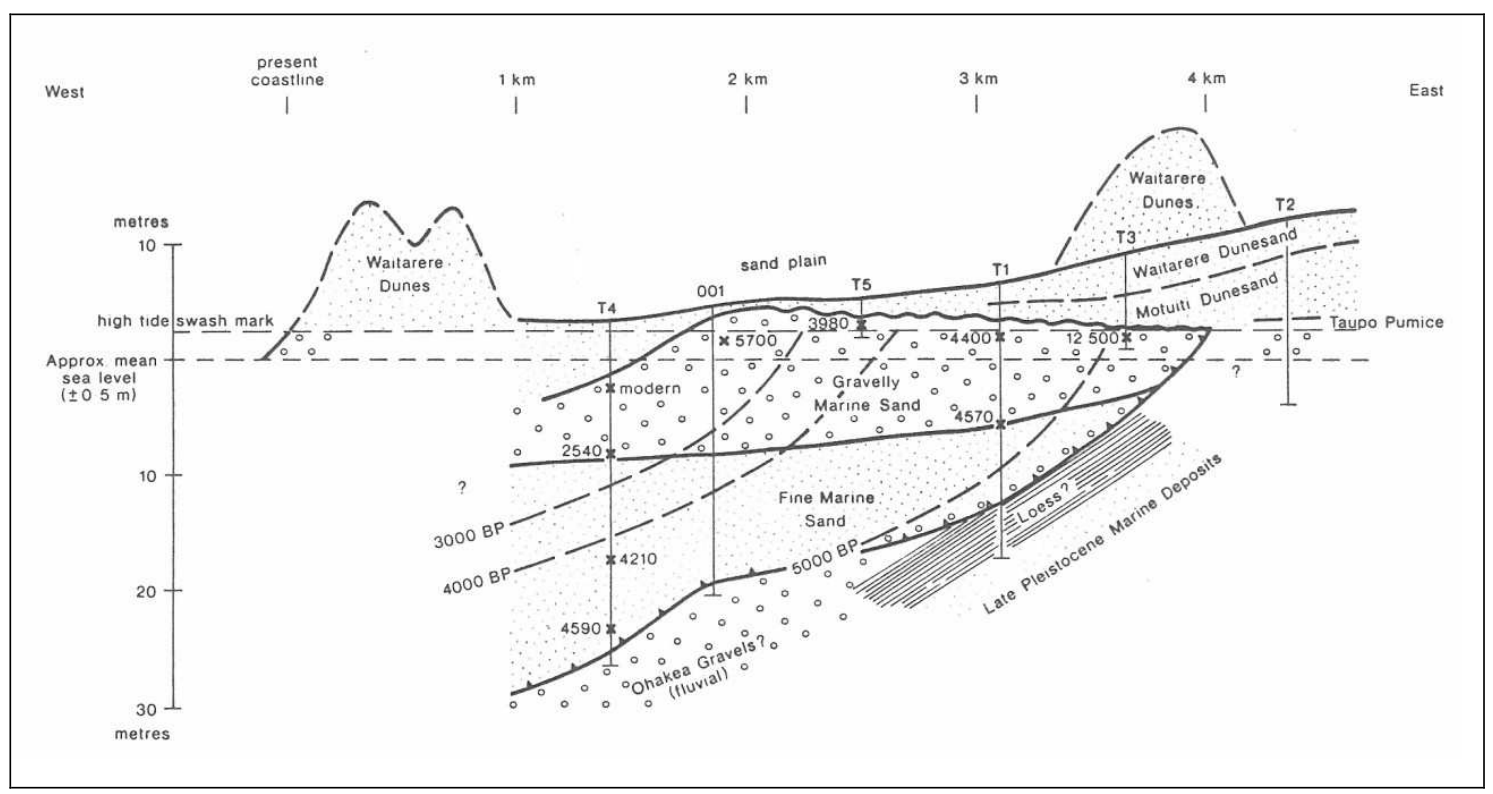

Figure 3.11 Section through the Holocene marine wedge near Tangimoana. (From Geological Society New Zealand, 1986)

The saline interface of the Foxton Aquifer in the Rangitikei delta has been estimated previously using the Ghyben-Herzberg solution (Gyopari, 2005). Gyopari calculated the saline interface was 3-4 km offshore given a hydraulic gradient of 0.0001 , and a groundwater head of $5 \mathrm{~m}$ amsl at the coast. As groundwater abstraction in this region is considered to exceed recharge, hydrostatic conditions were assumed. Using average transmissivity and storativity values, along with $100 \%$ consented pumping rate, Gyopari 
modelled the cumulative drawdown associated with irrigation abstractions in the delta area. It was found that a positive head of $1.5 \mathrm{~m}$ amsl is required to prevent saline intrusion (Figure 3.12).

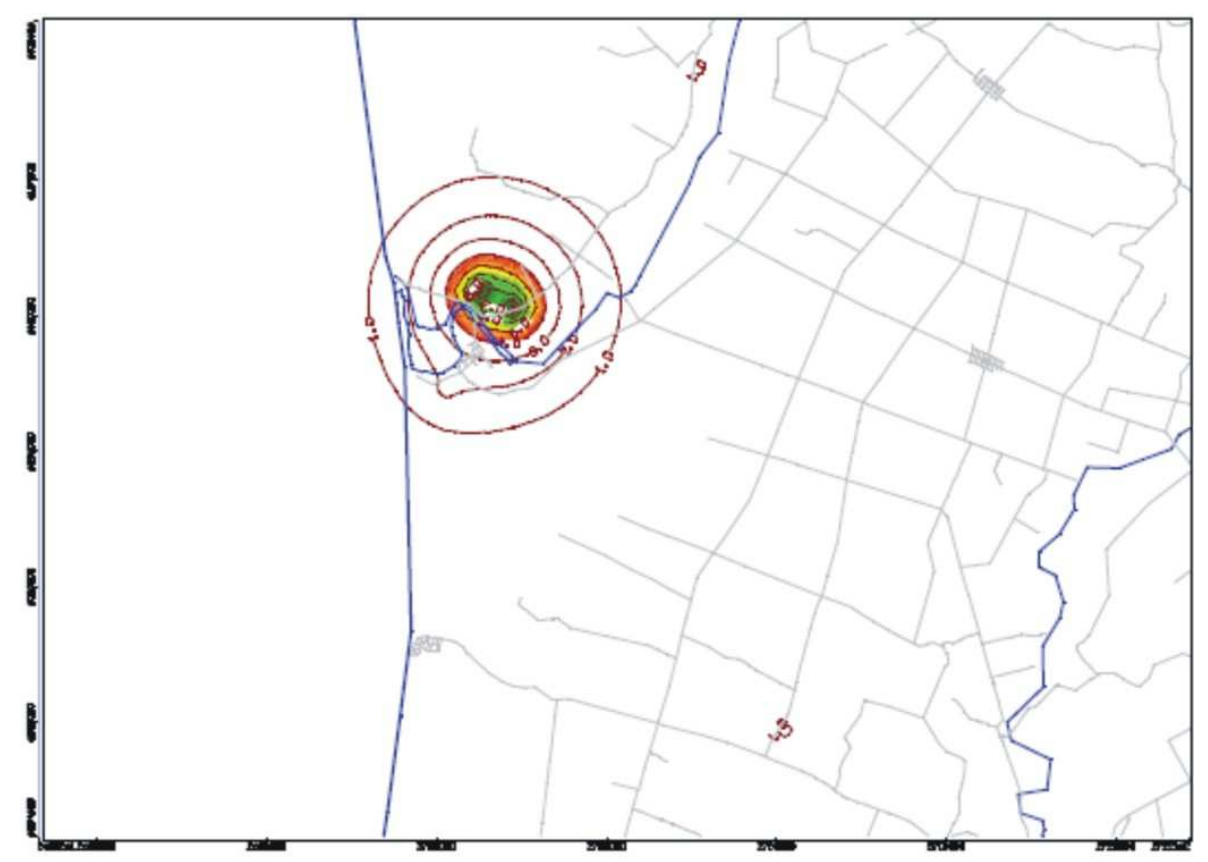

Figure 3.12 Modelled drawdown in the Upper Aquifer group in the Rangitikei delta area. (From Gyopari, 2005).

\subsection{Summary}

The study area focussed on the mouth of the Rangitikei River, in the Manawatu. The coast is characterised by a wide sandy foreshore, and large dynamic sand dunes and inter-dune swamps that have migrated inland. The region has moderate temperatures with warm summers and mild winters. Rainfall is reliable but the coastal and lowland area of the Manawatu is one of the driest parts of the North Island. The Rangitikei River has highly variable flows, ranging from approximately $135 \mathrm{~m}^{3} / \mathrm{s}$ in winter, to $10 \mathrm{~m}^{3} / \mathrm{s}$ during very dry periods. The soils in the sand country are predominantly sand based and range from excessively to moderately well drained. The soils of the river flats are formed from well-sorted alluvium. In parts, the levees obstruct drainage and produce a high water table on the river flats that are low lying. This creates poorly drained soils. There are three main aquifers in the area. This study focussed upon the upper aquifer 
zone, as it is shallow, unconfined and the majority of consented groundwater abstraction in the vicinity of the Rangitikei delta area comes from this aquifer zone. Water abstractions from the river and groundwater are largely used for agriculture. 


\section{Chapter 4.}

\section{Methodology}

\subsection{Introduction}

The aim of this research was to define the freshwater boundaries of shallow groundwater in the Rangitikei delta. This was to be done by determining the location, shape and dynamics of the saline interface of the shallow groundwater aquifer. The species and movement of total dissolved solids in the shallow groundwater were identified to determine the source of any salinity. The characteristics of the freshwater-saline interface were investigated using an integrative approach. Previous research of saline interfaces and saline intrusion have also used integrative approaches. In particular they have combined methods such as VES, resistivity traversing, and groundwater chemistry to delineate the interface (Carter et al., 2008; Choudhury and Saha, 2004; Ebraheem et al., 1997; Edet and Orekeke, 2001; Sherif et al., 2006; Song et al., 2007; Wilson et al., 2006).

Vertical electrical soundings (VES), using a Schlumberger array, were used to determine the basic geo-electric structure of the aquifer; and as far as possible to locate the position of the saline interface. Resistivity traverses using a Wenner array were then used to obtain two-dimensional sections, which would help to further delineate the interface. These resistivity results were then compared with data obtained from airborne electromagnetic methods. Chemical analyses of groundwater were used to calibrate the changes in salinity reflected in the geo-electric model. They made it possible to discriminate between the changes caused by lithology and those caused by water quality. 


\subsection{Direct Current resistivity}

\section{Vertical electrical soundings}

The initial fieldwork for this study was to determine the approximate location of the saline interface of the upper subsurface within the Rangitikei delta. These reconnaissance surveys were performed using VES in a Schlumberger configuration to give a one-dimensional indication of the variation of bulk resistivity with depth. VES are useful as a number can be made relatively quickly in different places. An electric current $(I)$ is injected into the ground through a pair of current electrodes $(\mathrm{A}, \mathrm{B})$ and the resulting potential difference $(\Delta V)$ between the two intermediate points $(\mathrm{M}, \mathrm{N})$ is measured (Figure 4.1). The vertical resistivity layering is resolved by step-wise increasing the distance between the outer electrodes to penetrate deeper into the ground (Ernstson and Kirsch, 2006; Wilson et al., 2006). An apparent resistivity can be calculated from $I, \Delta V$ and the electrode geometry. The apparent resistivity represents the average resistivity of the ground to a median depth of current penetration (Wilson et al., 2006). Using a Schlumberger configuration, the voltage electrodes $\mathrm{M}, \mathrm{N}$ are closely spaced, and fixed to the centre of the array. The current electrodes A, B move outwards. Under these conditions the geometrical factor approximates to:

$$
\mathrm{K}_{\mathrm{SCHLUMBERGER}}=\frac{\pi}{\mathrm{MN}} \cdot\left(\frac{\mathrm{AB}}{2}\right)^{2}
$$

(After Equation 3.3 in Ernstson and Kirch, (2006) page 88.) 


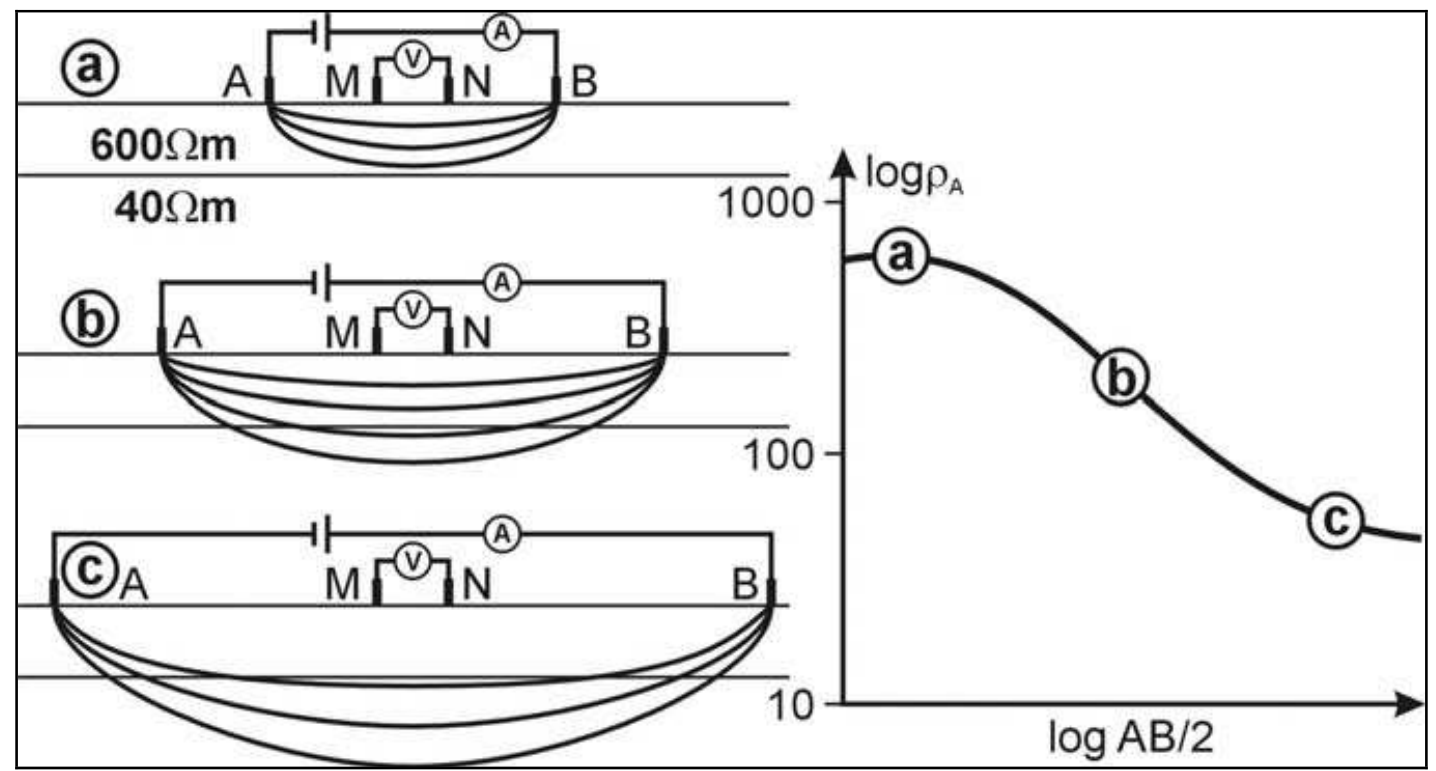

Figure 4.1 The Schlumberger configuration and modelled sounding curve (After Ernstson and Kirsch, 2006).

To determine the approximate location of the saline interface ten soundings were conducted on the southern side of the Rangitikei River mouth between 11 and 13 December 2006. A further six soundings were conducted on the northern side of the river on 20 February 2007. The locations of the soundings were chosen to give the widest spatial distribution, and were also determined by ease of access in the area of interest. The locations of these soundings are indicated by blue dots and labelled T1-T10 and S1-S6 on Figure 4.2.

The soundings were conducted using an ABEM SAS 300C Terrameter. A Schlumberger electrode configuration with a maximum current electrode separation of $80 \mathrm{~m}$ was employed. In a VES, the increasing spacing of the current electrodes $(\mathrm{AB} / 2)$ is usually chosen as equidistant in a logarithmic scale (Ernstson and Kirsch, 2006). Therefore, in the range from $1 \mathrm{~m}$ to $10 \mathrm{~m}$ there were as many apparent resistivity measurements as in the range from $10 \mathrm{~m}$ to $80 \mathrm{~m}$. The potential electrodes $(\mathrm{MN})$ were initially spaced $0.3 \mathrm{~m}$ apart. However, increasing $\mathrm{AB} / 2$ leads to a rapidly reduced potential difference at electrodes MN. This was compensated for by increasing the MN distance to $3.2 \mathrm{~m}$ and then $10 \mathrm{~m}$ to get a stronger signal. 
Modelling of the apparent resistivity data was performed using "Winsev", a onedimensional inversion code. The step-wise measured apparent resistivities $\left(\rho_{a}\right)$ were plotted against the current electrode spacing $(\mathrm{AB} / 2)$ on a $\log / \log$ scale and interpolated to a continuous curve. This plot is called a sounding curve. It produces estimates of the depth, thicknesses, and the apparent resistivity of the various layers beneath the centre of the sounding array (Figure 4.1) (Ernstson and Kirsch, 2006). When MN is increased, e.g., from $0.3 \mathrm{~m}$ to $3.2 \mathrm{~m}$, a static shift in the sounding curve is frequently observed because of near-surface resistivity inhomogeneities. This shift can be interpolated by overlapping measurements with each MN spacing (Ernston and Kirsch, 2006). The overlap of measurements were corrected to the greater potential electrodes spacing. This limited the effect of the noise created by variations in the surface, likely created by inhomogeneities and dry surface conditions. 


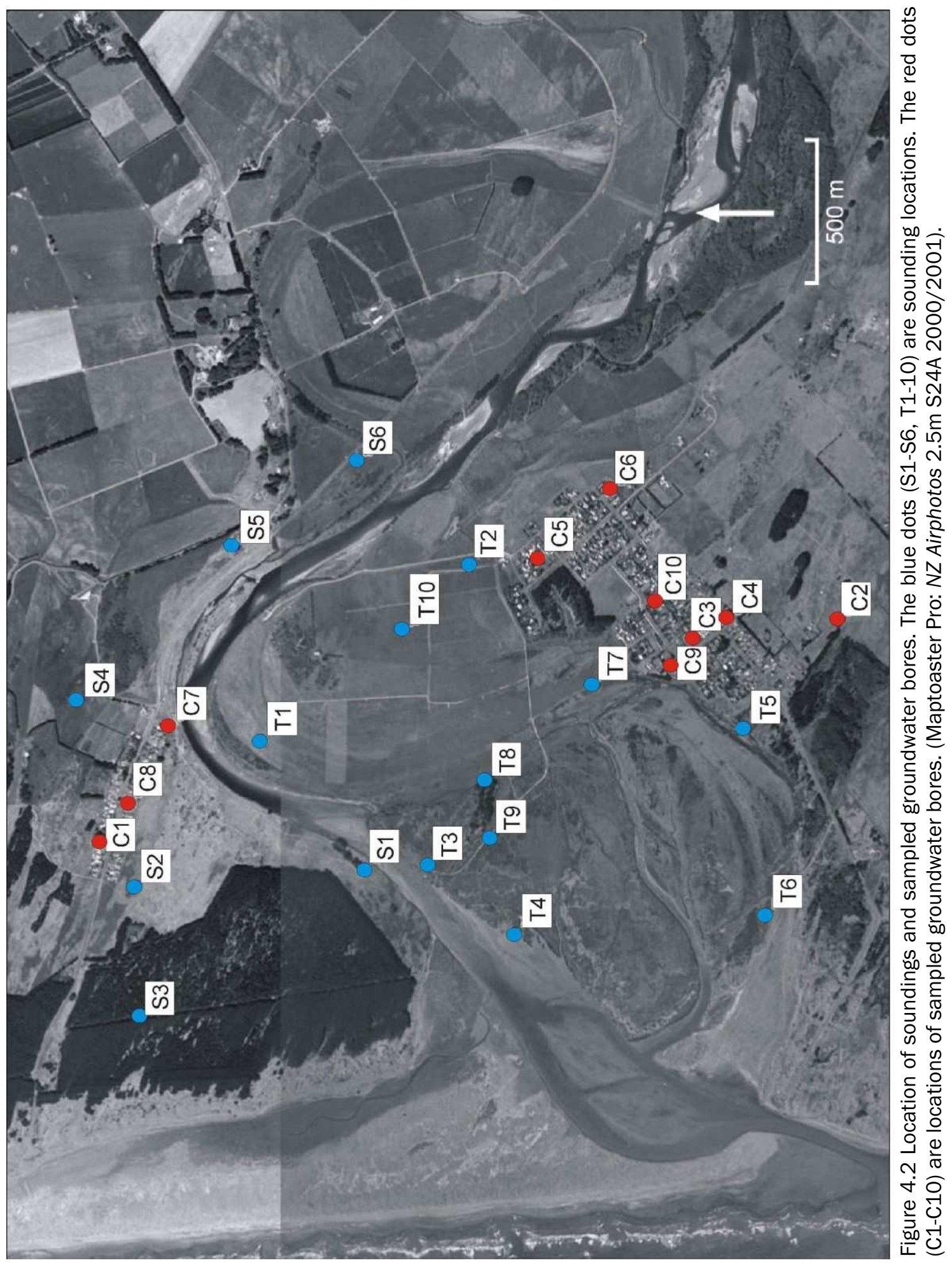




\section{Electrical resistivity traversing}

Once the area of investigation was established, resistivity traverses were performed. These provided detailed information, both laterally and vertically along the profile of the substrate. They were necessary as soundings do not take into account horizontal structure (Loke, 1999). The resistivity traverse assumes that there is no resistivity variation perpendicular to the profile (Ernston and Kirsch, 2006). Resistivity traversing uses a large number of electrodes arranged in a line. The Wenner array provides the most basic configuration, with electrodes having a constant spacing (a), (Figure 4.3). The array is good at resolving the vertical changes in the subsurface resistivity below the centre of the array. (Loke, 1999). Using the Wenner array, current is injected into and received from the ground through two outer electrodes ( $\mathrm{C} 1$ and $\mathrm{C} 2)$. As in the Schlumberger array, the potential difference is measured between two inner electrodes (P1 and P2). This configuration is kept constant and moved along the profile until all of the possible measurements have been made with an electrode spacing of $a$. Measurements are then made using electrode combinations that give a basic separation of $2 a, 3 a$, 4a, etc (Figure 4.3) so that information about deeper structure beneath the profile is obtained (Loke, 1999). Using the Wenner method the apparent resistivity can be obtained from:

$$
\rho_{a}=2 \pi a \frac{\Delta V}{I}
$$

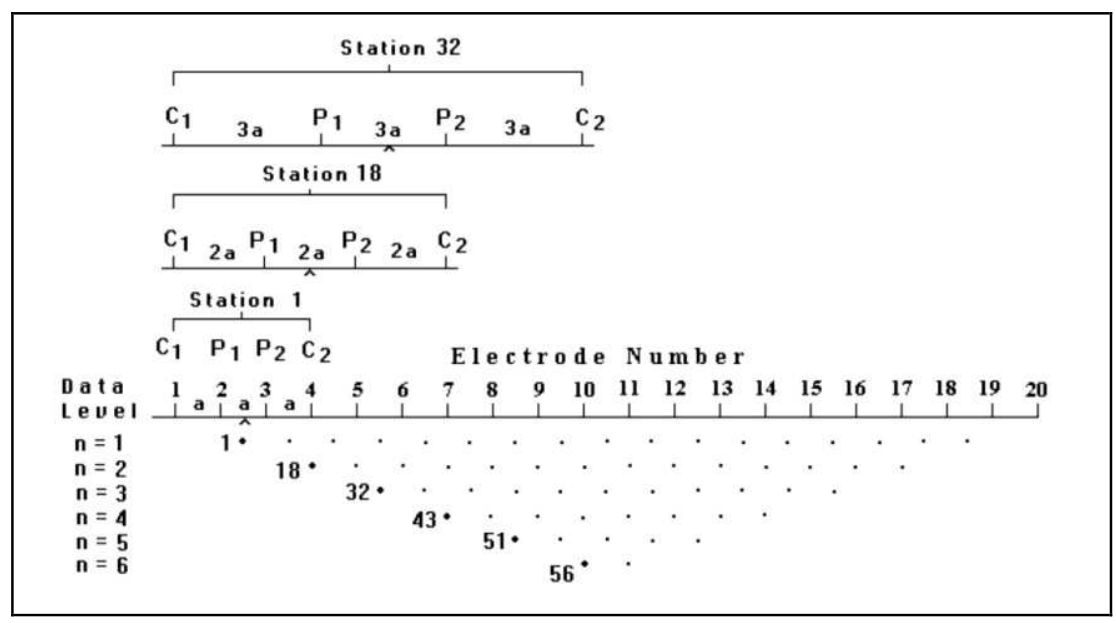

Figure 4.3 The arrangement of electrodes for a 2-D electrical survey and the sequence of measurements used to build up a pseudosection. (After Loke, 1999). 
Four resistivity traverses (W1-W4) were performed in January 2008. The locations of the traverses were determined from the previous soundings around Tangimoana. A further traverse (W5) was conducted on 21 February 2008 near Scott's Ferry. This was to confirm initial findings in this area, and to provide a calibration line for the airborne EM survey (Figure 4.4). The traverses varied in length from $580 \mathrm{~m}$ to $220 \mathrm{~m}$ with basic electrode spacing of 5 metres. The traverses were performed using an ARES-G4 automated resistivity system (Figure 4.5). Traverses W2 and W5 were unable to be conducted in a straight line and so have slight angles. These angles change the distance between the current and potential electrodes $(a)$. However, considering the distance of electrode spacing and the small angles, the error involved is considered to be negligible.

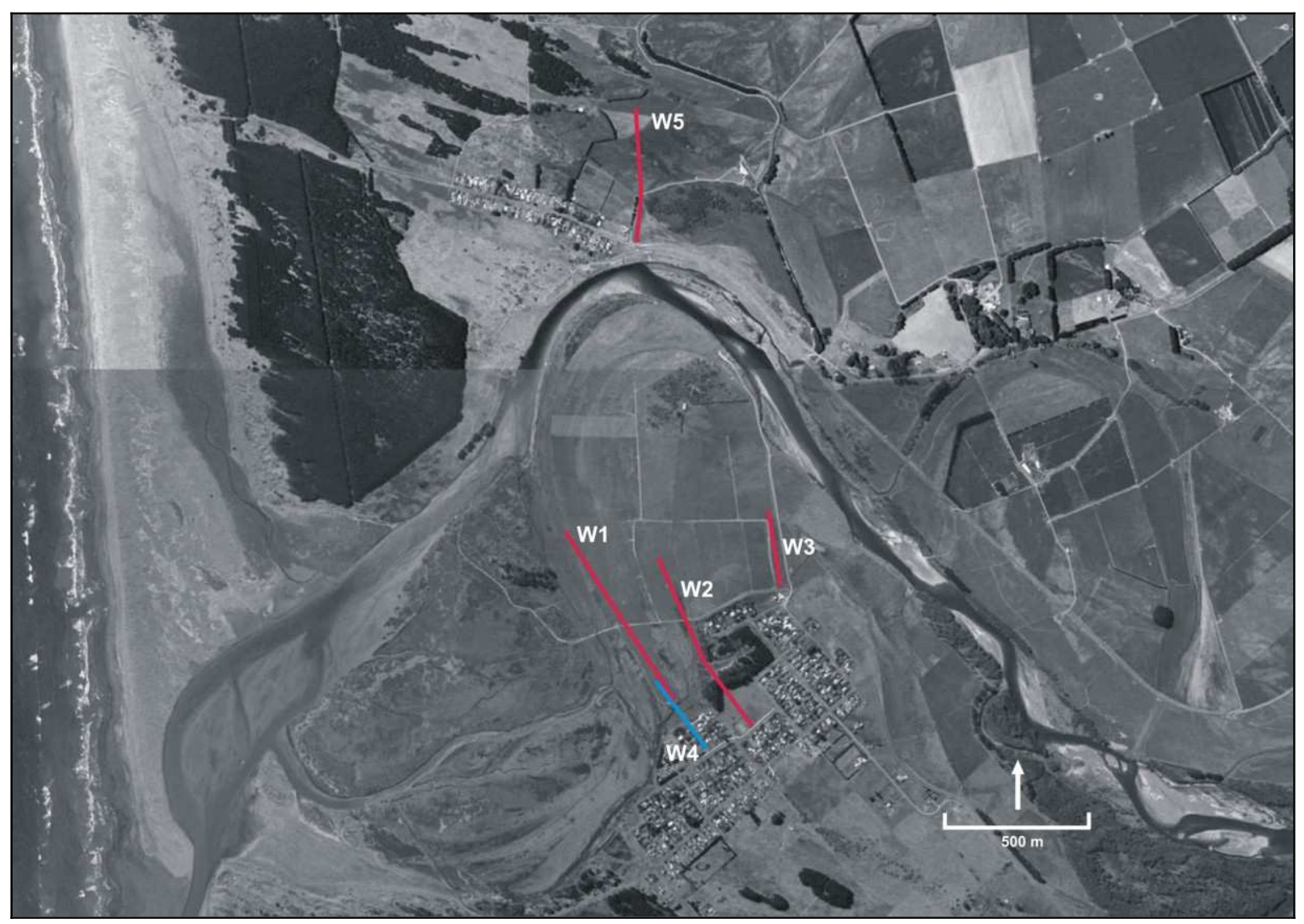

Figure 4.4 Locations of traverses W1-W5. (Maptoaster Pro: NZ Airphotos 2.5m S24A 2000/2001) 

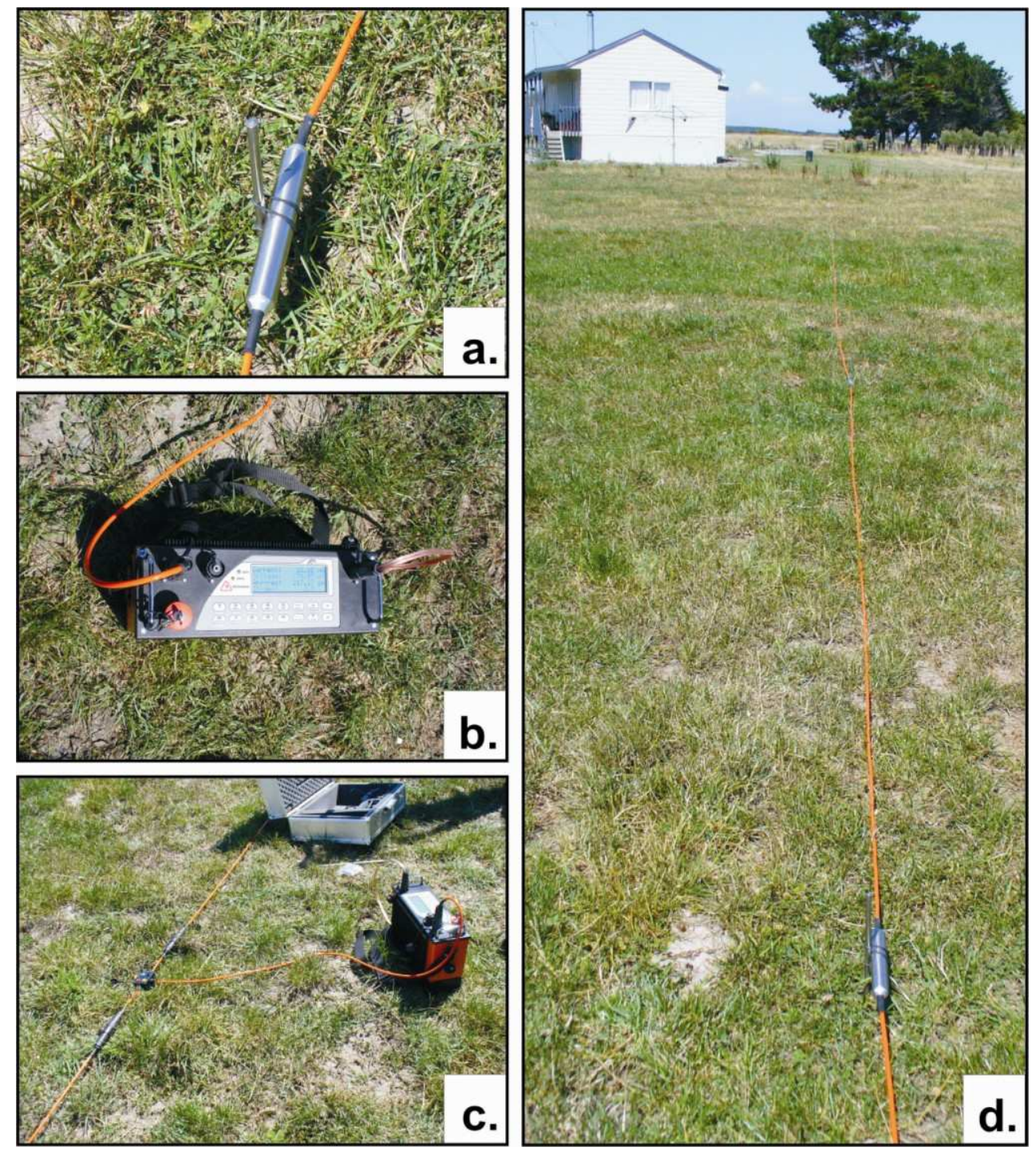

Figure 4.5 The ARES-G4 equipment used for resistivity traverses. a. non-polarisable electrodes b. 300 watt transmitter and receiver c. T-piece (for connection of multielectrode cable sections and cables for current and potential electrodes) d. Multi electrode cables spaced a constant $5 \mathrm{~m}$ apart.

Modelling of the resistivity traverses were performed using RES2DINV (ver. 3.55.61). This is a $2 \mathrm{D}$ inversion program that creates a model of the lateral and vertical variations in bulk resistivity of the subsurface profile. RES2DINV uses an iterative smoothnessconstrained least-squares inversion method. The inversion process minimizes the difference between the calculated and measured apparent resistivity values. The smoothness reduces the amount of noise in the resistivity model (Loke, 1999). RES2DINV determines the resistivity of 'rectangular blocks' that are the model parameters, and would produce an apparent resistivity pseudosection that corresponds with the measurements obtained from the traverse. The rectangular blocks are equal in 
number to the data points in the apparent resistivity pseudosection, and are arranged in a similar manner. The depths to the centres of the interior blocks are placed at a median depth of 0.5 times the electrode spacing for the Wenner array (Loke, 1999).

RES2DINV uses the Gauss-Newton least-squares optimization method to determine the resistivity of the rectangular blocks that minimize the differences between the calculated and measured apparent resistivity values (Loke and Barker, 1996). A measure of the difference between measured and modelled values is given by the root-means squared (RMS) error. The model with the lowest possible RMS error, however, is not always the most appropriate model as it can show unrealistic variations in the resistivity model (Loke, 1999). The standard least squares method uses the square of data misfit, and tends to give greater importance to data points with larger misfits. This makes it sensitive to bad data points. The smoothness constrained least-squares optimization method minimises the sum of squares of spatial changes in the model resistivity and the data misfit, this gives optimal results when the subsurface shows gradual changes in resistivity. However, the smoothness constrained model can smear the boundaries when a sharp transition in the subsurface resistivity is expected (Loke et al., 2003).

The data were edited to remove extreme and 'erroneous' datum points. Random low or high apparent resistivity values would distort the derived resistivity model. The finitedifference method was used as the data did not include topography. Given the relatively flat surfaces of the field area, it was concluded that the topography would not significantly affect the resistivity models. To make the calculated apparent resistivity values more accurate, the mesh grid used had 4 nodes between adjacent electrodes with a mesh refinement of intermediate mesh size. The distribution of the percentage difference between the logarithms of the observed and calculated apparent resistivity values was used to eliminate misfits of individual datum points.

The data from each transect were displayed using logarithmic contours, with a contour interval of four contours per decade. Contours began at a minimum resistivity of $1 \Omega \mathrm{m}$ and extended up to $5623 \Omega \mathrm{m}$. The inversion parameters and display logarithmic contours were constant for the five traverses to enable easy visual comparison. The contours lines reflect changes in the range of resistivity present in the substrate. The structure of the contours are indicative of changes in the substrate, e.g. closely spaced contours can 
signify a change in the saline content of the pore fluid, or alternatively changes in lithology.

\subsection{Airborne geophysical survey}

Airborne electromagnetic (AEM) surveys can be used to define the three-dimensional resistivity structure of the subsurface that depends on its pore fluid resistivity and substrate matrix. As the physical property that has the greatest effect on measurements is electrical conductivity (Palacky, 1993), AEM can be used to define saline and fresh groundwater zones. It can also indicate sub-surface variability in materials (Cresswell et al., 2007).

Generally in an AEM, the primary magnetic field is generated by sinusoidal current flow through the transmitter coil at a discrete frequency. The oscillating primary magnetic field is used to induce eddy currents in the ground, and a secondary magnetic field is produced by these currents. The strength of the secondary magnetic field is related to the strength of the eddy currents, which are directly related to the conductivity of the earth. The secondary magnetic field is picked up by the receiver coil and related to the primary magnetic field expected at the centre of the receiver coil (Siemon, 2006; Stewart, 1999). The background and theory of frequency domain AEM can be found in Siemon, (2006).

The AEM survey was conducted by Fugro BTW Ltd to obtain a 3-dimensional subsurface geological map of the coastal plain of the Manawatu. Fugro BTW Ltd used the RESOLVE system, which allows automated airborne calibration, minimal drift, lower noise, and real-time signal processing. The RESOLVE system uses frequencydomain EM, where the secondary magnetic field is recorded at one or more frequencies.

The survey used a helicopter flying about $60 \mathrm{~m}$ above ground level and towed a $9 \mathrm{~m}$ long sensor (or "bird") that was about $30 \mathrm{~m}$ above ground level (Figure 4.6). The flight path followed the contours of the land as much as possible. The survey area was crossed by flight lines $500 \mathrm{~m}$ apart, with occasional tie lines (Figure 4.7 and 4.8 ). The lower the frequency of the primary electromagnetic field the deeper the penetration of the field 
and resultant eddy current. An inversion programme was used to produce a resistivity map of the survey area. This provided information as to the layering and changes in the saline interface.

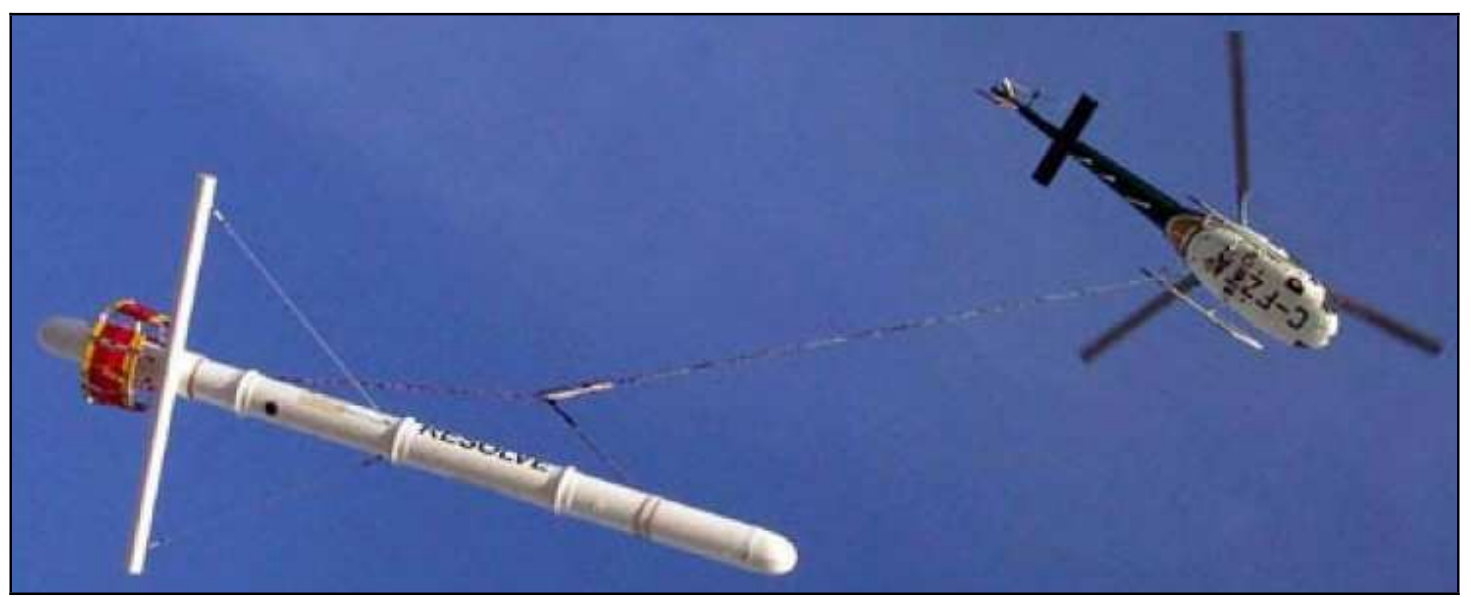

Figure 4.6 The helicopter and "bird" used for the airborne EM survey (provided by lan Brown Associates).

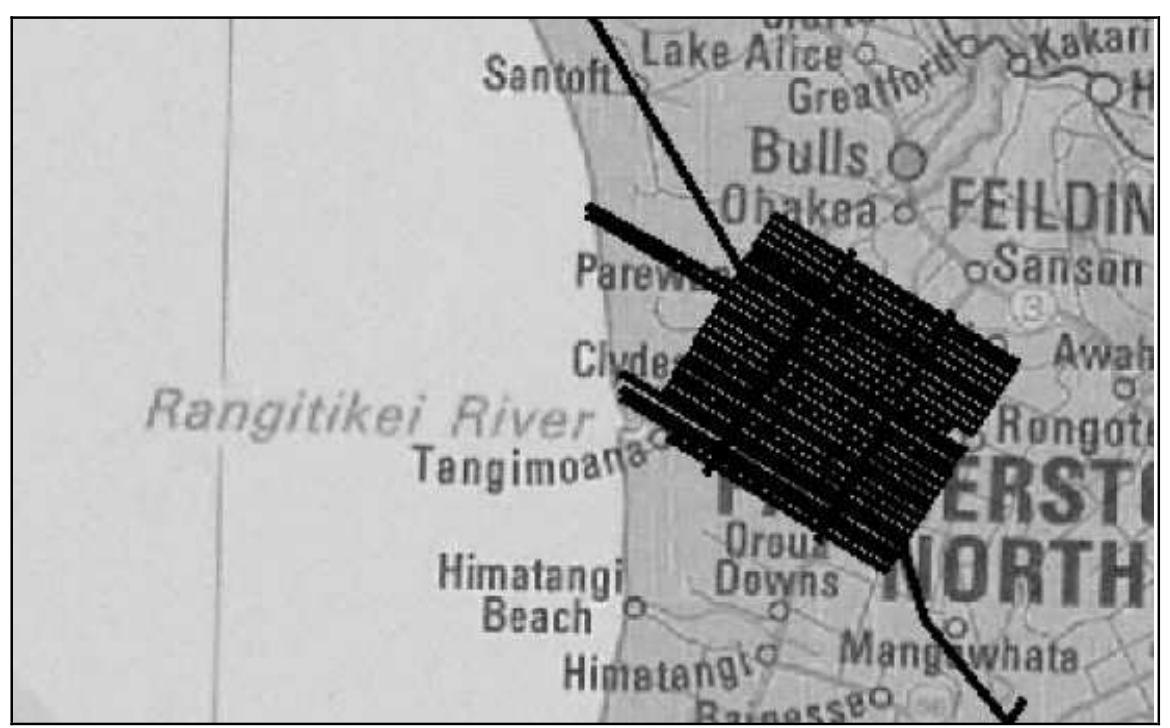

Figure 4.7 Airborne geophysical surveys and tie lines. 


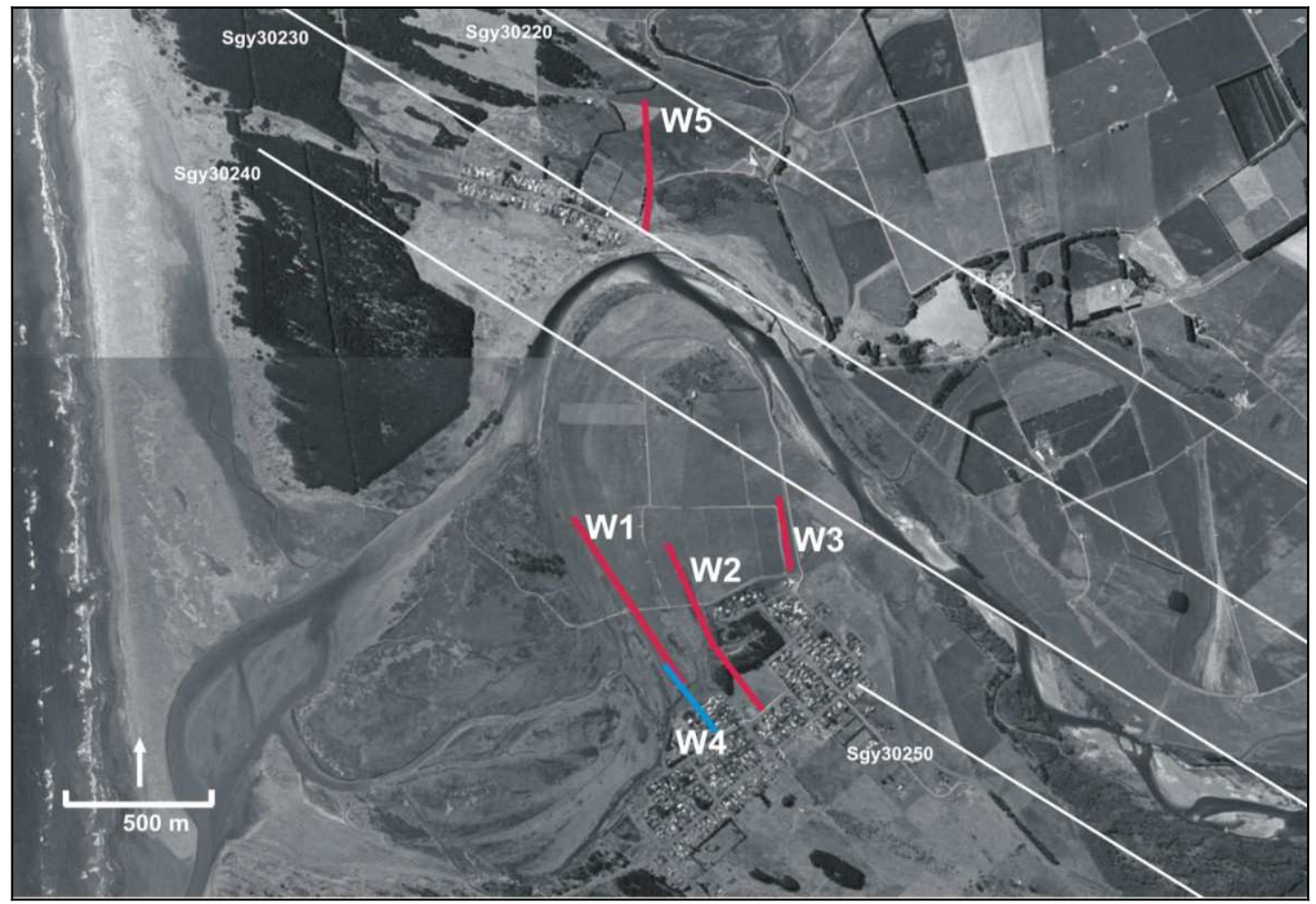

Figure 4.8 Geophysical survey lines of interest in relation to traverses.

\subsection{Hydrochemistry}

The most commonly used chemical indication of seawater mixing with freshwater is the presence of chloride ions in concentrations ranging from higher than background values to slightly less than seawater concentrations $(\sim 19,000 \mathrm{mg} / \mathrm{l})$. Chloride and bromide ions are ideal tracers of single salt-water sources as they are chemically conservative, and once in solution are not easily removed by ion exchange or precipitation (Richter and Kreitler, 1993). A combination of constituent ratios using these tracers can be used to distinguish between salt-water sources, such as seawater, halite-dissolution, connate water or sewage. Iron and manganese ions were also analysed as the shallow groundwater in the Rangitikei region is generally high in these ions (Bekesi, 2001).

Salinity is usually measured by proxy using total dissolved solids (TDS). The specific electrical conductance of the groundwater gives a convenient indication of TDS. Specific conductivity defines the conductance of a cubic centimetre of water at a 
standard temperature of $25{ }^{\circ} \mathrm{C} .1 \mathrm{mg} / 1$ of cations equate to $1.56 \mu \mathrm{S} / \mathrm{cm}$, as an approximate relationship for most natural groundwater (within the range of 100-5,000 $\mu \mathrm{S} / \mathrm{cm}$ ) (Todd and Mays, 2005). The total dissolved solids of the water samples were calculated from the major ions present using AquaChem. TDS can also be estimated using electrical conductivity:

$$
S=K A
$$

where:

$S=$ total dissolved solids $(\mathrm{mg} / \mathrm{l})$

$K=$ electrical conductivity $(\mu \mathrm{S} / \mathrm{cm}$

$A=$ a value between 0.55 and 0.96

(After Hem (1989), page 67)

Hydrogen ion concentration $(\mathrm{pH})$ is a measure of the water alkalinity or acidity. The $\mathrm{pH}$ is controlled by the amount of dissolved carbon dioxide $\left(\mathrm{CO}_{2}\right)$, carbonates $\left(\mathrm{CO}_{3}{ }^{2-}\right)$ and bicarbonates $\left(\mathrm{HCO}_{3}{ }^{-}\right)$(Sherif, et al., 2006).

To study the hydrochemical parameters of the groundwater in Tangimoana and Scott's Ferry, ten water samples were collected from existing residential groundwater bores. The bores ranged in depths from 6-35 m (Figure 4.2). Samples were collected on the 24 October and 5 November 2007. To ensure the groundwater samples were representative of the groundwater in the aquifer, water samples were collected using the sampling protocol recommended by the Ministry for the Environment, for the State of the Environment monitoring programme (MfE, 2006). Water samples were collected from the bores using a $12 \mathrm{~V}$ submersible pump, some bores were unable to be sampled with the pump, and so water was sampled from attached taps. Prior to sampling the bores were purged of at least three times the volume of the bore casing. Several samples were taken from bores that had pressure pumps that could not be by-passed. The pressure pumps were emptied three times with the permission of the owners. The pressure pumps were in general frequently emptied as the groundwater was utilised for household cold water supply. 
The $\mathrm{pH}$, temperature and electrical conductivity (EC) parameters were monitored during the purging process. They were recorded four separate times at intervals corresponding to the time required to extract one purge volume from the bore. These parameters were measured using a TPS 90-FLMV meter. Samples were collected once the parameter values of temperature, conductivity and $\mathrm{pH}$ were stable within the following limits: Temperature $\pm 0.2^{\circ} \mathrm{C}$, conductivity $\pm 3 \%$ and $\mathrm{pH} \pm 0.1 \mathrm{pH}$ unit. The TPS 90-FLMV meter did not work properly when the second set of water was sampled, and temperatures below zero were recorded. The field measurements of the other parameters could not be used as they are corrected for temperature. However, to ensure the sample was representative of the groundwater, the bore was purged for twice the amount of time purging took for the first set of samples.

The samples were filtered through a $45 \mu \mathrm{m}$ membrane using a syringe and syringe-tip filter. Samples for cation and metal analyses were stored with nitric acid preservative, and samples for anion analyses were stored in unpreserved PVC bottles provided by Hill Laboratories The samples were stored in ice, kept chilled, and sent to Hill Laboratories for analysis.

The constituents analysed were: calcium, sodium, magnesium, potassium, chloride, sulphate, iron, manganese, boron, strontium, nitrite, and nitrate ions. The methods and raw data used for analyses of the water samples are listed in Appendix 1. The chemical data were analysed using Aquachem (ver. 5.1), a hydrochemistry computer program.

\subsection{Summary}

The initial fieldwork for this study was to determine the approximate location of the saline interface of the upper subsurface. VES were used to investigate the variation of bulk resistivity with depth. A total of sixteen soundings were conducted on both sides of the Rangitikei River. The results were modelled as sounding curves that produced estimates of the depth, thicknesses, and the apparent resistivity of the various layers beneath the sounding array. Resistivity traverses were performed to obtain detailed 
information on the substrate, both laterally and vertically, along the profile. The Wenner array was used as it provided the most basic configuration, and it was good at resolving the vertical changes in the subsurface resistivity. Five resistivity traverses were conducted. Modelling of the resistivity traverses was performed using RES2DINV. This is a two-dimensional inversion program that creates a pseudosection of the lateral and vertical variations in bulk resistivity of the subsurface profile. The airborne EM survey was conducted to obtain a three-dimensional subsurface geological map of the coastal plain of the Manawatu. To study the hydrochemical parameters of the groundwater in Tangimoana and Scott's Ferry, ten water samples were collected. They were tested for major anions and cations. The chemical data were analysed to show the variation in water composition at different locations. 


\section{Chapter 5.}

\section{Results}

\subsection{Introduction}

This study focussed on the upper aquifer zone, as it is shallow, unconfined, and the majority of consented groundwater abstraction in the vicinity of the Rangitikei delta area comes from this aquifer. An integrative approach was used to investigate the saline interface. The results are first interpreted individually. They are then presented in context to each other in the next chapter.

Existing bore logs and sampled water depths were used to interpret the resistivity soundings. A contour map showing the variation in resistivity at a depth of $10 \mathrm{~m}$ was determined using the modelled sounding results. The apparent resistivity of the subsurface, determined from resistivity traverses, was modelled and presented as individual pseudosections. To allow straightforward comparison, the pseudosections have all been displayed with constant resistivity contours and horizontal and vertical scales. To summarise the traverse results, the pseudosections have been combined and positioned relative to each other. The initial results of the airborne EM survey are presented as lateral resistivity maps and profiles. The major constituents of the water samples are presented to characterise the water types of the groundwater in Tangimoana and Scott's Ferry. The absolute concentrations have been determined and ratios of the major ions have been calculated to determine the species of total dissolved solids present in the groundwater. 


\subsection{Vertical electrical soundings}

Sixteen soundings were conducted within the Rangitikei delta region, near Scott's Ferry and Tangimoana. The summary and interpretation of the one-dimensional modelling of the soundings are presented in Table 5.1; the sounding curves are given in Appendix 2. Modelling of the sounding data is non-unique and some combinations of resistivity and thickness of subsurface formations can produce identical sounding curves. The resistivity models obtained from sounding curves are on log-log scales. Therefore, the differences in resistivity should be interpreted in terms of orders of magnitude.

Soundings S2 and S4 were conducted near existing bores. The lithology described by the bore logs was used to interpret the modelled resistivity (Figure 5.1). Soundings S2 and S4, however, do not show layers comparable with the lithology. The modelled resistivity of $\mathrm{S} 2$ shows a thin layer $(0.68 \mathrm{~m})$ of high resistivity $(1068 \Omega \mathrm{m})$, underlain by a low resistivity layer $(46 \Omega \mathrm{m}) 3.6 \mathrm{~m}$ thick. Beneath these layers is a layer with a resistivity of $260 \Omega \mathrm{m}$. The sounding curve modelled for S2 does not resemble the lithology of either bore 322011 and 322029 that are both located within $500 \mathrm{~m}$ of S2.

The model of sounding S4 showed two upper layers that were both thin $(<0.20 \mathrm{~m})$ and had resistivity of more than $100 \Omega \mathrm{m}$. There is a $3.3 \mathrm{~m}$ thick layer of $98 \Omega \mathrm{m}$. Beneath these layers is a layer of $265 \Omega \mathrm{m}$. Comparison between the modelled resistivity and the bore $\log$ for 322017 does not show a distinct correlation between the resistivity and the lithology. The soundings do not compare well with the lithology from the bore logs, so it can be assumed that the bulk resistivity of the area is predominantly determined by fluid conductivity, as described by Archie's Law. 


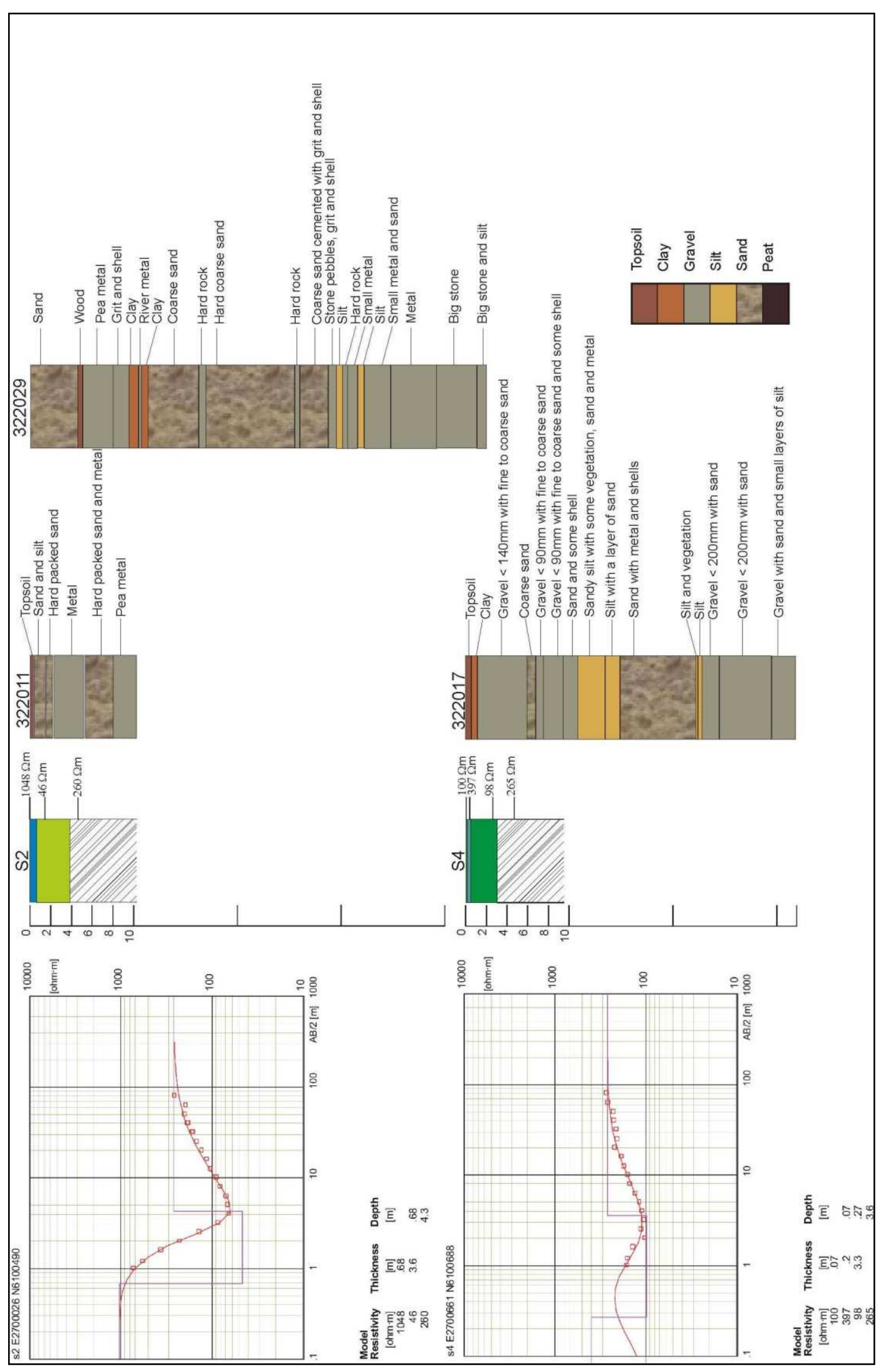

Figure 5.1 Comparison of soundings S2 and S4 with bore logs 
Surveys conducted inland on the northern side of the river (S2, S4 and S5) showed a typical resistivity of $151-265 \Omega \mathrm{m}$. Based on the lithology of bore logs in the vicinity, this resistivity value is likely to correlate with sands and gravels saturated with freshwater (Figure 5.1). Soundings conducted on the northern side of the Rangitikei River did not show extensive saline mixing. However, the soundings located closest to the river (S1 and S6) might be expected to show some sign of saline mixing because of their proximity to the tidal river mouth. $\mathrm{S} 1$, located within approximately $500 \mathrm{~m}$ of the coast showed a $1 \mathrm{~m}$ thick layer with resistivity of $27 \Omega \mathrm{m}$, within a metre of the surface, overlying a layer of $201 \Omega \mathrm{m}$ (Figure 5.2). This layer could possibly indicate saline mixing. S6, although considerably further from the coast, also showed a $5.4 \mathrm{~m}$ thick layer with lower resistivity (46 $\Omega \mathrm{m})$. This layer was overlying an extensive layer (24 m thick) with a resistivity of $84 \Omega \mathrm{m}$.

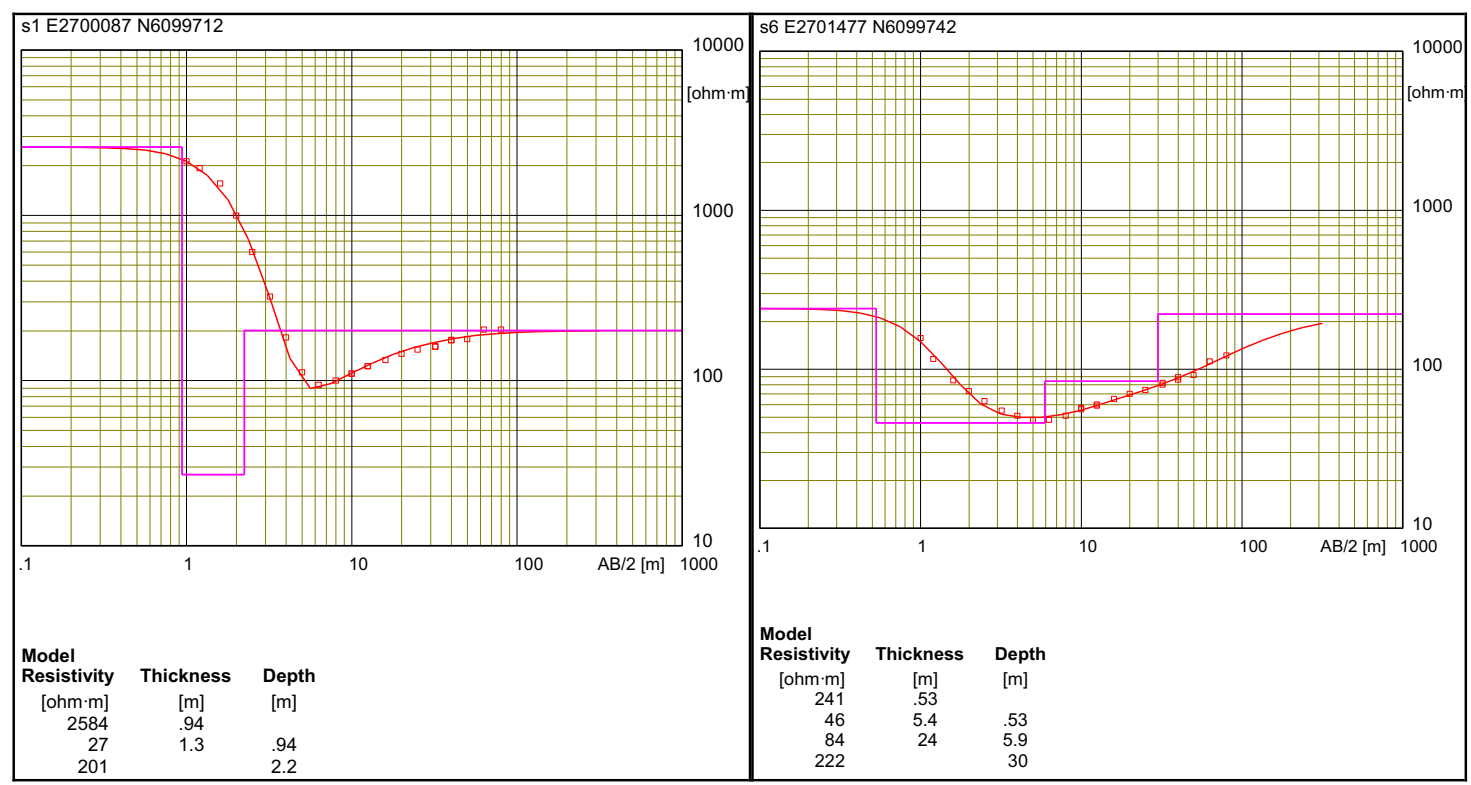

Figure 5.2 Sounding curves of S1 and S6

Soundings conducted on the southern side of the river appeared to show extensive saline mixing. As expected, the soundings conducted on the salt marsh (T6 and T4) show extensive low resistivity to depth. The low resistivity of the salt marsh extends inland into farmland, and very close to Tangimoana. Several soundings in this area show low resistivity to depth. Sounding T2, located the furthest from the coast on the southern side 
of the river (Figure 4.2), shows low resistivity $(59 \Omega \mathrm{m}$,) from $9.3-41 \mathrm{~m}$ depth. This is an extensive low resistivity layer that is also seen in sounding T10. Sounding T7, located on the northern edge of Tangimoana, and on the salt marsh boundary of the farmland, shows low resistivity $(30 \Omega \mathrm{m})$ from $4.2-47 \mathrm{~m}$ depth. T9 shows a low resistivity layer of 21-36 $\Omega \mathrm{m}$ at a depth of 1-29 $\mathrm{m}$. Soundings T8 and T9 were located in an area of significant topography, and show higher resistivity at depth.

To show the variation in resistivity, a contour map of resistivity at a depth of $10 \mathrm{~m}$ was prepared for the entire area from the interpreted sounding data (Figure 5.3). The sounding data from Scott's Ferry showed variation in resistivity at this depth, ranging from 84-396 $\Omega \mathrm{m}$. Fresh groundwater north of the river leads to higher resistivity $(>250$ $\Omega \mathrm{m})$ at $10 \mathrm{~m}$ depth, but has lower resistivity near the river. This is likely to be caused by brackish surface water and fresh groundwater interaction. The sounding data from the southern side of the river showed great variation in resistivity and ranged from 10 to 166 $\Omega \mathrm{m}$. In the salt marsh, resistivity is between 10 and $20 \Omega \mathrm{m}$. This low resistivity trend continued in a north-easterly direction inland. It could be seen beyond the salt marsh leading to relatively low $(\sim 58 \Omega \mathrm{m})$ resistivity on the outskirts of Tangimoana. The area of high resistivity on the southern side of the river also corresponds to a topographic high and an old river channel that had been in-filled. It is possible that this has created a preferential flow path for fresh groundwater. 


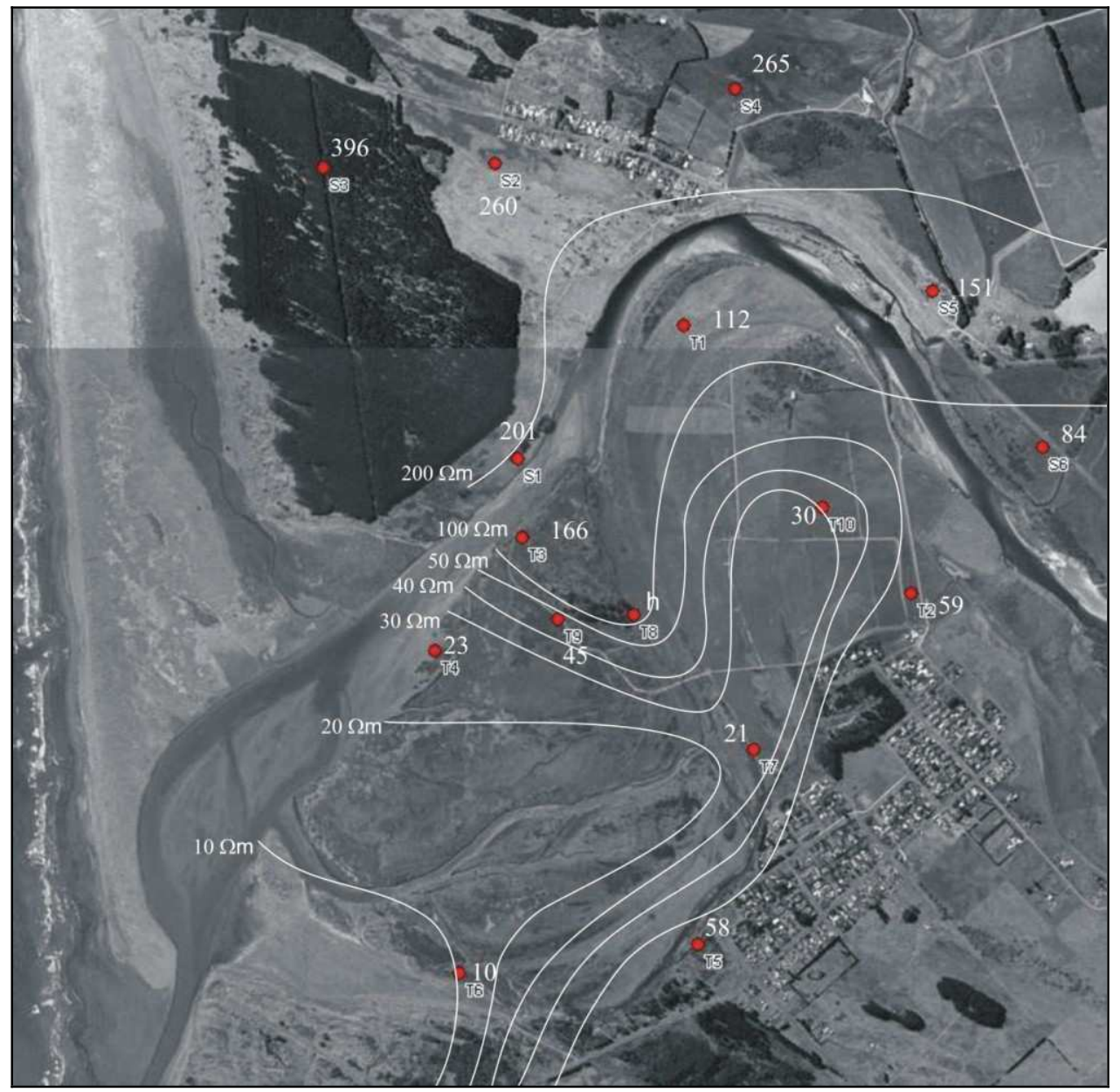

Figure 5.3 Variation in apparent resistivity at $10 \mathrm{~m}$ depth.

\subsection{Resistivity traverses}

The extent of the saline interface near Tangimoana was further investigated using four resistivity traverses (Figure 4.4). These provided a profile of the subsurface, and refined the location, and shape, of the saline interface. Although the groundwater in Scott's Ferry did not appear to have extensive saline mixing inland, a traverse was conducted to provide comparison with the AEM survey. It also provides a baseline for future monitoring of the saline interface, which is necessary, given the volume of groundwater abstracted from the aquifer in this area. The data obtained from these traverse are presented as pseudosections, representations of the subsurface resistivity distribution. See Appendix 3 for the complete inversion models. 
The resulting apparent resistivity profiles are shown in Figure 5.4-5.9. The profile modelled from traverse W1 is shown in Figure 5.4. The pseudosection obtained is from four iterations with an RMS error of $3.03 \%$. Profile W1 showed a layer of resistivity less than $10 \Omega \mathrm{m}$ to about $6 \mathrm{~m}$ depth, and then a layer of resistivity less than $30 \Omega \mathrm{m}$ to a much greater depth. These layers are consistent with the Schlumberger soundings (Figure 5.3). Resistivity increased with depth in the surface layers. The model showed ridges of high resistivity situated at $245 \mathrm{~m}$ and $560 \mathrm{~m}$ rising to approximately $10 \mathrm{~m}$ depth.

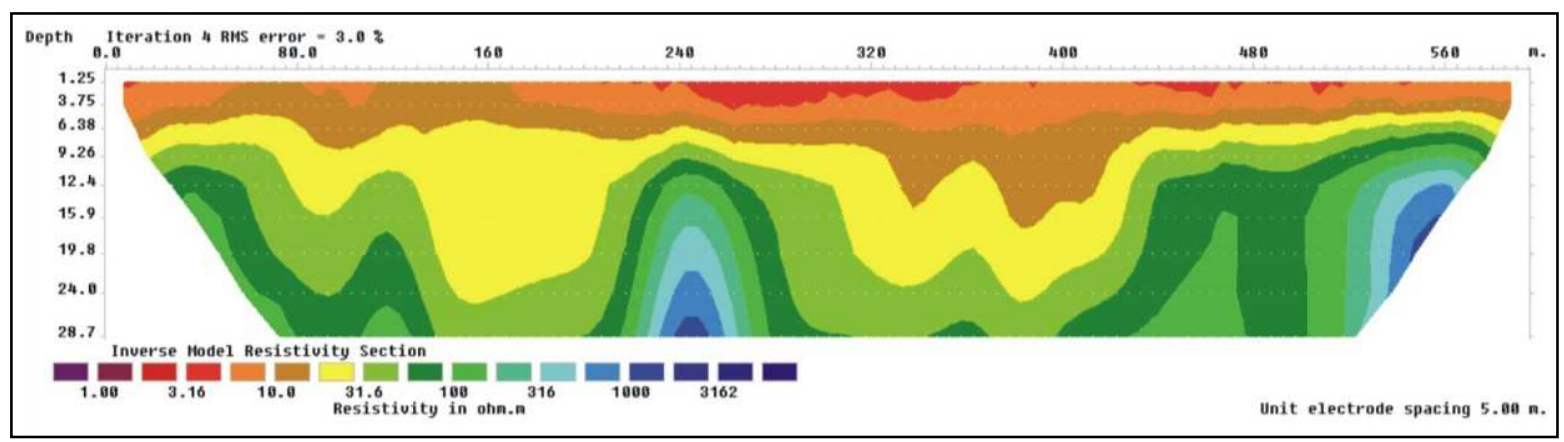

Figure 5.4 A 2-dimensional inversion model of Traverse W1. The profile is orientated in a SE-NW direction.

Traverse W4 extended traverse W1. The purpose of the profile was to determine the extent of the effect of saline groundwater from the salt marsh towards Tangimoana. The profile was conducted along a roadside in town and extended onto the salt marsh (Figure 4.4). Data points that were associated with five electrodes $(130-150 \mathrm{~m})$ were removed as there was no direct contact with the ground. This is because the traverse lay along a bridge, and there was also variable contact along the road edge. The removal of these data created gaps making the model difficult to resolve (RMS error $=17.6 \%)$. However, the general pattern of the profile shows that across the salt marsh there is low resistivity at the surface $(\rho \mathrm{a}<10 \Omega \mathrm{m})$ that increases with depth (Figure 5.5). This profile is consistent with traverse W1.

Between 100 and $120 \mathrm{~m}$ there is a narrow vertical structure with low resistivity $(\rho \mathrm{a}<31$ $\Omega \mathrm{m}$ ). It is possible that this is where the traverse passed near an estuary channel (see Figure 4.4). This part of the inversion model is also close to where the electrodes were removed so it could be that this was not a narrow structure but rather part of a larger 
layer that could not be resolved. An alternative explanation is that this structure is a relic of the inversion model attempting to fit datum points. The profile also shows that there is a thick (approximately $20 \mathrm{~m}$ ) resistivity layer of about $100 \Omega \mathrm{m}$, underlying a thin high resistivity $(\rho \mathrm{a}>316 \Omega \mathrm{m})$ surface layer that ceases at $\sim 90 \mathrm{~m}$. This coincides with the verge of the roadside. Fingers of high resistivity ( $\rho \mathrm{a}>300 \Omega \mathrm{m}$ ) around 80 and $100 \mathrm{~m}$ are associated with the missing electrodes and are considered relics of the inversion model. There is a ridge of high resistivity ( $\rho$ a $>1000 \Omega \mathrm{m}$ ) between 130 and $180 \mathrm{~m}$ at the bottom of the inversion model.

The data were inverted again using a robust inversion to reduce the effect of data misfits (Figure 5.6). The robust technique eliminates extreme values by under-weighting resistivity data points that deviate too far from the average values. The distribution of resistivity was approximately the same, with a reduced effect of the missing data points. The robust model showed a sharper transition from the surface to the high resistivity ridge. The low resistivity $(\rho a<31.6 \Omega \mathrm{m}$ ) surface layer on the salt marsh extends to approximately $7 \mathrm{~m}$ depth. Below this layer is a section of moderate resistivity $(31.6<\rho \mathrm{a}$ $<70 \Omega \mathrm{m})$.

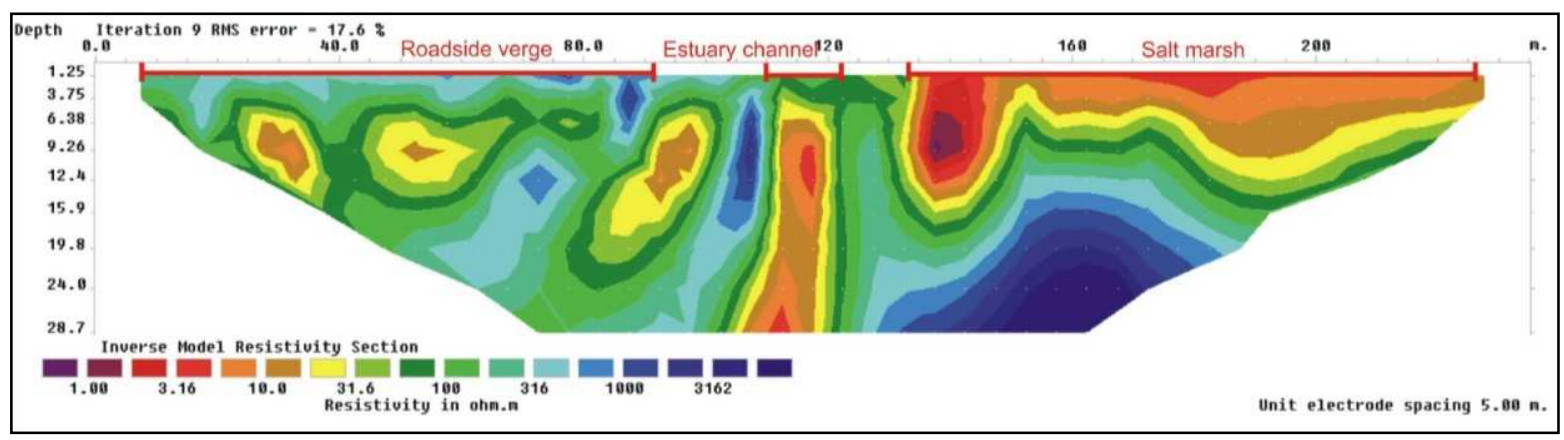

Figure 5.5 A 2-dimensional inversion model of Traverse W4. The profile is orientated in a SE-NW direction. 


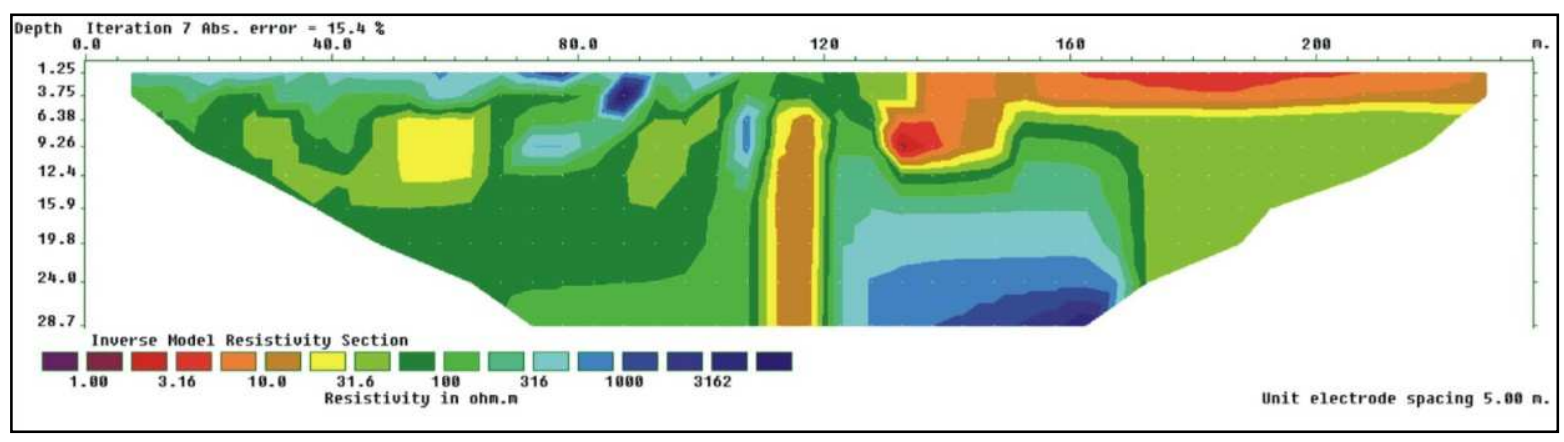

Figure 5.6 A 2-dimensional robust inversion model of Traverse W4. The profile is orientated in a SE-NW direction.

Traverse W2 was located at the inland limit of the salt marsh, next to the Ellison Reserve. The traverse extended from a playing field in Tangimoana towards the farmland (Figure 5.7). The variable modelled resistivity below the playing field is the result of a very dry surface giving variable electrical contact. The model had a RMS error of 7.6\%. The resistivity beneath the playing field ranged between $30-1000 \Omega \mathrm{m}$ at a depth of $25 \mathrm{~m}$. The resistivity beneath the salt marsh/farmland was less than $30 \Omega \mathrm{m}$ to a depth of $25 \mathrm{~m}$. The profile suggests a distinct "toe" of salinity dispersion (represented by the $<31.6 \Omega \mathrm{m}$ yellow contour line) seen to extend to a depth of $24 \mathrm{~m}$ (at $180 \mathrm{~m}$ ) towards Tangimoana. Underlying these layers is a layer of high resistivity ( $\rho \mathrm{a}>300 \Omega \mathrm{m}$ ). The resistivity of the profile is consistent with the distribution of resistivity found from the soundings (Figure 5.3).

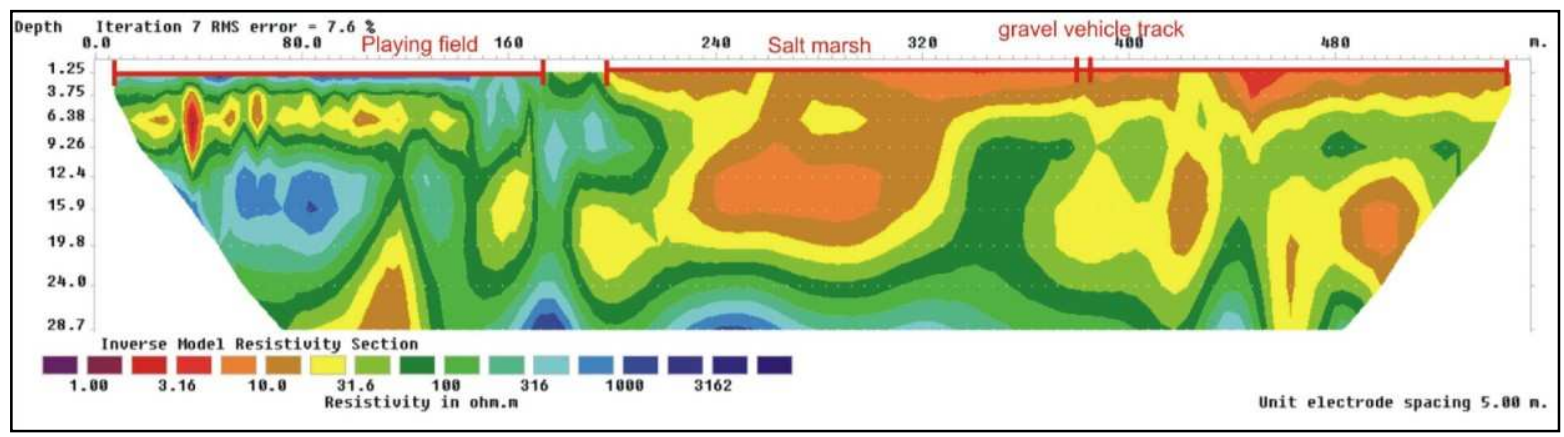

Figure 5.7 A 2-dimensional inversion model of Traverse W2. The profile is orientated in a SE-NW direction. 
Traverse W3 was to further define the apparent resistivity distribution that was demonstrated by the sounding contour map. The traverse was located close to sounding T2. Traverse W3 was located on the Parewanui silt loam that consists of finer alluvium, is poorly drained, and frequently flooded. This traverse showed little variation in resistivity and was well resolved (RMS error $=1.01 \%$ ) (Figure 5.8). The upper surface layer, about 1-5 $\mathrm{m}$ thick, is represented by the $\rho \mathrm{a} \sim 31.6 \Omega \mathrm{m}$ light green contour line. Beneath the surface layer was a layer of higher resistivity ( $\rho \mathrm{a}>100 \Omega \mathrm{m}$ ) to a depth of approximately $14 \mathrm{~m}$. A layer of similar resistivity to the surface layer ( $\rho \mathrm{a} \sim 31.6 \Omega \mathrm{m}$ ) was located between two layers of about $100 \Omega \mathrm{m}$. A layer of high resistivity ( $\rho \mathrm{a}>316$ $\Omega \mathrm{m})$ can be observed at the bottom limit of the inversion model. This profile was consistent with the trend of increasing resistivity inland from the salt marsh.

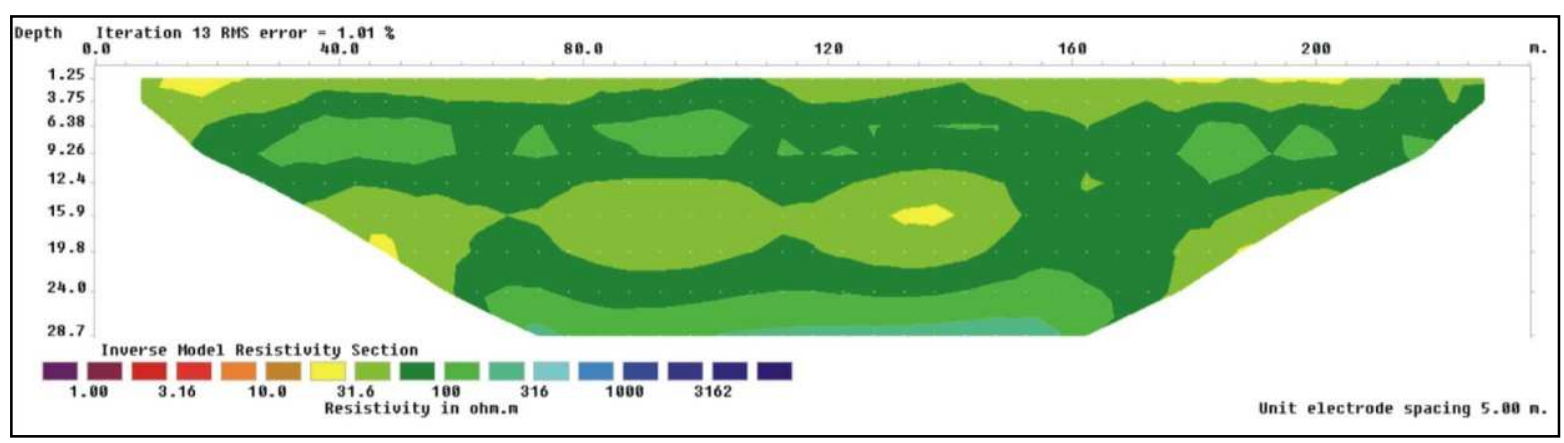

Figure 5.8 A 2-dimensional inversion model of Traverse W3. The profile is orientated in a SSE-NNW direction.

Traverse W5 was located on the northern side of the Rangitikei River, on the outskirts of Scott's Ferry. The surface layer between 0.0 and $110 \mathrm{~m}$, and 235 and $390 \mathrm{~m}$ showed a resistivity of approximately $31.6 \Omega \mathrm{m}$. This coincides with saturated poor drainage areas (Figure 5.9). Beneath this surface layer, the resistivity was relatively high ( $\rho \mathrm{a}>70 \Omega \mathrm{m}$ ) and likely indicates fresh water in a predominantly gravel matrix. This profile shows no indication of salinity at present. 


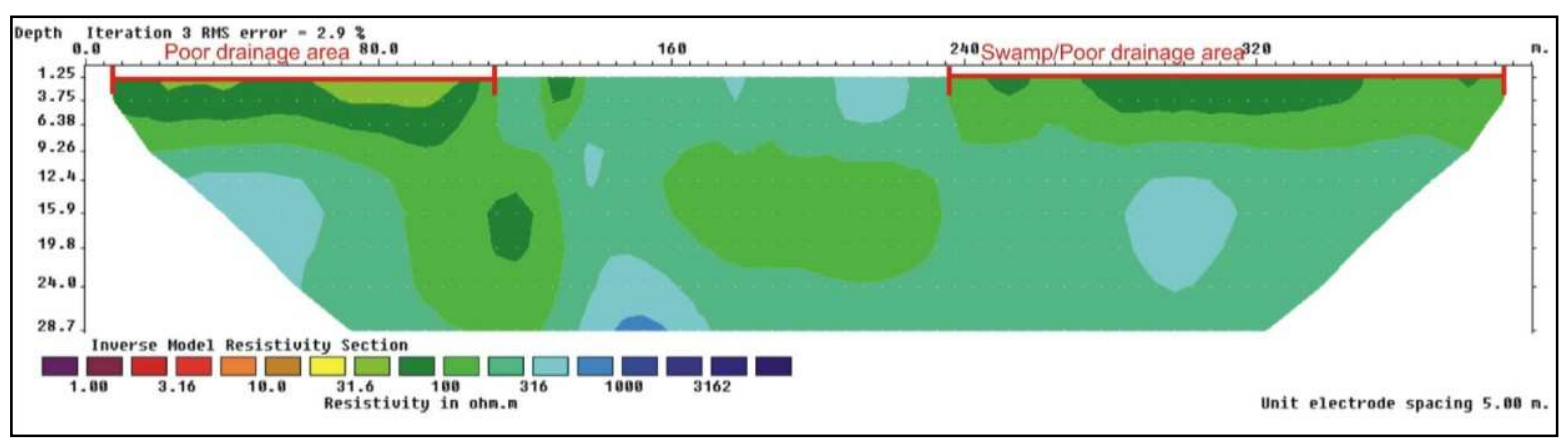

Figure 5.9 A 2-dimensional inversion model of Traverse W5. The profile is orientated in an S-N direction.

The inversions of the data from the southern traverses were combined and positioned relative to each other (Figure 5.10). The traverses located in the salt marsh (W1, W2 and W4) all showed the same stratification of increasing resistivity with depth. Traverse W1 and W2 showed a similar low resistivity $(\sim 31.6 \Omega \mathrm{m})$ "bulge" between 130-220 $\mathrm{m}$ and 220-330 m, respectively. All of the traverses showed an underlying layer of high resistivity ( $\rho \mathrm{a}>300 \Omega \mathrm{m}$ ) at a depth of approximately $24 \mathrm{~m}$. The general profile resistivity increases inland in an easterly direction, as the influence of the salt marsh decreases. The resistivity also increases inland towards Tangimoana. Although the resolution of W4 and W2 beneath the dry surfaces is poor, both of these profiles appear to have low resistivity layers at approximately $10 \mathrm{~m}$ depth. 


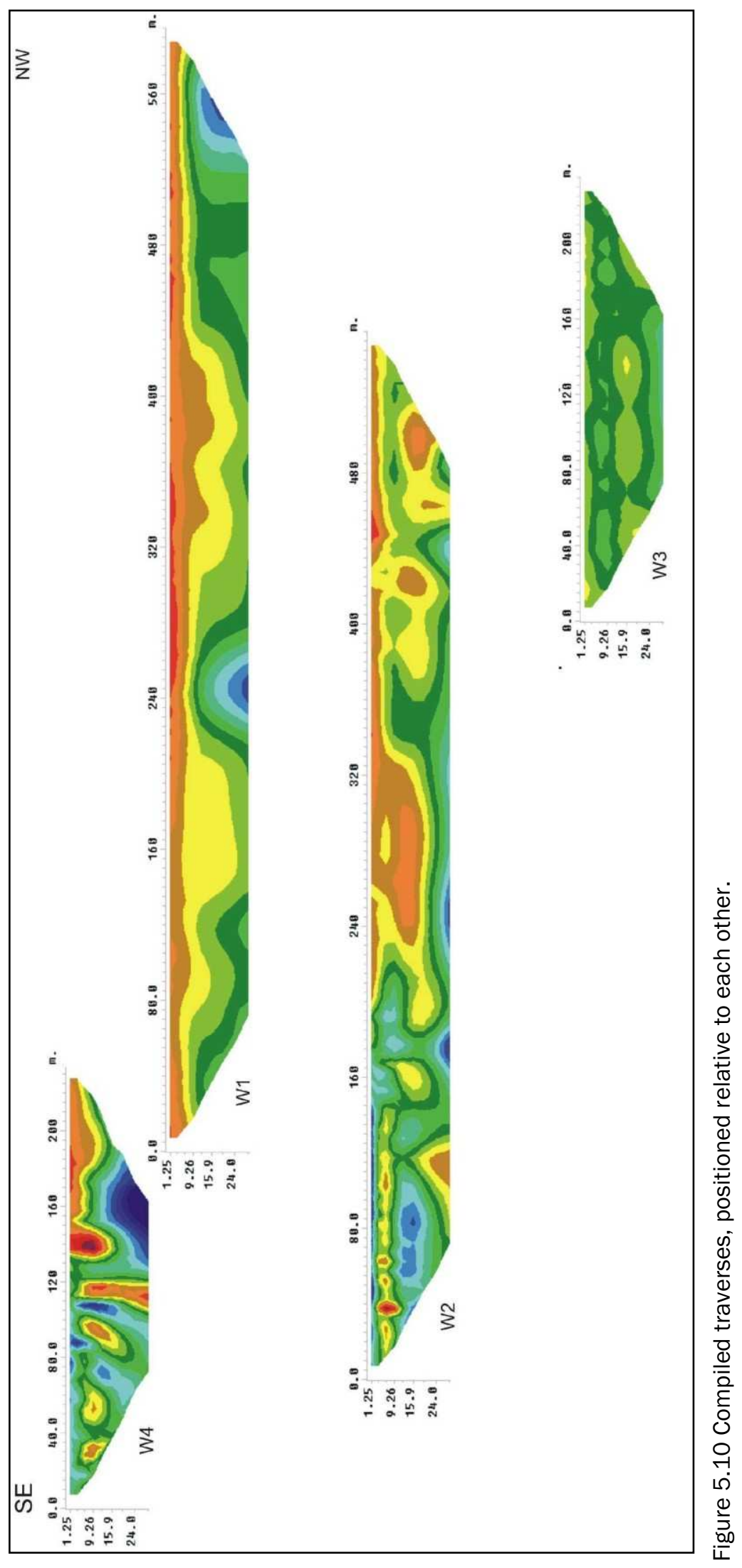




\subsection{Airborne EM survey}

Airborne electromagnetic surveys can provide rapid assessment of the bulk resistivity of the subsurface of large areas. They have an important role where other data are scarce (Cresswell et al., 2007; Dent, 2007). Sources of fresh groundwater have been predicted by calculating groundwater salinity from calibrated depth images of bulk resistivity derived from airborne electromagnetics. Calibration of an AEM survey is essential for realistic interpretations of the airborne geophysical signals. This is usually achieved using: subsurface conductivity; radiometric and magnetic susceptibility; the subsurface matrix; bore water levels and groundwater conductivity; chemical and physical analysis of groundwater and soil samples, particularly with respect to salinity; and, the assessment of field conditions and landscape features (Cresswell et al, 2007).

The following lateral resistivity maps and profiles were provided by Ian Brown Associates. The maps have not been calibrated with groundwater chemistry or ground resistivity. However, the model from the AEM survey can provide valuable information about the relative resistivity, and spatial patterns of resistivity, of the area. The airborne resistivity maps were used as a direct visual comparison of the spatial patterns of resistivity. The ground geophysics and groundwater chemistry in this study will provide a priori for the calibration and re-interpretation of the AEM survey data that is beyond the scope of this study. The lateral resistivity maps will be briefly described, and will be further discussed in the next chapter. The depth of the frequency penetration is dependent on decreasing frequency and increasing resistivity, e.g. a frequency $40 \mathrm{k} \mathrm{Hz}$ would only penetrate within a depth of one metre, whereas a frequency of $1800 \mathrm{~Hz}$ would penetrate much deeper to a depth greater than $50 \mathrm{~m}$ (Siemon, 2006).

It should be noted that the contours between the lateral resistivity maps and the resistivity profiles do not have a constant colour scale. Careful consideration should therefore be given to the apparent resistivity ranges. As the lateral resistivity maps and profiles have not been calibrated, the resistivity will be interpreted by broad colour categories: blue $=$ low resistivity $(5-100 \Omega \mathrm{m})$, green $=$ moderate resistivity $(100-230$ $\Omega \mathrm{m})$, and orange $=$ high resistivity $(>250 \Omega \mathrm{m})$. The main area of interest is encompassed by a yellow circle. 
The lateral resistivity map obtained for a frequency $40 \mathrm{k} \mathrm{Hz}$ (Figure 5.11) shows moderate resistivity around Scott's Ferry and the top of the southern side of the river. Resistivity decreases towards the coast from Scott's Ferry; this is shown by a blue zone north west of the township. There is a blue zone of low resistivity that extends south-east from the top of the river bend towards Tangimoana. This zone can be seen on both sides of the river. The pattern in this lateral resistivity map is consistent with the variation of resistivity depicted by the sounding contour map (Figure 5.3), given the limited overlap of measurements.

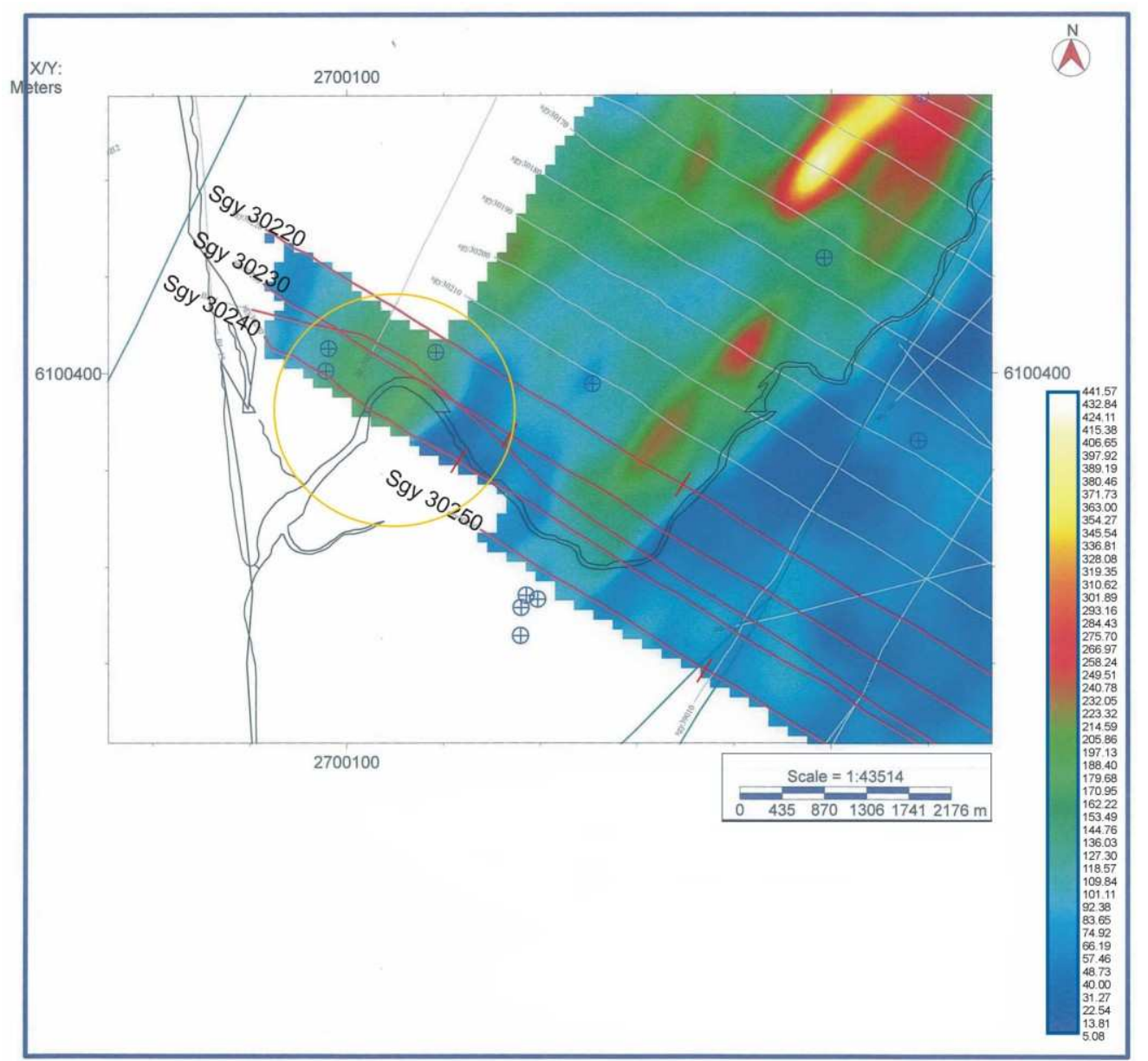

Figure 5.11 A lateral resistivity map for the frequency of $40 \mathrm{k} \mathrm{Hz}$, the yellow circle depicts the main area of interest. Sourced from Ian Brown Associates. 
The lateral resistivity map for a frequency of $8200 \mathrm{~Hz}$ is shown in Figure 5.12. There is an orange zone of high resistivity located near Scott's Ferry, and across the top of the river bend on the southern side of the river. This zone has the same distribution as the green zone of moderate resistivity found in Figure 5.11. A small blue patch of low resistivity is located on the southern side of the river. It appears to have a relatively sharp boundary with the zone of high resistivity. The orange zone of high resistivity is consistent with the variation in resistivity found in the soundings (Figure 5.3) and the traverse W5 (Figure 5.9).

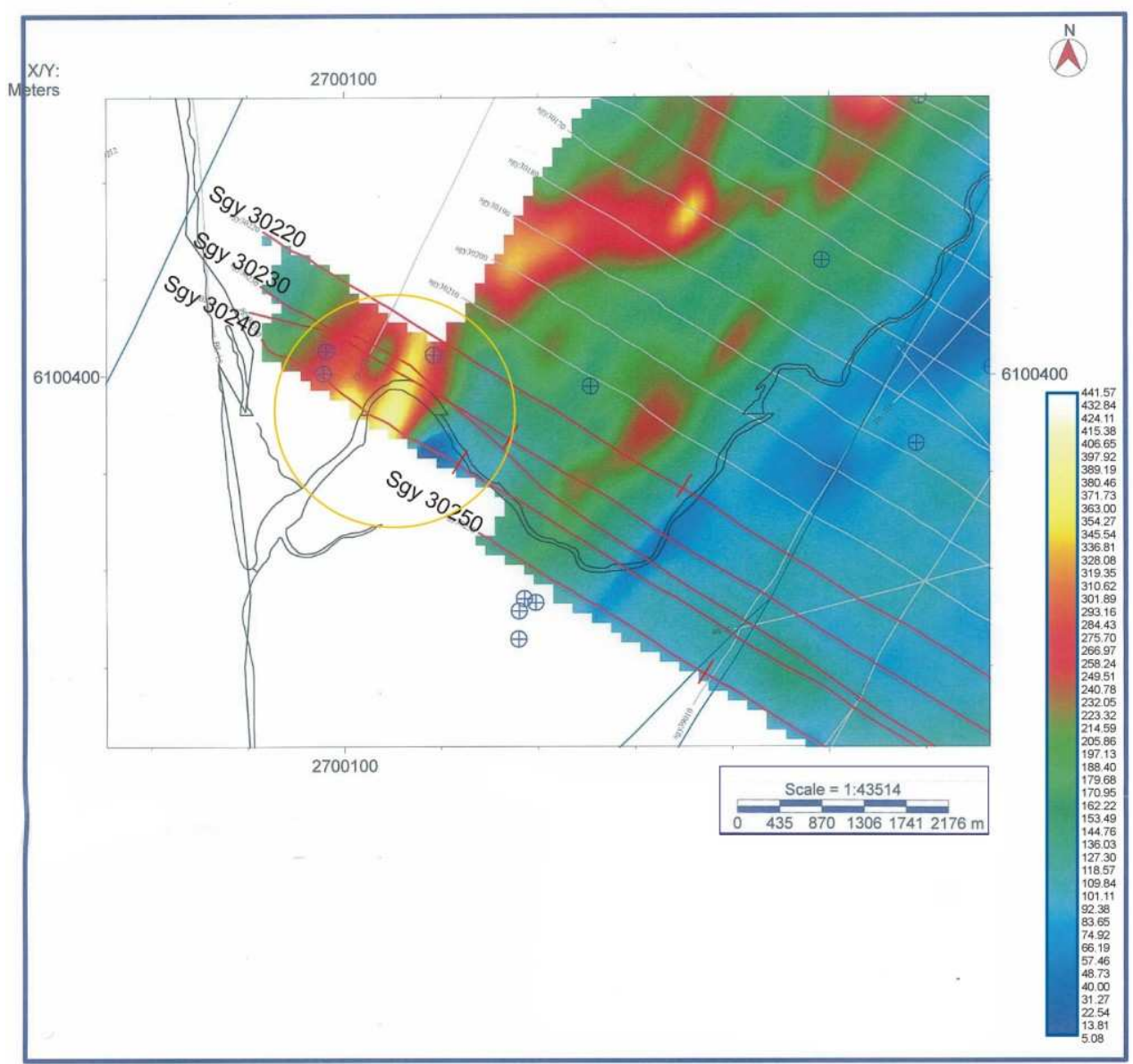

Figure 5.12 A lateral resistivity map for the frequency of $8200 \mathrm{~Hz}$. Sourced from lan Brown Associates. 
The lateral resistivity map obtained for a frequency of $1800 \mathrm{~Hz}$ (Figure 5.13) shows moderate to low resistivity in the vicinity of Scott's Ferry. A small zone of high resistivity is located on the inside of the river bend. The extent of the blue zone of low resistivity suggests that the depth obtained from this frequency shows the underlying Himatangi aquifer. Alternatively, the low resistivity might be caused by geological processes and is beyond the scope of this study.

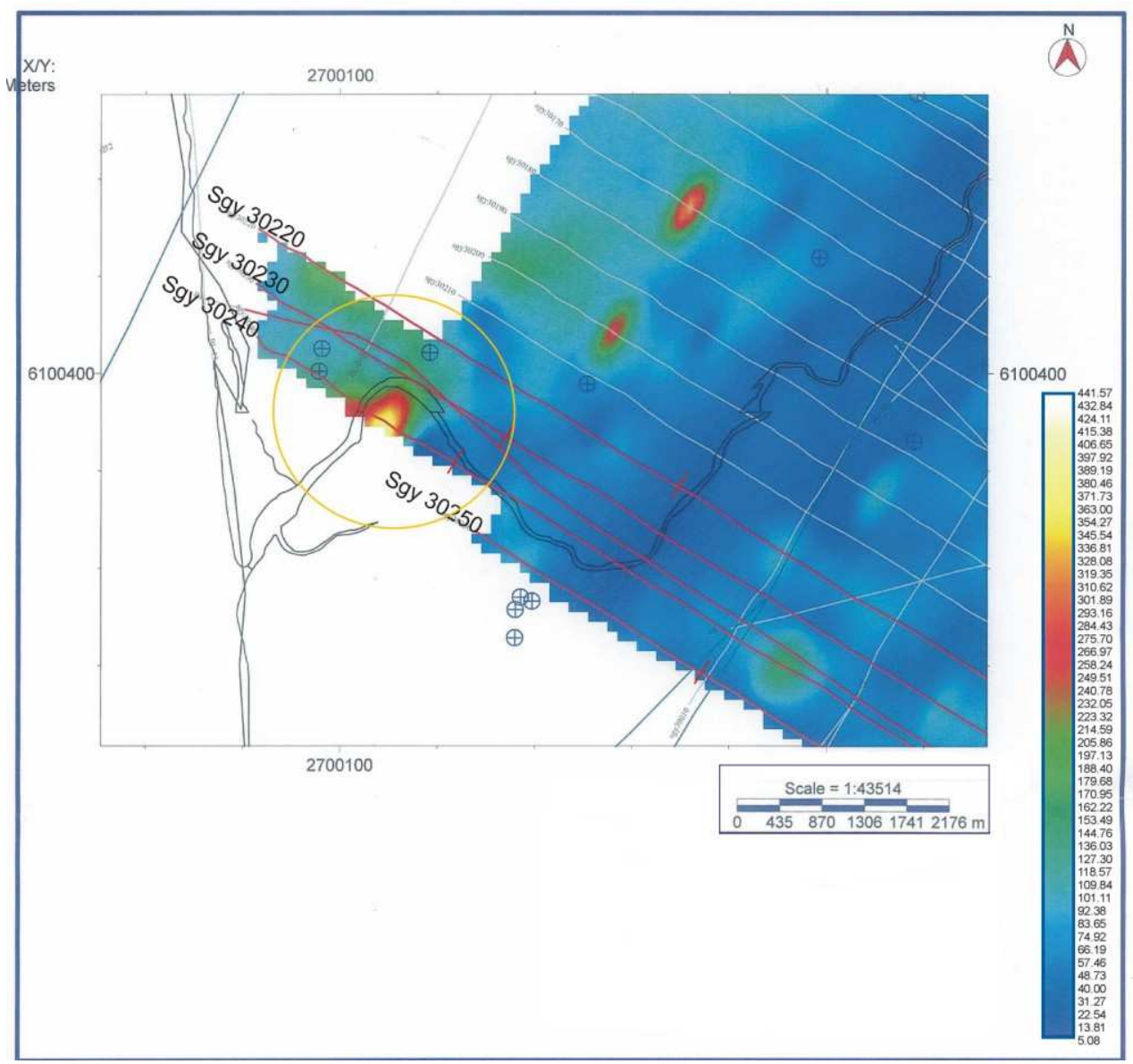

Figure 5.13 A lateral resistivity map for the frequency of $1800 \mathrm{~Hz}$. Sourced from lan Brown Associates.

The profiles show the resistivity of the subsurface along the survey lines. The locations of these lines are shown as red lines on the lateral resistivity maps, with an orientation of NW-SE. The small red line perpendicular to the flight line is the termination of the profile image (Figure 5.11-5.13). The purple areas of the profiles indicate missing and erroneous data that have been removed. The colour contours of the resistivity plots have an upper limit of $300 \Omega \mathrm{m}$. The depths indicated on the profiles have been derived from 
the bore logs, and although they give an approximation of depth, they should only be taken as a guide. The horizontal and vertical scales are not constant between the profiles. The profiles are all aligned in a NW-SE direction, NW corresponds to $0.0 \mathrm{~m}$.

The apparent resistivity profile sgy30220 starts at $0.0 \mathrm{~m}$ north-west and extends in a south-east direction for $5000 \mathrm{~m}$. The profile shows distinct layers of apparent resistivity ranges (Figure 5.14). The upper-most layer ranges in apparent resistivity from $40 \Omega \mathrm{m}<$ $\rho \mathrm{a}<100 \Omega \mathrm{m}$, and it is depicted by a blue layer. The depths of this layer range between $20 \mathrm{~m}$ in the north-west and decrease towards the surface around $2000 \mathrm{~m}$ along the profile. The layer then continues on from $2500 \mathrm{~m}$ to $5000 \mathrm{~m}$ along the profile at a depth of $10-20 \mathrm{~m}$.

The second layer of apparent resistivity ranges from $100 \Omega \mathrm{m}$ to $200 \Omega \mathrm{m}$. This depicted by a green layer. In the north-west, this layer ranges from about $25 \mathrm{~m}$ depth to the bottom limit of the model. The depth to this layer decreases steadily to the surface over a distance of $2000 \mathrm{~m}$. At $2500 \mathrm{~m}$ along the profile, the layer again increases in depth to between $40 \mathrm{~m}$ and $80 \mathrm{~m}$.

A discrete layer of high resistivity ( $\mathrm{a}>300 \Omega \mathrm{m}$ ) is depicted by the orange layer from $500 \mathrm{~m}$ to $2500 \mathrm{~m}$ along the profile. This layer is located about 20-40 m deep, and extends to the bottom of the profile. Underlying the green layer is a layer of low resistivity ( $\rho \mathrm{a}<80 \Omega \mathrm{m}$ ) from $3000 \mathrm{~m}$ to $5000 \mathrm{~m}$, at a variable depth of $40-60 \mathrm{~m}$. At $5000 \mathrm{~m}$ along the profile there is a discrete patch of high resistivity $(\rho \mathrm{a}>300 \Omega \mathrm{m})$ at a depth between 20-40 m. This could be caused by an erroneous data point. However, comparison between this profile and lateral resistivity maps of $40 \mathrm{k}$ and $8200 \mathrm{~Hz}$ indicate that this high resistivity area continues in a north-east direction. It is therefore likely to be a large continuous geological structure. 


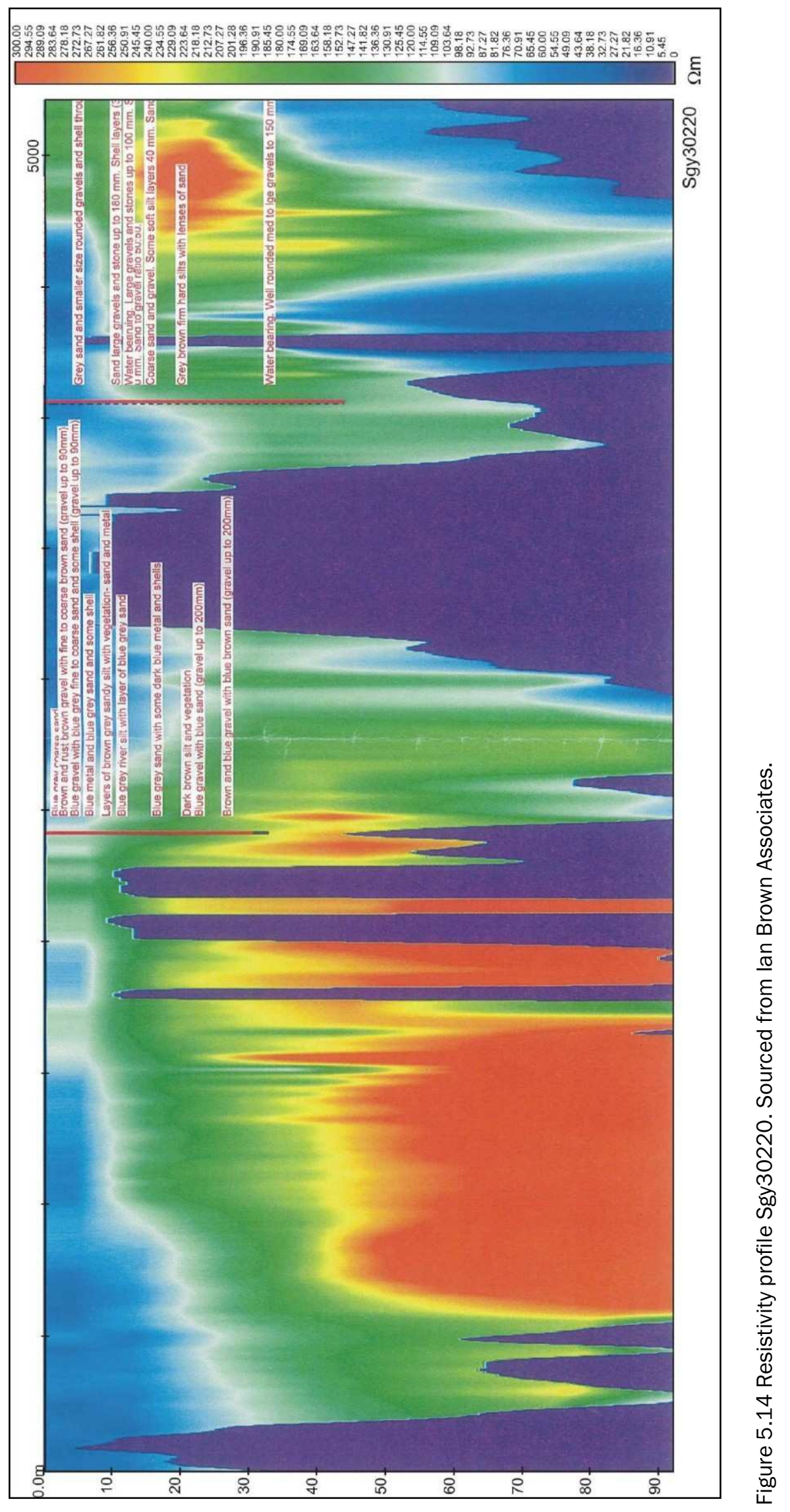


The resistivity section sgy30230 also shows distinct layers of resistivity ranges (Figure 5.15). The profile starts at $0.0 \mathrm{~m}$ north-west and extends in a south-east direction for $3000 \mathrm{~m} .1500 \mathrm{~m}$ along the profile is just north east of Scott's Ferry. As with the previous section, the upper-most layer ranges in apparent resistivity from $40 \Omega \mathrm{m}<\rho \mathrm{a}<100 \Omega \mathrm{m}$, and it is depicted by a blue layer. This lies between 10-20 m below the surface in the north-west and shallows towards the surface around $1000 \mathrm{~m}$. The layer continues around $2500 \mathrm{~m}$ long the profile to a depth of $20 \mathrm{~m}$.

The second layer ranges in apparent resistivity from $100 \Omega \mathrm{m}$ to $200 \Omega \mathrm{m}$. It is depicted in green. In the north-west it ranges from about $25 \mathrm{~m}$ below the surface to the bottom of the profile. The depth of this layer decreases steadily to the surface over a distance of 1000 $\mathrm{m}$. At $2500 \mathrm{~m}$ the layer again increases in depth. Below this layer is an area in the profile with a lot of distortion/noise. A clear resistivity layer cannot be interpreted. A comparison of the profile with a lateral resistivity map (Figure 5.11), and a map of the study area (Figure 4.8) suggest that this corresponds with Scott's Ferry. It is likely that infrastructure such as roads and power lines may have interfered with the EM signal. A comparison with the survey lines either side of this profile suggests that this area is likely a continuation of a layer of high resistivity $(\rho \mathrm{a}>300 \Omega \mathrm{m})$. It is depicted by an orange layer that extends from $1600 \mathrm{~m}$ to $2250 \mathrm{~m}$, at a depth of about $20 \mathrm{~m}$ to the bottom of the profile. Further south-west, at $2500 \mathrm{~m}$ along the profile, the beginning of a lower resistivity $(40 \Omega \mathrm{m}<\rho \mathrm{a}<100 \Omega \mathrm{m})$ layer emerges. This profile sgy30230 closely resembles the pattern of resistivity layering found in sgy 30220. It is consistent with the resistivity obtained from traverse W5. 


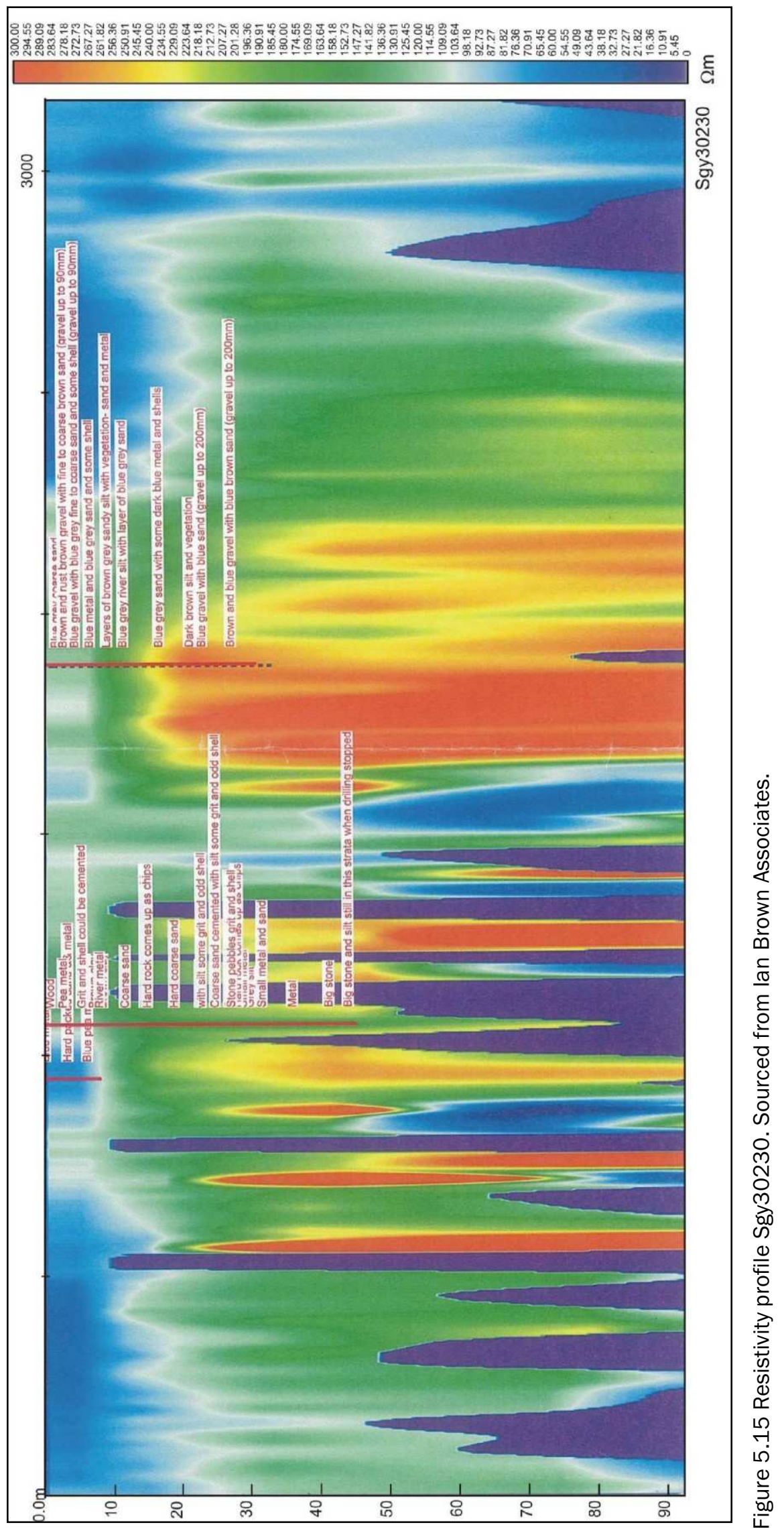


The resistivity section sgy30240 crosses through the main area of ground-based DC resistivity. This profile shows three distinct layers of resistivity ranges (Figure 5.16). The profile starts at $0.0 \mathrm{~m}$ north-west and extends south east for $2600 \mathrm{~m}$. The uppermost layer is very similar to the upper layer observed in the previous profiles (Figure 5.14 and 5.15). This layer ranges in apparent resistivity from $40 \Omega \mathrm{m}<\rho \mathrm{a}<100 \Omega \mathrm{m}$, and it is depicted by a blue layer. This layer is between $10-20 \mathrm{~m}$ below the surface in the north-west and decreases to the surface at $750 \mathrm{~m}$ along the profile. This upper blue layer continues from around $2000 \mathrm{~m}$ for $600 \mathrm{~m}$ to the south-east end of the profile. This blue layer extends from the surface to a depth of $50 \mathrm{~m}$. At the end of the profile it extends to the bottom of the profile and is consistent with the low resistivity identified immediately to the north-west of Tangimoana by the DC resistivity measurements. Of note in this layer is a patch of very low resistivity $(\rho \mathrm{a}<10 \Omega \mathrm{m}$ ) from $2200 \mathrm{~m}$ to $2500 \mathrm{~m}$ around a depth of $10-30 \mathrm{~m}$.

A second layer has an apparent resistivity range of $100 \Omega \mathrm{m}$ to $200 \Omega \mathrm{m}$. This is depicted by a green layer and extends from about $25 \mathrm{~m}$ below the surface to the bottom of the profile. The depth of the layer decreases steadily to the surface over a distance of 1000 $\mathrm{m}$. At $2000 \mathrm{~m}$ along the profile the green layer underlies the blue layer and increases in depth, extending to the bottom of the profile.

Beneath the green layer is a layer of high resistivity ( $\rho \mathrm{a}>300 \Omega \mathrm{m}$ ). This is depicted by an orange layer that emerges from $200 \mathrm{~m}$ to $2000 \mathrm{~m}$ along the profile. This layer ranges between 20-30 m below the surface, and extends to the bottom of the profile. The transition from this higher resistivity to the lower resistivity to the south-east is similar to that seen, for example, on traverse W1 (Figure 5.10). This AEM resistivity profile also closely resembles profiles sgy 30220 and 30230. 


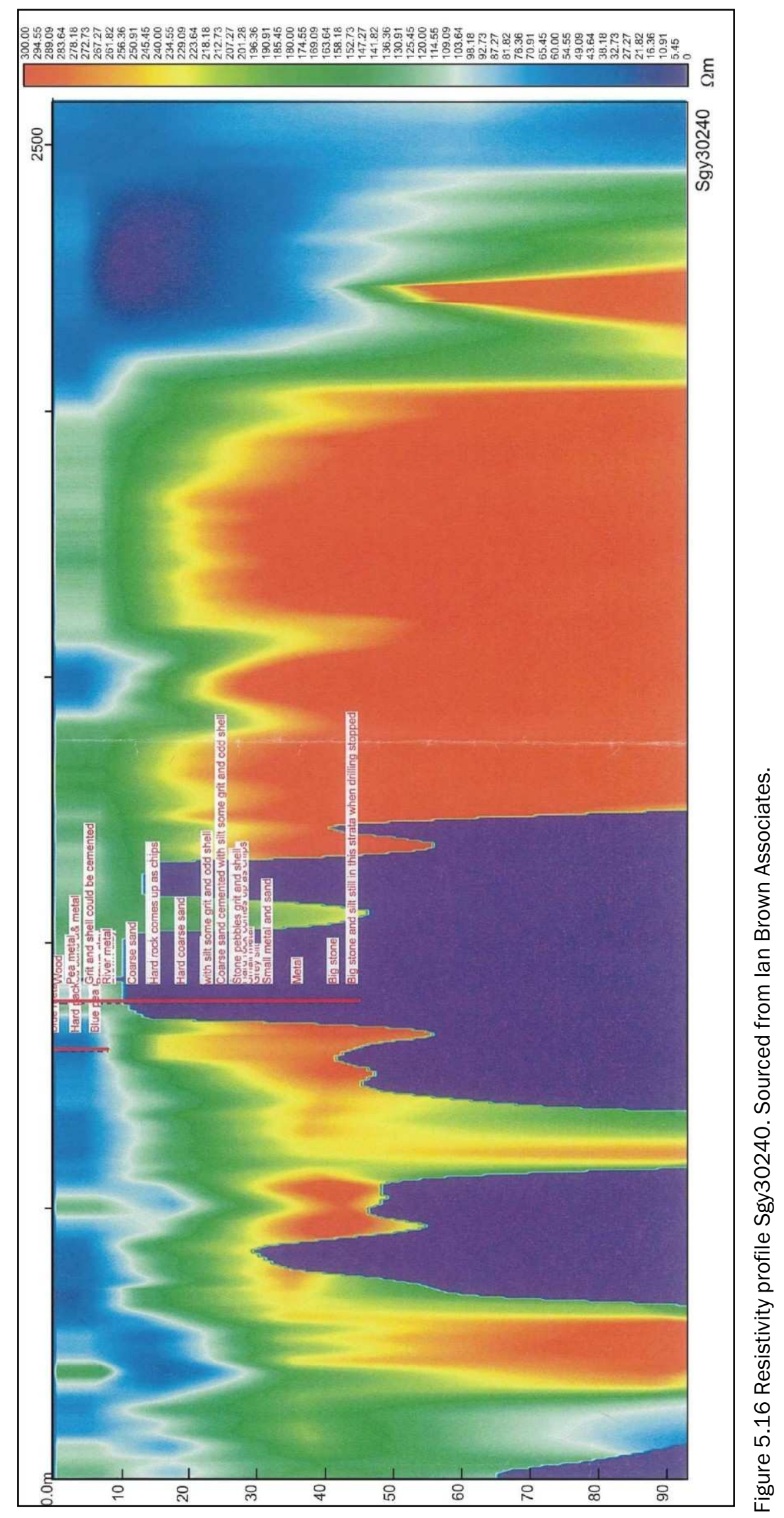


The resistivity section sgy30250 was located south of Tangimoana. It should be noted that this profile has a different resistivity contour scale to the other profiles. The profile does not show layering, but shows three distinctive areas of apparent resistivity variation (Figure 5.17). The majority of the profile shows moderately low apparent resistivity (40 $<\rho a<100 \Omega \mathrm{m})$. However, there are two patches of higher apparent resistivity $(110<\rho \mathrm{a}$ $<230 \Omega \mathrm{m}$ ). One of these patches is located $20 \mathrm{~m}$ below the surface, and extends down to the bottom of the profile. This patch continues from the start of the profile to about 750 $\mathrm{m}$. The second patch of higher apparent resistivity is located from about $60 \mathrm{~m}$ below the surface and extends to the bottom of the profile. This patch is located approximately $1000 \mathrm{~m}$ along the profile and peaks at $2000 \mathrm{~m}$.

\section{Summary of AEM}

As the lateral resistivity maps and profiles were uncalibrated, the apparent resistivity was broadly interpreted using resistivity categories. This showed the spatial patterns and relative resistivity of the area. The apparent resistivity obtained from the AEM survey can be best calibrated by matching the survey lines sgy30240 and sgy32030 with the resistivity traverses. These are the survey lines that overlap the resistivity traverses.

The AEM profiles north of Tangimoana all showed three distinctive layers of increasing resistivity with depth. All of the DC resistivity traverses show a high resistivity layer at a depth of approximately $25-30 \mathrm{~m}$. It is possible that this high resistivity layer is the same that can be seen in the survey lines sgy 30220-sgy 30240, and Figure 5.12. The relatively high resistivity seen on traverse W5 is consistent with the pattern of resistivity in the survey line sgy30230. The transition from higher resistivity to the lower resistivity to the SE observed in sgy30240 is similar to that seen on traverse W1. A comparison of the resistivity obtained from the traverses and the AEM shows a good correlation between the two sets of results. This will be discussed further in the next chapter. 


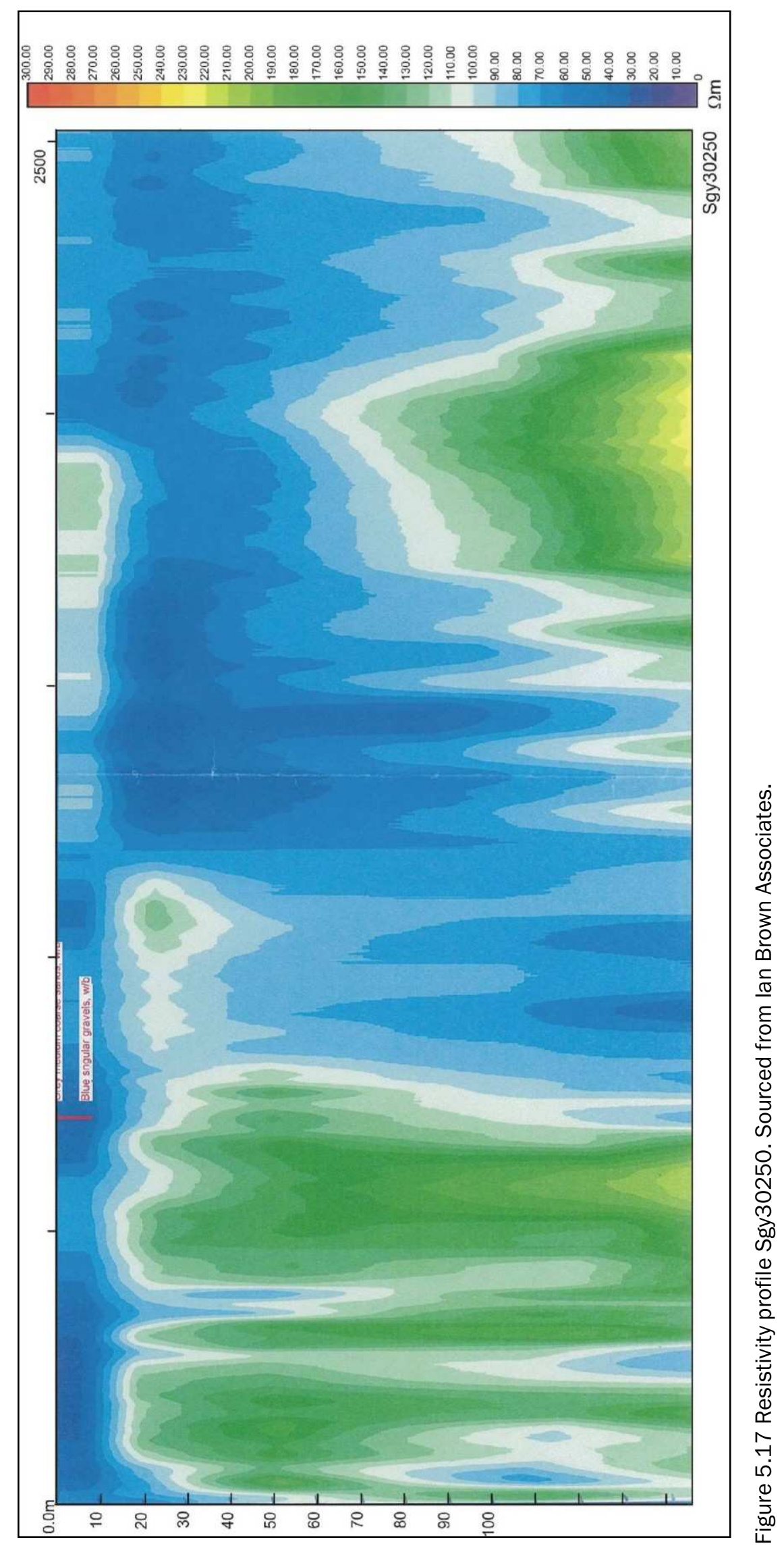




\subsection{Hydrochemistry}

To study the hydrochemical parameters of the groundwater of Tangimoana and Scott's Ferry, 10 water samples were collected in October and November 2007 (Figure 5.18). Eight of the bores (C1-C6, C9, \& $\mathrm{C} 10)$ ranged between $6-17 \mathrm{~m}$ below the surface and tapped the upper aquifer zone. Two of the bores (C7 \& C9) were significantly deeper $(\sim 30 \mathrm{~m})$ and tapped the Foxton Aquifer. C7 and C9 were sampled from the Scott's Ferry Motor Camp, and the Tangimoana Motor Camp respectively. These were single discrete measurements, so consideration should be given to how representative these samples are of the aquifer. A more accurate representation would need a sampling programme over a longer period of time.

Water is electrically neutral and therefore the total charges of the cations and anions should be equal, i.e. the sum of all ions should be zero. The calculated charge balance can be used to measure the accuracy of the laboratory results. In general a limit of up to $5 \%$ is taken as an acceptable degree of variation between total anions and cations in water samples. However, Jones and Baker (2005) suggested a range of 4.35-6.35\% was acceptable depending on TDS concentrations. The ion balance error should certainly be less than $10 \%$ Lloyd and Heathcote (1985) suggest that an ion balance error of greater than $10 \%$ corresponds to an analytical error, or an unanalysed ion. As saline waters are dominated by $\mathrm{Na}+$ and $\mathrm{Cl}$ - ions, small errors in these ions will produce larger errors in the ion balance. Ion balance errors between 5 and $10 \%$ are common in dilute groundwater and are considered acceptable for validation of the analyses (Faye et al., 2003).

All of the water samples had an ion balance error less than $10 \%$, although samples $\mathrm{C} 1$ C4 and C6 had ion balance errors greater than 6.35\%. These samples all showed negative percentage errors, indicating an anion excess (Jones and Baker, 2005). A summary of the major ions and ion balance errors of the samples can be found in Appendix 1. 


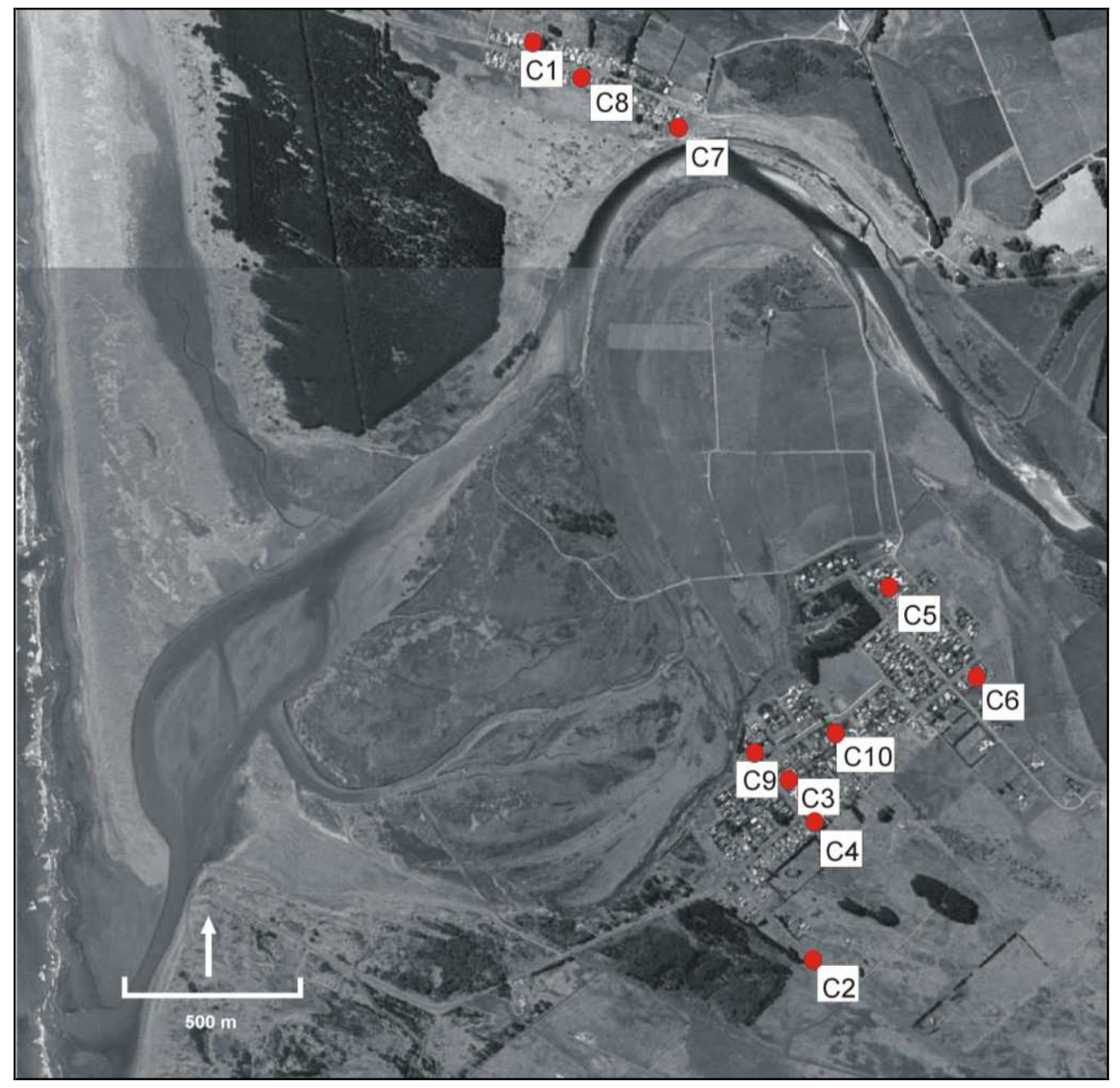

Figure 5.18 Locations of sampled groundwater bores (C1-C10)

\section{Water chemistry analyses}

The hydrochemistry of an aquifer is important to delineate the interaction between the groundwater, surface water and geological units (Jankowski and Beck, 2000). The chemical parameters of the water samples are summarised in Table 5.1. The $\mathrm{pH}$ of the water samples ranged between 6.8 and 8. EC in the groundwater ranged from $224-801$ $\mathrm{uS} / \mathrm{cm}$. The EC of the shallow groundwater in Tangimoana ranged from $695-801 \mathrm{uS} / \mathrm{cm}$. The water sample $\mathrm{C} 2$ had the lowest EC of $224 \mathrm{uS} / \mathrm{cm}$ and the EC of $\mathrm{C} 1$ was $444 \mathrm{uS} / \mathrm{cm}$. The Na concentration in the groundwater ranged from 13-51 mg/l. The highest Na concentration was found in $\mathrm{C} 10$. The concentration of $\mathrm{Mg}$ was variable and ranged between 4.3 and $27.1 \mathrm{mg} / \mathrm{l}$. The highest value was found in $\mathrm{C} 6$. The concentration of $\mathrm{Fe}$ ranged from 0.01 to $3.50 \mathrm{mg} / 1$. The lowest concentration of Fe was found in $\mathrm{C} 5$, which also had the lowest concentration of $\mathrm{Mn}(0.07 \mathrm{mg} / \mathrm{l})$, and the highest concentration of 
$\mathrm{SO}_{4}(18.9 \mathrm{mg} / \mathrm{l})$. The calculated concentration of $\mathrm{HCO}_{3}$ varied from $65.8-412.1 \mathrm{mg} / \mathrm{l}$. The concentration of $\mathrm{Cl}$ varied from approximately $15 \mathrm{mg} / \mathrm{l}$ found in the deeper groundwater samples (C7 \& C9) to $74.1 \mathrm{mg} / 1$ found in water sample C6.

The shallow groundwater samples from Tangimoana showed the highest concentrations of $\mathrm{Na}, \mathrm{Ca}, \mathrm{Cl}$ and $\mathrm{HCO}_{3}$. Water samples $\mathrm{C} 3$ and $\mathrm{C} 4$ had similar water chemistry and showed very little difference in any of the parameters analysed. These samples were collected closest to the salt marsh. The samples taken from deeper groundwater were very similar; and apart from $\mathrm{C} 2$, tended to show the smallest concentrations of $\mathrm{Br}, \mathrm{Sr}$, $\mathrm{Na}, \mathrm{Ca}, \mathrm{Cl}$ and $\mathrm{HCO}_{3}$. Water sample $\mathrm{C} 6$ had the highest concentrations of $\mathrm{Mg}, \mathrm{Fe}, \mathrm{B}, \mathrm{Cl}$, and $\mathrm{HCO}_{3}$. $\mathrm{C} 8$ was sampled from the shallow groundwater of Scott's Ferry and showed similar concentrations of $\mathrm{Na}, \mathrm{Cl}$ and $\mathrm{Br}$ to the shallow groundwater of Tangimoana, although it had lesser concentrations of $\mathrm{Ca}$ and $\mathrm{HCO}_{3}$. 
Table 5.1 Chemical composition of groundwater samples. (ND) denotes ion was not detected.

\begin{tabular}{|c|c|c|c|c|c|c|c|c|c|c|c|c|c|c|c|}
\hline Water sample & $\mathrm{pH}$ & $\begin{array}{l}\mathrm{EC} \\
\mathrm{uS} / \mathrm{cm}\end{array}$ & $\begin{array}{l}\text { Alkalinity } \\
\text { mg/l CaCO3 }\end{array}$ & $\begin{array}{l}\mathrm{K} \\
\mathrm{mg} / \mathrm{I}\end{array}$ & $\begin{array}{l}\mathrm{Na} \\
\mathrm{mg} / \mathrm{l}\end{array}$ & $\begin{array}{l}\mathrm{Ca} \\
\mathrm{mg} / \mathrm{l}\end{array}$ & $\begin{array}{l}\mathrm{Mg} \\
\mathrm{mg} / \mathrm{I}\end{array}$ & $\begin{array}{l}\mathrm{Fe} \\
\mathrm{mg} / \mathrm{l}\end{array}$ & $\begin{array}{l}\mathrm{Mn} \\
\mathrm{mg} / \mathrm{I}\end{array}$ & $\begin{array}{l}\mathrm{Br} \\
\mathrm{mg} / \mathrm{I}\end{array}$ & $\begin{array}{l}\mathrm{Sr} \\
\mathrm{mg} / \mathrm{I}\end{array}$ & $\begin{array}{l}\mathrm{B} \\
\mathrm{mg} / \mathrm{I}\end{array}$ & $\begin{array}{l}\mathrm{Cl} \\
\mathrm{mg} / \mathrm{l}\end{array}$ & $\begin{array}{l}\mathrm{SO}_{4} \\
\mathrm{mg} / \mathrm{l}\end{array}$ & $\begin{array}{l}\mathrm{HCO}_{3} \\
\mathrm{mg} / \mathrm{I}\end{array}$ \\
\hline $\mathrm{C} 1$ & 7.8 & 444 & 182 & 4 & 17.4 & 46 & 7.6 & 1.41 & 0.51 & 0.08 & 0.31 & 0.05 & 28.9 & 2.0 & 221.9 \\
\hline c8 & 7.5 & - & 240 & 5.2 & 35 & 64 & 12 & 2.80 & 0.78 & 0.24 & 0.44 & 0.07 & 50.0 & 0.78 & 292.6 \\
\hline $\mathrm{C} 2$ & 6.8 & 224 & 54 & 3 & 13 & 14 & 4.3 & 0.76 & 0.13 & ND & 0.09 & ND & 28.5 & 6.5 & 65.8 \\
\hline $\mathrm{C} 3$ & 7.7 & 760 & 291 & 5 & 39.4 & 81 & 9.6 & 1.73 & 0.93 & 0.22 & 0.62 & ND & 67.1 & ND & 354.8 \\
\hline $\mathrm{C} 4$ & 7.4 & 741 & 284 & 5 & 36.8 & 78 & 11.1 & 1.93 & 0.95 & 0.20 & 0.50 & 0.04 & 63.5 & 0.90 & 346.3 \\
\hline $\mathrm{C} 5$ & 7.6 & 695 & 278 & 10 & 24.9 & 85 & 10.5 & 0.01 & 0.07 & 0.19 & 0.45 & 0.07 & 42.7 & 18.9 & 339.0 \\
\hline $\mathrm{C} 6$ & 7.8 & 801 & 338 & 9 & 34.5 & 70 & 27.1 & 2.25 & 0.56 & 0.21 & 0.47 & 0.12 & 74.1 & ND & 412.1 \\
\hline C10 & 7.7 & - & 280 & 4.5 & 51 & 69 & 14 & 3.50 & 0.41 & 0.25 & 0.50 & 0.07 & 61.0 & 10.0 & 341.4 \\
\hline $\mathrm{C} 7$ & 8 & - & 130 & 3.2 & 14 & 32 & 7.4 & 0.45 & 0.37 & 0.05 & 0.22 & 0.05 & 16.0 & 8.8 & 158.5 \\
\hline C9 & 7.5 & - & 130 & 2.7 & 16 & 29 & 11 & 1.50 & 0.76 & 0.05 & 0.21 & 0.05 & 15.0 & 11.0 & 158.5 \\
\hline
\end{tabular}




\section{Major ion chemistry}

Water type categories can be used to help identify flow paths within the aquifer, and the interaction of groundwater with surface water features (Osborne, 2006). Water types, or chemical facies, are determined by converting the milliequivalants per litre (meq/l) of the major cations and anions to percentages. The water type is formed by listing the ions with concentrations greater than $10 \%$ in decreasing order, the cations are listed first (Rosen, 2001). The water types were determined using AquaChem. The most common type of water found (60\%) was $\mathrm{Ca}-\mathrm{Na}-\mathrm{HCO}_{3}-\mathrm{Cl}$ (Table 5.2). Water samples $\mathrm{C} 1, \mathrm{C} 5$ and $\mathrm{C} 7$ were categorised as $\mathrm{Ca}-\mathrm{HCO}_{3}$. Water samples $\mathrm{C} 6$ and $\mathrm{C} 9$ both contain significant concentration of $\mathrm{Mg}$.

Table 5.2 The water type of groundwater sampled (*) denotes water sampled from approximately $30 \mathrm{~m}$.

\begin{tabular}{|l|l|}
\hline Water sample & Water type \\
\hline $\mathrm{C} 1$ & Ca-HCO3 \\
\hline $\mathrm{C} 2$ & Ca-Na-HCO3-Cl \\
\hline $\mathrm{C} 3$ & Ca-Na-HCO3-Cl \\
\hline C4 & Ca-Na-HCO3-Cl \\
\hline C5 & Ca-HCO3 \\
\hline C6 & Ca-Mg-HCO3-Cl \\
\hline C7 & Ca-HCO3 \\
\hline C8 & Ca-Na-HCO3-Cl \\
\hline C9* & Ca-Mg-Na-HCO3 \\
\hline C10 & Ca-Na-HCO3-Cl \\
\hline
\end{tabular}

The major ion chemistry for each sample is also presented as stiff diagrams, to allow easy identification of relationships between the water samples (Figure 5.19). The concentrations of the ions are shown as milliequivalents per litre (meq/l). The use of milliequivalents takes into account each ion's molecular weight so that all unit concentrations are chemically equivalent (Hem, 1989). The water samples are grouped together in relation to bore location and depth. The major anion trend for all of the samples is $\mathrm{HCO}_{3}{ }^{-}>\mathrm{Cl}^{-}>\mathrm{SO}_{4}{ }^{2-}$. The major cation trend was $\mathrm{Ca}^{2+}>\mathrm{Na}^{+}>\mathrm{Mg}^{2+}$ for water samples C3-C5, C8, and $\mathrm{C} 10$ and was $\mathrm{Ca}^{2+}>\mathrm{Na}^{+} \approx \mathrm{Mg}^{2+}$ for water samples $\mathrm{C} 1, \mathrm{C} 2, \mathrm{C} 7$, and $\mathrm{C}$. The water sample $\mathrm{C} 6$ had a cation trend of $\mathrm{Ca}^{2+}>\mathrm{Mg}^{2+}>\mathrm{Na}^{+}$. Water samples 
$\mathrm{C} 7$ and C9 were taken from deeper groundwater bores and have similar compositions of water chemistry. $\mathrm{HCO}_{3}{ }^{-}$has a concentration of about $2.8 \mathrm{meq} / 1$, and a $\mathrm{Ca}^{2+}$ of about 1.4 meq/l. The shallow groundwater sampled from Scott's Ferry (C1 and C8) showed lesser concentrations of $\mathrm{HCO}_{3}{ }^{-}$(3.64 and 4.8meq/1) and concentrations of $\mathrm{Ca}^{2+}$ (2.3 and 3.19) than the shallow groundwater samples from Tangimoana. The groundwater sampled from south of Tangimoana (C2) showed smaller concentrations of all major ions when compared to the other samples. 


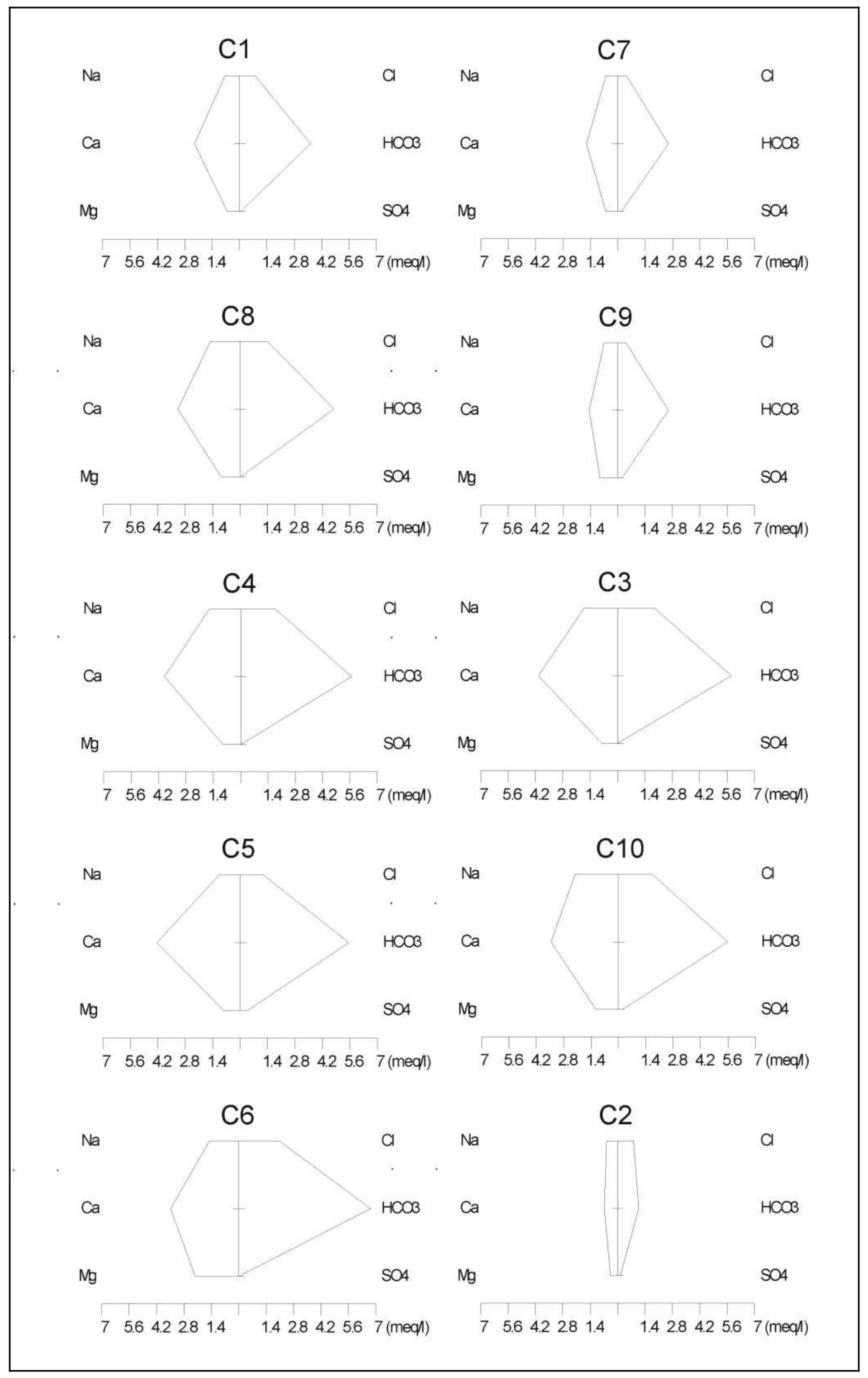

Figure 5.19 Stiff diagrams of groundwater samples (C1-C10). 


\section{Ion ratios}

The source of salinity was determined by observing the ratios of the major constituents in the water samples. Absolute ion concentrations can indicate the extent, and magnitude, of salinity. A combination of constituent ratios using these tracers can be used to distinguish between salt-water sources, such as seawater, connate water or sewage. Halite and other evaporite dissolution are not considered in this study as they do not occur in New Zealand (Rosen, 2001).

The ratio of calcium to bicarbonate was presented on a bivariate plot with a carbonate dissolution line (Figure 5.20). If the dissolution of calcite or plagioclase feldspar controls the water chemistry then the $\mathrm{Ca}: \mathrm{HCO}_{3}$ ratio will be $1: 1$. All of the water samples showed a high degree of bicarbonate compared to calcium. They were all below the 1:1 ratio of the carbonate dissolution line. Water sample $\mathrm{C} 6$ had a $\mathrm{HCO}_{3}$ concentration nearly twice that of $\mathrm{Ca}$ with a ratio of 0.52 .

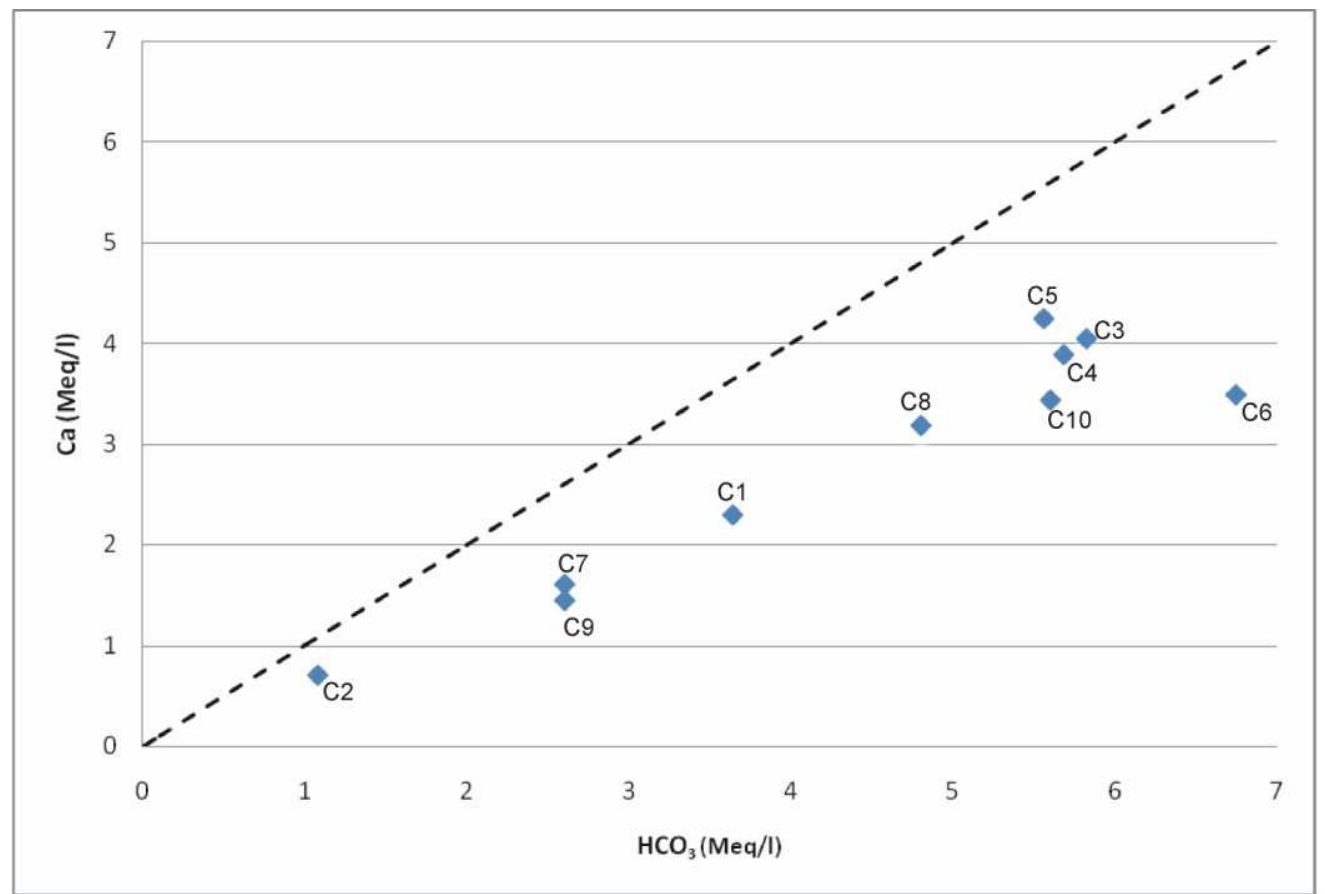

Figure 5.20 Bivariate plot of Calcium and Bicarbonate, with a solid line shows the 1:1 ratio of $\mathrm{Ca}: \mathrm{HCO}_{3}$ found in most freshwaters (Rosen, 2001). 
The ratio of sodium to chloride was presented on a bivariate plot, with a seawater concentration-dilution line (SCDL) (Figure 5.21). The SCDL represents water with the same proportional concentration of sodium and chloride as seawater. The $\mathrm{Na}: \mathrm{Cl}$ ratio for seawater is 0.566 (Jones and Baker, 2005; Richter and Kreitler, 1993). Water samples $\mathrm{C} 1-\mathrm{C} 5$ had $\mathrm{Na}: \mathrm{Cl}$ ratios similar to the SCDL. Na was enriched relative to $\mathrm{Cl}$ for water samples $\mathrm{C} 7-\mathrm{C} 10$. $\mathrm{C} 10$ had a ratio of 0.836 . C6 showed $\mathrm{Na}$ depletion compared to $\mathrm{Cl}$, with a ratio of 0.466 .

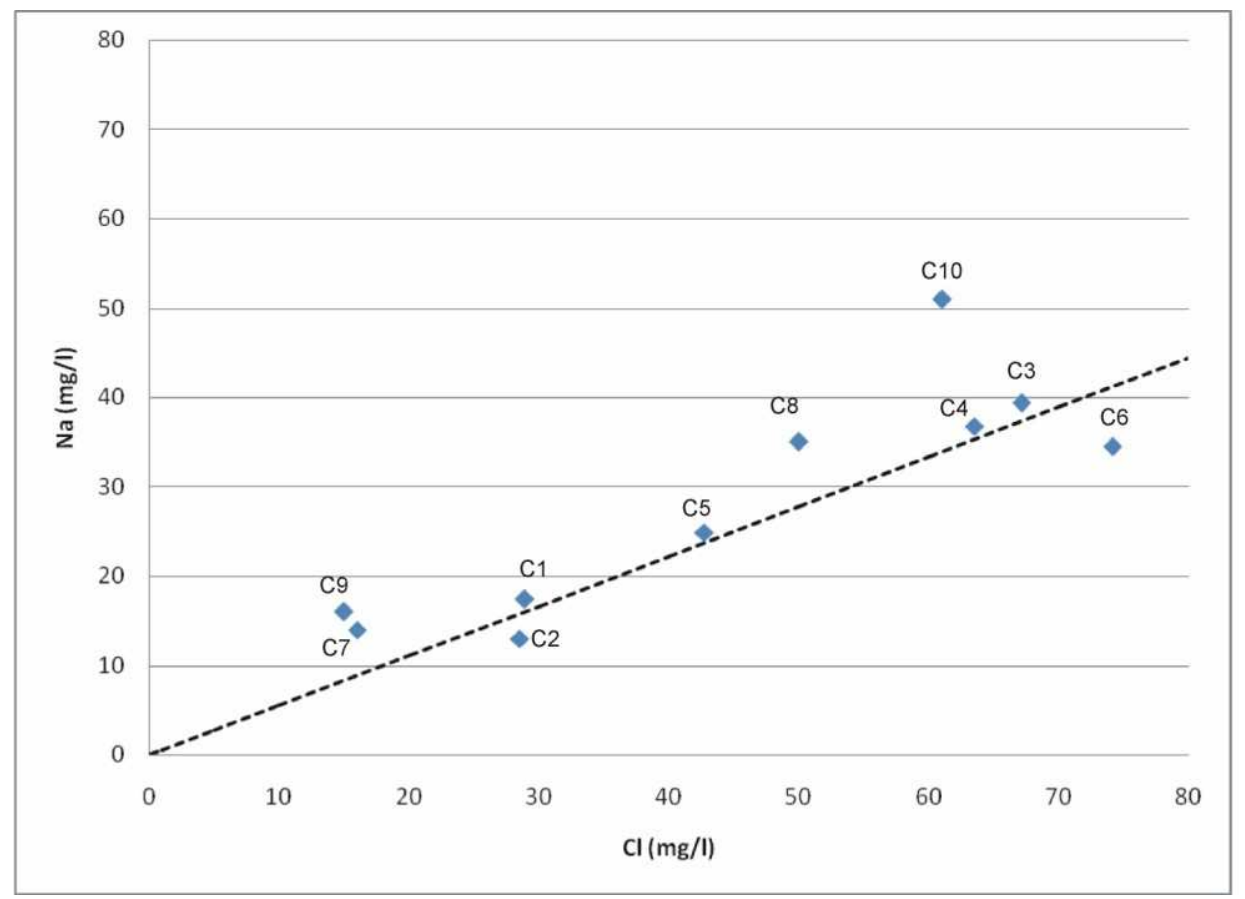

Figure 5.21 Bivariate plot of Sodium and Chloride, showing a SCDL that represents water with the same proportional concentrations of sodium and chloride as seawater (the ratio of $\mathrm{Na:Cl}$ is 0.556, (Jones and Baker, 2005; Richter and Kreitler, 1993)).

The ratio of calcium to chloride was presented on a bivariate plot, with a seawater concentration-dilution line (SCDL) (Figure 5.22). The SCDL represents water with the same proportional concentration of calcium and chloride as seawater. The $\mathrm{Ca}: \mathrm{Cl}$ ratio for seawater used was 0.021 (Lloyd and Heathcote, 1985). The water samples showed a high degree of calcium enrichment compared to chloride, with little scatter. However, sample $\mathrm{C} 2$ had the most similar ratio to the SCDL. It was an order of magnitude greater (0.491). C5 showed the greatest degree of calcium enrichment with a $\mathrm{Ca}: \mathrm{Cl}$ ratio of 1.99 . 


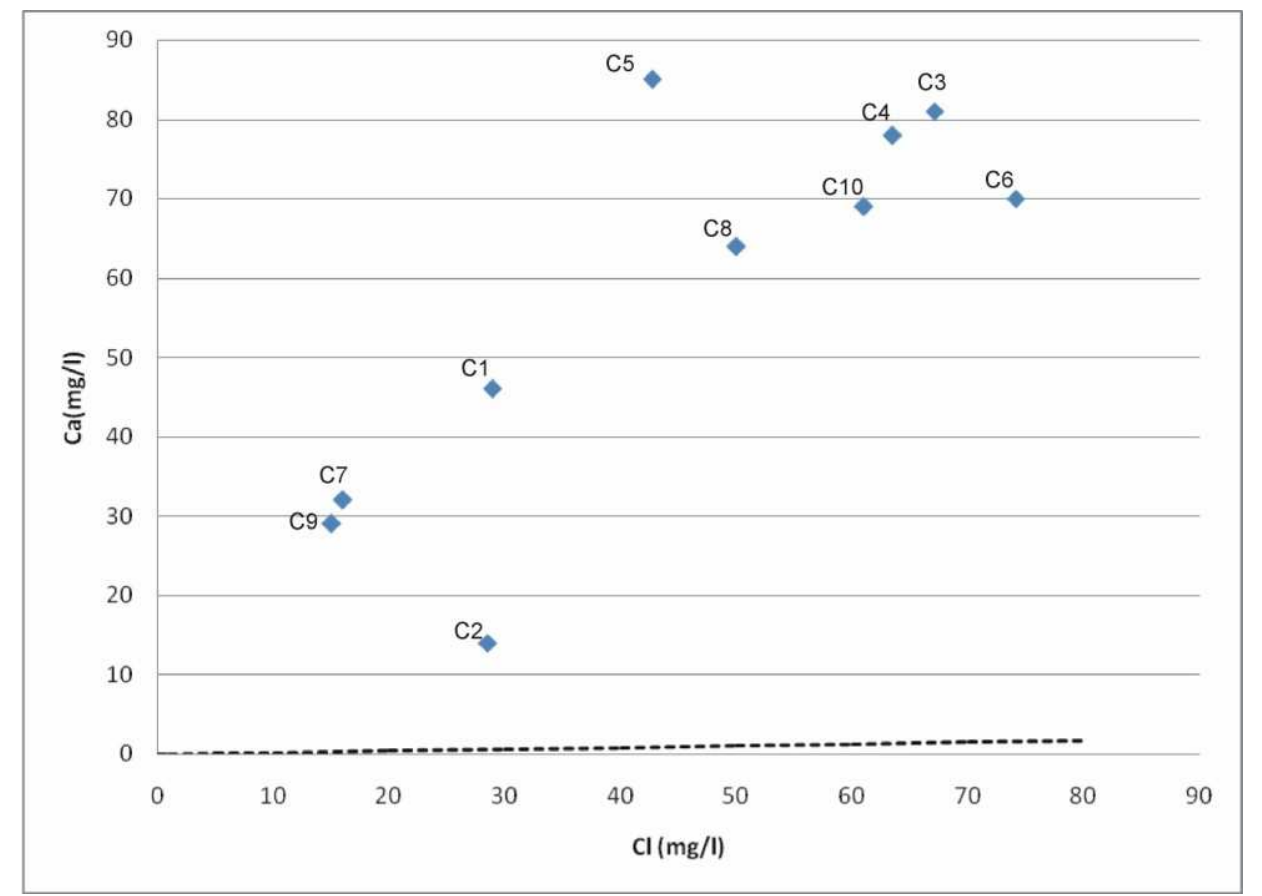

Figure 5.22 Bivariate plot of Calcium and Chloride, showing a SCDL that represents water with the same proportional concentrations of calcium and chloride as seawater (the ratio of $\mathrm{Ca}: \mathrm{Cl}$ is 0.021 , (Lloyd and Heathcote, 1985)).

\section{Iron and Manganese}

High concentrations of iron and manganese are commonly found in New Zealand aquifers (Rosen, 2001). Sources of iron and manganese are rarely anthropogenic, and instead are typically introduced to groundwater through natural water and rock interaction (Daughney, 2003). Sand and gravel aquifers generally have the highest Fe and Mn concentrations in New Zealand. Groundwaters from these aquifers are likely to have Fe and Mn concentrations that are greater than Drinking Water Standards of New Zealand guidelines (DWSNZ) $(\mathrm{MoH}, 2005)$. Shallow groundwater in the Rangitikei region is high in iron and therefore its use is restricted to areas near surface watercourses (Bekesi, 2001). The solubility of iron and manganese depend upon $\mathrm{pH}$ and the redox potential of groundwater. High microbiological activity within estuarine environments reduce iron and manganese (Thamdrup, 2000). Therefore, it is expected that there would be high Fe and Mn concentrations in the groundwater sampled. This is important with respect to the interpretation of the geophysical survey as iron and manganese have high ionic conductance (Wilson, 2003). 
The iron concentrations of the samples were highly variable. They ranged from 0.014 to $3.5 \mathrm{mg} / \mathrm{l}$ (Figure 5.23). The highest concentration of iron was found in $\mathrm{C} 10$, the shallowest groundwater bore sampled. The lowest concentration was found in C5. C3 and C4 had similar iron concentrations. They are close together and at similar depths. The majority of the samples had Fe concentrations higher than the median values usually found in Manawatu aquifers $(0.205 \mathrm{mg} / \mathrm{l})$; and in New Zealand sand and gravel aquifers (0.685 mg/l and 0.061 mg/l, respectively) (Daughney, 2003).

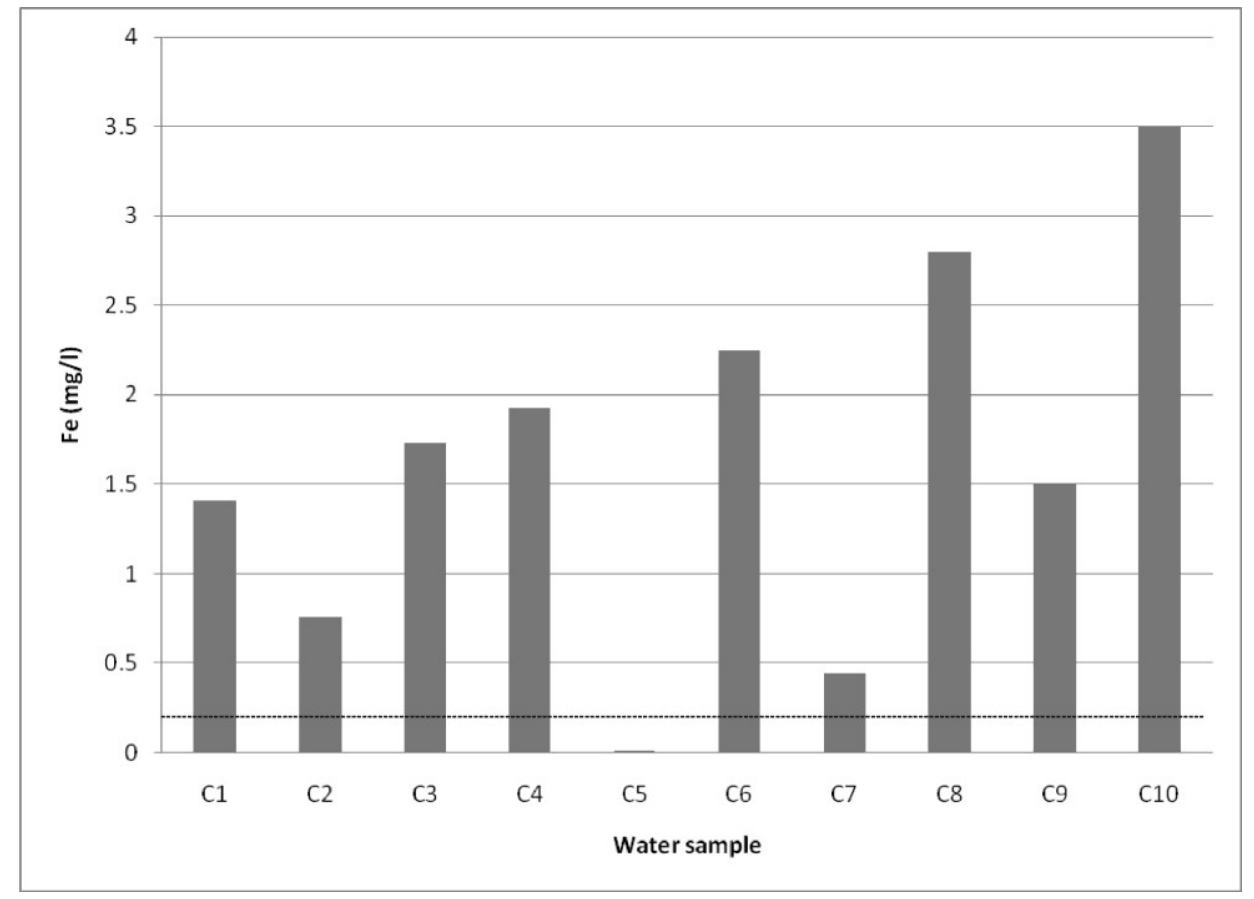

Figure 5.23 Concentration of dissolved Fe ions in groundwater sampled. The dotted line indicates the $0.2 \mathrm{mg} / \mathrm{I} \mathrm{Fe} \mathrm{DWSNZ} \mathrm{guideline} \mathrm{for} \mathrm{aesthetic} \mathrm{value.}$

The concentrations of manganese were also highly variable and ranged from 0.065 to $0.95 \mathrm{mg} / \mathrm{l}$ (Figure 5.24). The highest concentrations were found in C3 and C4 (0.934 and $0.95 \mathrm{mg} / \mathrm{l})$. The lowest concentration was again found in $\mathrm{C} 5$. The majority of the samples had $\mathrm{Mn}$ concentrations higher than the median values usually found in Manawatu aquifers $(0.068 \mathrm{mg} / \mathrm{l})$. The manganese concentrations of the groundwater samples were also greater than the values found in other sand and gravel aquifers in New Zealand (0.337 mg/l and 0.068 mg/1, respectively) (Daughney, 2003). 


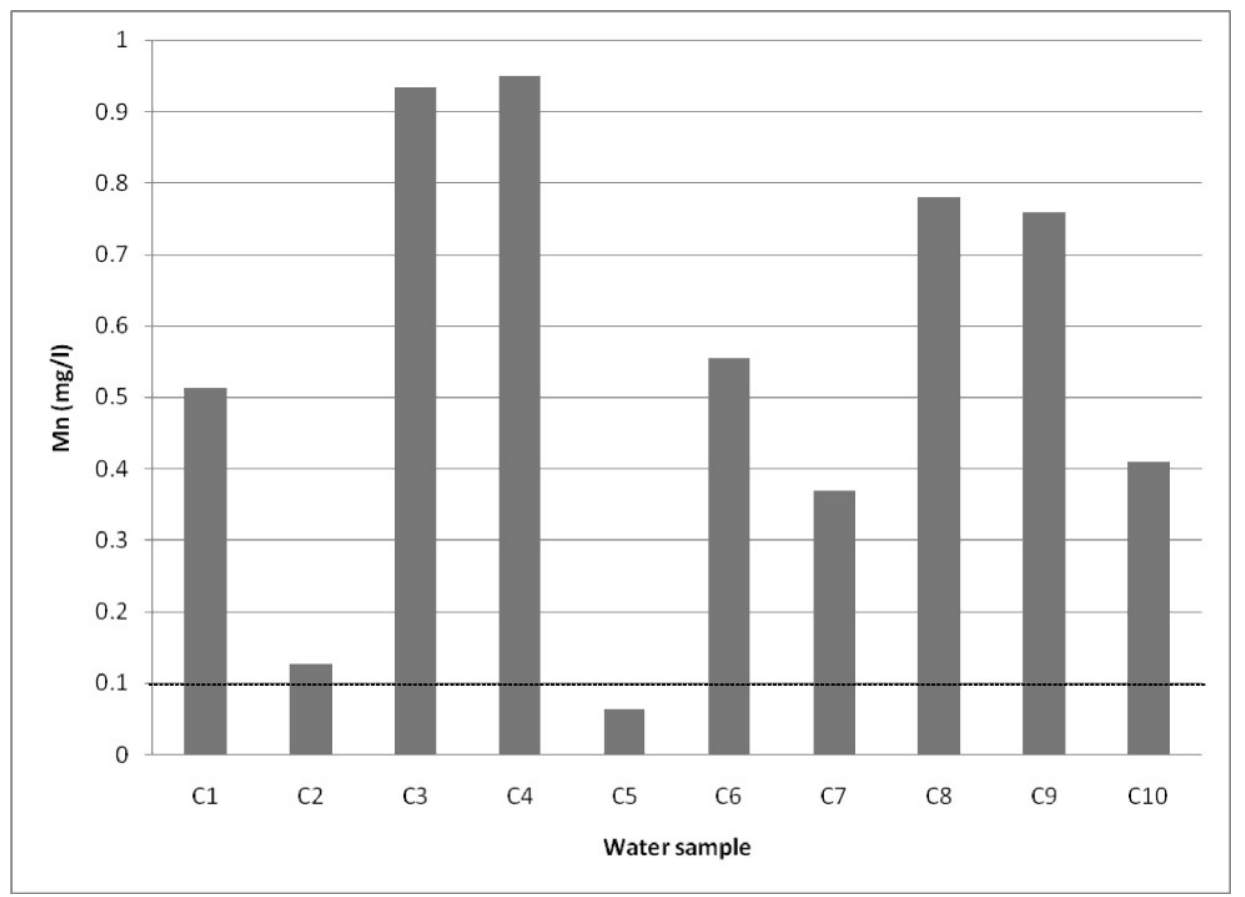

Figure 5.24 Concentration of dissolved $\mathrm{Mn}$ ions in groundwater sampled. The dotted line indicates the $0.1 \mathrm{mg} / \mathrm{I} \mathrm{Mn} \mathrm{DWSNZ} \mathrm{guideline} \mathrm{threshold} \mathrm{for} \mathrm{taste.}$

\section{Electrical conductivity}

The electrical conductivity (EC) of water is controlled by the concentration of dissolved ions. It shows how well groundwater conducts electricity (Sherif et al, 2006). The EC of water samples C1-C6 were measured in the field. The EC of samples C7-C10 were unable to be measured because of a faulty meter. The electrical resistivity was calculated as the reciprocal of electrical conductivity $\left(\rho_{w}=1 / \sigma_{w}\right)$ (Table 5.3). Water samples C3-C6 had low resistivity values of less than $15 \Omega \mathrm{m}$. The electrical resistivity of $\mathrm{C} 1$ and $\mathrm{C} 2$ was 22.52 and $44.64 \Omega \mathrm{m}$, respectively. Figure 5.25 shows the relationship between EC and calculated TDS concentrations has little scatter. A linear regression shows TDS $=0.753$ EC, and has an $r^{2}$ value of 0.987 . 
Table 5.3 The electrical conductivity, electrical resistivity, and calculated total dissolved solids of the groundwater sampled.

\begin{tabular}{|c|c|c|c|}
\hline Water Sample & $\begin{array}{c}\text { Electrical Conductivity } \\
(\mu \mathrm{S} / \mathrm{cm})\end{array}$ & $\begin{array}{c}\text { Electrical Resistivity } \\
(\Omega \mathrm{m})\end{array}$ & Calculated TDS (mg/l) \\
\hline C1 & 444 & 22.52 & 330.23 \\
\hline C2 & 224 & 44.64 & 137.06 \\
\hline C3 & 760 & 13.49 & 560.96 \\
\hline C4 & 741 & 13.16 & 545.29 \\
\hline C5 & 695 & 14.38 & 533.18 \\
\hline C6 & 801 & 12.48 & 630.93 \\
\hline C7 & - & - & 241.05 \\
\hline C8 & - & - & 463.94 \\
\hline C9 & - & - & 245.78 \\
\hline C10 & - & - & 558.64 \\
\hline
\end{tabular}

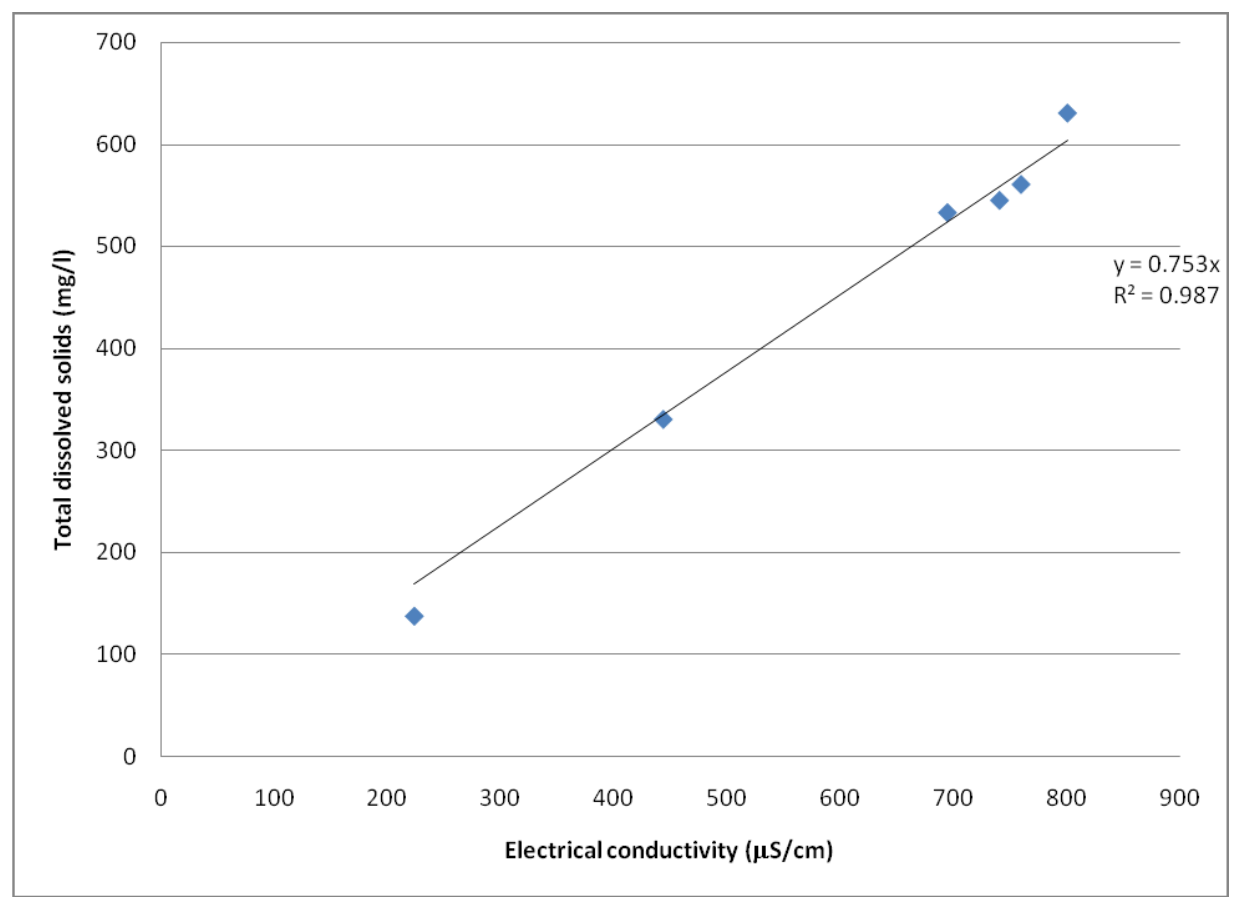

Figure 5.25 Relationship between electrical conductivity and total dissolved solids. 


\subsection{Summary}

An integrative approach was used to investigate the saline interface of the shallow groundwater in the study area. The results of the methods used were individually interpreted. They will be presented in context to each other in the next chapter.

Soundings conducted on the northern side of the Rangitikei River did not show saline mixing. However, the soundings conducted on the southern side of the river showed mixing of saline and freshwater. A contour map showed a low resistivity trend continued beyond the salt marsh, inland in a north easterly direction. The resistivity on the outskirts of Tangimoana was relatively low.

The resistivity traverses located in the salt marsh all showed the same stratification of increasing resistivity with depth. All traverses showed an underlying layer of high resistivity. This appears to be distributed over the entire area, and could be related to a large geological formation. In general, resistivity increases inland in an easterly direction, as the influence of the salt marsh decreases. The resistivity also increases inland towards Tangimoana.

The initial results of the AEM survey showed three distinct layers of low, moderate and high resistivity with increasing depth. The survey also showed a high resistivity structure about $30 \mathrm{~m}$ below the surface that extended in a SW-NE direction from the river meander. The lateral resistivity maps and profiles were consistent with several of the overlapping traverses.

The most common type of water found was $\mathrm{Ca}-\mathrm{Na}-\mathrm{HCO}_{3}-\mathrm{Cl}$. Many of the water samples showed $\mathrm{Na}: \mathrm{Cl}$ ratios similar to seawater. All of the water samples showed a high degree of calcium enrichment compared to chloride. The majority of the samples had $\mathrm{Fe}$ and Mn concentrations higher than the median values usually found in Manawatu aquifers, and in those found in New Zealand sand and gravel aquifers. Electrical conductivity ranged from 224 to $801 \mu \mathrm{S} / \mathrm{cm}$. A linear regression of TDS $=0.753 \mathrm{EC}$ showed the relationship between EC and TDS in the groundwater samples. 


\section{Chapter 6.}

\section{Interpretation and Discussion}

\subsection{Introduction}

The characteristics of the saline interface were determined for the shallow groundwater aquifer in the vicinity of Tangimoana, Scott's Ferry and the Rangitikei River estuary. Hydrochemistry and various geophysical methods defined the freshwater boundaries; determined the location, shape and dynamics of the saline interface of the aquifer; and identified the species and movement of total dissolved solids. These results will be interpreted and discussed in context of each other to obtain a clear understanding of the nature of the groundwater in the Rangitikei delta.

\subsection{Geophysical methods}

\section{Electrical resistivity soundings}

The resistivity data obtained from the soundings was largely a function of the water conductivity. Lithology did not have a large effect on the variation of resistivity. A contour map showed the variation in resistivity beneath the Rangitikei River. A common depth of $10 \mathrm{~m}$ was used (Figure 5.3). The northern side of the river is highly resistive compared to the south side. The salt marsh showed low resistivity. This is expected as it is vertically connected to saline water, and it is inundated during spring tides and storm 
surges. As the water from the surface of the salt marsh evaporates the concentration of solutes builds up. These solutes are only re-mobilised when rainfall infiltrates the soil zone.

The northern edge of the salt marsh showed increasing resistivity over a short distance. This area corresponds to a topographic high and change in vegetation. The contour lines follow the path of an old river channel. This suggests preferential flow of fresher groundwater from river discharge. This water follows the old channel after the estuary was straightened. The low resistivity trend of the salt marsh continues in a north easterly direction inland across open farmland. The low resistivity beneath the farmland might also reflect the old river channel as the saline mixing zone of the estuary would have been located further inland than it is now. However, it is more likely that the spatial distribution of resistivity reflects the interaction between the modern fresh groundwater and saline water mixing zone. It therefore shows the landward boundary of the zone of diffusion. The physical boundary of the salt marsh and the old river channel, are both located very close to Tangimoana. It is therefore likely that the trend of low resistivity continues beneath Tangimoana but this could not be assessed.

\section{Electrical resistivity traverses}

The extent of the saline interface near Tangimoana was further investigated using four resistivity traverses. These provided a profile of the subsurface, and refined the location and shape of the saline interface. A traverse was also conducted on the northern side of the river to confirm the high resistivity modelled from the Schlumberger soundings. An interpretation of the results (Figure 5.4 - 5.9) follows.

\section{Traverse W1}

This traverse was located on the boundary between the salt marsh and the farmland (Figure 5.4). Resistivity increased with depth in the surficial layers. This indicates infiltration of solutes from storm surges, coastal rain, and wind blown salts. A thick zone of low resistivity either side of the high resistivity ridge suggests the presence of brackish water. This indicates that the influence of the salt marsh extends inland towards the farmland. 


\section{Traverse W4}

Traverse W4 was an extension of traverse W1. The profile was conducted along a roadside in town, and extended onto the boundary between the salt marsh and farmland. The model of traverse W4 was difficult to resolve. This was because of having to delete a number of data points. The most appropriate way to interpret this profile is to look at the broad scale changes, and not to focus on anomalies (Figure $5.5 \& 5.6$ ). The profile is then consistent with traverse W1. Resistivity increases with depth in the salt marsh, indicating surficial infiltration of solutes. The thick low resistivity layer beneath the surficial layers indicates the presence of brackish water. Variable electrical contact has limited the resolution of the model along the roadside. However, the profile shows low resistivity beneath a highly resistive surface. This indicates that the pore fluid was more conductive. This may show that the influence of the salt marsh extends into Tangimoana, or that there is another source of salinity.

\section{Traverse W2}

Traverse W2 was located at the inland limit of the salt marsh, next to the Ellison Reserve. Variable electrical contact along the playing field limited the resolution of the model in this area. The profile shows low resistivity beneath the dry surface. The distribution of the low resistivity with depth below the surface suggests that this could indicate the water table. The pore fluid is conductive. The position of this low resistivity is similar in depth and thickness to that on traverse W4. Traverse W2 also shows the influence of the salt marsh. The thick low resistivity layer beneath the surficial layers again suggests the presence of brackish water. This extends as a distinct "toe" of salinity dispersion south east towards Tangimoana.

\section{Traverse W3}

Traverse W3 was located on the eastern side of the farmland. This was the traverse furthest from the salt marsh. The traverse was located on Parewanui silt loam; a finer alluvium that is poorly drained, and frequently flooded. The profile suggests some surficial infiltration of solutes. This was, however, much less than on the previous traverses that were nearer the salt marsh. The low resistivity in the middle of the profile might indicate the landward limit of the saline interface. The landward limit of the saline interface was more clearly demonstrated on the resistivity contour map (Figure 5.3). 


\section{Traverse W5}

Traverse W5 was located on the northern side of the river. The profile shows very little variation. The areas of higher resistivity could indicate fresh water in a predominantly gravel matrix. Groundwater in high hydraulic conductivity substrates such as gravels, tend to have low total dissolved solid concentrations. This is because of the low residence time (Osborne, 2006; Yadav and Abolfazli, 1998). The two areas of moderate resistivity coincided with saturated areas with poor drainage. The discontinuous lens in the middle of the profile may be finer alluvium. This profile shows no indication of salinity at present.

\section{Summary of Traverses}

The traverses located in the salt marsh/farmland all showed the same stratification of increasing resistivity with depth. This is likely to be caused by surficial infiltration of solutes. Traverses W1 and W2 showed similar low resistivity "bulges" that were in alignment. This suggests that there may be a preferential flow path, or old drainage channel in an east-west orientation. The traverses on either side of the river showed an underlying layer of high resistivity at a depth of approximately $24 \mathrm{~m}$. This layer appears to be distributed over the entire area. It could be related to a large geological formation. In general, resistivity increases inland (towards the east), as the influence of saline mixing decreases. Resistivity also increases inland towards Tangimoana. However, shallow low resistivity layers in Tangimoana were present on both traverse W4 and W2. The distribution and depth of this layer suggests that this is the top of the water table. The groundwater may have high concentrations of total dissolved solids.

\section{Airborne electromagnetic survey}

The spatial pattern of resistivity across the study area was broadly interpreted using lateral resistivity maps, and profiles from uncalibrated AEM survey data. The maps obtained from frequencies $40 \mathrm{k}$ and $8200 \mathrm{~Hz}$ appear to correspond to the depths measured using the ground DC resistivity. 


\section{0k Hz Frequency}

The lateral resistivity map obtained for a frequency of $40 \mathrm{k} \mathrm{Hz}$ showed moderate resistivity in the vicinity of Scott's Ferry, and around the top of the southern side of the river. A comparison with the AEM profile indicates that this layer is near the surface. The moderate resistivity of the green would suggest fresh water bearing gravels and sand. Resistivity decreases towards the coast from Scott's Ferry. It is probable that the relatively low resistivity indicates water bearing sands with a higher salt concentration nearer the coast. The blue zone of low resistivity that extends across the farmland on the southern side of the river, towards the northeast, is consistent with the resistivity shown in the sounding contour map (Figure 5.3). The distribution of this zone is consistent with the Parewanui soil series. This is likely to be saturated soils that are poorly drained.

\section{$8200 \mathrm{~Hz}$ Frequency}

The frequency of $8200 \mathrm{~Hz}$ penetrated deeper than the 40k Hz. The lateral maps still had the same pattern of variation, but showed higher resistivity. The lithology of several bore logs (322029 and 322017) shows that there are layers of hard rock and cemented sand between 17 and $30 \mathrm{~m}$ depth. It is unlikely that this substrate contains significant amounts of water. It therefore has very high resistivity. Elsewhere, the substrate appears to be constant. This suggests that the pore fluid has a lower concentration of solutes, and is less conductive, than the pore fluid closer to the surface. An area of low resistivity can still be seen on the edge of the farmland. This could be the landward side of the saline interface that is apparent on the sounding contour map and on traverse W3. This zone of low resistivity shows a sharp boundary with the surrounding higher resistivity areas. The high resistivity is therefore caused by the geological formation suggested previously.

\section{AEM Profiles}

The AEM profiles north of Tangimoana all showed three distinct layers of resistivity, and similar patterns of variation. The lowest resistivity layer was likely water bearing soils and sands containing electrically conductive water. The moderate resistivity of the green zone would suggest fresh water bearing gravels and sand. This moderate resistivity of the profile is consistent with the resistivity seen in traverse W5. All three profiles showed a mound of high resistivity. The lateral maps and the profiles indicate that this formation continues north east from near Scott's Ferry. A layer of high 
resistivity was also apparent in all of the traverses. It is possible that this is a continuation of the compacted gravels and sands. The transition from higher resistivity on the northern edge of the farmland to the lower resistivity to the south east shown in profile sgy30240 is consistent with the resistivity shown in traverse W1 and the resistivity contour map.

The AEM profile to the south of Tangimoana showed little variation in resistivity. This may be caused by the recent sand dunes and inter-dunal wetland in this area. The soils are predominantly sandy, have little profile development, and have somewhat excessive drainage. The low resistivity of the surface could be related to poorly drained soils that have accumulated between dunes. The Hokio sand, peaty phase occurs on poorly drained, low-lying, sand plains where the water table is near the surface.

\section{Summary of geophysical methods}

The resistivity modelled from the soundings, traverses and AEM survey are all consistent and show a similar pattern of spatial variation. The contour map showed a good over view of the resistivity of the salt marsh, farmland, and the northern side of the river. The traverses obtained more detailed information of the resistivity both laterally and vertically. They confirmed the resistivity found at a depth of $10 \mathrm{~m}$ obtained from the soundings. The resistivity maps and profiles from AEM showed the same variation in resistivity as the traverses. The AEM indicates that the underlying layer of high resistivity in the traverses may be cemented sands and gravels. The AEM also confirmed the resistivity distribution showed in the contour map. The northern side of the river was shown to be highly resistive when compared to the southern side. All three resistivity methods showed relatively low resistivity on the eastern edge of the farmland. This could be the landward boundary of the modern fresh groundwater and saline water mixing zone. 


\subsection{Hydrochemistry}

The chemical composition of groundwater is principally a function of recharge water chemistry and aquifer mineralogy (Janowski and Beck, 2000; Lloyd and Heathcote, 1985). The aquifer medium can produce chemical reactions including: dissolutionprecipitation, ion exchange, oxidation-reduction and sorption (Hiroshiro et al., 2006; Richter and Kreitler, 1993; Wicks et al., 1995). The chemical composition of sea water changes as it intrudes a freshwater aquifer. These changes occur in response to freshwater and saline mixing and the consequential chemical reactions. They are usually the most distinct within the leading edge of the seawater front. The transition zone can be characterised by chloride concentrations from just above background concentration values to just less than those of seawater (Richter and Kreitler, 1993).

\section{Water chemistry analyses}

Minor changes in mineralogy can produce large changes in the chemical composition of groundwater. The groundwater hydrochemistry was analysed to determine the spatial distribution of the chemical parameters.

The main sources of magnesium in New Zealand aquifers are silicates and their concentrations rarely exceed $15 \mathrm{mg} / \mathrm{l}$ (Rosen, 2001). Magnesium concentrations were positively correlated with both $\mathrm{Ca}$ and $\mathrm{HCO}_{3}$. This indicates that some of the magnesium might be derived from the dissolution of $\mathrm{CaMg}\left(\mathrm{CO}_{3}\right)_{2}$ present in shell material. The only water sample that had a concentration greater than this value was C6 $(27.1 \mathrm{mg} / \mathrm{l})$. The variation in $\mathrm{Mg}$ concentration did not show any spatial pattern, and ranged between 4.3 $14 \mathrm{mg} / \mathrm{l}$.

Chloride and bromide usually behave conservatively. They do not react easily with the aquifer medium. However, bromide does react in the presence of high amounts of organic matter (Jones et al., 1999). In New Zealand the main source of chloride and bromide is from rainwater containing evaporated seawater solutes (Rosen, 2001). The chloride concentration of coastal rainwater can vary from 1-20 mg/l (Richter and 
Kreitler, 1993). The chloride concentrations found in all of the samples were well below the DWSNZ guide of $250 \mathrm{mg} / \mathrm{l}$. The concentrations of chloride and bromide in the shallow groundwater of Tangimoana were much greater than the deeper groundwater, e.g. samples $\mathrm{C} 1$ and $\mathrm{C} 2$.

The water sample $\mathrm{C} 2$ had the lowest values of $\mathrm{pH}$, EC, TDS, potassium, sodium, magnesium, strontium, and bromide; and boron was not detected. $\mathrm{C} 2$ was a shallow groundwater sample taken from the outskirts of Tangimoana. It was beyond the influence of the salt marsh. The low EC and $\mathrm{pH}$ indicate that this sample may have been taken from clean sand (Jankowski and Beck, 2000).

\section{Water type}

The analysis of major ion chemistry provides valuable information on the interaction between groundwater, recharge and the aquifer medium. The most common type of water found was $\mathrm{Ca}-\mathrm{Na}-\mathrm{HCO}_{3}-\mathrm{Cl}$. Second most common was $\mathrm{Ca}-\mathrm{HCO}_{3}$. All of the water samples were dominated by $\mathrm{Ca}$ and $\mathrm{HCO}_{3}$. This is consistent with other coastal aquifers in New Zealand (Rosen, 2001). Calcium dominates where carbonate pebbles, cements, and shell material are present in the aquifer substrate. This is particularly common in New Zealand coastal aquifers. $\mathrm{Ca}-\mathrm{HCO}_{3}$ is considered to be 'fresher' water, and is usually associated with recharge areas (Faye et al., 2003; Osborne, 2006). The dominance of $\mathrm{Na}$ and $\mathrm{Cl}$ could be from the influence of the saline interface, given the proximity of the salt marsh to Tangimoana. Alternatively, they could be from $\mathrm{Na}$ and $\mathrm{Cl}$ dominated rainwater recharge. Most of the shallow groundwater samples $(\mathrm{C} 1, \mathrm{C} 3-\mathrm{C} 6$, C8, \& C10) have relatively similar chemical compositions. They have much greater concentrations of $\mathrm{Ca}$ and $\mathrm{HCO}_{3}$ than the other major ions. However, the shallow groundwater bores in Scott's Ferry $(\mathrm{C} 1 \& \mathrm{C} 8)$ show a dominance of $\mathrm{Ca}$ and to a lesser degree $\mathrm{HCO}_{3}$. The deeper groundwater samples (C7 \& C9) also show $\mathrm{Ca}$ and $\mathrm{HCO}_{3}$ dominance but to a much lesser degree. Although the groundwater sample $\mathrm{C} 2$ is classified as a $\mathrm{Ca}-\mathrm{Na}-\mathrm{HCO}_{3}-\mathrm{Cl}$ water type, it shows a much lower major ion concentration than any of the other groundwater samples. 


\section{Ion ratios}

The major source of calcium and bicarbonate is likely to be from the dissolution of calcium carbonate. The $\mathrm{Ca}: \mathrm{HCO}_{3}$ bivariate plot showed a good correlation $\left(\mathrm{r}^{2}=0.898\right)$ between concentrations of both these ions. Deviation from the 1:1 line is likely to be caused by the interaction of dissolved atmospheric $\mathrm{CO}_{2}$ with organic matter in the soil zone that washes $\mathrm{HCO}_{3}$ into the shallow groundwater (Jankowski and Beck, 2000; Rosen, 2001). The source of the calcium and bicarbonate is consistent with the correlation of calcium and strontium ions $\left(\mathrm{r}^{2}=0.909\right)$. Both are present in shell material. Most wells found in the National Groundwater Monitoring database in New Zealand have a greater proportion of $\mathrm{HCO}_{3}$ when compared to $\mathrm{Ca}$ (Rosen, 2001).

Generally, water sampled from shallow groundwater near the coast often has similar ion ratios to seawater. This is because of the salts dissolved in rain water (Jones and Baker, 2005; Rosen, 2001). Most of the groundwater samples showed a $\mathrm{Na}: \mathrm{Cl}$ similar to the seawater concentration dilution line (the ratio of $\mathrm{Na}: \mathrm{Cl}$ for seawater is 0.556 ). The strong positive correlation also indicates that the sodium and chloride ions in the shallow groundwater had the same source. The water samples C2 and C6 showed sodium depletion compared to chloride. However, the only natural sink for $\mathrm{Na}$ is reverse ion exchange. This does not commonly occur in New Zealand (Rosen, 2001). Therefore, it is

probable that source of sodium and chloride in water samples $\mathrm{C} 2$ and $\mathrm{C} 6$, with ratios of 0.46 and 0.47 respectively, were derived from the ocean. Water samples C7-C10 all show enrichment of sodium compared to chloride. Sodium enrichment can occur either because of water-rock interaction with plagioclase feldspar, ion exchange or input from various land uses (Rosen, 2001).

In response to the landward movement of seawater, an ion exchange reaction may occur at the front of the zone of diffusion. Sodium is taken out of solution and adsorbed onto mineral exchange sites on fine grain sediments. This releases calcium into solution (Richter and Kreitler, 1993; Lloyd and Heathcote, 1985). However, as ion exchange occurs at the front of the zone of diffusion, this process should not occur at a relatively static interface zone. That is, it should not occur at Tangimoana with a low energy salt marsh. The water samples showed a positive correlation between $\mathrm{Ca}$ and $\mathrm{Cl}$; with a high degree of calcium enrichment compared to chloride. However, as the ion exchange 
reaction is coupled with a reduction in $\mathrm{Na}$, there should be a negative correlation between $\mathrm{Na}$ and $\mathrm{Ca}$ (Jankowski and Beck, 2000). The groundwater showed a positive relationship between $\mathrm{Na}$ and $\mathrm{Ca}$. Therefore, it is highly unlikely that ion exchange is a dominant process affecting the water chemistry.

The dissolution of carbonate material can occur when saline and freshwater mix. This increases both $\mathrm{Ca}$ and $\mathrm{HCO}_{3}$ concentrations. The mixing water dissolves the carbonates and $\mathrm{Ca}$ and $\mathrm{HCO}_{3}$ concentrations will increase. This is because under-saturation of carbonate minerals occurs irrespective of the two mixing waters being supersaturated (Lloyd and Heathcote, 1985; Richter and Kreiter, 1993). This process may explain the higher concentration of $\mathrm{Ca}$ and $\mathrm{HCO}_{3}$ found in the shallow groundwater of Tangimoana.

\section{Iron and manganese ions}

A relatively static interface zone produces localised reducing conditions because of the decomposition of dissolved organic matter in the sediments (Hem, 1989). The lithology of the shallow aquifer in the Rangitikei is highly heterogeneous. The concentrations of $\mathrm{Fe}$ and $\mathrm{Mn}$ in the groundwater varied greatly. Apart from samples $\mathrm{C} 3 \& \mathrm{C} 4$, they showed no spatial pattern. This suggests that the concentrations of Fe and Mn were determined by localised redox conditions and the aquifer medium. The lowest concentrations of both Fe and Mn were found in C5. This sample also had the highest concentration of $\mathrm{SO}_{4}$. This suggests that this may have come from an oxidising environment. However, it is more likely that as this sample came from a bore with a pressure pump, the Fe and $\mathrm{Mn}$ ions may have adsorbed to the surface of the pump.

The concentration of both Fe and Mn were compared to the EC of the samples. Water sample C5 was not included. Fe concentrations showed a strong positive correlation with EC $\left(r^{2}=0.913\right)$. Mn showed a positive correlation with EC, but had more scatter. This indicates that EC is not affected greatly by the concentration of $\mathrm{Mn}$ in the samples. The electrical conductivity, and the calculated total dissolved solids, of the samples were compared. They showed a strong correlation $\left(\mathrm{r}^{2}=0.987\right)$. As the total dissolved solids were not calculated using Fe ions it can be concluded that the concentrations of Fe and 
Mn ions do not significantly contribute to the electrical conductivity of the sampled groundwater.

\section{Electrical resistivity}

The electrical resistivity of the water samples was calculated as the reciprocal of the electrical conductivity. EC of water shows how well the sample conducts electricity and is controlled by the concentration of dissolved ions.

The shallow groundwater in Tangimoana had low resistivity $(12.48-14.38 \Omega \mathrm{m})$. C2 had the highest resistivity at $44 \Omega \mathrm{m}$. C1 had a resistivity of $22 \Omega \mathrm{m}$. To estimate the resistivity of water samples that were unable to be measured in the field, the electrical resistivity was calculated using the relationship of TDS $=0.753 \mathrm{EC}$. This was derived from the measured electrical conductivity of samples C1-C6. The resistivity of the deeper groundwater (C7 \& C9) was estimated at approximately $31 \Omega \mathrm{m}$. Samples C8 and C10 were estimated at approximately 16 and $13 \Omega \mathrm{m}$ respectively.

\section{Summary of hydrochemistry}

The process of carbonate dissolution in the saline freshwater mixing water may explain the higher concentrations of $\mathrm{Ca}$ and $\mathrm{HCO}_{3}$ found at Tangimoana. The most common type of water found was $\mathrm{Ca}-\mathrm{Na}-\mathrm{HCO}_{3}-\mathrm{Cl}$. Second most common was $\mathrm{Ca}-\mathrm{HCO}_{3}$. All of the water samples were dominated by $\mathrm{Ca}$ and $\mathrm{HCO}_{3}$. The major source of calcium and bicarbonate is likely to be from the dissolution of carbonate pebbles, cements and shell material in the aquifer medium. The source of the calcium and bicarbonate is consistent with the correlation of calcium and strontium ions found in shell materials. The positive relationship between sodium and calcium indicated that it was highly unlikely that ion exchange was occurring. This is not the cause of calcium enrichment.

In most of the samples sodium and chloride had the same source. This could be evaporated solutes in the rainwater or given the proximity of the sea, the salt marsh and saline interface to Tangimoana. 
The concentrations of $\mathrm{Fe}$ and $\mathrm{Mn}$ were variable. They showed no spatial pattern, and were almost all greater than the DWSNZ guidelines. Fe and Mn ions, however, did not significantly contribute to the electrical conductivity of the sampled groundwater. The shallow groundwater in Tangimoana showed the highest electrical conductivity.

\subsection{Integration of hydrochemistry and geophysical}

The use of the chemistry analyses and geophysical methods can reduce the uncertainties involved in aquifer interpretation. Traverses W2 and W4 suggest that there is a low resistivity layer at $10 \mathrm{~m}$ depth. This could represent groundwater that has a high concentration of total dissolved solids. This was confirmed by water samples C3 and C4, the closest samples to these traverses at the same depth. The samples both showed electrical conductivity of about $750 \mu \mathrm{S} / \mathrm{cm}$. This equates to an electrical resistivity of approximately $13.3 \Omega \mathrm{m}$. Therefore, the low resistivity layer seen in traverses W2 and W4 can be explained.

The deeper groundwater samples (C7 and C9) had lower electrical conductivity and concentrations of total dissolved solids than shallower samples. This is consistent with the deeper high resistivity layers of the traverses.

The Schlumberger soundings and traverses suggest that the saline interface is located close to Tangimoana. However, the groundwater at Tangimoana does not have excessive chloride; the usual indicator of saline intrusion. However, chloride concentrations ranging from just above background values to just less than those of seawater can indicate the transition zone of fresh and saline water mixing (Richter and Kreitler, 1993). As this study provided the first groundwater analyses for chloride ions in the area it is not known if chloride concentrations are increasing. This can now be confirmed by future monitoring. 


\section{Formation factor}

The measurements made in a resistivity investigation are of the bulk resistivity of the subsurface. As previously discussed, bulk resistivity is a function of the pore fluid resistivity and the formation factor; this is described by Archie's Law (Equation 2.8). If the pore fluid resistivity and the bulk resistivity are known, a formation factor can be calculated. The formation factor is important for future resistivity work in the area as it provides a method of calculating groundwater resistivity from bulk resistivity measurements (Wilson, 2003). It is also useful when assessing the significance of the geology on the electrical conductivity of the ground (Osborne, 2006).

Two significant geological units can be distinguished: gravel and sands; and coastal and marine sediments, which include a range of sediments such as sand and silt. The mean electrical resistivity of water samples $\mathrm{C} 3$ and $\mathrm{C} 4$ was used for the coastal and marine sediments. The bulk resistivity was estimated using traverses W4 and W2, as both these traverses are located within the township. Water sample C7 was used for the gravel and sands. This is because the bore $\log 322017$ (Figure 5.1) suggests that there are gravel with sands located at approximately $30 \mathrm{~m}$ depth at Scott's Ferry. The bulk resistivity measurements from traverse W5 was used for the gravel and sands.

Table 6.1 The calculated formation factor for the geological units present in the traverses

\begin{tabular}{|c|c|c|c|}
\hline Unit & $\begin{array}{c}\text { Groundwater resistivity } \\
\left(\rho_{\mathrm{w}}\right) \Omega \mathrm{m}\end{array}$ & $\begin{array}{c}\text { Estimated bulk resistivity } \\
(\rho) \Omega \mathrm{m}\end{array}$ & $\begin{array}{c}\text { Formation Factor } \\
(\mathrm{F})\end{array}$ \\
\hline Gravel and sand & 31 & 200 & 6.5 \\
\hline $\begin{array}{c}\text { Coastal and marine } \\
\text { sediments }\end{array}$ & 13.3 & 40 & 3.0 \\
\hline
\end{tabular}

The coastal and marine sediments had a formation factor of 3.0. This value is comparable to similar studies on the Kapiti Coast. Wilson (2003) estimated a value of $2.8 \pm 0.2$, Osborne (2006) 3.5, and Morrow (2007) 3.1.

The gravels had a formation factor of 6.5. This value was calculated using an electrical resistivity value derived from the calculated total dissolved solids concentration of water sample C7. Therefore, this formation factor should only be considered an approximation. 
Broadbent and Callender (1991) found similar values for gravels on the Canterbury Plains. However, Osborne (2006) found a higher formation factor of 10.4 for the gravels at Waikanae. A high formation factor indicates that gravels impede the flow of electrical current (Osborne, 2006). Yadav and Abolfazli (1998) found that there is a positive correlation between hydraulic conductivity and bulk resistivity; and it is possible that the concentration of TDS is low because of the short residence time.

These formation factors can then be used to approximate the pore-fluid resistivity of the traverses through coastal and marine sediments, and gravels. The pore fluid resistivity of the salt marsh and farmland was estimated using the formation factor derived for the coastal and marine sands (Table 6.2). The total dissolved solid concentration was estimated from EC using the relationship previously derived. These values should only be considered as approximate, as they have been derived using several steps and assumptions. The seawater values are used for comparison. However, values measured from local seawater would have provided a more realistic comparison.

Table 6.2 Estimated fluid resistivity, conductivity, and TDS for the bulk resistivity contours of Traverses W1-W4. The seawater values are average values (Stumm and Morgan, 1996).

\begin{tabular}{|c|c|c|c|}
\hline Bulk resistivity $(\rho) \Omega m$ & $\begin{array}{c}\text { Groundwater resistivity } \\
\left(\rho_{\mathrm{w}}\right) \Omega \mathrm{m}\end{array}$ & $\mathrm{EC}(\mu \mathrm{S} / \mathrm{cm})$ & TDS $(\mathrm{mg} / \mathrm{l})$ \\
\hline 100 & 33.3 & 300.3 & 226.1 \\
\hline 31.6 & 10.5 & 952.4 & 717 \\
\hline 10 & 3.33 & 3003 & 2261 \\
\hline 3.16 & 1.05 & 9523.8 & 7171.4 \\
\hline Seawater & $\sim 0.2$ & $\sim 50,000$ & $\sim 38,750$ \\
\hline
\end{tabular}

\subsection{Summary}

The resistivity modelled from the soundings, traverses, and AEM survey are all consistent and show similar spatial variation. The three resistivity methods showed relatively low resistivity on the eastern edge of the farmland. This could be the landward boundary of the modern fresh groundwater and saline water mixing zone. Resistivity 
contour lines followed the path of the old river channel. Preferential flow of fresher groundwater from river discharge occurs in this zone

The boundary of the salt marsh and the old river channel are both located close to Tangimoana. Shallow, low resistivity layers in Tangimoana were observed on the two traverses. Water samples confirmed the low resistivity of the groundwater indicated in these layers.

The data from VES, resistivity traverses, AEM survey, and hydrochemistry all suggest that the northern side of the river is not subject to saline intrusion.

The shallow groundwater in Tangimoana showed high concentrations of $\mathrm{Ca}$ and $\mathrm{HCO}_{3}$. Carbonate dissolution at the interface may explain the high Ca concentrations. In most of the samples sodium and chloride had the same source. This was evaporated solutes in the rainwater; or given the proximity of the salt marsh to Tangimoana, the influence of the saline interface. 


\section{Chapter 7.}

\section{Conclusion and Implications}

\subsection{Summary and conclusions}

The coastal communities of Tangimoana and Scott's Ferry have a long history of using shallow groundwater bores. The cumulative effect of pumping over decades has the potential to affect the saline interface. This is especially true given the close proximity of the communities to the seashore and river estuary. It is important to quantify the effects of pumping on both the shallow groundwater system, and the dynamics of the saline interface, to protect against saline intrusion. This is becoming critical with the increased number of high volume groundwater consents. Locating the saline/freshwater interface and monitoring its dynamics are essential for managing coastal groundwater systems. Therefore, the aims of this research were to define the freshwater boundaries of the shallow groundwater in the Rangitikei delta; and to determine the location, shape and dynamics of the saline interface. The identification of the species and movement of total dissolved solids in the shallow groundwater helps to quantify the quality of the groundwater in both communities.

Resistivity soundings and traverses, coupled with chemical analyses of groundwater, was found to be effective for defining the saline interface. Vertical electrical soundings were undertaken at sixteen locations throughout the delta. These showed the approximate location of the saline interface. It extends from the salt marsh to beneath the farmland north of Tangimoana. The position of the interface was then confirmed using resistivity traverses, and AEM resistivity maps and profiles. 
The saline interface is a zone of diffusion. Freshwater mixes with brackish water from the estuary. The infiltration of brackish surface waters into sediments of the salt marsh also forms a surficial mixing zone. The effect of this decreased with increasing distance from the salt marsh. Resistivity traverses showed the presence of preferential flow paths from the salt marsh through the farmland towards the Ellison Reserve. Resistivity traverses and hydrochemistry indicated that the saline interface is on the outskirts of Tangimoana, and likely extends beneath the township.

The shallow groundwater in Tangimoana showed high concentrations of $\mathrm{Ca}$ and $\mathrm{HCO}_{3}$ ions. This is the result of carbonate dissolution, which can occur when saline and freshwater mix. The mixing of water dissolves carbonates and increases the concentrations of $\mathrm{Ca}$ and $\mathrm{HCO}_{3}$. The major source of sodium and chloride ion is likely rainwater; with evaporated solutes from seawater.

There was no evidence of saline intrusion on the northern side of the river. The resistivity modelled from the VES, traverses, and AEM survey all showed high resistivity in the vicinity of Scott's Ferry. The water chemistry in Scott's Ferry was varied, but had $\mathrm{Ca}, \mathrm{HCO}_{3}, \mathrm{Na}$, and $\mathrm{Cl}$ concentrations that were all less than those found in Tangimoana.

Shallow groundwater in the Rangitikei delta tended to have high concentrations of both iron and manganese. The majority of the samples showed concentrations greater that the maximum recommended by DWSNZ. The iron and manganese did not have a significant effect on the electrical conductivity of the groundwater.

The species of the total dissolved solids was determined to be predominantly $\mathrm{Ca}, \mathrm{Na}$, $\mathrm{HCO}_{3}$ and $\mathrm{Cl}$ ions. The electrical conductivity of the water allowed the formation factor of coastal and marine sediments, and gravel and sand sediments to be determined. This was used to estimate the electrical resistivity of the groundwater under the farmland. 


\subsection{Implications for groundwater management}

This study has produced a range of information specific to the saline interface and the shallow groundwater in the Rangitikei delta. This will be helpful in the management of this water resource.

Horizons Regional Council has incorporated the management of coastal aquifers, and the risk management of saltwater intrusion, as policy 6-26 in the proposed One Plan (HRC, 2007). New consent applications for groundwater abstraction within $5 \mathrm{~km}$ of the coastal mean high water spring line are required to perform pumping tests and other hydrogeological assessments to determine the risk of inducing saltwater intrusion. Groundwater abstraction within the $5 \mathrm{~km}$ limit can be restricted, or suspended, if electrical conductivity thresholds are reached or exceeded.

There is no indication of salinity in the area north of the Rangitikei River. This area was most at risk of contamination from saline intrusion because of the high volume groundwater abstractions (Figure 3.12) (Gyopari, 2005). The resistivity traverses have provided a baseline for future monitoring of the interface.

The presence of the salt marsh and saline mixing zone close to Tangimoana, combined with the cumulative effect of years of household groundwater abstraction, appears to have reduced water quality. The saline interface near Tangimoana appears to be relatively static, but the estuary and salt marsh are areas of low relief. There are preferential flows paths across the salt marsh to the farmland. These factors make the shallow groundwater in the Rangitikei delta vulnerable to saline intrusion. This can be caused by: reduced freshwater gradient, produced as a result of over abstraction; or from future sea level rise.

The shallow groundwater in Scott's Ferry and Tangimoana tended to show high concentrations of iron and manganese. These were much higher than the DWSNZ. The water also had hardness levels higher than $200 \mathrm{mg} / \mathrm{l}$. Although this water is mostly used for gardens, and for cold water use within households, these levels can stain laundry and plumbing fittings. They can also cause scale deposition and scum formation $(\mathrm{MoH}$, 2005). 


\subsection{Recommendations for future research}

This study defined the location and shape of the saline interface, and determined the hydrochemistry of the groundwater in the Rangitikei delta. This information provides a good basis for future monitoring of the saline interface. Future work in the Rangitikei delta should include:

- Monitoring of water quality, particularly chloride concentrations in Tangimoana. This study sampled groundwater in spring. It is likely that the groundwater chemistry changes over dry periods without rainfall recharge. Periodic sampling may identify changes in the water quality over seasons, and show yearly trends. This would also help to quantify the effect of flooding on the groundwater quality in Scott's Ferry and Tangimoana.

- The development of a long term record of shallow groundwater levels around Tangimoana. This could be used to identify trends, quantify the effect of tidal activity, and monitor the effect of any large groundwater abstractions.

- A detailed investigation of the hydraulic parameters, such as transmissivity, specific yield, and hydraulic conductivity of the aquifer. This data would assist in the development of future hydrologic models for the area.

- Hydrologic modelling, integrated with detailed field investigations, to predict the landward movement of the saline interface in response to groundwater abstraction and sea level rise.

- An investigation of the various components of aquifer recharge, and their relative significance.

- Periodic electrical resistivity surveys to identify any changes in the subsurface resistivity, particularly with regard to the saline interface. This allows the interface to be monitored without invasive methods. 


\section{References}

Anderton, P.W. 1981. Structure and evolution of the South Wanganui Basin, New Zealand. New Zealand Journal of Geology and Geophysics 24: 39-63.

Ataie-Ashtiani, B., Volker, R. E. and Lockington, D. A.. 1999. Tidal effects on sea water intrusion in unconfined aquifers. Journal of Hydrology 216: 17-31

Barlow, P.M. 2003. Ground water in fresh water-salt water environments of the Atlantic Coast. U.S. Geological Survey Circular 1262, 113 p.

Bear, J. 2007. Hydraulics of groundwater. Dover Publications, Mineola, 569p.

Bear, J., and Cheng, A.H.-D. 1999. Introduction. In: Bear, J., et al., (eds). Seawater intrusion in coastal aquifers - concepts, methods and practices. Kluwer Academic Publishers, Dordrecht, $640 \mathrm{pp}$.

Bear, J., Cheng, A.H.-D., Sorek, S., Ouazar, D. and Herrera, I. 1999. Seawater intrusion in coastal aquifers - concepts, methods and practices. Kluwer Academic Publishers, Dordrecht, $640 \mathrm{pp}$.

Begg, J.G., Palmer, A. and Gyopari, M. 2005. Geological synopsis of the ManawatuHorowhenua area for a review of the region's hydrogeology. 2005/172, Institute of Geological and Nuclear Sciences prepared for Horizons Manawatu Regional Council. $36 p$.

Bekesi, G. 1998. Aquifer vulnerability assessment for the Manawatu region. Unpublished $\mathrm{PhD}$ thesis, Victoria University of Wellington. 256p.

Bekesi, G. 2001. Manawatu-Wanganui. In: M.R. Rosen and P.A. White (eds). Groundwaters of New Zealand. New Zealand Hydrologcal Society Inc., Wellington. p387-396

Bower , J.W., Motz, L.H., and Durden, D.W. 1999. Analytical solution for determining the critical condition of saltwater upconing in a leaky artesian aquifer. Journal of Hydrology 221: 43-54

Broadbent, M. and Callander, P.F. 1991. A resistivity survey near Waimakariri River, Canterbury Plains, to improve understanding of local groundwater flow and of the capabilities of the survey method. New Zealand Journal of Geology and Geophysics 34(4): 441-453.

Burgess S.M. 1988. The climate and weather of Manawatu and Horowhenua. New Zealand Meteorological Service Miscellaneous Publications, 115(18): $47 \mathrm{p}$. 
Campbell, I.B. 1978. Soils of Rangitikei County, North Island, New Zealand. New Zealand Soil Bureau 38, New Zealand Department of Scientific and Industrial Research, Wellington

Carter, E.S., White, S.M., and Wilson, A.M. 2008. Variation in groundwater salinity in a tidal salt marsh basin, North Inlet Estuary, South Carolina. Estuarine, Coastal and Shelf Science 76: 543-552

Cartwright, N., Li, L. and Nielsen, P. 2004. Response of the salt-fresh water interface in a coastal aquifer to a wave induced groundwater pulse: field observation and modelling. Advances in Water Resources 27: 297-303.

Choudhury, K., and Saha, D.K. 2004. Integrated geophysical and chemical study of saline water intrusion. Ground Water 42(5): 671-677.

Cowie, J.D. 1963. Dune-building phases in the Manawatu district, New Zealand. New Zealand Journal of Geology and Geophysics, 6: 268-280.

Cowie, J.D. and Fitzgerald P. 1966. Soil map of Manawatu-Rangitikei sand country, North Island, New Zealand Sheet 1 (1: 63,360) Department of Scientific and Industrial Research.

Cowie, J.D., Fitzgerald, P. and Owers, W. 1967. Soils of the Manawatu-Rangitikei sand country. New Zealand Soil Bureau Bulletin, 29. New Zealand Department of Scientific and Industrial Research, Wellington, 58p.

Cresswell, R.I., Mullen, I.C., Kingham, R., Kellett, J., Dent, D.L., and Jones, G.L.. 2007. Airborne electromagnetics supporting salinity and natural resource management decisions at the field scale in Australia. International Journal of Applied Earth Observation and Geoinformation 9: 91-102

Daughney, C. 2003. Iron and Manganese in New Zealand's groundwater. Journal of Hydrology (NZ) 42(1): 11-26

Dent, D. 2007. Environmental geophysics mapping salinity and water resources. International Journal of Applied Earth Observation and Geoinformation 9: 130-136

MoH. 2005. Drinking water standards for New Zealand. Wellington: Ministry of Health

Ebraheem, A.-A. M., Senosy, M. M. and Dahab, K. A. 1997. Geoelectrical and hydrogeochemical studies for delineating ground-water contamination due to saltwater intrusion in the northern part of the Nile delta, Egypt. Ground Water 35: 216222.

Edet, A.E., and Okereke, C.S. 2001. A regional study of saltwater intrusion in southeatern Nigeria based on the analysis of geoelectrical and hydrchemical data. Environmental Geology 40: 1278-1289

Ernstson, K., and Kirsch, R. 2006. Geoelectrical methods. In: R. Kirsch (ed) Groundwater geophysics: A tool for hydrogeology. Springer, Berlin. 493p

Essaid, H.I. 1986. Comparison of the coupled fresh water-salt water flow and the GhybenHerzberg sharp interface approaches to modeling of transient behavior in coastal aquifer systems. Journal of Hydrology 86: 169-193 
Faye, S., Faye, S.C., Ndoye, S., and Faye, A. 2003. Hydrogeochemistry of the Saloum (Senegal) superficial coastal aquifer. Environmental Geology 44: 127-136

Fitterman, D.V., and Yin, C. 2004. Effect of bird maneuver on frequency-domain helicopter EM response. Geophysics, 69(5): 1203-1215

Fleming, C.A. 1953. The geology of the Wanganui Subdivision. New Zealand Geological Survey bulletin 52. Wellington, New Zealand.

Fountain, D. 1998. Airborne electromagnetic systems - 50 years of development. Exploration Geophysics 29: 1-11

Freeze, R.A. and Cherry, J.A. 1979. Groundwater. Prentice-Hall Inc, Englewood Cliffs. 604 $\mathrm{pp}$.

Geological Society of New Zealand. 1986. Geological Society of New Zealand Inc 1986 Annual conference, Massey University, Palmerston North, 1st-5th December 1986: field trip guides. Geological Society of New Zealand miscellaneous publication No 35B.

Gyopari, M. 2005. Assessment of the seawater intrusion hazard in the Manawatu coastal aquifers and monitoring action plan. Phreatos Limited prepared for Horizons Regional Council, $22 \mathrm{pp}$.

Harvey, J.W., Germann, P.F., and Odum, W.E. 1987. Geomorphological control of subsurface hydrology in the creekbank zone of tidal marshes. Estuarine, Coastal and Shelf Science 25: 677-691

Heerdegen, R.G. and Shepherd, M.J. 1992. Manawatu landforms - Product of tectonism, climate change and process. In: J.M. Soons and M.J. Selby (Eds), Landforms of New Zealand. Longman Paul Limited, Auckland, pp. 308-333.

Hem, J.D. 1989. Study and interpretation of the chemical characteristics of natural water. US geological survey water-supply paper 2254 , $3^{\text {rd }}$ Edition.

Hesp, P.A. 2001. The Manawatu dunefield: environmental change and human impacts. New Zealand Geographer, 57: 33-40

Hiroshiro, Y., Jinno, K., and Berndtsson, R. 2006. Hydrogeochemical properties of a salinityaffected coastal aquifer in western Japan. Hydrological Processes 20: 1425-1435

Horizons Regional Council. 2002. Manawatu-Wanganui Regional Council regional coastal plan change $1 \& 2$. Report No. 2001/EXT/466

Horizons Regional Council. 2004a. Groundwater Allocation Methodology for the Manawatu and Horowhenua Regions. McCarron, C. and Gyopari, M. Report No. 2004/EXT/597

Horizons Regional Council. 2004b. Water allocation project Rangitikei River: water resource assessment - allocation limits and minimum flows: technical report to support policy development. Roygard, J. and Carlyon, G. Report No. 2004/EXT/606

Horizons Regional Council. 2005. State of the environment report of the ManawatuWanganui region. Report No.2004/EXT/608. 
Horizons Regional Council. 2007. The Proposed one plan-the consolidated resource policy statement, regional plan and regional coastal plan for the Manawatu-Wanganui region.

Hubbert, M.K. 1940. The theory of groundwater motion. Journal of Geology. 48: 785-944

Hughes, C.E., Binning, P., Willgoose, G.R. 1998. Characterisation of the hydrology of an estuarine wetland. Journal of Hydrolology 211: 34-49.

Ingham, M., McConchie, J.A., Wilson, S.R. and Cozens, N. 2006. Measuring and monitoring saltwater intrusion in shallow unconfined coastal aquifers using direct current resistivity traverses. Journal of Hydrology (NZ), 45(2): 89-102.

Jackson, J., Van Dissen, R.J., Berryman, K.R. 1998. Tilting of active folds and faults in the Manawatu region, New Zealand: evidence from surface drainage patterns. New Zealand Journal of Geology and Geophysics 41: 377-386.

Jankowski, J. and Beck, P. 2000. Aquifer heterogeneity: hydrogeological and hydrochemical properties of the Botany Sands aquifer and their impact on contaminant transport. Australian Journal of Earth Sciences 47: 45-64

Jones, A. and Baker, T. 2005. Groundwater monitoring technical report. Greater Wellington Regional Council. Wellington. 142p.

Jones, B.F., Vengosh, A., Rosenthal, E., and Yechieli, Y. 1999. Geochemical Investigations. In: J. Bear et al., (Eds) Seawater intrusion in coastal aquifers - concepts, methods, practices. Kluwer Academic Publishers, Dordrecht.

Kirsch, R. 2006. Petrophysical properties of permeable and low-permeable rocks. In: R. Kirsch (ed) Groundwater geophysics: A tool for hydrogeology. Springer, Berlin. 493p

Laurenson, S.G. 1979. Rangitikei, the day of striding out. Dunmore Press, Palmerston North. $225 p$

Lloyd, J.W. and Heathcote, J.A. 1985. Natural inorganic hydrochemistry in relation to groundwater: An introduction. Clarendon Press, Oxford, 296p

Loke, M.H., Acworth, I., and Dahlin, T. 2003. A comparison of smooth and blocky inversion methods in 2D electrical imaging surveys. Exploration Geophysics 34: 182-187

Loke, M.H. and Barker, R.D. 1996. Practical techniques for 3D resistivity surveys and data inversion. Geophysical Prospecting 44(3): 499-523.

Loke, M.H. 1999. Electrical imaging surveys for environmental and engineering studies: $A$ practical guide to 2-D and 3-D surveys. Available online at www.geoelectrical.com

Lowe, D..J. and Green, J.D. 1992. Lakes. In: Soons JM and S. MJ (Eds), Landforms of New Zealand. Longman Paul Limited, Auckland, pp. 107-143.

MAF, 2002. "Landuse by Territorial Authority: at 30 June 2002" Retrieved 13/12/2007 from http://www.maf.govt.nz/statistics/primaryindustries/land-use-and-farm-counts/

Mao, X., Enot, P., Barry, D.A., Li, L., Binley, A., Jeng, D.-S. 2006. Tidal influence on behaviour of a coastal aquifer adjacent to a low-relief estuary. Journal of Hydrology. 327, 110127. 
McDonald, R. J., Russill, N. R. W., Miliorizos, M. \& Thomas, J. W. 1998. A geophysical investigation of saline intrusion and geological structure beneath areas of tidal coastal wetland at Langstone Harbour, Hampshire, UK. In: Robins, N. S. (ed.) Groundwater Pollution, Aquifer Recharge and Vulnerability. Geological Society, London, Special Publications. 130: 77-94.

MfE. 2006. A national protocol for State of the Environment groundwater sampling in New Zealand. Ministry for the Environment Manatū Mō Te Taiao publication 781. 54p

Milne, J.D.G. 1973. Upper Quaternary geology of the Rangitikei drainage basin, North Island, New Zealand, Unpublished PhD thesis. Victoria University of Wellington, Wellington, $347 \mathrm{p}$

Moore, W.S. 1999. The subterranean estuary: a reaction zone of ground water and sea water. Marine Chemistry. 65, 111-125.

Morrow, F.J. 2007. Dynamics of the saline interface of the shallow unconfined aquifer of the Kapiti Coast. Unpublished MSc thesis, School of Geography, Environmental and Earth Sciences, Victoria University of Wellington. Wellington. 119p

Muckersie, C. and Shepherd, M.J. 1995. Dune phases as time-transgressive phenomena, Manawatu, New Zealand. Quaternary International, 26: 61-67

Naish, T., Kamp, P.J.J. 1995. Pliocene-Pleistocene marine cyclothems, Wanganui Basin, New Zealand: a lithostratigraphic framework. New Zealand Journal of Geology and Geophysics 38: 223-243.

Nielson, P. 1990. Tidal dynamics of the water table in beaches. Water Resources Research 26:2127-2134

Nuttle, W.K., and Harvey J.W. 1995. Fluxes of water and solute in a coastal wetland sediment. 1. The contribution of regional groundwater discharge. Journal of Hydrology 164: 89-107

Osborne, A.M. 2006. Movement of water within the Waikanae shallow gravel aquifer and its interaction with the Waikanae River. Unpublished MSc thesis, School of Geography, Environmental and Earth Sciences, Victoria University of Wellington. Wellington. $160 p$

Palacky, G.J. 1993. Use of airborne electromagnetic methods for resource mapping. Advances in space research 13 (11):5-14

Ranjan, S.P., Kazama, S., and Sawamoto, M. 2006. Effects of climate and land use changes on groundwater resources in coastal aquifers. Journal of Environmental Management 80: 25-35

Reilly, T.E., Goodman, A.S. 1987. Analysis of saltwater upconing beneath a pumping well. Journal of Hydrology 89: 169-204.

Richter, B.C., and Kreitler, C.W. 1993. Groundwater techniques for identifying sources of groundwater salinization. CRC Press, Boca Raton. 258p

Rosen, M.R. 2001. Hydrochemistry of New Zealand's aquifers. In: M.R. Rosen and P.A. White (Eds), Groundwaters of New Zealand. The Caxton Press. Christchurch, New Zealand. 77-110. 
Schwartz, F.W. and Zhang, H. 2003. Fundamentals of Groundwater. John Wiley \& Sons, New York, United States. 592p.

Sophocleous, M. 2002. Interactions between groundwater and surface water: the state of the science. Hydrogeology Journal 10(1): 52-67.

Sherif, M., El Mahmoudi A., Garamoon, H., Kacimov, A., Akram, S. Ebraheem, A., Shetty, A. 2006. Geoelectrical and hydrgeochemical studies for delineating seawater intrusion in the outlet of Wadi Ham, UAE. Environmental Geology 49: 536-551.

Siemon B. 2006. Electromagnetic methods - frequency domain. In: R. Kirsch (ed) Groundwater geophysics: A tool for hydrogeology. Springer, Berlin. 493p

Song, S-H., Lee, J-Y., and Park, N. 2007. Use of vertical electrical soundings to delineate seawater intrusion in a coastal area of Byunsan, Korea. Environmental Geology 52: $1207-1219$

Stewart, M.T. 1999. Geophysical Investigations. In: Bear, J., et al., (eds). Seawater intrusion in coastal aquifers - concepts, methods and practices. Kluwer Academic Publishers, Dordrecht, $640 \mathrm{pp}$.

Strack, O.D.L. 1976. A single-potential solution for regional interface problems in coastal aquifers. Water Resources Research 12(6): 1165-1174

Te Punga, M.T. 1952: The geology of the Rangitikei Valley. Department of Scientific and Industrial Research, New Zealand Geological Survey Memoir 8. Wellington, New Zealand.

Todd, D.K. and Mays, L.W. 2005. Groundwater Hydrology. Third Edition. John Wiley and Sons, Inc., Hoboken, New Jersey, United States. 336p.

Toth, J. 1962. A theory of groundwater motion in small drainage basins in Central Alberta, Canada. Journal of Geophysical Research 67(11): 4375 - 4387.

Toth, J. 1963. A theoretical analysis of groundwater flow in small drainage basins. Journal of Geophysical Research 67(16): 4795 - 4812.

Thamdrup, B. 2000. Microbial manganese and iron reduction in aquatic sediments. Advances in Microbial Ecology, 16:41-84

Trefry, M.G., Svensson, T.J.A., and Davis G.B. 2007.Hypoaigic influences on groundwater flux to a seasonally saline river. Journal of Hydrology 335: 330-353.

Watson, S.J., Barry, D.A., Schotting R.J., and Hassanizadeh S.M. 2002. Validation of classical density-dependent solute transport theory for stable, high-concentration-gradient brine displacements in coarse and medium sands. Advances in Water Resources 25: $611-635$

Westbrook, S.J., Rayner, J.L., Davis, G.B., Clement, T.P., Bjerg, P.L., Fisher, S.J. 2005. Interaction between shallow groundwater, saline surface water and contaminant discharge at a seasonally- and tidally-forced estuarine boundary. Journal of Hydrology 302: 255-269.

Wicks, C.M., Herman, J.S., Randazzo, A.F., and Jee, J.L. 1995. Water-rock interactions in a modern coastal mixing zone. Geological Society of America Bulletin 107: 10231032 
Wilson, S.R., Ingham, M. and McConchie, J.A., 2006. The applicability of earth resisivity methods for saline interface definition. Journal of Hydrology 316: 301-312.

Winter, T.C., Harvey, J.W., Frank, O.L., and Alley, W.M. 1998. Ground water and surface water: a single resource. U.S. Geological Survey Circular 1139.

Yadav, G.S. and Abolfazli, H. 1998. Geoelectrical soundings and their relationship to hydraulic parameters in semiarid regions of Jalore, northwestern India. Journal of Applied Geophysics 39(1): 35-51.

Younger, P. L. 2007. Groundwater in the Environment: an introduction. Malden, MA, Blackwell Publishing. 318p. 
Appendix 1.

Hydrochemistry 
Client: Victoria University

Address: $P$ O Box 600 ,

Wellington

Contact: Jack McConchie
Laboratory No: 467284

Date Registered: 26/10/2007

Date Completed: 8/11/2007

Page Number: 1 of 3

\section{Client's Reference: Desiree Craig-Saline Samples}

The results for the analyses you requested are as follows:

Sample Type: Water,

\begin{tabular}{|l|c|c|c|c|c|c|}
\hline Sample Name & Lab No & $\begin{array}{c}\mathrm{pH} \\
\text { (pH units) }\end{array}$ & $\begin{array}{c}\text { Total Alkalinity } \\
\text { (g.m-3 as } \\
\text { CaCO3) }\end{array}$ & $\begin{array}{c}\text { Dissolved } \\
\text { Calcium } \\
\text { (g.m-3) }\end{array}$ & $\begin{array}{c}\text { Dissolved } \\
\text { Magnesium } \\
\text { (g.m-3) }\end{array}$ & $\begin{array}{c}\text { Dissolved } \\
\text { Sodium } \\
\text { (g.m-3) }\end{array}$ \\
\hline 5 Punga 24/10/07 15:30 & $467284 / 1$ & 7.8 & 338 & 70 & 27.1 & 34.5 \\
\hline 5 Nuku 24/10/07 14:30 & $467284 / 2$ & 7.6 & 278 & 85 & 10.5 & 24.9 \\
\hline 5 Kouru 24/10/07 12:00 & $467284 / 3$ & 7.7 & 291 & 81 & 9.6 & 39.4 \\
\hline $\begin{array}{l}47 \text { Punga 24/10/07 } \\
\text { 13:00 }\end{array}$ & $467284 / 4$ & 7.6 & 284 & 78 & 11.1 & 36.8 \\
\hline 322011 24/10/07 & $467284 / 5$ & 7.8 & 182 & 46 & 7.6 & 17.4 \\
\hline 332033 24/10/07. 11:30 & $467284 / 6$ & 6.8 & 54 & 14 & 4.3 & 13.0 \\
\hline
\end{tabular}

\begin{tabular}{|l|c|c|c|c|c|c|}
\hline Sample Name & Lab No & $\begin{array}{c}\text { Dissolved } \\
\text { Potassium } \\
\text { (g.m-3) }\end{array}$ & $\begin{array}{c}\text { Nitrate-N + } \\
\text { Nitrite-N (TON) } \\
(\mathbf{g} \cdot \mathbf{m}-3)\end{array}$ & $\begin{array}{c}\text { Nitrate-N } \\
\text { (g.m-3) }\end{array}$ & $\begin{array}{c}\text { Nitrite-N } \\
\text { (g.m-3) }\end{array}$ & $\begin{array}{c}\text { Chloride } \\
\text { (g.m-3) }\end{array}$ \\
\hline 5 Punga 24/10/07 15:30 & $467284 / 1$ & 9 & 0.003 & 0.002 & $<0.002$ & 74.1 \\
\hline 5 Nuku 24/10/07 14:30 & $467284 / 2$ & 10 & 1.43 & 1.38 & 0.051 & 42.7 \\
\hline 5 Kouru 24/10/07 12:00 & $467284 / 3$ & 5 & $<0.002$ & $<0.002$ & $<0.002$ & 67.1 \\
\hline $\begin{array}{l}47 \text { Punga 24/10/07 } \\
\text { 13:00 }\end{array}$ & $467284 / 4$ & 5 & 0.019 & 0.019 & $<0.002$ & 63.5 \\
\hline $32201124 / 10 / 07$ & $467284 / 5$ & 4 & 0.043 & 0.043 & $<0.002$ & 28.9 \\
\hline $33203324 / 10 / 0711: 30$ & $467284 / 6$ & 3 & 0.850 & 0.848 & 0.002 & 28.5 \\
\hline
\end{tabular}

\begin{tabular}{|l|c|c|c|c|c|c|}
\hline Sample Name & Lab No & $\begin{array}{c}\text { Bromide } \\
\text { (g.m-3) }\end{array}$ & $\begin{array}{c}\text { Sulphate } \\
\text { (g.m-3) }\end{array}$ & $\begin{array}{c}\text { Dissolved } \\
\text { Boron } \\
\text { (g.m-3) }\end{array}$ & $\begin{array}{c}\text { Dissolved Iron } \\
\text { (g.m-3) }\end{array}$ & $\begin{array}{c}\text { Dissolved } \\
\text { Manganese } \\
\text { (g.m-3) }\end{array}$ \\
\hline 5 Punga 24/10/07 15:30 & $467284 / 1$ & 0.21 & $<0.5$ & 0.12 & 2.25 & 0.555 \\
\hline 5 Nuku 24/10/07 14:30 & $467284 / 2$ & 0.19 & 18.9 & 0.07 & 0.014 & 0.065 \\
\hline 5 Kouru 24/10/07 12:00 & $467284 / 3$ & 0.22 & $<0.5$ & $<0.04$ & 1.73 & 0.934 \\
\hline $\begin{array}{l}47 \text { Punga 24/10/07 } \\
\text { 13:00 }\end{array}$ & $467284 / 4$ & 0.20 & 0.9 & 0.04 & 1.93 & 0.950 \\
\hline 322011 24/10/07 & $467284 / 5$ & 0.08 & 2.0 & 0.05 & 1.41 & 0.513 \\
\hline 332033 24/10/07 11:30 & $467284 / 6$ & $<0.05$ & 6.5 & $<0.04$ & 0.758 & 0.128 \\
\hline
\end{tabular}

365 This Laboratory is accredited by International Accreditation New Zealand (IANZ), which represents New Zealand in the International aboratory ACcreditation Cooperation (ILAC). Through the ILAC Mutual Recognition Arrangement (ILAC-MRA) this accreditation is internationally recognised. 


\begin{tabular}{|l|l|c|}
\hline Sample Name & Lab No & $\begin{array}{c}\text { Dissolved Strontium } \\
\text { (g.m-3) }\end{array}$ \\
\hline 5 Punga 24/10/07 15:30 & $467284 / 1$ & 0.474 \\
\hline 5 Nuku 24/10/07 14:30 & $467284 / 2$ & 0.447 \\
\hline 5 Kouru 24/10/07 12:00 & $467284 / 3$ & 0.616 \\
\hline $\begin{array}{l}47 \text { Punga 24/10/07 } \\
\text { 13:00 }\end{array}$ & $467284 / 4$ & 0.498 \\
\hline 322011 24/10/07 & $467284 / 5$ & 0.314 \\
\hline 332033 24/10/07 11:30 & $467284 / 6$ & 0.0913 \\
\hline
\end{tabular}

\section{Sample Containers}

The following table shows the sample containers that were associated with this job.

\begin{tabular}{|l|c|c|}
\hline Container Description & Container Size $(\mathrm{mL})$ & Number of Containers \\
\hline Unpreserved $(250 \mathrm{~mL})$ & 250 & 6 \\
\hline Filtered, Nitric preserved $(100 \mathrm{~mL})$ & 100 & 6 \\
\hline
\end{tabular}

Details of sample bottle preparation procedures are available upon request.

\section{Summary of Methods Used and Detection Limits}

The following table(s) gives a brief description of the methods used to conduct the analyses for this job.

The detection limits given below are those attainable in a relatively clean matrix. Detection limits may be higher for individual samples should insufficient sample be available, or if the matrix requires that dilutions be performed during analysis

\section{Substance Type: Water}

\begin{tabular}{|c|c|c|}
\hline Parameter & Method Used & Detection Limit \\
\hline Sample filtration for general testing & Sample filtration through $0.45 \mu \mathrm{m}$ membrane filter. & N/A \\
\hline $\mathrm{pH}$ & Saline sample. pH meter APHA 4500- $\mathrm{H}^{+}$B $21^{2}$ ed. 2005. & $0.1 \mathrm{pH}$ units \\
\hline Total Alkalinity & Saline sample. Titration to $\mathrm{pH} 4.5$. & $1 \mathrm{~g} \cdot \mathrm{m}-3$ as $\mathrm{CaCO} 3$ \\
\hline Dissolved Calcium & $\begin{array}{l}\text { Saline sample (Filtered); ICP-MS. Ultratrace method. APHA } 3125 \\
\text { B } 21^{\text {th }} \text { ed. } 2005 \text {. }\end{array}$ & $1 \mathrm{~g} \cdot \mathrm{m}-3$ \\
\hline Dissolved Magnesium & $\begin{array}{l}\text { Saline sample (Filtered). ICP-MS. Uitratrace method. APHA } 3125 \\
\text { B } 21^{\text {t5 }} \text { ed. } 2005 \text {. }\end{array}$ & $0.4 \mathrm{~g} \cdot \mathrm{m}-3$ \\
\hline Dissolved Sodium & $\begin{array}{l}\text { Saline sample (Filtered). ICP-MS. Ultratrace method. APHA } 3125 \\
\text { B } 21^{\text {t }} \text { ed. } 2005 \text {. }\end{array}$ & $0.4 \mathrm{~g} \cdot \mathrm{m}-3$ \\
\hline Dissolved Potassium & $\begin{array}{l}\text { Saline sample (Filtered). ICP-MS. Ultratrace method. APHA } 3125 \\
\text { B } 21^{\text {st }} \text { ed. } 2005 \text {. }\end{array}$ & $1 \mathrm{~g} \cdot \mathrm{m}-3$ \\
\hline Nitrate-N + Nitrite-N (TON) & $\begin{array}{l}\text { Saline sample. Total oxidised nitrogen. Automated cadmium } \\
\text { reduction, Flow injection analyser. APHA } 4500-\mathrm{NO}_{3}^{\prime} 1 \text { (modified) } 21^{\text {st }} \\
\text { ed. } 2005 \text {. }\end{array}$ & $0.002 \mathrm{~g} \cdot \mathrm{m}-3$ \\
\hline Nitrate- $\mathrm{N}$ & Saline sample. Calculation: (Nitrate-N + Nitrite-N) - Nitrite-N. & $0.002 \mathrm{~g} \cdot \mathrm{m}-3$ \\
\hline Nitrite-N & $\begin{array}{l}\text { Saline sample. Automated Azo dye colorimetry, Flow injection } \\
\text { analyser. APHA 4500-NO; I (modified) } 21^{\text {st }} \text { ed. } 2005 \text {. }\end{array}$ & $0.002 \mathrm{~g} \cdot \mathrm{m}-3$ \\
\hline Chloride & $\begin{array}{l}\text { Filtered sample. Ferric thiocyanate colorimetry. Discrete Analyser. } \\
\text { APHA } 4500-\mathrm{Cl} \text { E (modified from continuous-flow analysis) } 21^{16} \text { ed. } \\
2005 \text {. }\end{array}$ & $0.5 \mathrm{~g} \cdot \mathrm{m} \cdot 3$ \\
\hline Bromide & Filtered sample. Ion Chromatography. APHA 4110 B $21^{\text {s }}$ ed. 2005. & $0.05 \mathrm{~g} \cdot \mathrm{m}-3$ \\
\hline Sulphate & Filtered sample. Ion Chromatography. APHA 4110 B $21^{\text {st }}$ ed. 2005. & $0.5 \mathrm{~g} \cdot \mathrm{m}-3$ \\
\hline Dissolved Boron & $\begin{array}{l}\text { Saline sample (Filtered). ICP-MS. Ultratrace method. APHA } 3125 \\
\text { B } 21^{\circ t} \text { ed. } 2005 \text {. }\end{array}$ & $0.04 \mathrm{~g} \cdot \mathrm{m}-3$ \\
\hline Dissolved Iron & $\begin{array}{l}\text { Saline sample (Filtered). ICP-MS. Ultratrace with dynamic reaction } \\
\text { cell. APHA } 3125 \mathrm{~B} 21^{5} \text { ed. } 2005 \text {. }\end{array}$ & $0.004 \mathrm{~g} \cdot \mathrm{m}-3$ \\
\hline Dissolved Manganese & $\begin{array}{l}\text { Saline sample (Filtered). ICP-MS. Ultratrace with dynamic reaction } \\
\text { cell. APHA } 3125 \text { B } 21^{13} \text { ed. } 2005 \text {. }\end{array}$ & $0.001 \mathrm{~g} \cdot \mathrm{m}-3$ \\
\hline Dissolved Strontium & $\begin{array}{l}\text { Saline sample (Filtered). ICP-MS. Ultratrace method. APHA } 3125 \\
\text { B } 21^{\text {st }} \text { ed. } 2005 \text {. }\end{array}$ & 0.0002 g.m-3 \\
\hline
\end{tabular}




\section{Analyst's Comments:}

These samples were collected by yourselves and analysed as received at the laboratory.

Samples are held at the laboratory after reporting for a length of time depending on the preservation used and the stability of the analytes being tested. Once the storage period is completed the samples are discarded unless otherwise advised by the submitter.

This report must not be reproduced, except in full, without the written consent of the signatory.

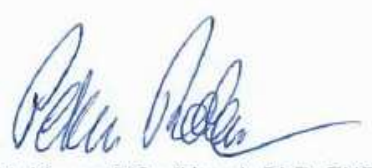

Peter Robinson MSc (Hons), PhD, FNZIC

Client Services Manager - Environmental Division
Graham Corban MSc Tech (Hons) Client Services Manager - Environmental Division 


ANALYSISREPORTRPage 1 of 2

\begin{tabular}{|c|c|c|c|c|c|c|c|}
\hline $\begin{array}{l}\text { Client: } \\
\text { Contact: }\end{array}$ & \multicolumn{2}{|c|}{$\begin{array}{l}\text { Victoria University } \\
\text { McConchie, Jack } \\
\text { clo Victoria University } \\
\text { P O Box } 600 \\
\text { Wellington }\end{array}$} & & \multicolumn{2}{|c|}{$\begin{array}{l}\text { Lab No: } \\
\text { Date Registered: } \\
\text { Date Reported: } \\
\text { Quote No: } \\
\text { Order No: } \\
\text { Client Reference: } \\
\text { Submitted By: }\end{array}$} & $\begin{array}{l}\text { 618540 } \\
\text { 08-Nov-2007 } \\
\text { 20-Nov-2007 } \\
\\
\text { Desiree Craig- } \\
\text { McConchie, Ja }\end{array}$ & SPV1 \\
\hline \multicolumn{8}{|c|}{ Sample Type: Ground Water } \\
\hline & & Sample Name: & $\begin{array}{l}27 \text { SF } 1941 \\
\text { 05-Nov-2007 } \\
12: 20 \mathrm{pm}\end{array}$ & $\begin{array}{c}\text { 1S Ferry } \\
05-\text { Nov-2007 } \\
12: 00 \mathrm{pm}\end{array}$ & $\begin{array}{c}322030 \\
\text { 05-Nov-2007 1:40 } \\
\text { pm }\end{array}$ & $\begin{array}{c}\text { Anderson } \\
\text { 05-Nov-2007 2:30 } \\
\text { pm }\end{array}$ & \\
\hline & & Lab Number: & 618540.1 & 618540.2 & 618540.3 & 618540.4 & \\
\hline $\mathrm{pH}$ & & pHUnits & 7.5 & 8.0 & 7.5 & 7.7 & $\cdot$ \\
\hline Total Alkalini & & $\mathrm{g} / \mathrm{m}^{3}$ as $\mathrm{CaCO}_{3}$ & 240 & 130 & 130 & 280 & - \\
\hline Bicarbonate ${ }^{*}$ & & $\mathrm{~g} / \mathrm{m}^{3}$ at $25^{\circ} \mathrm{C}$ & 290 & 160 & 160 & 340 & $\cdot$ \\
\hline Dissolved Bo & & $g / m^{3}$ & 0.070 & 0.045 & 0.049 & 0.065 & - \\
\hline Dissolved $\mathrm{Ca}$ & alcium & $g^{\prime} \mathrm{m}^{3}$ & 64 & 32 & 29 & 69 & - \\
\hline Dissolved Iro & & $\mathrm{g} / \mathrm{m}^{3}$ & 2.8 & 0.45 & 1.5 & 3.5 & - \\
\hline Dissolved $M_{c}$ & agnesium & $g / m^{3}$ & 12 & 7.4 & 11 & 14 & - \\
\hline Dissolved $M=$ & anganese & $\mathrm{g} / \mathrm{m}^{3}$ & 0.78 & 0.37 & 0.76 & 0.41 & - \\
\hline Dissolved Po & tassium & $\mathrm{g} / \mathrm{m}^{3}$ & 5.2 & 3.2 & 2.7 & 4.5 & - \\
\hline Dissolved So & dium & $\mathrm{g} / \mathrm{m}^{3}$ & 35 & 14 & 16 & 51 & - \\
\hline Dissolved St & rontium & $\mathrm{g} / \mathrm{m}^{3}$ & 0.44 & 0.22 & 0.21 & 0.50 & - \\
\hline Bromide & & $\mathrm{g} / \mathrm{m}^{3}$ & 0.24 & 0.050 & 0.050 & 0.25 & - \\
\hline Chloride & & $g / m^{3}$ & 50 & 16 & 15 & 61 & - \\
\hline Nitrite-N & & $g^{\prime} / \mathrm{m}^{3}$ & $<0.0020$ & $<0.0020$ & $<0.0020$ & $<0.0020$ & - \\
\hline Nitrate-N & & $\mathrm{g} / \mathrm{m}^{3}$ & $<0.0020$ & $<0.0020$ & $<0.0020$ & $<0.0020$ & - \\
\hline Nitrate- $\mathrm{N}+\mathrm{N}$ & Sitrite-N & $\mathrm{g} / \mathrm{m}^{3}$ & $<0.0020$ & $<0.0020$ & $<0.0020$ & $<0.0020$ & - \\
\hline Sulphate & & $\mathrm{g} / \mathrm{m}^{3}$ & 0.78 & 8.8 & 11 & 10 & - \\
\hline
\end{tabular}

${ }^{365}$ This Laboratory is accredited by Internationel Accreditation New Zealand (ANZ), which represents New Zealand in the International (II) Laboratory Accreditation

internationally recognised. are not accredited 


\section{SUMMARY OF METHODS}

The folowing table(s) gives a briet description of the metheds used to conduct the analyses for this job. The detection ilmits given below are those altainable in a relatively clean matrix

\begin{tabular}{|c|c|c|c|}
\hline Test & Method Description & Default Detection Limit & Samples \\
\hline Filtration, Unpreserved & Sample filtration through $0.45 \mu \mathrm{m}$ membrane filter. & $\cdot$ & $1-4$ \\
\hline $\mathrm{pH}$ & pH meter. APHA 4500-H+ B 21 12t ed. 2005. & $0.1 \mathrm{pH}$ Units & $1-4$ \\
\hline Total Alkalinity & $\begin{array}{l}\text { Titration to } \mathrm{pH} 4.5 \text { (M-alkalinity), autotitrator. APHA } 2320 \text { B } \\
\text { (Modified for alk }<20 \text { ) } 21^{\text {st }} \text { ed. } 2005 \text {. }\end{array}$ & $1.0 \mathrm{~g}^{3} \mathrm{~m}^{3}$ as $\mathrm{CaCO}_{3}$ & $1-4$ \\
\hline Bicarbonatet & $\begin{array}{l}\text { Calculation: from alkalinity and pH, valid where TDS is not > } \\
500 \mathrm{mg} / \mathrm{L} \text { and alkalinity is almost entirely due to hydroxides, } \\
\text { carbonates or bicarbonates. } \\
\text {. APHA } 4500-\mathrm{CO}_{2} \mathrm{D} 21^{\text {tt }} \text { ed. } 2005 \text {. }\end{array}$ & $1.0 \mathrm{~g} / \mathrm{m}^{3}$ at $25^{\circ} \mathrm{C}$ & $1-4$ \\
\hline Dissolved Boron & $\begin{array}{l}\text { Filtered sample, ICP-MS, trace level. APHA } 3125 \text { B 21:i ed. } \\
2005 .\end{array}$ & $0.0050 \mathrm{~g} / \mathrm{m}^{3}$ & $1-4$ \\
\hline Dissolved Calcium & $\begin{array}{l}\text { Filtered sample, ICP-MS, trace level. APHA } 3125 \text { B 21"ll ed. } \\
2005 .\end{array}$ & $0.050 \mathrm{~g} / \mathrm{m}^{3}$ & $1-4$ \\
\hline Dissolved Iron & $\begin{array}{l}\text { Filtered sample, ICP-MS, trace level. APHA } 3125 \text { B } 21^{\text {tl }} \text { ed. } \\
2005 .\end{array}$ & $0.020 \mathrm{~g} / \mathrm{m}^{3}$ & $1-4$ \\
\hline Dissolved Magnesium & $\begin{array}{l}\text { Filtered sample, ICP-MS, trace level. APHA } 3125 \text { B } 21^{\text {st }} \text { ed, } \\
2005 .\end{array}$ & $0.020 \mathrm{~g} / \mathrm{m}^{3}$ & $1-4$ \\
\hline Dissolved Manganese & $\begin{array}{l}\text { Filtered sample, ICP-MS, trace level. APHA } 3125 \text { B } 21^{\text {st }} \text { ed. } \\
2005 .\end{array}$ & $0.00050 \mathrm{~g} / \mathrm{m}^{3}$ & $1-4$ \\
\hline Dissolved Potassium & $\begin{array}{l}\text { Filtered sample, ICP-MS, trace level. APHA } 3125 \text { B } 21^{\text {st }} \text { od. } \\
2005 \text {. }\end{array}$ & $0.050 \mathrm{~g} / \mathrm{m}^{3}$ & $1-4$ \\
\hline Dissolved Sodium & $\begin{array}{l}\text { Filtered sample, ICP-MS, trace level. APHA } 3125 \text { B } 21^{\text {st }} \text { ed. } \\
2005 .\end{array}$ & $0.020 \mathrm{~g} / \mathrm{m}^{3}$ & $1-4$ \\
\hline Dissolved Strontium & $\begin{array}{l}\text { Filtered sample, ICP-MS, trace level. APHA } 3125 \text { B } 21^{\text {st }} \text { ed. } \\
2005 \text {. }\end{array}$ & $0.00050 \mathrm{~g} / \mathrm{m}^{3}$ & $1-4$ \\
\hline Bromide & $\begin{array}{l}\text { Filtered sample. Ion Chromatography. APHA } 4110 \text { B } 21^{\text {st }} \text { ed. } \\
2005 .\end{array}$ & $0.050 \mathrm{~g} / \mathrm{m}^{3}$ & $1-4$ \\
\hline Chloride & $\begin{array}{l}\text { Filtered sample. Ferric thiocyanate colorimetry. Discrete } \\
\text { Analyser. APHA } 4110 \mathrm{Cr} E \text { (modified from continuous flow } \\
\text { analysis) } 21^{\text {st }} \text { ed. } 2005 \text {. }\end{array}$ & $0.50 \mathrm{~g} / \mathrm{m}^{3}$ & $1-4$ \\
\hline Nitrite-N & $\begin{array}{l}\text { Automated } \mathrm{Azo}_{\text {dye colorimetry, Flow injection analyser. }} \\
\text { APHA 4500-NO }{ }_{3}^{-1} \text { I (Proposed) } 21^{\text {st }} \text { ed. } 2005 \text {. }\end{array}$ & $0.0020 \mathrm{~g} / \mathrm{m}^{3}$ & $1-4$ \\
\hline Nitrate- $\mathrm{N}$ & Calculation: (Nitrate-N + Nitrite-N) - NO2N. & $0.0020 \mathrm{~g} / \mathrm{m}^{3}$ & $1-4$ \\
\hline Nitrate $-\mathrm{N}+$ Nitrite- $\mathrm{N}$ & $\begin{array}{l}\text { Total oxidised nitrogen. Automated cadmium reduction, flow } \\
\text { injection analyser. APHA } 4500-\mathrm{NO}_{3} \text { I I (Proposed) } 21^{\text {t5 }} \text { ed. } \\
2005 \text {. }\end{array}$ & $0.0020 \mathrm{~g} / \mathrm{m}^{3}$ & $1-4$ \\
\hline Sulphate & $\begin{array}{l}\text { Filtered sample. Ion Chromatography. APHA } 4110 \text { B } 21^{\text {st }} \text { ed. } \\
2005 \text {. }\end{array}$ & $0.50 \mathrm{~g} / \mathrm{m}^{3}$ & $1-4$ \\
\hline
\end{tabular}

These samples were collected by yourselves (or your agent) and analysed as received at the laboratory.

Samples are held at the laboratory after reporting for a length of time depending on the preservation used and the stability of the analytes being tested. Once the storage period is completed the samples are discarded unless otherwise advised by the client.

This report must not be reproduced, except in full, without the written consent of the signatory.

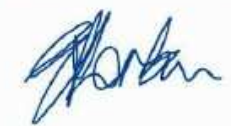

Graham Corban MSc Tech (Hons)

Client Services Manager - Environmental Division 


Sample ID
Sample Date
Station
Bore Depth
Watertype
Temperature $\left({ }^{\circ} \mathrm{C}\right)$
pH
Conductivity
Sum of Anions
Sum of Cations
Balance
Total dissolved solids
Total hardness
Alkalinity
Major ion composition
$\mathrm{Na}$
$\mathrm{K}$
$\mathrm{Ca}$
$\mathrm{Mg}$
$\mathrm{Cl}$
$\mathrm{SO} 4$
$\mathrm{NO} 3$
$\mathrm{HCO} 3$

Sample ID

Sample Date

Station

C1

10/24/2007

322011

$10 \mathrm{~m}$

$\mathrm{Ca}-\mathrm{HCO} 3$

14.80

7.80

$444.00 \mathrm{uS} / \mathrm{cm}$

4.50meq/L

$3.81 \mathrm{meq} / \mathrm{L}$

$-8.36 \%$

$330.23 \mathrm{mg} / \mathrm{L}$

$146.18 \mathrm{mg} / \mathrm{I} \mathrm{CaCO} 3$

$182.00 \mathrm{mg} / \mathrm{I} \mathrm{CaCO} 3$

$\begin{array}{rrr}\mathrm{mg} / \mathrm{l} & \mathrm{mmol} / \mathrm{l} & \mathrm{meq} / \mathrm{l} \\ 17.40 & 0.76 & 0.76 \\ 4.00 & 0.102 & 0.102 \\ 46.00 & 1.15 & 2.30 \\ 7.60 & 0.31 & 0.63 \\ 28.90 & 0.82 & 0.82 \\ 2.00 & 0.02 & 0.04 \\ 0.04 & 0.00 & 0.00 \\ 221.91 & 3.64 & 3.64\end{array}$

Comparison to Seawater

Ratios

$\mathrm{Ca} / \mathrm{Mg}$

$\mathrm{Ca} / \mathrm{SO} 4$

$\mathrm{Na} / \mathrm{Cl}$

$\mathrm{Cl} / \mathrm{Br}$

$\begin{array}{rrrr}\mathrm{mg} / \mathrm{l} & \mathrm{mmol} / \mathrm{l} & \mathrm{mg} / \mathrm{l} & \mathrm{mmol} / \mathrm{l} \\ 6.05 & 3.67 & 0.319 & 0.194 \\ 23.00 & 55.09 & 0.152 & 0.364 \\ 0.60 & 0.93 & 0.556 & 0.858 \\ 361 & 814 & 287 & 648\end{array}$


C2 Summary Report

\begin{tabular}{|c|c|c|c|c|}
\hline Sample ID & \multicolumn{2}{|c|}{ Location } & \multicolumn{2}{|c|}{ E2700929 N6098107 \pm 5m } \\
\hline Sample Date & \multicolumn{4}{|l|}{$10 / 24 / 2007$} \\
\hline Station & \multicolumn{4}{|l|}{332033} \\
\hline Bore Depth & \multicolumn{4}{|l|}{$10 \mathrm{~m}$} \\
\hline Watertype & \multicolumn{4}{|l|}{$\mathrm{Ca}-\mathrm{Na}-\mathrm{HCO} 3-\mathrm{Cl}$} \\
\hline Temperature $\left({ }^{\circ} \mathrm{C}\right)$ & \multicolumn{4}{|l|}{14.40} \\
\hline $\mathrm{pH}$ & \multicolumn{4}{|c|}{6.80} \\
\hline Conductivity & \multicolumn{4}{|c|}{$224.00 \mathrm{uS} / \mathrm{cm}$} \\
\hline Sum of Anions & \multicolumn{4}{|c|}{$2.04 \mathrm{meq} / \mathrm{L}$} \\
\hline Sum of Cations & \multicolumn{4}{|c|}{ 1.70meq/L } \\
\hline Balance & \multicolumn{4}{|c|}{$-8.96 \%$} \\
\hline Total dissolved solids & \multicolumn{4}{|c|}{$137.06 \mathrm{mg} / \mathrm{L}$} \\
\hline Total hardness & \multicolumn{4}{|c|}{$52.67 \mathrm{mg} / \mathrm{I} \mathrm{CaCO} 3$} \\
\hline Alkalinity & \multicolumn{4}{|c|}{$54.00 \mathrm{mg} / \mathrm{I} \mathrm{CaCO} 3$} \\
\hline Major ion composition & $\mathrm{mg} / \mathrm{l}$ & $\mathrm{mmol} / \mathrm{l}$ & $\mathrm{meq} / \mathrm{l}$ & \\
\hline $\mathrm{Na}$ & 13.00 & 0.57 & 0.57 & \\
\hline K & 3.00 & 0.077 & 0.077 & \\
\hline $\mathrm{Ca}$ & 14.00 & 0.35 & 0.70 & \\
\hline $\mathrm{Mg}$ & 4.30 & 0.18 & 0.35 & \\
\hline $\mathrm{Cl}$ & 28.50 & 0.80 & 0.80 & \\
\hline SO4 & 6.50 & 0.07 & 0.14 & \\
\hline N03 & 0.85 & 0.01 & 0.01 & \\
\hline \multirow[t]{2}{*}{$\mathrm{HCO} 3$} & 65.84 & 1.08 & 1.08 & \\
\hline & & \multicolumn{3}{|c|}{ Comparison to Seawater } \\
\hline Ratios & $\mathrm{mg} / \mathrm{l}$ & $\mathrm{mmol} / \mathrm{l}$ & $\mathrm{mg} / \mathrm{l}$ & $\mathrm{mmol} / \mathrm{l}$ \\
\hline $\mathrm{Ca} / \mathrm{Mg}$ & 3.26 & 1.97 & 0.319 & 0.194 \\
\hline $\mathrm{Ca} / \mathrm{SO} 4$ & 2.15 & 5.16 & 0.152 & 0.364 \\
\hline $\mathrm{Na} / \mathrm{Cl}$ & 0.46 & 0.70 & 0.556 & 0.858 \\
\hline $\mathrm{Cl} / \mathrm{Br}$ & 570 & 1285 & 287 & 648 \\
\hline
\end{tabular}


C3 Summary Report

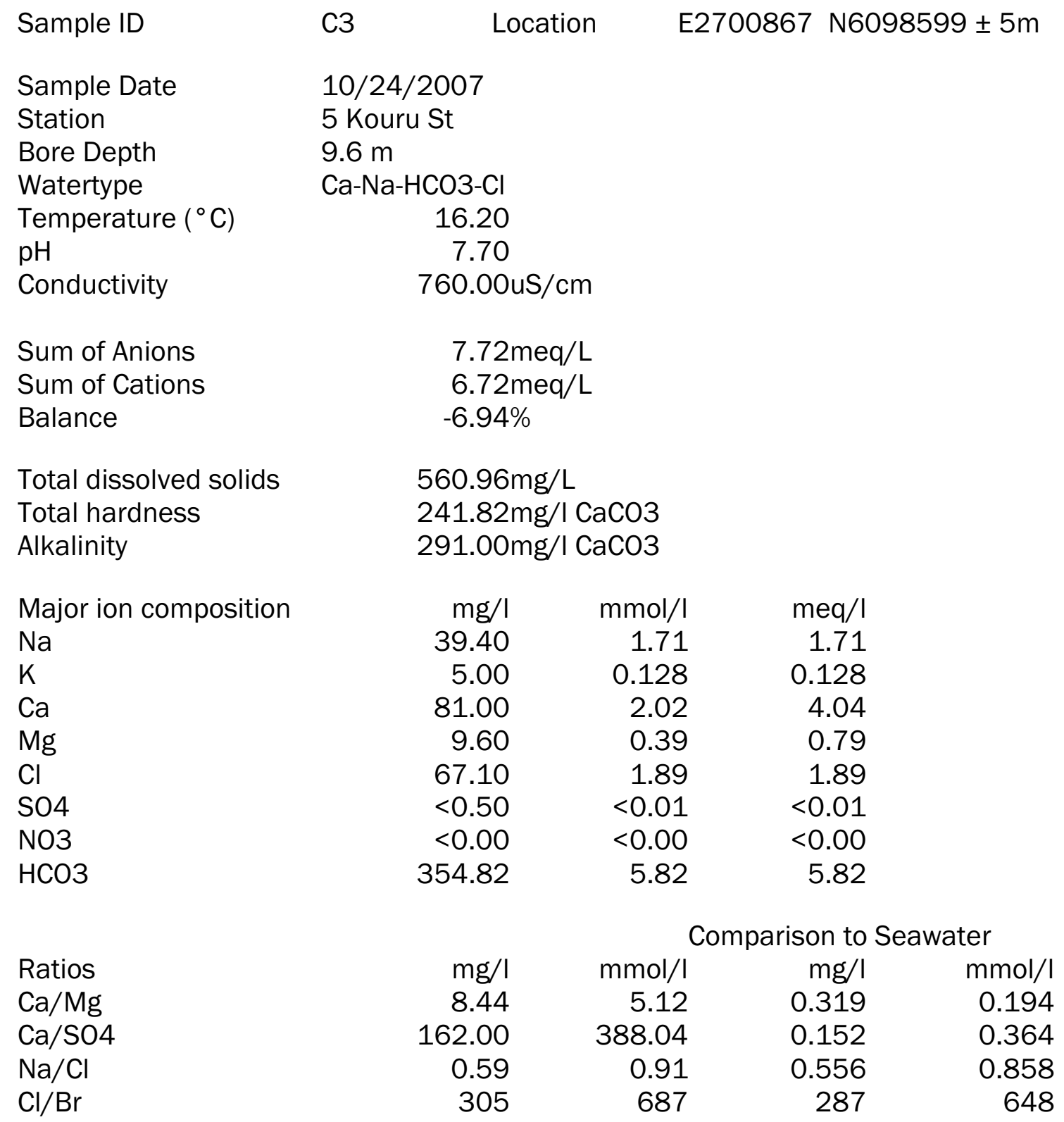


C4 Summary Report

\begin{tabular}{|c|c|c|c|c|}
\hline Sample ID & \multicolumn{2}{|c|}{ Location } & \multicolumn{2}{|c|}{ E2700936 N6098482 $\pm 5 m$} \\
\hline Sample Date & \multicolumn{4}{|l|}{$10 / 24 / 2007$} \\
\hline Station & \multicolumn{4}{|l|}{47 Punga St } \\
\hline Bore Depth & \multicolumn{4}{|l|}{$8.5 \mathrm{~m}$} \\
\hline Watertype & \multicolumn{4}{|l|}{$\mathrm{Ca}-\mathrm{Na}-\mathrm{HCO}-\mathrm{Cl}$} \\
\hline Temperature $\left({ }^{\circ} \mathrm{C}\right)$ & \multicolumn{4}{|l|}{15.80} \\
\hline $\mathrm{pH}$ & \multicolumn{4}{|c|}{7.37} \\
\hline Conductivity & \multicolumn{4}{|c|}{$741.00 \mathrm{uS} / \mathrm{cm}$} \\
\hline Sum of Anions & \multicolumn{4}{|c|}{ 7.49meq/L } \\
\hline Sum of Cations & \multicolumn{4}{|c|}{$6.58 \mathrm{meq} / \mathrm{L}$} \\
\hline Balance & \multicolumn{4}{|c|}{$-6.48 \%$} \\
\hline Total dissolved solids & \multicolumn{4}{|c|}{$545.29 \mathrm{mg} / \mathrm{L}$} \\
\hline Total hardness & \multicolumn{4}{|c|}{$240.51 \mathrm{mg} / \mathrm{I} \mathrm{CaCO} 3$} \\
\hline Alkalinity & \multicolumn{4}{|c|}{ 284.00mg/I CaCO3 } \\
\hline Major ion composition & $\mathrm{mg} / \mathrm{l}$ & mmol/l & meq/l & \\
\hline $\mathrm{Na}$ & 36.80 & 1.60 & 1.60 & \\
\hline K & 5.00 & 0.128 & 0.128 & \\
\hline $\mathrm{Ca}$ & 78.00 & 1.95 & 3.89 & \\
\hline $\mathrm{Mg}$ & 11.10 & 0.46 & 0.91 & \\
\hline $\mathrm{Cl}$ & 63.50 & 1.79 & 1.79 & \\
\hline SO4 & 0.90 & 0.01 & 0.02 & \\
\hline N03 & 0.09 & 0.00 & 0.00 & \\
\hline \multirow[t]{2}{*}{$\mathrm{HCO} 3$} & 346.28 & 5.68 & 5.68 & \\
\hline & & \multicolumn{3}{|c|}{ Comparison to Seawater } \\
\hline Ratios & $\mathrm{mg} / \mathrm{l}$ & $\mathrm{mmol} / \mathrm{l}$ & $\mathrm{mg} / \mathrm{l}$ & $\mathrm{mmol} / \mathrm{l}$ \\
\hline $\mathrm{Ca} / \mathrm{Mg}$ & 7.03 & 4.26 & 0.319 & 0.194 \\
\hline $\mathrm{Ca} / \mathrm{SO} 4$ & 86.67 & 207.60 & 0.152 & 0.364 \\
\hline $\mathrm{Na} / \mathrm{Cl}$ & 0.58 & 0.89 & 0.556 & 0.858 \\
\hline $\mathrm{Cl} / \mathrm{Br}$ & 318 & 716 & 287 & 648 \\
\hline
\end{tabular}


C5 Summary Report

\begin{tabular}{|c|c|c|c|c|}
\hline Sample ID & \multicolumn{2}{|c|}{ Location } & \multicolumn{2}{|c|}{ E2701144 N6099125 土 7m } \\
\hline Sample Date & \multicolumn{4}{|l|}{$10 / 24 / 2007$} \\
\hline Station & \multicolumn{4}{|l|}{5 Nuku St } \\
\hline Bore Depth & \multicolumn{4}{|l|}{$9.1 \mathrm{~m}$} \\
\hline Watertype & \multicolumn{4}{|l|}{$\mathrm{Ca}-\mathrm{HCO} 3$} \\
\hline Temperature $\left({ }^{\circ} \mathrm{C}\right)$ & \multicolumn{4}{|l|}{14.50} \\
\hline $\mathrm{pH}$ & \multicolumn{4}{|c|}{7.60} \\
\hline Conductivity & \multicolumn{4}{|c|}{$695.00 u S / c m$} \\
\hline Sum of Anions & \multicolumn{4}{|c|}{ 7.18meq/L } \\
\hline Sum of Cations & \multicolumn{4}{|c|}{ 6.46meq/L } \\
\hline Balance & \multicolumn{4}{|c|}{$-5.33 \%$} \\
\hline Total dissolved solids & \multicolumn{4}{|c|}{$533.18 \mathrm{mg} / \mathrm{L}$} \\
\hline Total hardness & \multicolumn{4}{|c|}{$255.52 \mathrm{mg} / \mathrm{I} \mathrm{CaCO} 3$} \\
\hline Alkalinity & \multicolumn{4}{|c|}{$278.00 \mathrm{mg} / \mathrm{I} \mathrm{CaCO3}$} \\
\hline Major ion composition & $\mathrm{mg} / \mathrm{l}$ & $\mathrm{mmol} / \mathrm{l}$ & $\mathrm{meq} / \mathrm{l}$ & \\
\hline $\mathrm{Na}$ & 24.90 & 1.08 & 1.08 & \\
\hline K & 10.00 & 0.256 & 0.256 & \\
\hline $\mathrm{Ca}$ & 85.00 & 2.12 & 4.24 & \\
\hline $\mathrm{Mg}$ & 10.50 & 0.43 & 0.86 & \\
\hline $\mathrm{Cl}$ & 42.70 & 1.20 & 1.20 & \\
\hline SO4 & 18.90 & 0.20 & 0.39 & \\
\hline N03 & 1.38 & 0.02 & 0.02 & \\
\hline \multirow[t]{2}{*}{$\mathrm{HCO} 3$} & 338.97 & 5.56 & 5.56 & \\
\hline & & \multicolumn{3}{|c|}{ Comparison to Seawater } \\
\hline Ratios & $\mathrm{mg} / \mathrm{l}$ & $\mathrm{mmol} / \mathrm{l}$ & $\mathrm{mg} / \mathrm{l}$ & $\mathrm{mmol} / \mathrm{l}$ \\
\hline $\mathrm{Ca} / \mathrm{Mg}$ & 8.10 & 4.91 & 0.319 & 0.194 \\
\hline $\mathrm{Ca} / \mathrm{SO} 4$ & 4.50 & 10.77 & 0.152 & 0.364 \\
\hline $\mathrm{Na} / \mathrm{Cl}$ & 0.58 & 0.90 & 0.556 & 0.858 \\
\hline $\mathrm{Cl} / \mathrm{Br}$ & 225 & 507 & 287 & 648 \\
\hline
\end{tabular}


C6 Summary Report

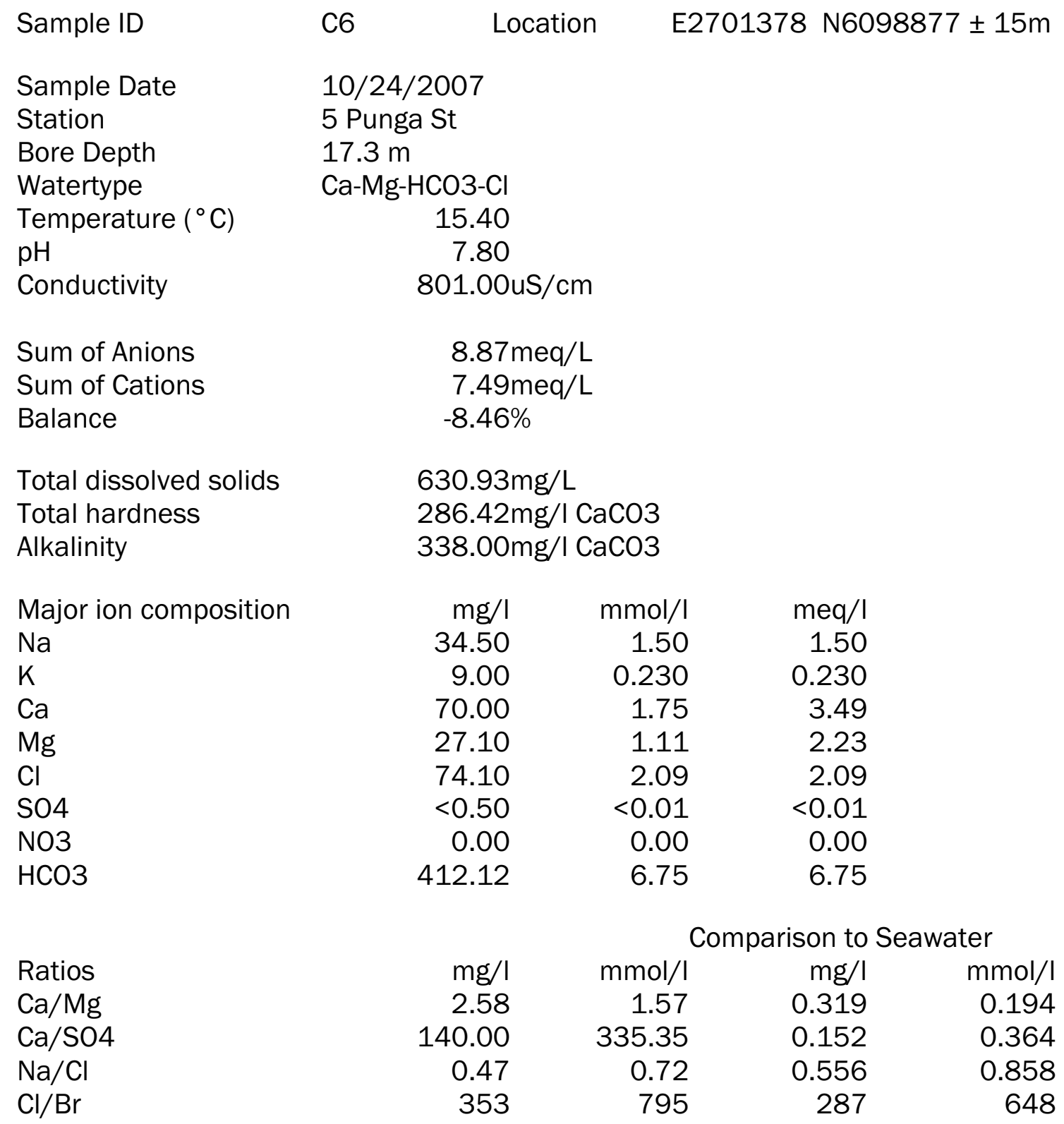


C7 Summary Report

Sample ID

Sample Date

Station

Bore Depth

Watertype

Temperature $\left({ }^{\circ} \mathrm{C}\right)$

$\mathrm{pH}$

Conductivity

Sum of Anions

Sum of Cations

Balance

Total dissolved solids

Total hardness

Alkalinity

Major ion composition

$\mathrm{Na}$

$\mathrm{K}$

$\mathrm{Ca}$

$\mathrm{Mg}$

$\mathrm{Cl}$

$\mathrm{SO} 4$

$\mathrm{NO} 3$

$\mathrm{HCO} 3$

Ratios

$\mathrm{Ca} / \mathrm{Mg}$

$\mathrm{Ca} / \mathrm{SO} 4$

$\mathrm{Na} / \mathrm{Cl}$

$\mathrm{Cl} / \mathrm{Br}$
C7

Location

E2700574 N6100379 $\pm 4 m$

8.00

$11 / 5 / 2007$

$1 \mathrm{~S}$ Ferry

$\sim 30 \mathrm{~m}$

$\mathrm{Ca}-\mathrm{HCO} 3$

$\mathrm{uS} / \mathrm{cm}$

$3.24 \mathrm{meq} / \mathrm{L}$

$2.92 \mathrm{meq} / \mathrm{L}$

$-5.24 \%$

$241.05 \mathrm{mg} / \mathrm{L}$

$110.39 \mathrm{mg} / \mathrm{I} \mathrm{CaCO} 3$

$130.00 \mathrm{mg} / \mathrm{I} \mathrm{CaCO} 3$

$\begin{array}{rrr}\mathrm{mg} / \mathrm{l} & \mathrm{mmol} / \mathrm{l} & \mathrm{meq} / \mathrm{l} \\ 14.00 & 0.61 & 0.61 \\ 3.20 & 0.082 & 0.082 \\ 32.00 & 0.80 & 1.60 \\ 7.40 & 0.30 & 0.61 \\ 16.00 & 0.45 & 0.45 \\ 8.80 & 0.09 & 0.18 \\ <0.00 & <0.00 & <0.00 \\ 158.51 & 2.60 & 2.60\end{array}$

Comparison to Seawater

$\mathrm{mg} / \mathrm{l}$

$\mathrm{mmol} / \mathrm{l}$

$\mathrm{mg} / \mathrm{l}$

$\mathrm{mmol} / \mathrm{l}$

4.32

2.62

0.319

0.194

3.64

8.71

0.152

0.364

0.88

1.35

320

721

0.556

287

0.858

648 
C8 Summary Report

\begin{tabular}{|c|c|c|c|c|}
\hline Sample ID & \multicolumn{2}{|c|}{ Location } & \multicolumn{2}{|c|}{ E2700310 N6100526 $\pm 4 m$} \\
\hline Sample Date & $11 / 5 / 2007$ & & & \\
\hline Station & 27 SF 1941 & & & \\
\hline Bore Depth & $8 \mathrm{~m}$ & & & \\
\hline Watertype & $\mathrm{Ca}-\mathrm{Na}-\mathrm{HCO}-\mathrm{Cl}$ & & & \\
\hline \multicolumn{5}{|l|}{ Temperature $\left({ }^{\circ} \mathrm{C}\right)$} \\
\hline $\mathrm{pH}$ & 7.50 & & & \\
\hline Conductivity & \multicolumn{2}{|c|}{$\mathrm{uS} / \mathrm{cm}$} & & \\
\hline Sum of Anions & \multicolumn{2}{|c|}{$6.23 \mathrm{meq} / \mathrm{L}$} & & \\
\hline Sum of Cations & \multicolumn{2}{|c|}{$5.88 \mathrm{meq} / \mathrm{L}$} & & \\
\hline Balance & \multicolumn{2}{|c|}{$-2.95 \%$} & & \\
\hline Total dissolved solids & \multicolumn{2}{|c|}{$463.94 \mathrm{mg} / \mathrm{L}$} & & \\
\hline Total hardness & \multicolumn{2}{|c|}{ 209.25mg/l CaCO3 } & & \\
\hline Alkalinity & \multicolumn{2}{|c|}{ 240.00mg/I CaCO3 } & & \\
\hline Major ion composition & $\mathrm{mg} / \mathrm{l}$ & $\mathrm{mmol} / \mathrm{l}$ & meq/l & \\
\hline $\mathrm{Na}$ & 35.00 & 1.52 & 1.52 & \\
\hline K & 5.20 & 0.133 & 0.133 & \\
\hline $\mathrm{Ca}$ & 64.00 & 1.60 & 3.19 & \\
\hline $\mathrm{Mg}$ & 12.00 & 0.49 & 0.99 & \\
\hline $\mathrm{Cl}$ & 50.00 & 1.41 & 1.41 & \\
\hline SO4 & 0.78 & 0.01 & 0.02 & \\
\hline N03 & $<0.00$ & $<0.00$ & $<0.00$ & \\
\hline \multirow[t]{2}{*}{$\mathrm{HCO} 3$} & 292.63 & 4.80 & 4.80 & \\
\hline & & \multicolumn{3}{|c|}{ Comparison to Seawater } \\
\hline Ratios & $\mathrm{mg} / \mathrm{l}$ & $\mathrm{mmol} / \mathrm{l}$ & $\mathrm{mg} / \mathrm{l}$ & $\mathrm{mmol} / \mathrm{I}$ \\
\hline $\mathrm{Ca} / \mathrm{Mg}$ & 5.33 & 3.23 & 0.319 & 0.194 \\
\hline $\mathrm{Ca} / \mathrm{SO} 4$ & 82.05 & 196.54 & 0.152 & 0.364 \\
\hline $\mathrm{Na} / \mathrm{Cl}$ & 0.70 & 1.08 & 0.556 & 0.858 \\
\hline $\mathrm{Cl} / \mathrm{Br}$ & 208 & 470 & 287 & 648 \\
\hline
\end{tabular}


C9 Summary Report

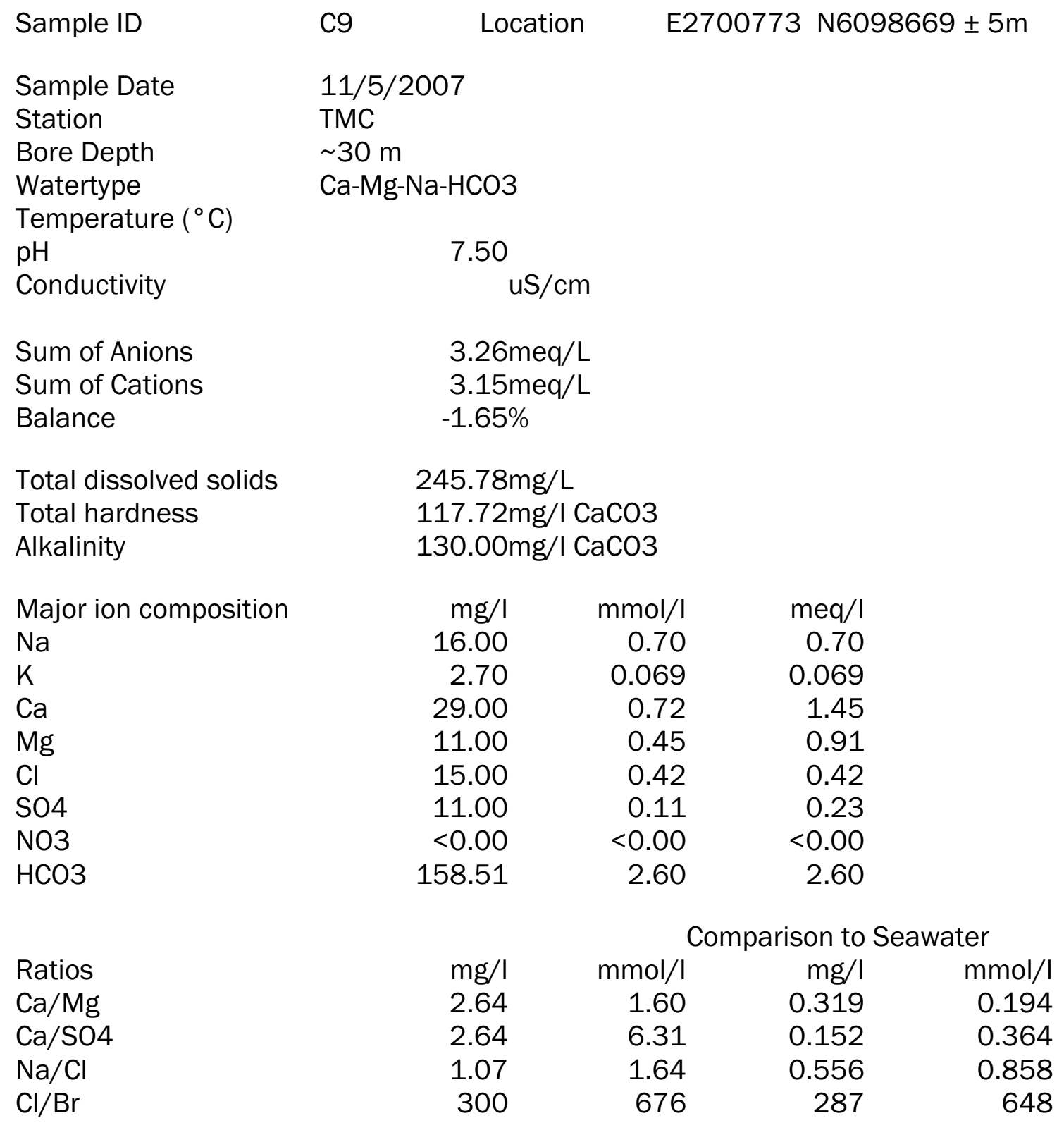




\section{C10 Summary Report}

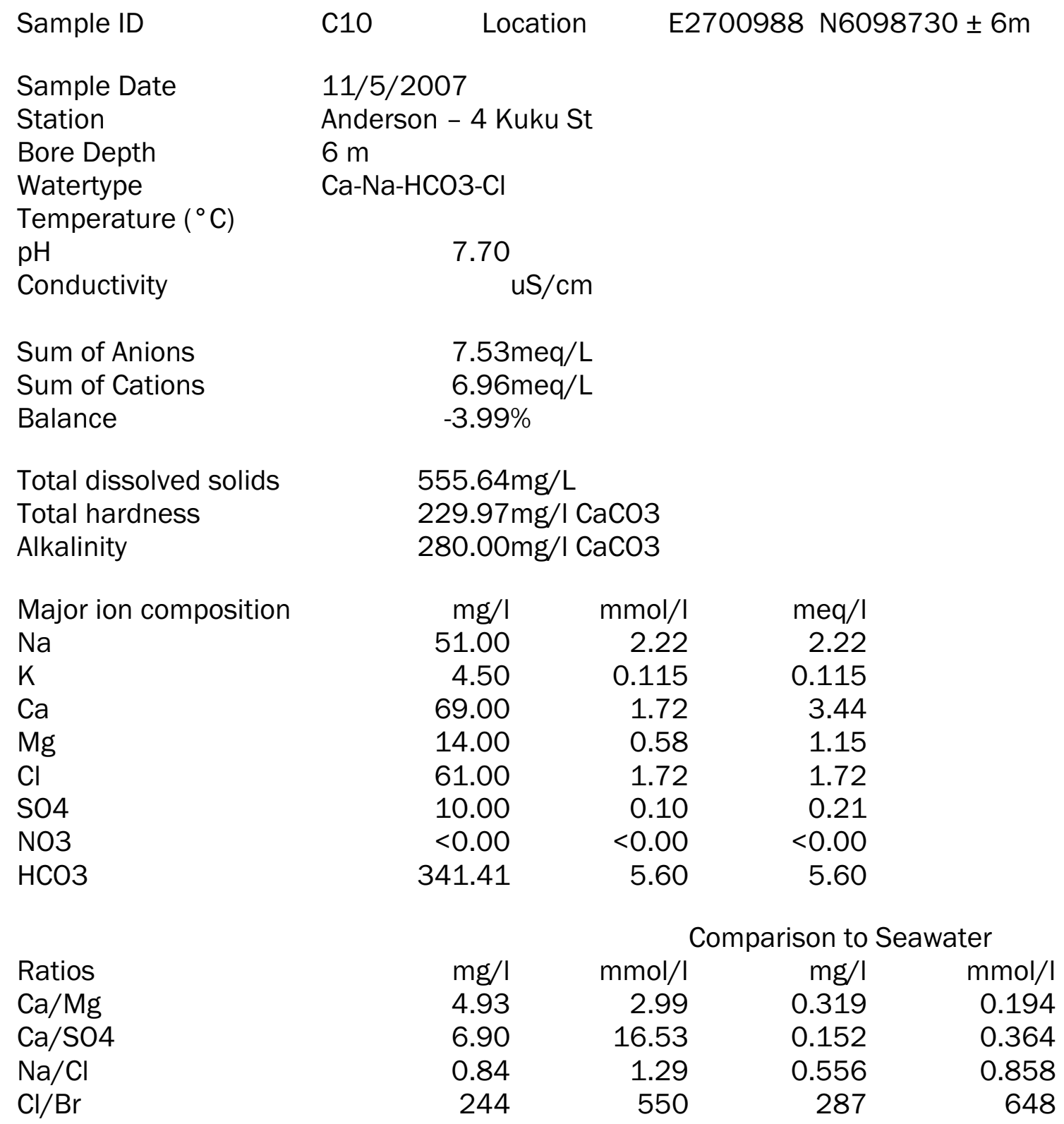


Appendix 2.

Sounding curves 
Electrical sounding Schlumberger - t1.WS3

T1 E2700525 N6100062

Shift on new MN

10000

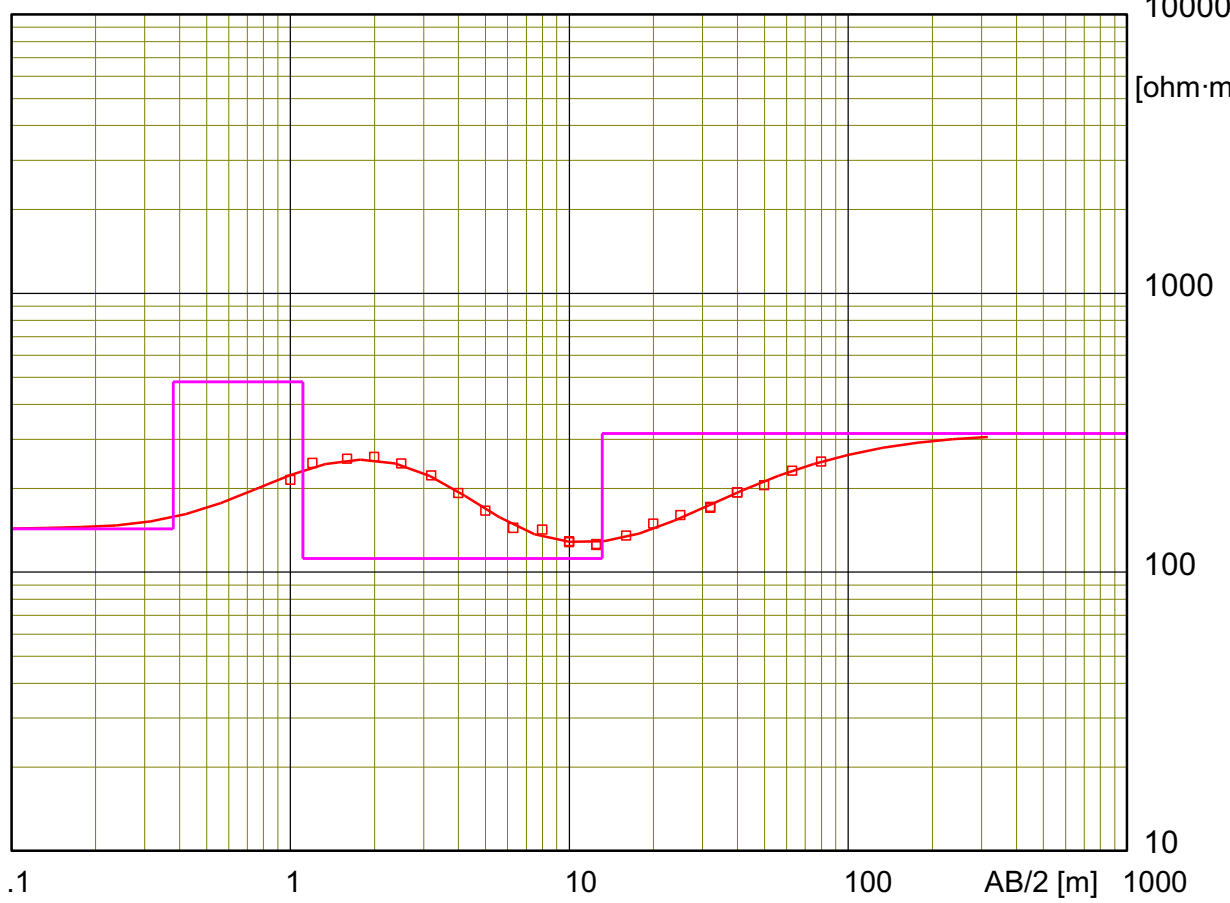

Model

Resistivity Thickness Depth

[ohm $[\mathrm{m}] \quad[\mathrm{m}] \quad[\mathrm{m}]$

$143 \quad .38$

$\begin{array}{lll}481 & .73 & .38\end{array}$

$112 \quad 12 \quad 1.1$

314 
Electrical sounding Schlumberger - t2.WS3

T2 E2701127 N6099355

Shift on new MN

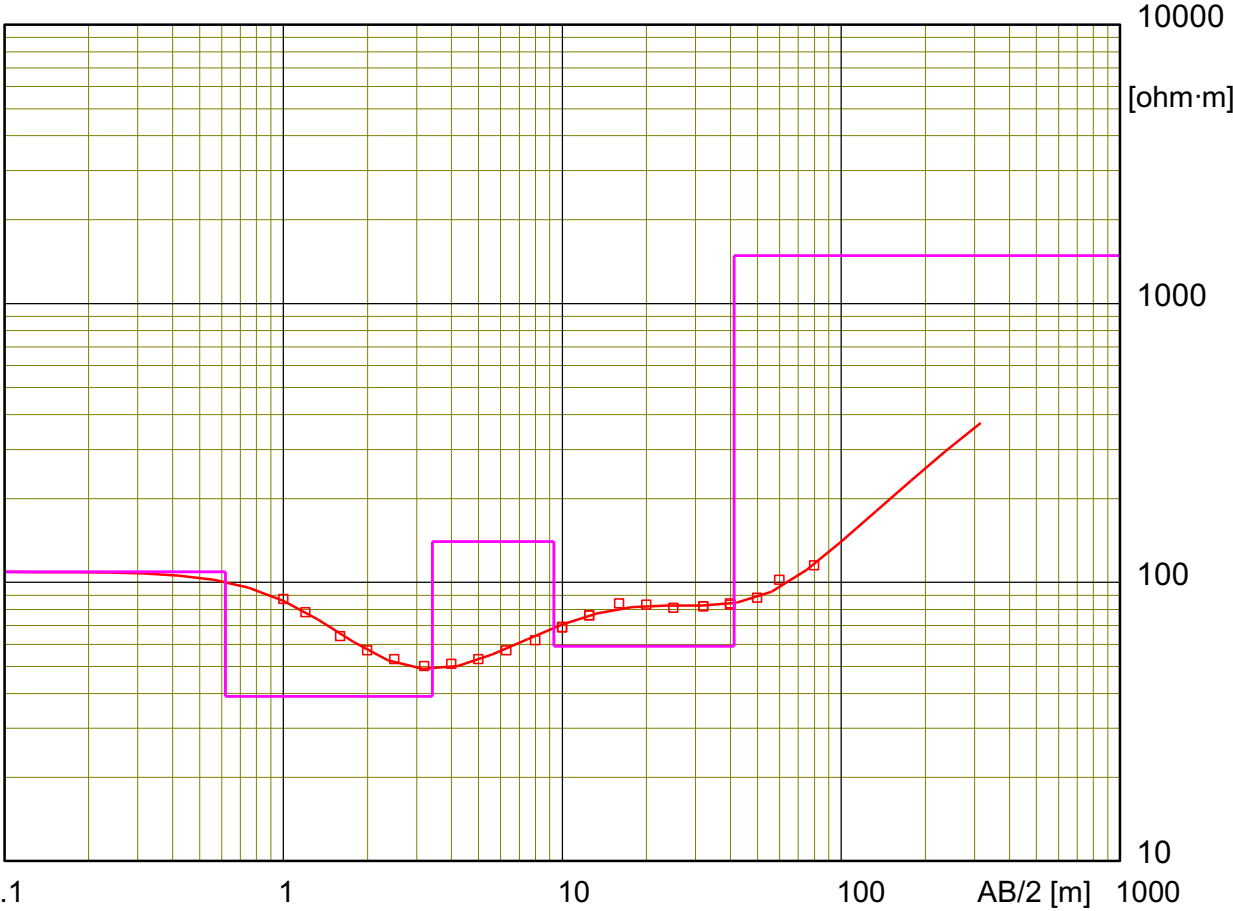

Model

Resistivity Thickness Depth

[ohm.m] [m] [m]

$\begin{array}{rr}109 & .62 \\ 39 & 2.8\end{array}$

$\begin{array}{lll}140 & 5.9 & 3.4\end{array}$

$\begin{array}{lll}59 & 32 & 9.3\end{array}$

$\begin{array}{lll}1484 & 41\end{array}$ 
Electrical sounding Schlumberger - t3.WS3

t3 E2700097 N6099502

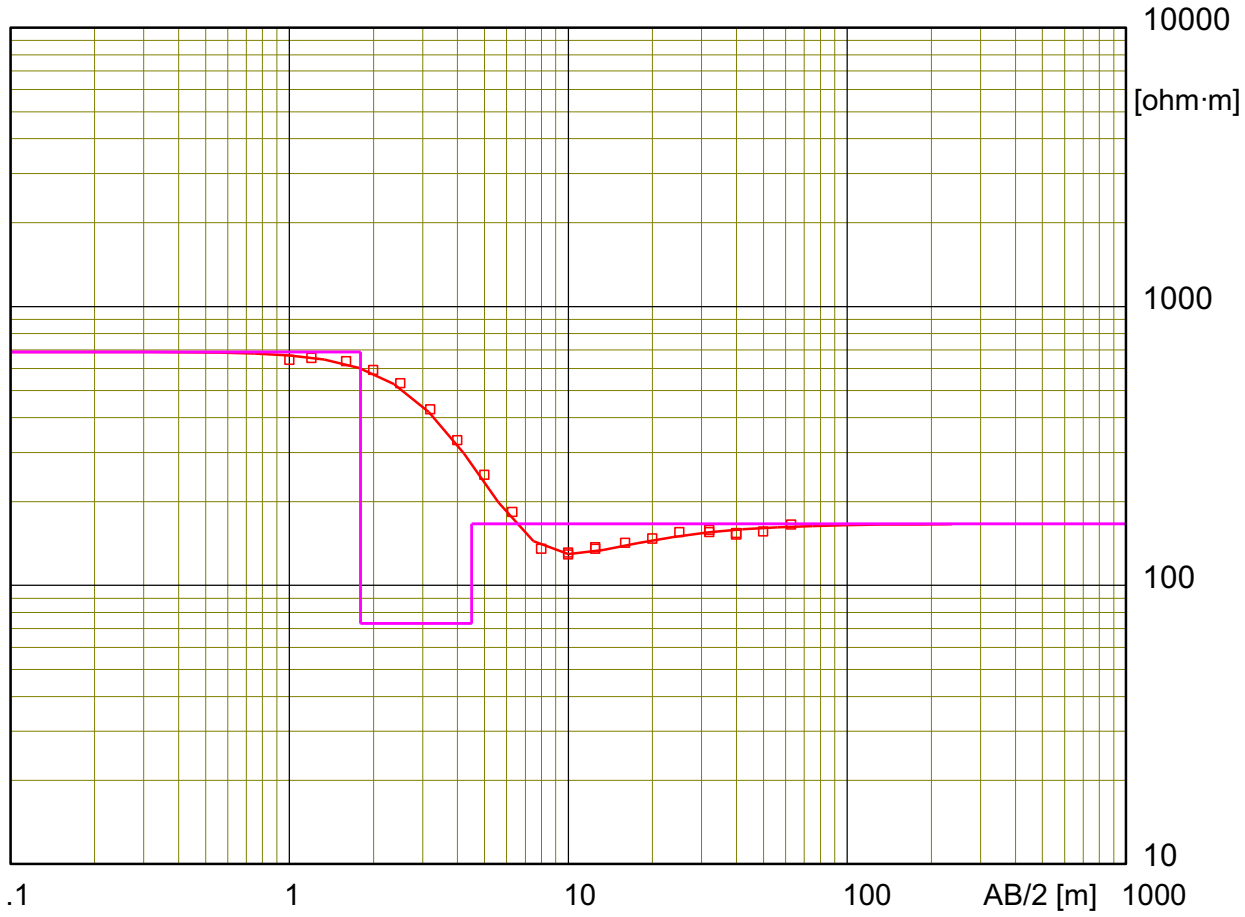

Model

Resistivity Thickness Depth

[ohm $\cdot \mathrm{m}] \quad[\mathrm{m}] \quad[\mathrm{m}]$

$687 \quad 1.8$

$\begin{array}{lll}73 & 2.7 & 1.8\end{array}$

$166 \quad 4.5$

W-GeoSoft / WinSev 5.1 


\section{Electrical sounding Schlumberger - t4.WS3}

t4 E2699868 N6099202

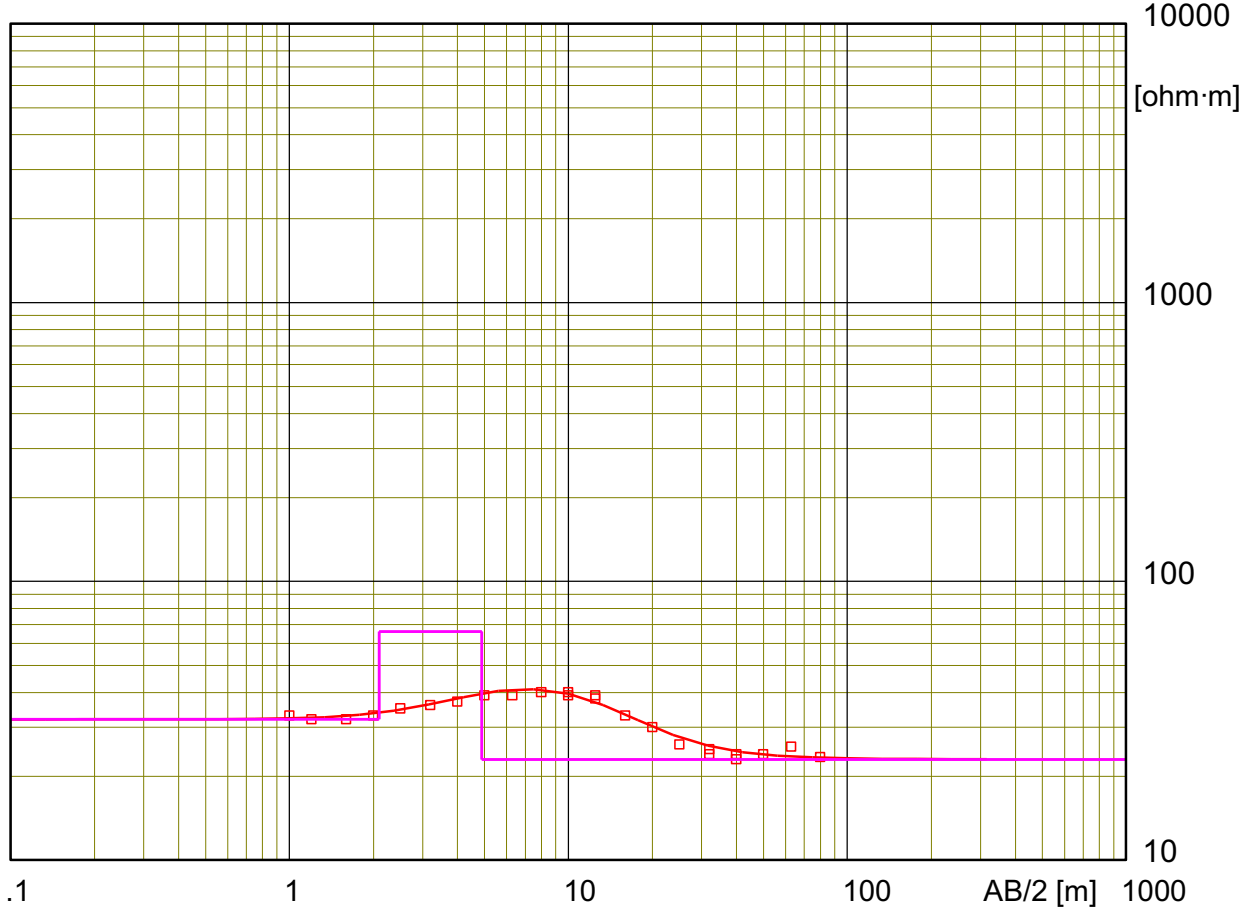

$\begin{array}{rcc}\begin{array}{l}\text { Model } \\ \text { Resistivity } \\ \text { [ohm·m] }\end{array} & \begin{array}{c}\text { Thickness } \\ {[\mathrm{m}]}\end{array} & \begin{array}{c}\text { Depth } \\ {[\mathrm{m}]}\end{array} \\ 32 & 2.1 & \\ 66 & 2.8 & 2.1 \\ 23 & & 4.9\end{array}$


Electrical sounding Schlumberger - t5.WS3

t5 E2700566 N6098425

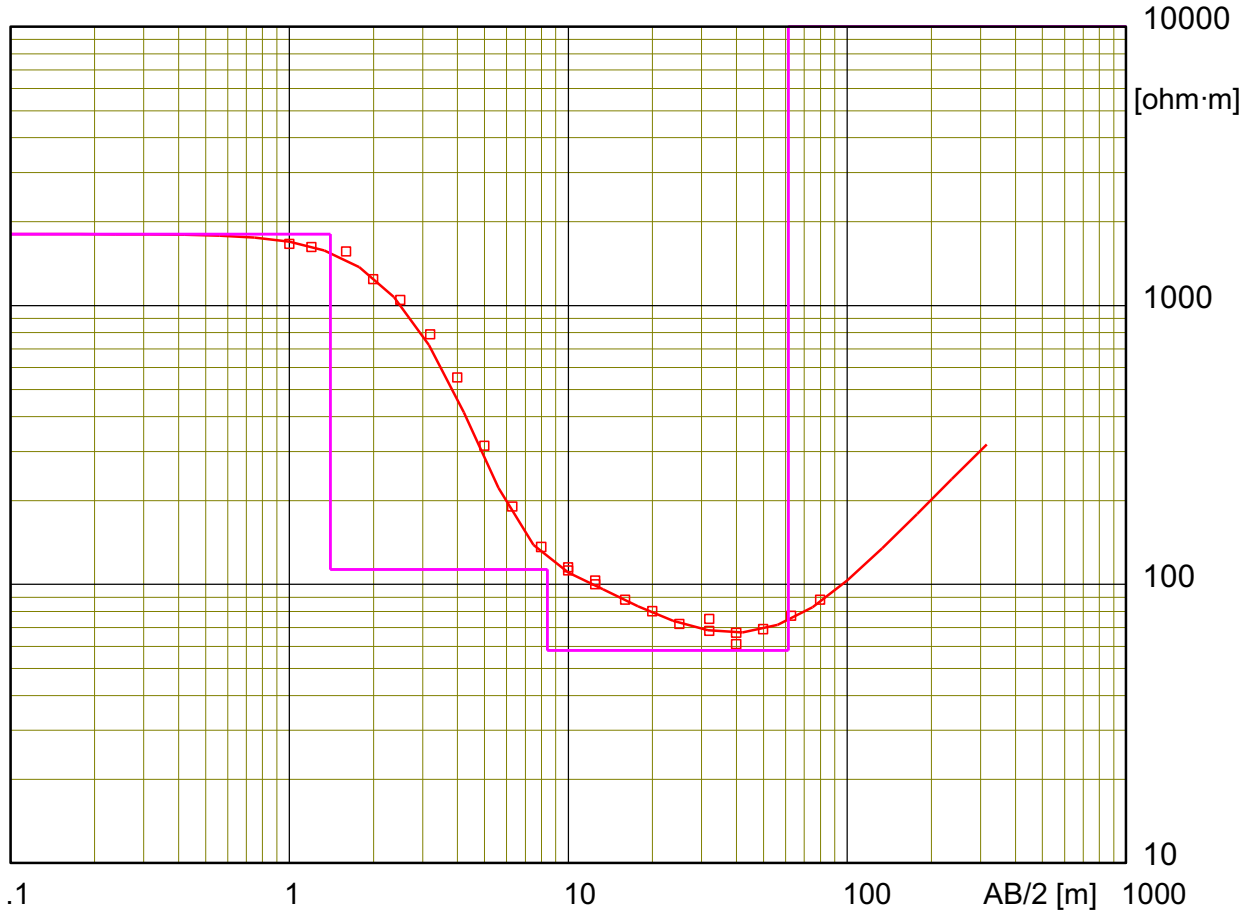

Model

Resistivity Thickness Depth

[ohm $\mathrm{m}] \quad[\mathrm{m}] \quad[\mathrm{m}]$

$\begin{array}{rrr}1801 & 1.4 & \\ 113 & 7 & 1.4\end{array}$

$\begin{array}{rrr}113 & 7 & 1.4 \\ 58 & 53 & 8.4\end{array}$

99999

61 
Electrical sounding Schlumberger - t6.WS3

t6 E2699930 N6098350

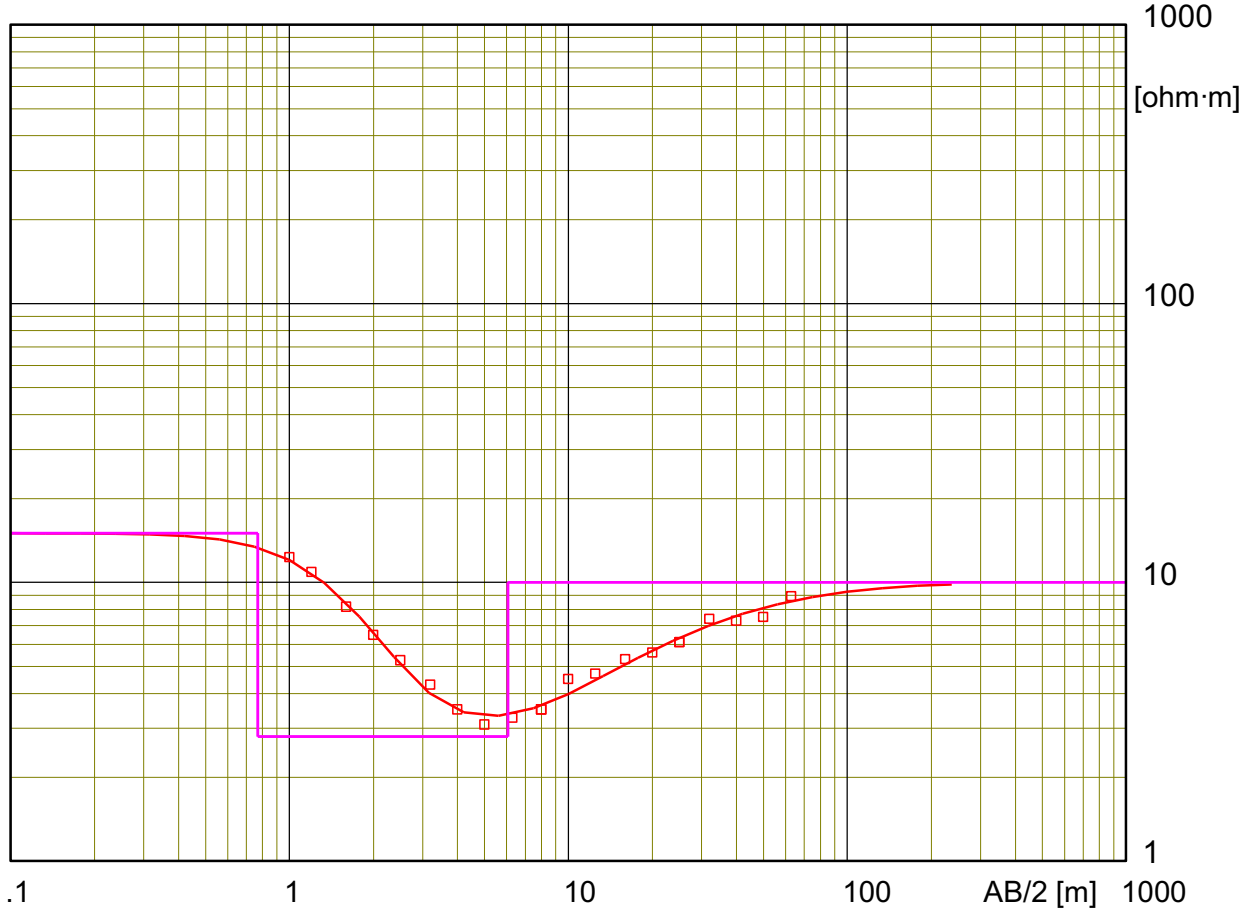

Model

Resistivity Thickness Depth

$\begin{array}{rrr}\text { [ohm } \cdot \mathrm{m}] & {[\mathrm{m}]} & {[\mathrm{m}]} \\ 15 & .77 & \end{array}$

$\begin{array}{lll}2.8 & .77 & .77\end{array}$

$\begin{array}{ll}10 & 6.1\end{array}$

W-GeoSoft / WinSev 5.1 
Electrical sounding Schlumberger - t7.WS3

t7 E2700711 N6098941

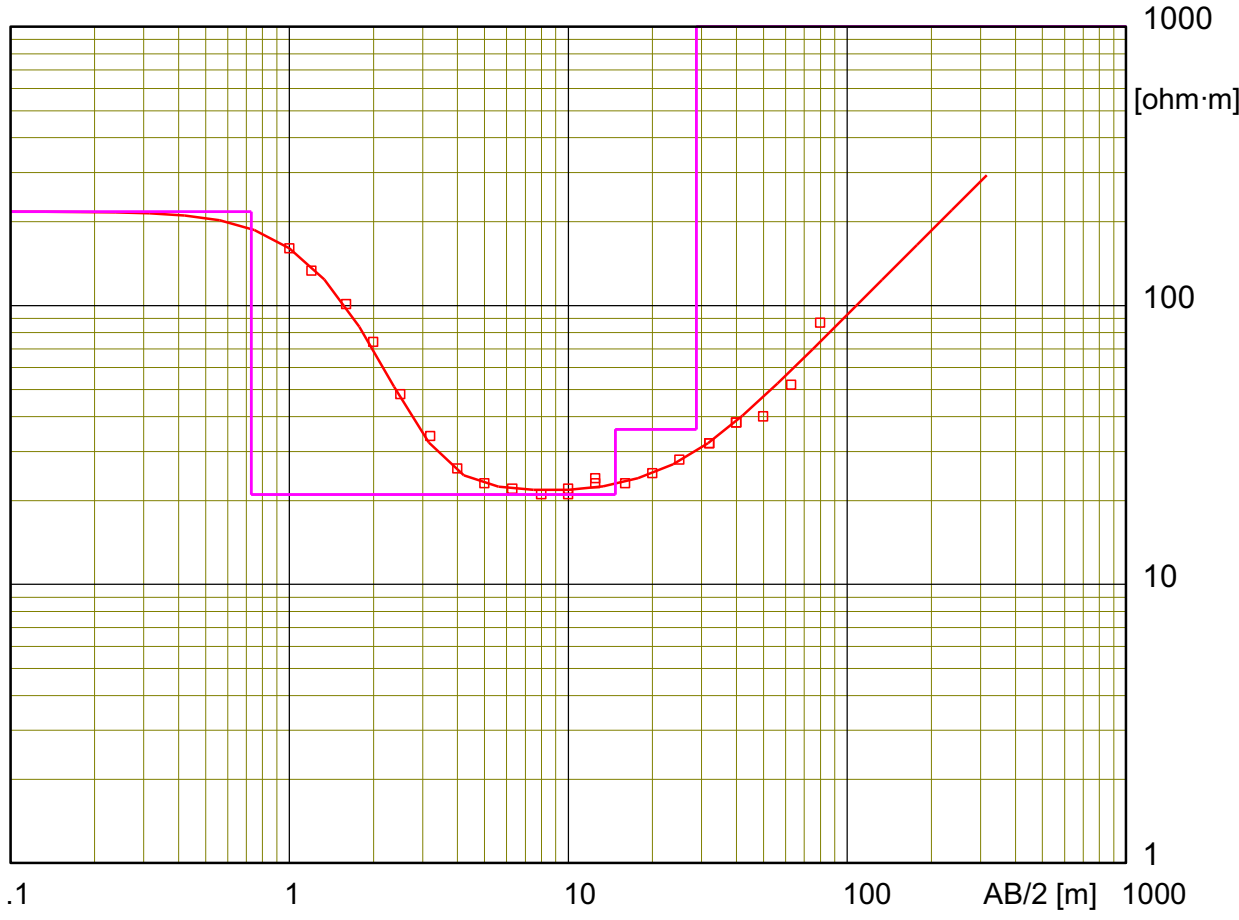

$\begin{array}{rcc}\begin{array}{l}\text { Model } \\ \text { Resistivity } \\ \text { [ohm·m] }\end{array} & \begin{array}{c}\text { Thickness } \\ {[\mathrm{m}]}\end{array} & \begin{array}{c}\text { Depth } \\ {[\mathrm{m}]}\end{array} \\ 217 & .73 & \\ 21 & 14 & .73 \\ 36 & 14 & 15 \\ 99999 & & 29\end{array}$


Electrical sounding Schlumberger - t8.WS3

t8 E2700393 N6099299

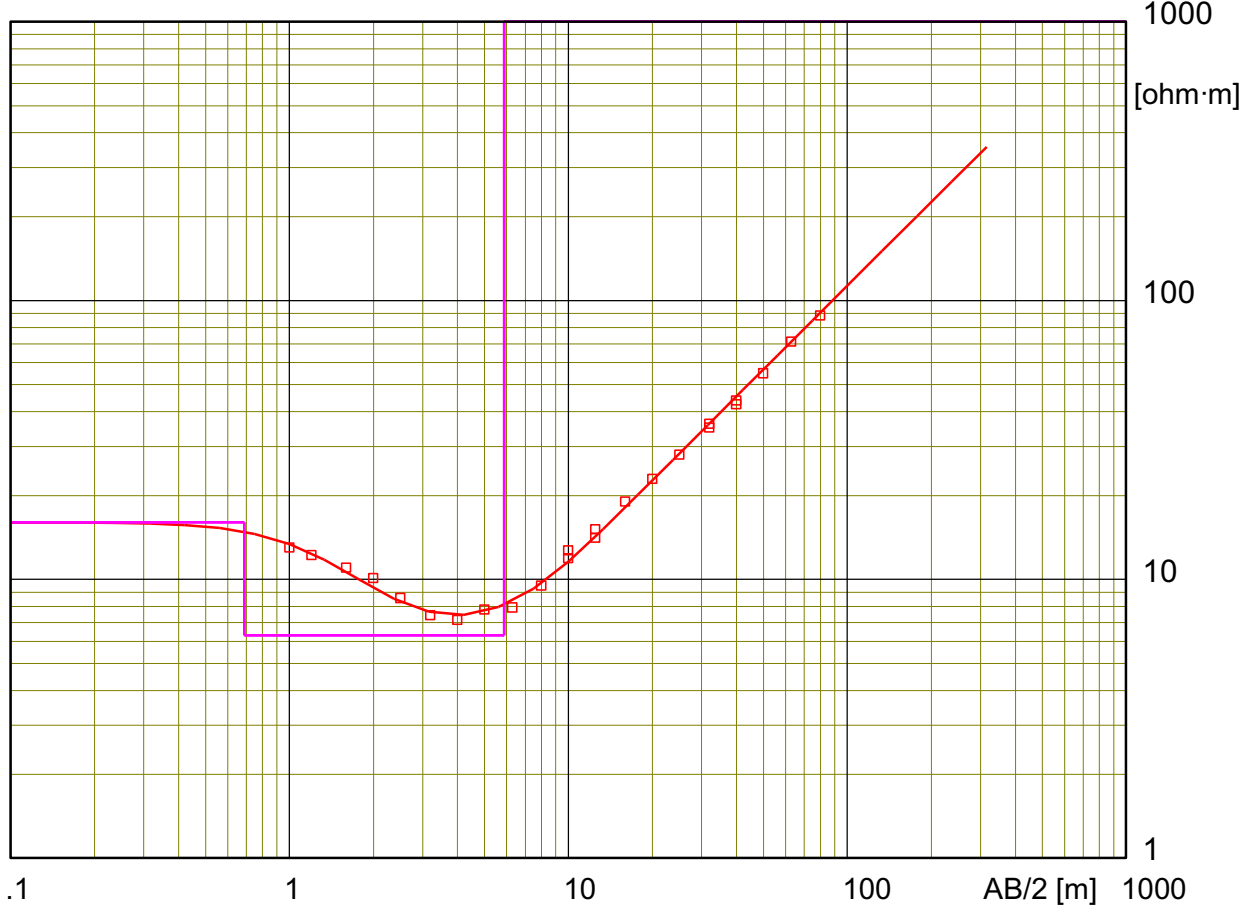

Model

Resistivity Thickness Depth

[ohm $\cdot \mathrm{m}] \quad[\mathrm{m}] \quad[\mathrm{m}]$

$\begin{array}{rrr}16 & .69 & \\ 6.3 & 5.2 & .69\end{array}$

$21444 \quad 5.9$ 
Electrical sounding Schlumberger - t9.WS3

t9 E2700193 N6099286

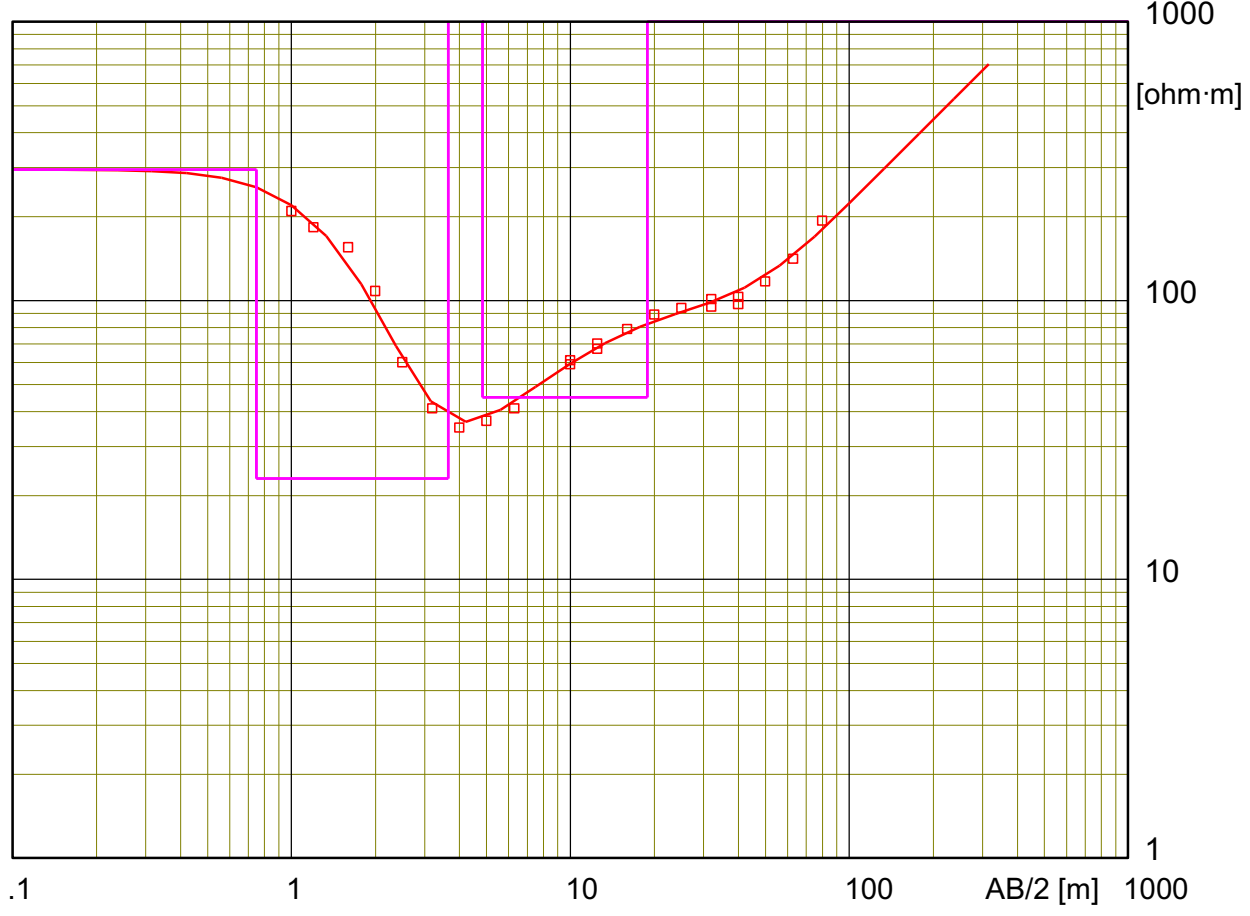

Model

Resistivity Thickness Depth

$\begin{array}{rrr}\text { [ohm } \cdot \mathrm{m}] & {[\mathrm{m}]} & {[\mathrm{m}]} \\ 295 & .75 & \end{array}$

$\begin{array}{lll}23 & 2.9 & .75\end{array}$

$\begin{array}{lll}1068 & 1.2 & 3.6\end{array}$

$\begin{array}{lll}45 & 14 & 4.8\end{array}$

$\begin{array}{ll}99999 & 19\end{array}$ 


\section{Electrical sounding Schlumberger - t10.WS3}

t10 E2700893 N6099583

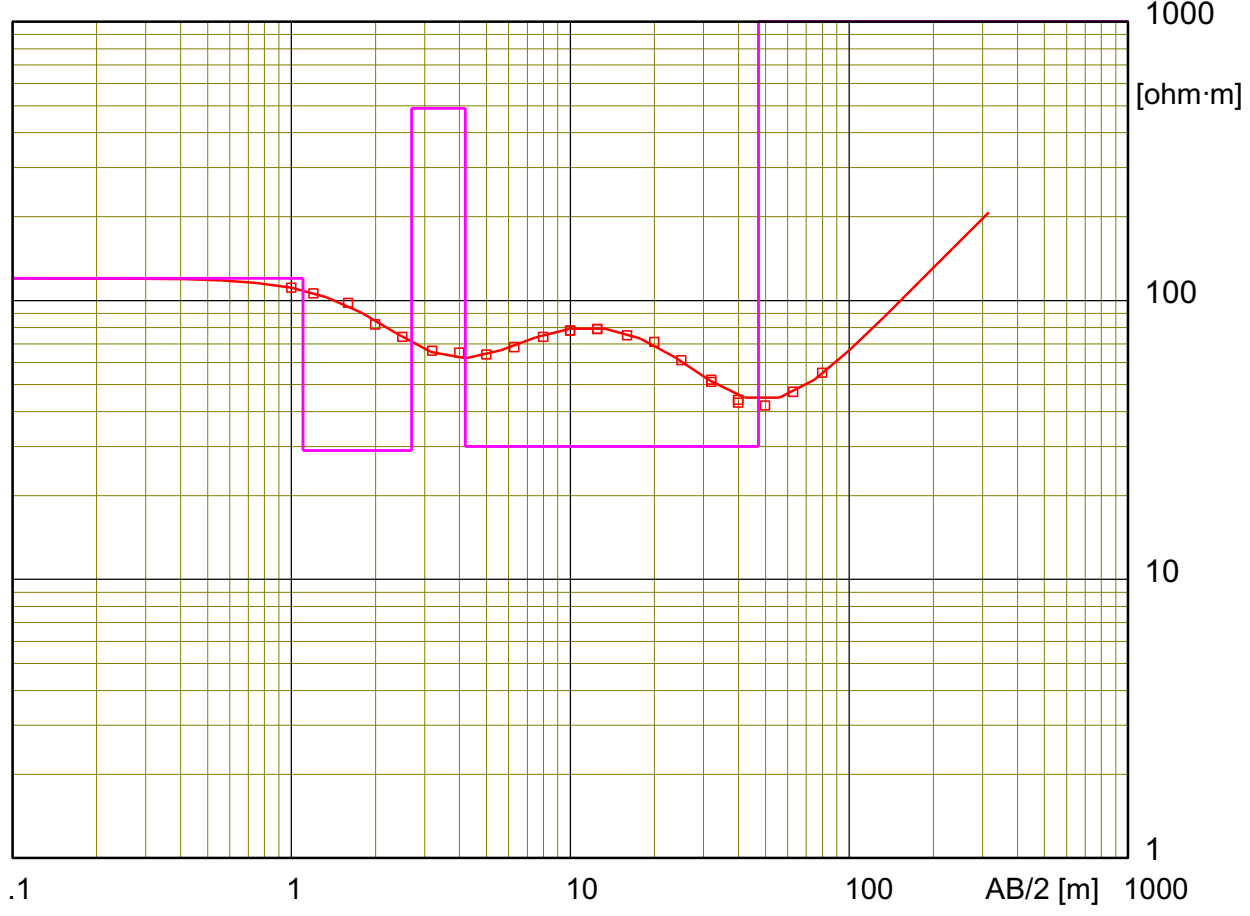

$\begin{array}{rcc}\begin{array}{l}\text { Model } \\ \text { Resistivity } \\ \text { [ohm·m] }\end{array} & \begin{array}{c}\text { Thickness } \\ \text { [m] }\end{array} & \begin{array}{c}\text { Depth } \\ {[\mathrm{m}]}\end{array} \\ 120 & 1.1 & \\ 29 & 1.6 & 1.1 \\ 489 & 1.5 & 2.7 \\ 30 & 43 & 4.2 \\ 99999 & & 47\end{array}$




\section{Electrical sounding Schlumberger - s1.WS3}

s1 E2700087 N6099712

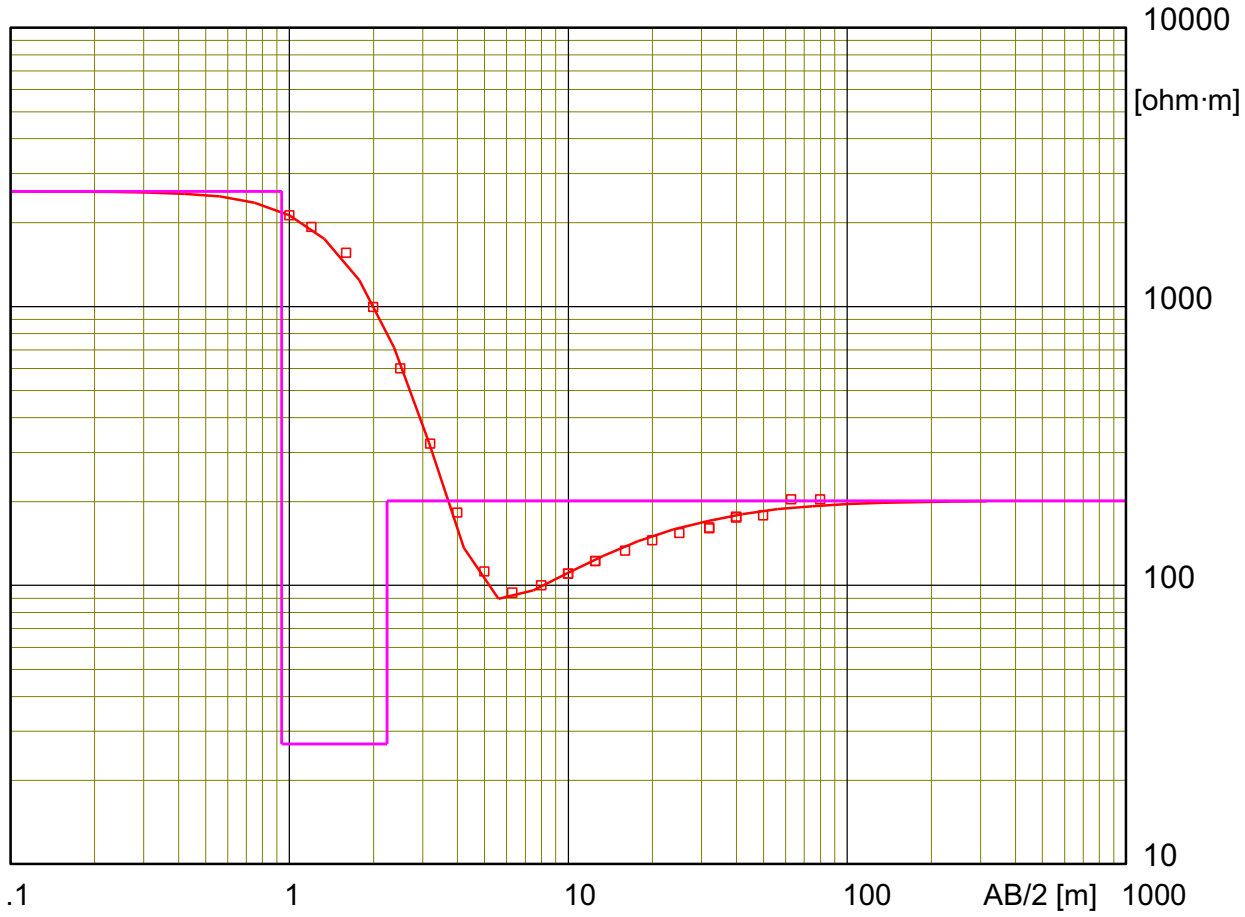

Model

Resistivity Thickness Depth

[ohm.m] [m] [m]

$\begin{array}{rrr}2584 & .94 & \\ 27 & 1.3 & 94\end{array}$

$201 \quad 2.2$


Electrical sounding Schlumberger - s2.WS3

s2 E2700026 N6100490

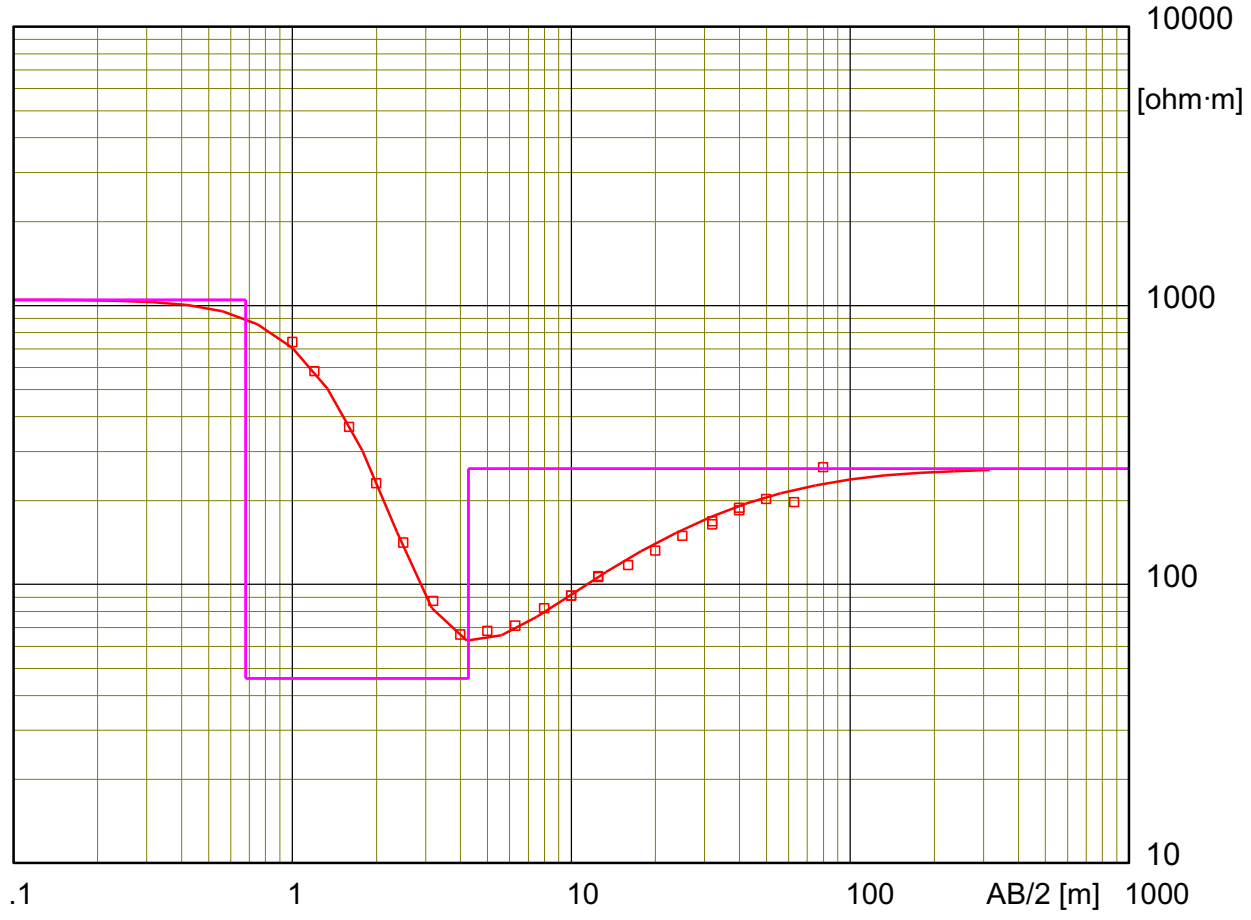

Model

Resistivity Thickness Depth

[ohm $\cdot \mathrm{m}] \quad[\mathrm{m}] \quad[\mathrm{m}]$

$\begin{array}{rrr}1048 & .68 & \\ 46 & 3.6 & 68\end{array}$

$260 \quad 4.3$

W-GeoSoft / WinSev 5.1 
Electrical sounding Schlumberger - s3.WS3

s3 E2699573 N6100481

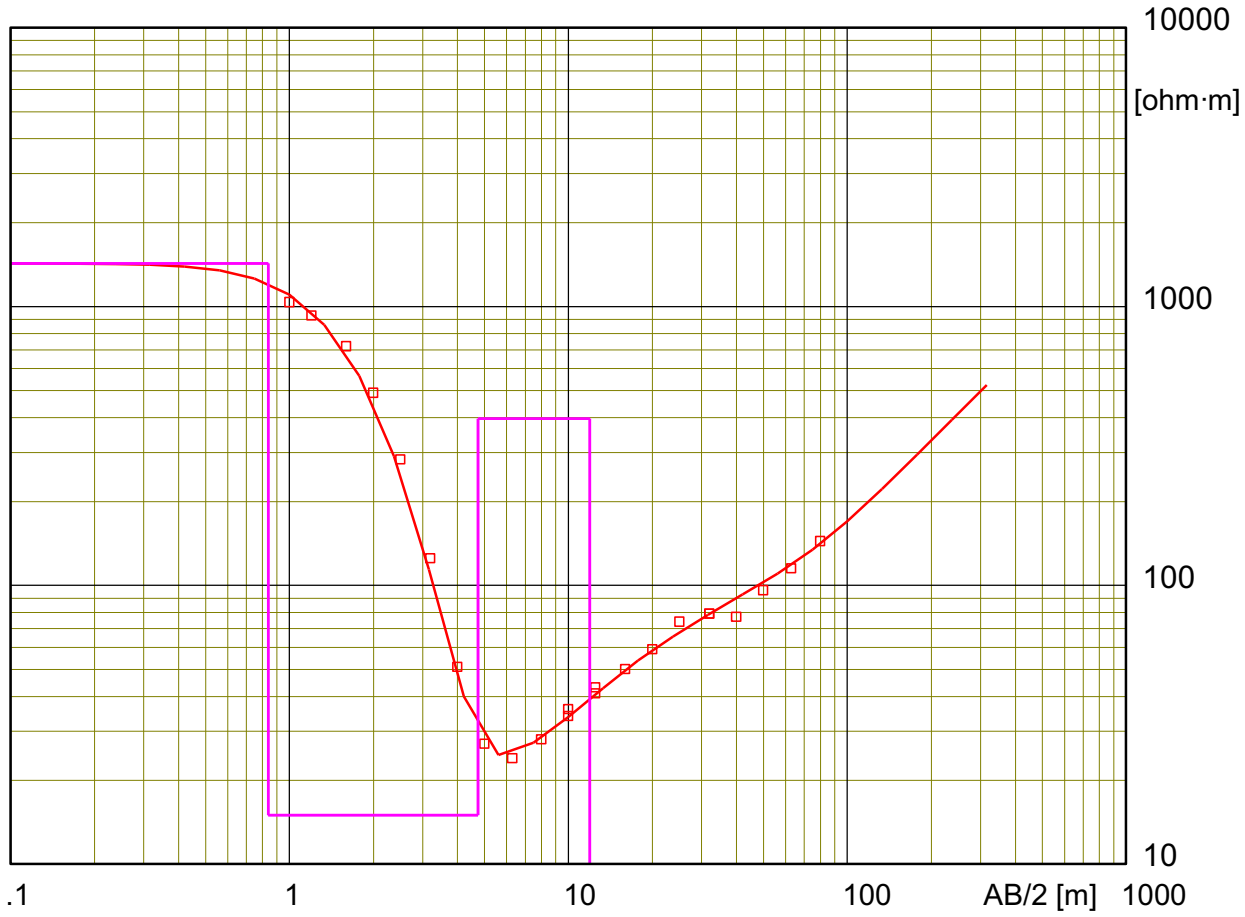

Model

Resistivity Thickness Depth

[ohm.m] [m] [m]

$\begin{array}{rrr}1426 & .84 & \\ 15 & 3.9 & 84\end{array}$

$\begin{array}{lll}396 & 7.2 & 4.7\end{array}$

$\begin{array}{lll}5.4 & 1.7 & 12\end{array}$

$99999 \quad 14$ 


\section{Electrical sounding Schlumberger - s4.WS3}

s4 E2700661 N6100688

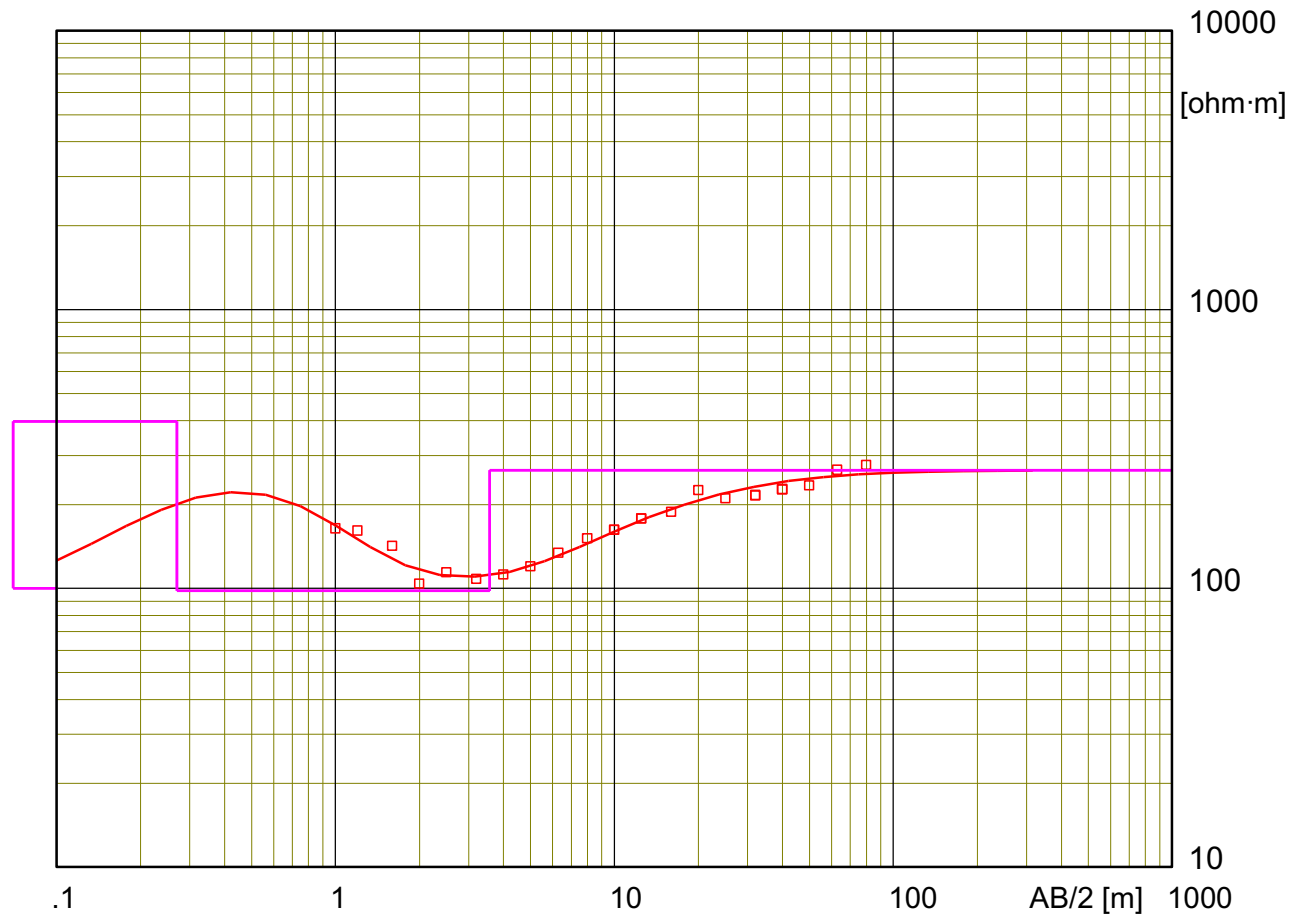

$\begin{array}{rcc}\begin{array}{l}\text { Model } \\ \text { Resistivity } \\ \text { [ohm } \cdot \mathrm{m}]\end{array} & \begin{array}{c}\text { Thickness } \\ {[\mathrm{m}]}\end{array} & \begin{array}{c}\text { Depth } \\ {[\mathrm{m}]}\end{array} \\ 100 & .07 & \\ 397 & .2 & .07 \\ 98 & 3.3 & .27 \\ 265 & & 3.6\end{array}$


Electrical sounding Schlumberger - s5.WS3

s5 E2701185 N6100155

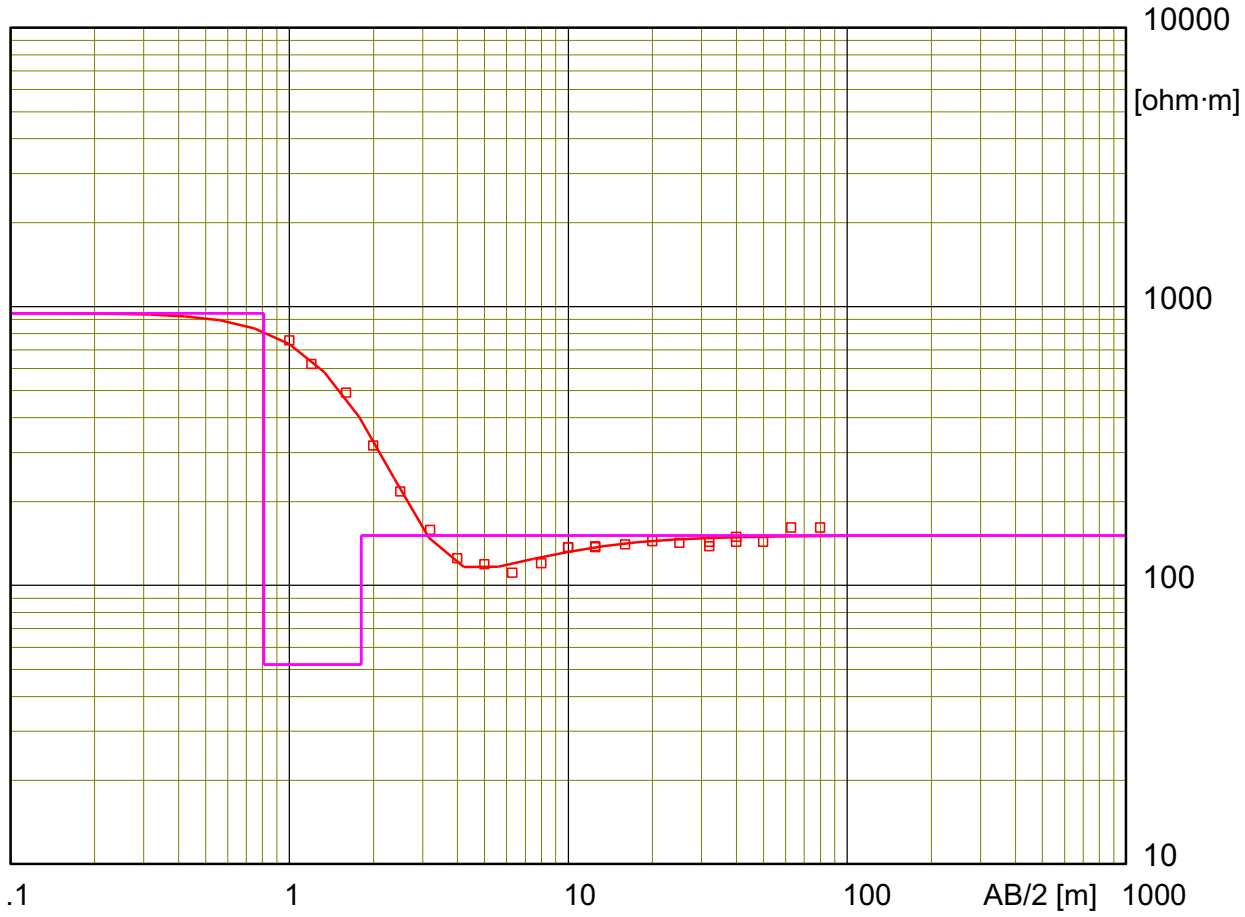

Model

Resistivity Thickness Depth

[ohm $\cdot \mathrm{m}] \quad[\mathrm{m}] \quad[\mathrm{m}]$

$\begin{array}{rrr}946 & .81 & \\ 52 & 1 & .81\end{array}$

$\begin{array}{ll}151 & 1.8\end{array}$ 
Electrical sounding Schlumberger - s6.WS3

s6 E2701477 N6099742

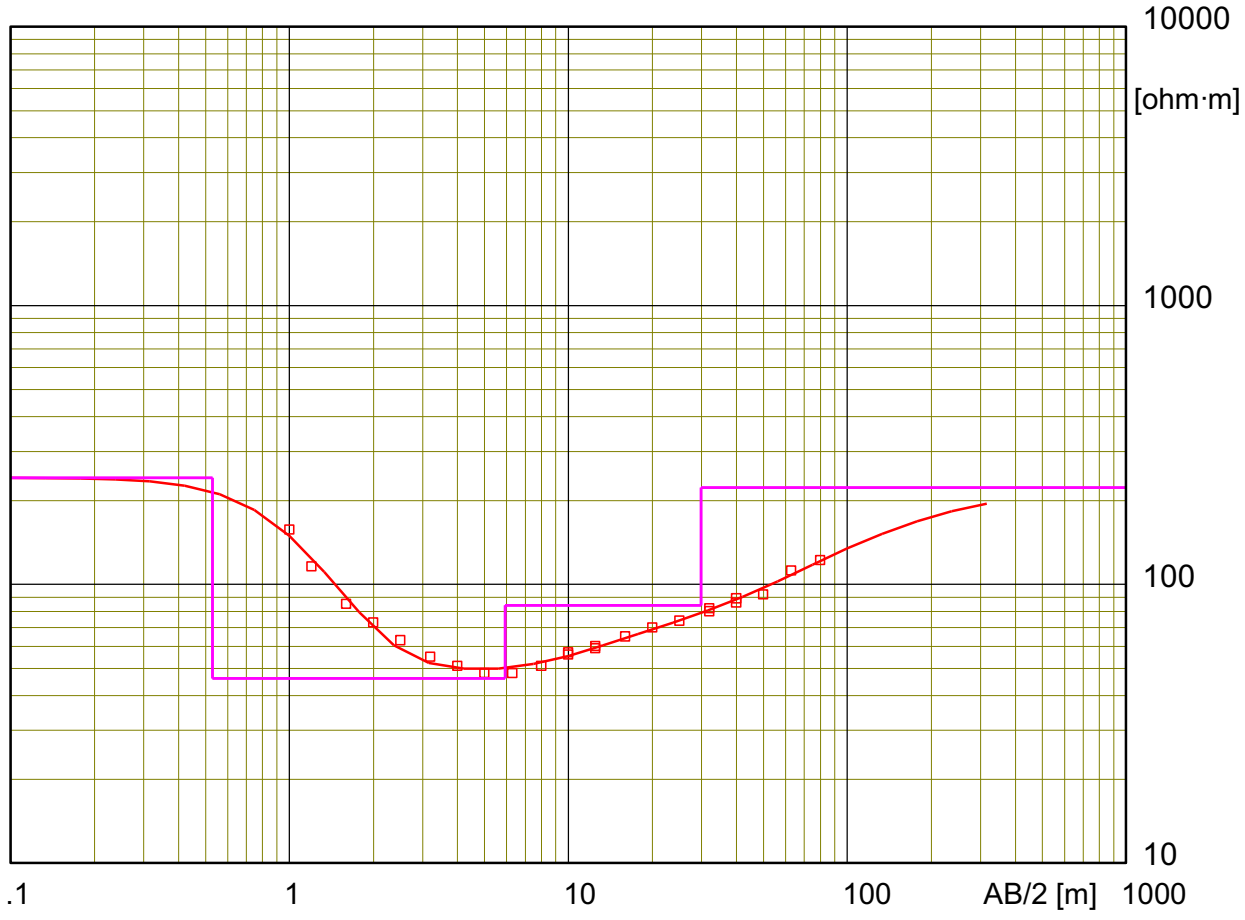

Model

Resistivity Thickness Depth

[ohm $[\mathrm{m}] \quad[\mathrm{m}]$

$\begin{array}{rrr}241 & .53 & \\ 46 & 5.4 & .53\end{array}$

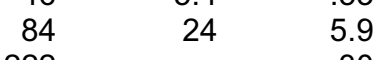

$222 \quad 30$ 
Appendix 3.

Resistivity traverses 

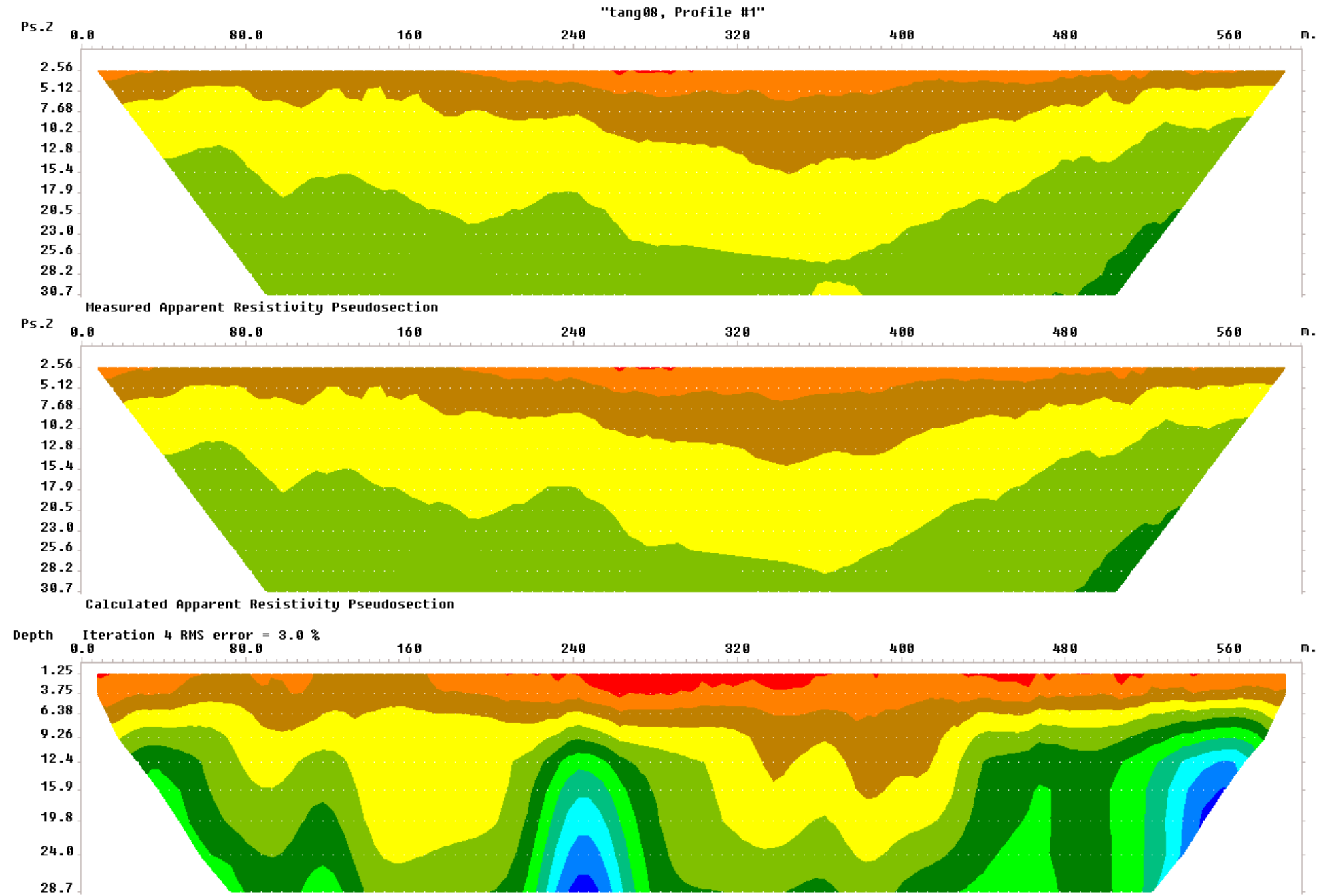

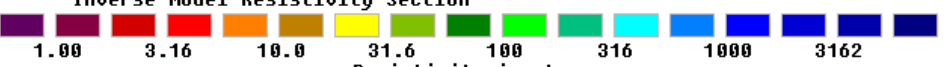

Traverse W1

Unit electrode spacing $5.00 \mathrm{~m}$. 

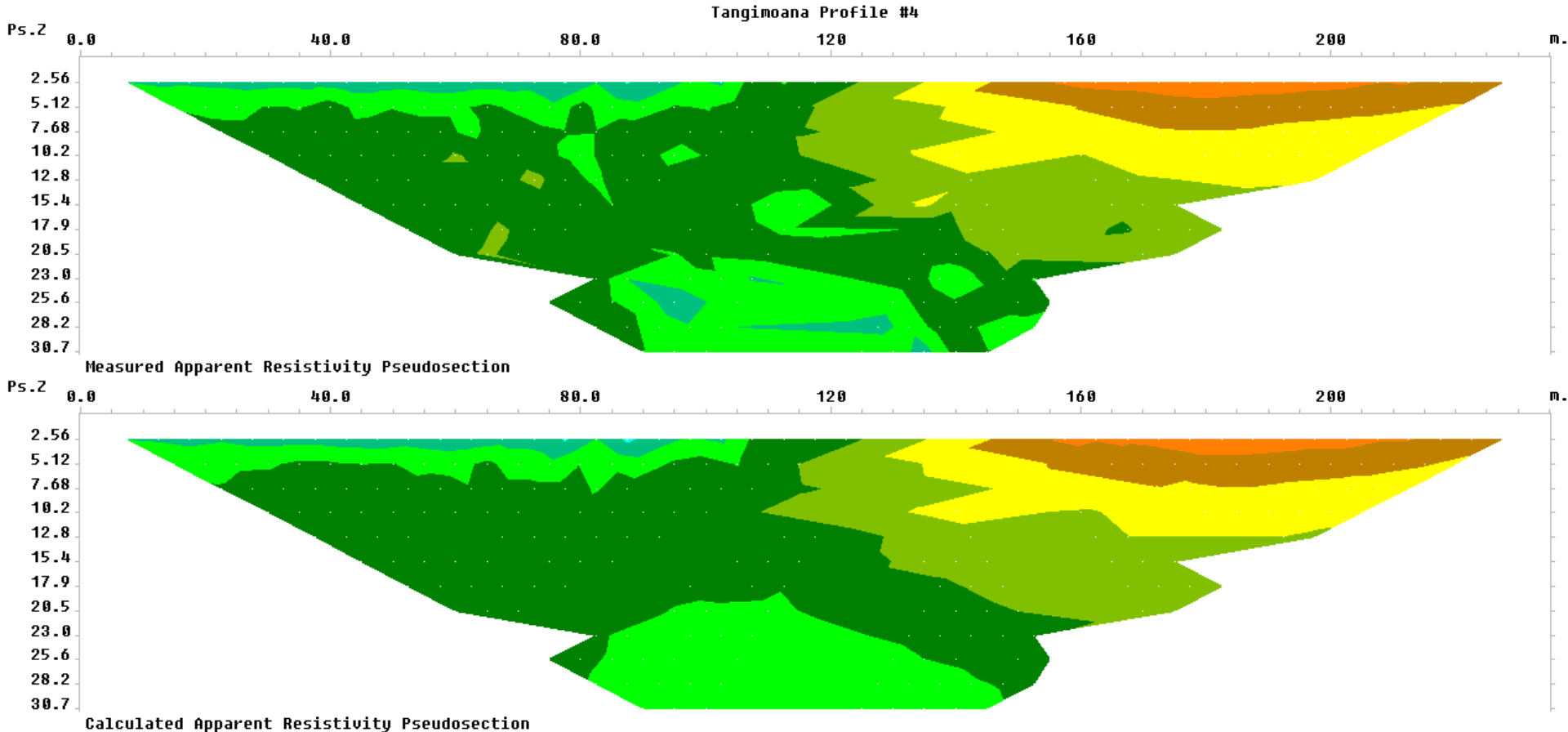

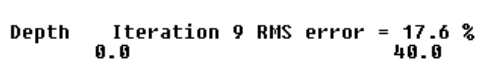

160

200

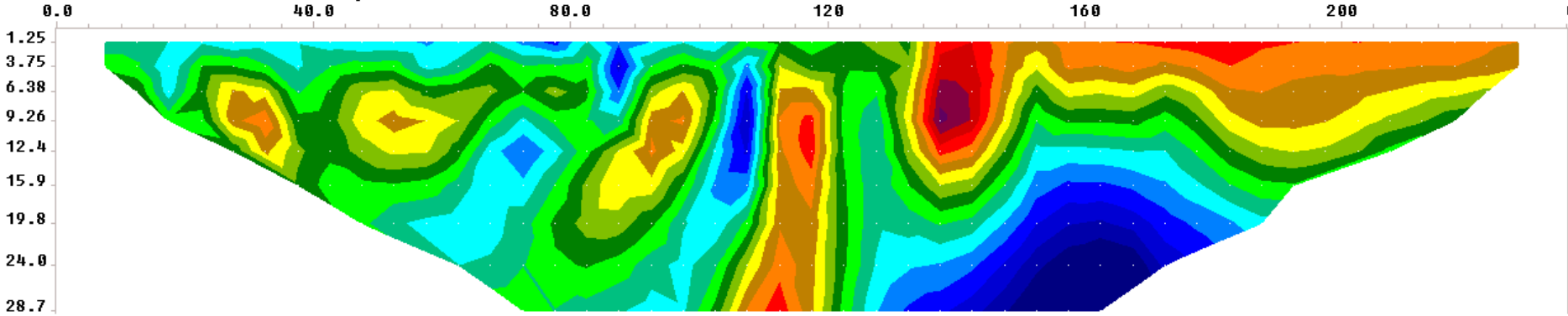

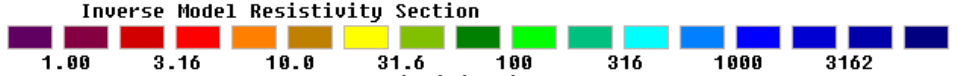

Traverse W4

Unit electrode spacing $5.80 \mathrm{~m}$. 

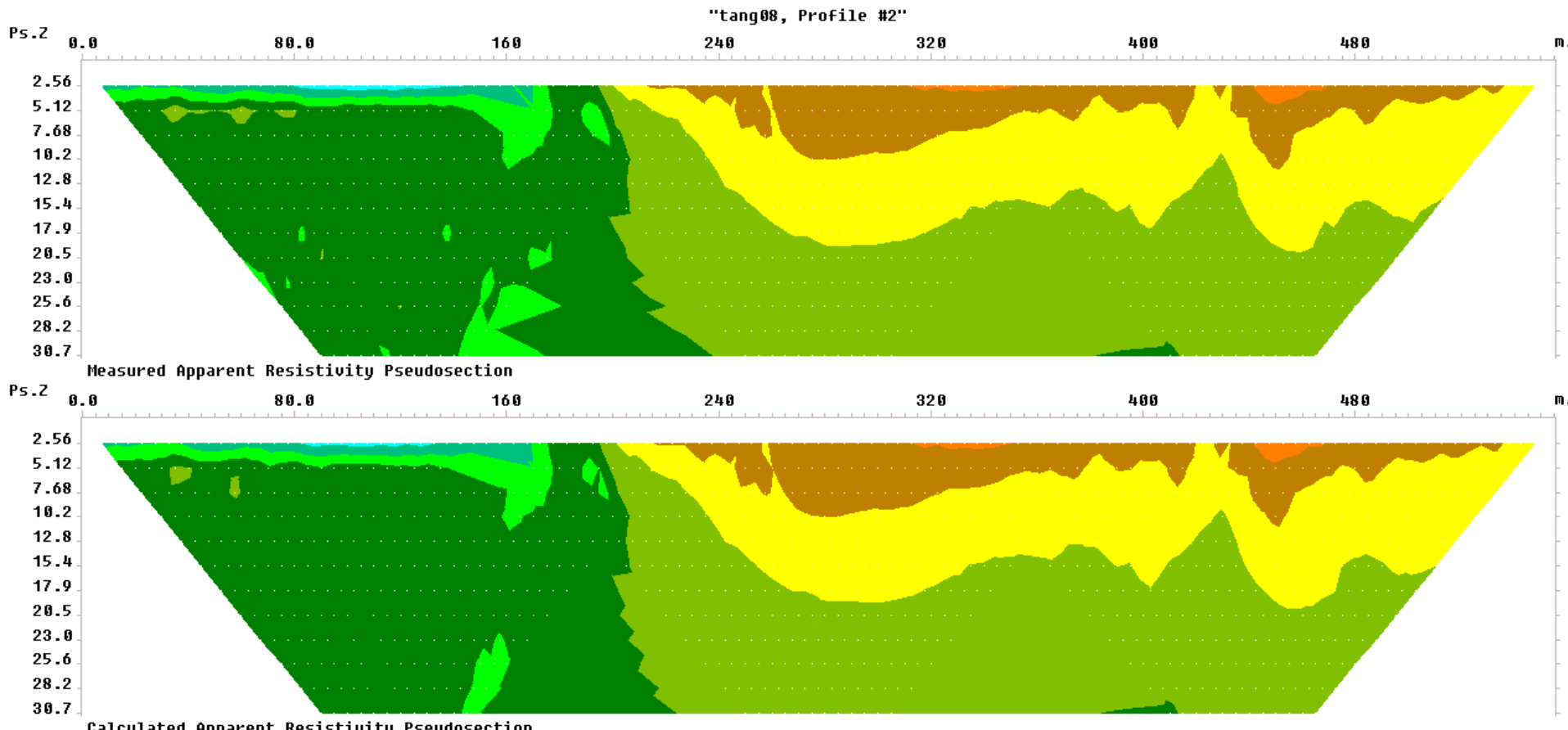

Calculated Apparent Resistivity Pseudosection

Depth Iteration 7 RMS error $=7.6 \%$

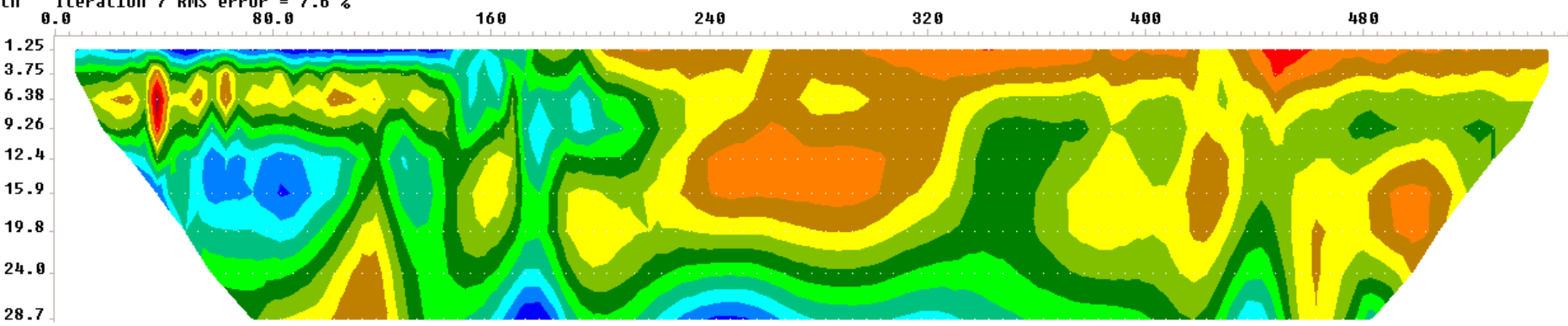

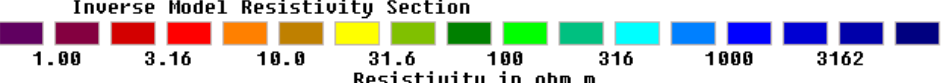

Traverse W2

Unit electrode spacing $5.80 \mathrm{~m}$ 


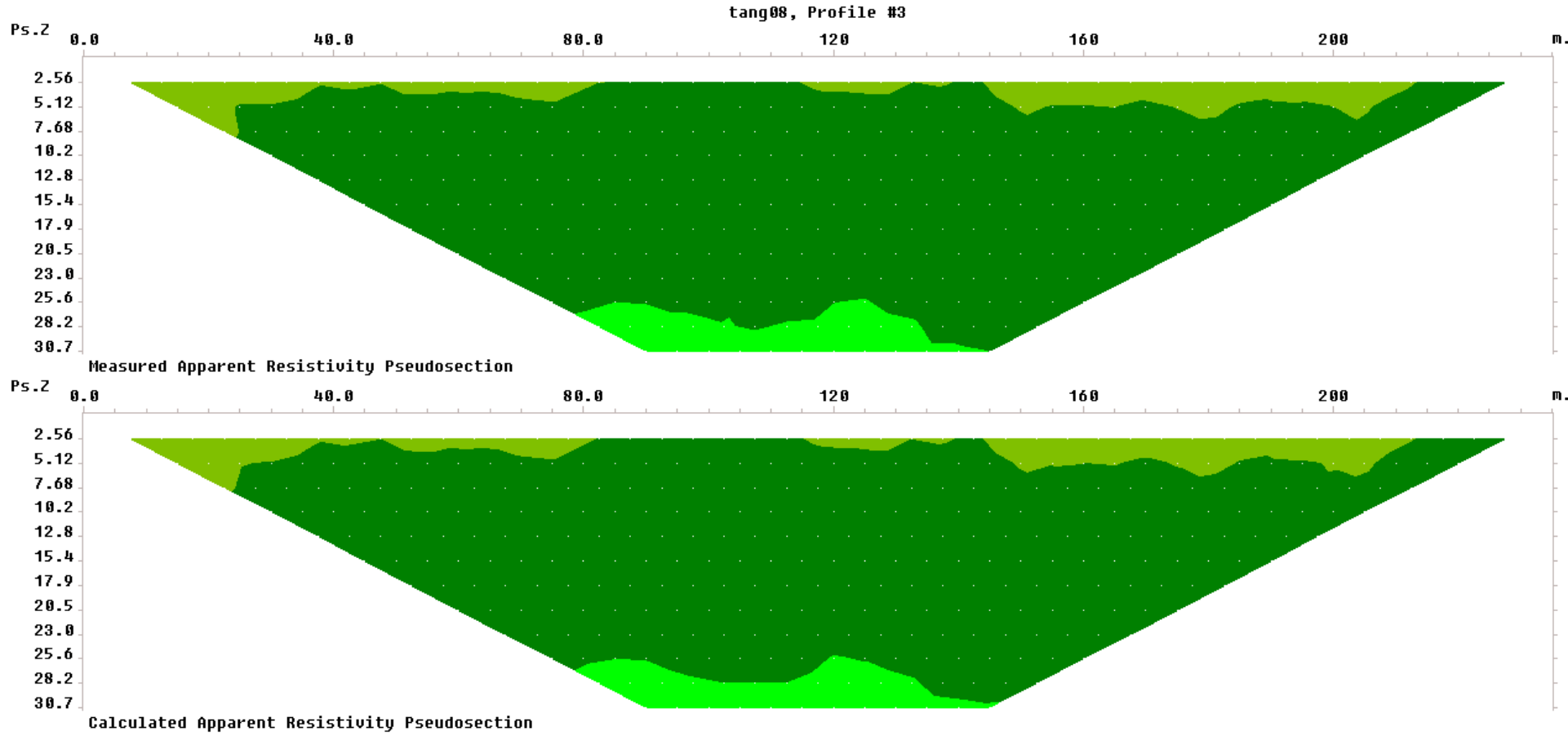

Depth Iteration 13 RMS error $=1.81 \%$

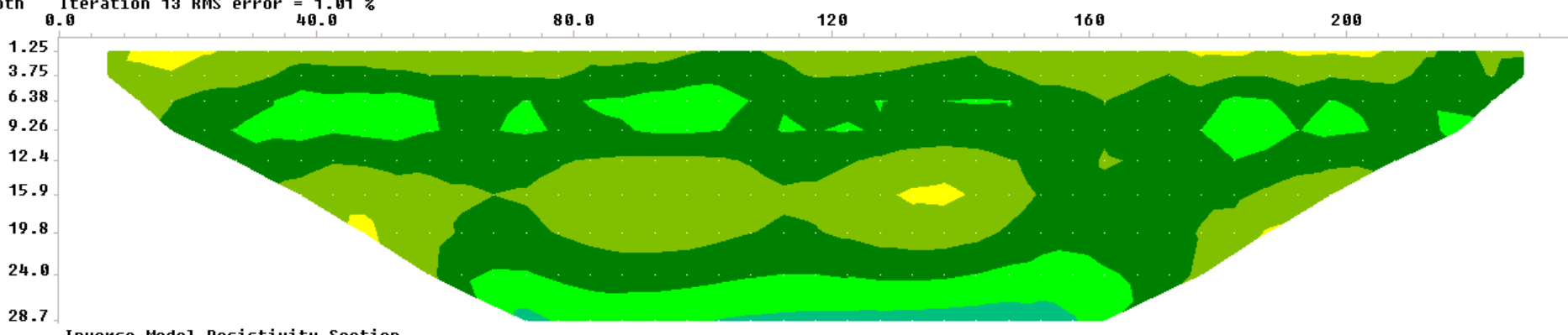

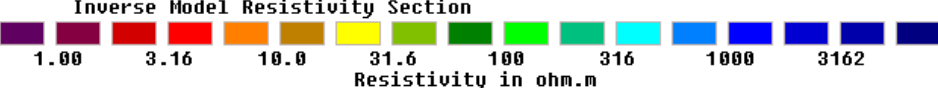

Unit electrode spacing $5.00 \mathrm{~m}$

Traverse W3 

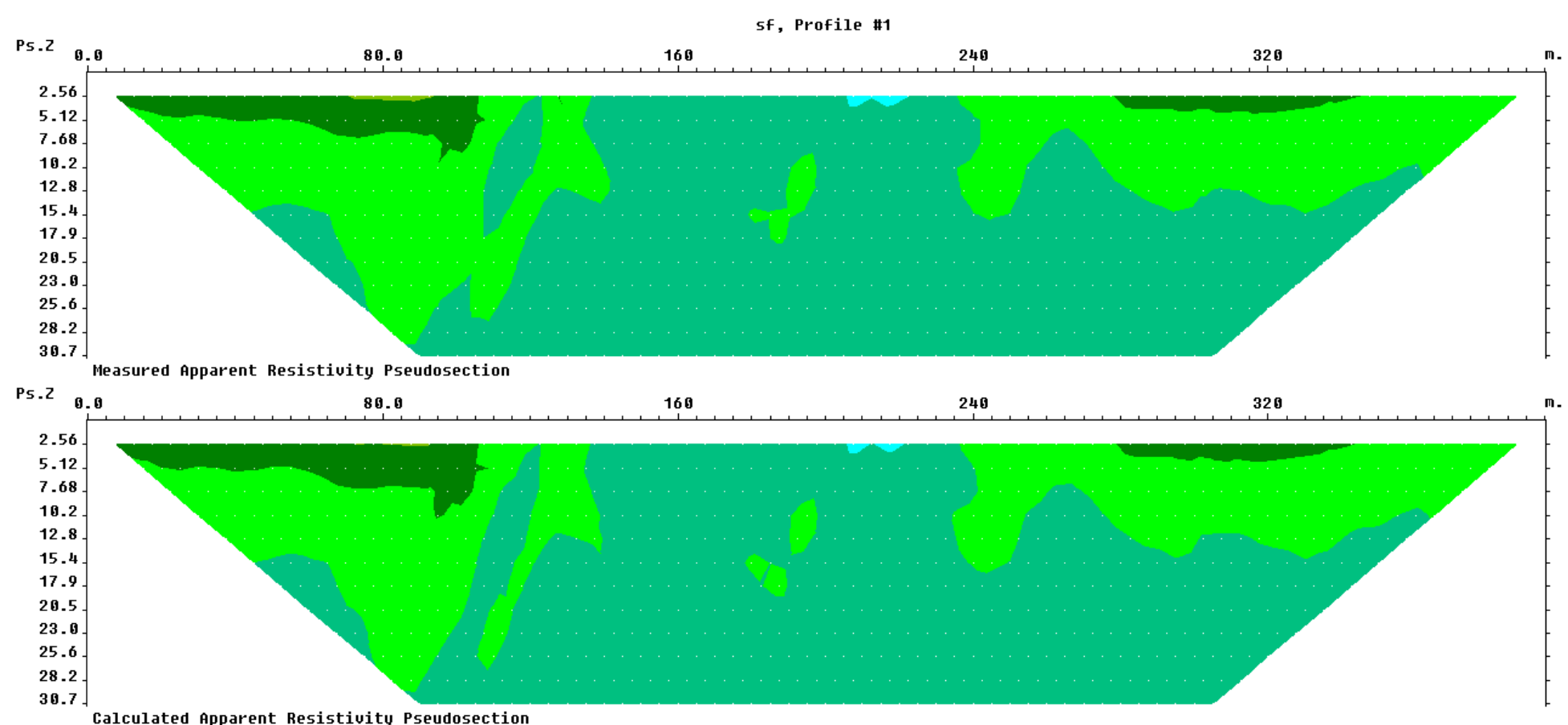

Depth Iteration 3 RMS error $=2.9 \%$

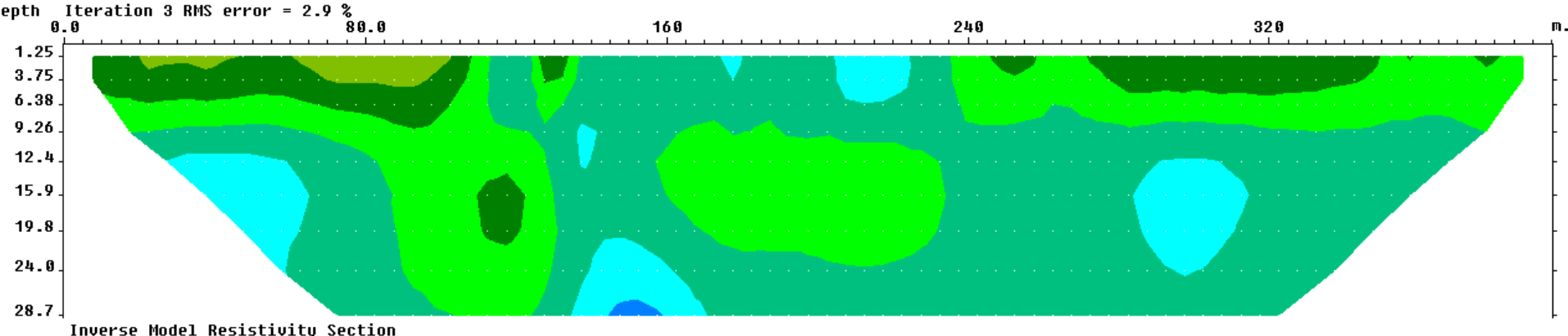

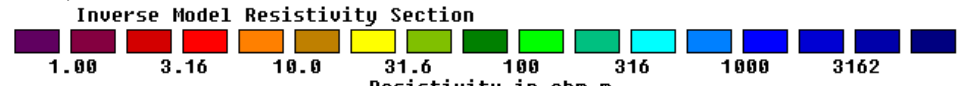

Traverse W5 